UNIVERSIDADE DE SÃO PAULO

ESCOLA DE ARTES, CIÊNCIAS E HUMANIDADES

PROGRAMA DE PÓS-GRADUAÇÃO EM TURISMO

JULIANA FERREIRA DOS SANTOS

Pós-graduação stricto sensu em turismo no Brasil:

uma análise da produção docente.

SÃO PAULO

2018 
Pós-graduação stricto sensu em turismo no Brasil:

uma análise da produção docente.

Dissertação apresentada à Escola de Artes, Ciências e Humanidades da Universidade de São Paulo como parte dos requisitos para a obtenção do título de Mestre em Ciências pelo Programa de Pós-Graduação em Turismo.

Versão corrigida contendo as alterações solicitadas pela comissão julgadora em 27 de novembro de 2018 A versão original encontra-se em acervo reservado na Biblioteca da EACH/USP e na Biblioteca Digital de Teses e Dissertações da USP (BDTD), de acordo com a Resolução CoPGr 6018, de 13 de outubro de 2011.

Área de Concentração:

Desenvolvimento em turismo

Orientador: Prof. Dr. Alexandre Panosso

Netto

\section{SÃO PAULO}


Autorizo a reprodução e divulgação total ou parcial deste trabalho, por qualquer meio convencional ou eletrônico, para fins de estudo e pesquisa, desde que citada a fonte.

CATALOGAÇÃO-NA-PUBLICAÇÃO

(Universidade de São Paulo. Escola de Artes, Ciências e Humanidades. Biblioteca) CRB 8 - 4936

Santos, Juliana Ferreira dos

Pós-graduação stricto sensu em turismo no Brasil: uma análise da produção docente / Juliana Ferreira dos Santos ; orientador, Alexandre Panosso Netto. - 2018.

$224 \mathrm{f}$. : il

Dissertação (Mestrado em Ciências) - Programa de PósGraduação em Turismo, Escola de Artes, Ciências e Humanidades, Universidade de São Paulo Versão corrigida

1. Turismo - Brasil - 2013-2016. 2. Pós-graduação Brasil. 3. Publicações acadêmicas - Brasil - 2013-2016. 4. Pesquisa científica. 5. Professores. I. Panosso Netto, Alexandre, orient. II. Título.

CDD 22.ed. - 910.720981 
Dissertação da autoria de Juliana Ferreira dos Santos, sob o título, "PósGraduação stricto sensu em turismo no Brasil: Uma análise da produção docente" apresentado à Escola de Artes, Ciências em Humanidades da Universidade de São Paulo, como requisito parcial para obtenção do título de Mestre em Ciências pelo Programa de Pós-Graduação em Turismo, na área de concentração Desenvolvimento do Turismo, aprovada em 27 de novembro de 2018 pela comissão julgadora constituída pelos doutores:

\section{Banca Examinadora}

Prof. Dr. Alexandre Panosso

Netto

Julgamento:

Prof. Dr. Glauber Oliveira

Santos

Julgamento:

Prof. Dr. Marília Gomes

Ansarah

Julgamento:

Prof. Dr. Sérgio Leal

Julgamento:
Instituição: USP Universidade de São Paulo

Assinatura:

Instituição: USP Universidade de São Paulo

Assinatura:

Instituição: UNIP Universidade Paulista

Assinatura:

Instituição: UFPE Universidade Federal de Pernambuco

Assinatura: 
Dedico esta dissertação a Deus, minha família, meu avô Afonso Ferreira e aos meus professores da Bahia e da USP. 


\section{AGRADECIMENTOS}

Agradeço a todas as forças divinas que operaram enquanto eu produzia este trabalho, agradeço a toda a minha família, em especial a minha mãe, Terezinha Ferreira, meu pai, José Alves, meu irmão Marcos Ferreira, minha sobrinha Maria Clara Ferreira, meu padrinho e primo Moabe Breno Ferreira pelo carinho, estimo e palavras positivas. E sem dúvidas a todos os meus parentes, sem exceção, pois o meu sucesso eu devo a todos eles, pelos elogios, pelas críticas e incentivos, (nossa!), que eram muitos. Agradeço aos meus amigos e companheiros de jornada acadêmica, destes, agradeço especialmente a todos os meus amigos da Bahia, em especial a Valquiria Bahia, Thalita Bahia, Fabiana Maria, Everaldo Santos, Karla Carvalho, Lara Carvalho, Yane Cordeiro, Guilianne Magalhães, Claúdia Gregori, Roberto Gregori, kaliane Barroso, Marilce Tavares, Lorena Nery, Marivalda Jesus, Juscélia Santos, Jorleide Moura, Telma Silva ,Luiz Diogo, Maria Caldas e Maria Nilza Xavier, por toda a torcida que se fez presente mesmo antes de meu ingresso no mestrado, e em especialmente para Hérica Pinheiro, pois a sua amizade foi, e ainda é, bálsamo para os dias mais difíceis e um presente a se guardar para sempre. Agradeço a Ribamar Júnior e a Raquel Mota que desde o primeiro dia de aula na USP me acolheram como se fôssemos velhos conhecidos; à Ticiane Oliveira que me ajudou na adaptação em São Paulo, estendo meus agradecimentos também ao professor Dr. Mena-Jesus, Dr Luciano Digiampietri, Dr. Glauber Oliveira e a Dra Marília Ansarah pelas palavras produtivas. E também para minhas assistentes Natalia Crispim e Neusa Franzoi, pelo carinho, atenção e pelas conversas divertidas no melhor apartamento do Crusp, a USP não seria a mesma sem vocês. Para além dos colegas da USP, fui bastante afortunada em encontrar mais pessoas que além de acadêmicos inspiradores, peço aqui a licença para chamar de amigos, falo de Maria das Graças, Catarina Martins, João Maria, Terezinha Barbosa, Breno Wilson, Fabiano Prado, Tatine Barbosa, Bruna Laura e Marcos Costa. Obrigada por me acolherem. Cumpre ressaltar que um aluno sem mestre jamais seria capaz de progredir em sua jornada, sou uma pessoa de sorte em ter os melhores professores desde a graduação como Renata Reis, Márcio Leal, Samuel Mattos, Isabel Pacheco, Aline Nascimento, Aleselma Pereira, Claúdia Ribeiro e André Rosa. E na USP não foi diferente, agradeço a Dr. Edmur Stoppa, Dr. Reinaldo Pacheco, Dr. Luiz Trigo, Dr. Ricardo Uvinha e o Dr. Edegar Tomazzoni em suas ponderações em sala de aula, e pelo apoio na minha dissertação. Deixo aqui os meus profundos agradecimentos a meu orientador, Dr. Alexandre Panosso, que com paciência me acolheu nestes 3 anos de jornada sem desistir de mim, foi uma experiência positiva em materializar este trabalho sob sua orientação. 


\section{RESUMO}

\section{SANTOS, Juliana Ferreira dos. Pós-graduação stricto sensu em turismo no}

Brasil: uma análise da produção docente. 2018. 224p. Dissertação (Mestrado

em Turismo) - Escola de Artes, Ciências e Humanidades, Universidade de São Paulo, 2018, Versão Corrigida.

Na área do turismo, o processo de consolidação dos programas de pós-graduação stricto sensu está acelerado, porque, em 2013, havia seis programas que ofereciam mestrado e apenas dois que ofertavam o doutorado; já em 2018, passou a existir onze programas oferecendo mestrado, incluídos os de caráter profissional e os acadêmicos, e quatro programas, o doutorado. Diante desse cenário, questionamos, neste estudo, como está estruturada a pós-graduação stricto sensu em turismo no Brasil a partir da análise da produção docente. $O$ objetivo geral deste trabalho é a análise da produção bibliográfica dos docentes dos programas de pós-graduação stricto sensu em turismo no Brasil no período de janeiro 2013 a dezembro 2016. Os objetivos específicos definem realizar um exame quantitativo e qualitativo que (re)conheça a estrutura acadêmica desses programas, a partir do fazer-saber de seus docentes. O corpus selecionado foi o conjunto dos dados divulgados nos currículos dos professores permanentes, inativos e colaboradores de nove programas de pós-graduação stricto sensu em turismo no Brasil: Universidade Federal do Paraná-UFPR, Universidade de São Paulo - USP, Universidade Anhembi Morumbi-UAM, Universidade Caxias do Sul -UCS, Universidade do Rio Grande do Norte-UFRN, Universidade Estadual do Ceará-UECE, Universidade do Vale do Itajaí-UNIVALI, Universidade de BrasíliaUNB, Universidade Federal Fluminense-UFF. Esses dados foram coletados, por meio da plataforma Lattes. O escopo temporal selecionado foi escolhido, porque esse período foi utilizado pela Coordenação de Aperfeiçoamento de Pessoal de Nível Superior (CAPES) para avaliar os programas de pós-graduação no último quadriênio. A metodologia utilizada para a interpretação dos dados foi a Análise do Conteúdo (AC), proposta por Bardin (1977) e Krippendorff (1990). Essa perspectiva teórica é um procedimento que compreende os dados como fenômenos simbólicos de estruturas subjacentes, qualitativa e quantitativamente. Diante dos dados coletados e analisados, constatou-se que aumentou a internacionalização da pesquisa produzida pelos docentes analisados, porque houve o acréscimo do número de indexação dos periódicos nacionais e o número de publicação em periódicos internacionais. Em relação aos artigos científicos, observou-se que as instituições que se destacaram quantitativamente foram: UFRN, UFPR e UAM, já qualitativamente UNIVALI, USP e a UFPR. Considerando as palavras-chave dos artigos, livros e capítulos de livros, verificou-se que existe um viés desenvolvimentista na área do turismo. Apesar de todos os benefícios em coautoria, os dados evidenciam que, dos 157 docentes analisados, 59 não publicam em coautoria. Em relação ao Índice $\mathrm{H}$, notou-se que é preciso melhorar as variáveis de análise, pois ater-se apenas e somente em uma ou duas variáveis de produtividade não garante a validade da análise em seus critérios qualitativos 
e quantitativos. Tentamos fazer com que a interpretação dos dados, na perspectiva da análise do conteúdo (BADIN, 1977), correlacionasse diferentes e diversos indicadores de produtividade acadêmica. Como uma das contribuições desta pesquisa, constatou-se que o fator tempo não é definidor para o maiorou o menor índice de produção docente em um programa. Este estudo, portanto, representa um retrato contemporâneo do cenário da pesquisa feita pelos docentes em turismo no Brasil nos programas de pós-graduação stricto sensu.

PALAVRAS-CHAVE: Turismo. Brasil. Docente. Pós-graduação stricto sensu. Produção bibliográfica. 


\begin{abstract}
SANTOS, Juliana Ferreira dos. Post-graduation stricto sensu in tourism in Brazil: an analysis of teaching production. Dissertation (Master em Turismo) - School of Arts, Sciences and Humanities, University of São Paulo, 2018. 222p. Original Version.
\end{abstract}

In the area of tourism, the process of graduate programs consolidation is accelerated, because, in 2013, there were six programs offering masters and only two offering the doctorate; yet in 2018, there were eleven master's degree programs, including those of a professional and academic nature, and four programs offering the doctorate. Given the scenario, we questioned, in this study, how the programs of master's an doctor's degrees in tourism in Brazil are structured from the analysis of teaching production. The general objective of this study is the analysis of the bibliographic production of the professors of the programs of master's and doctor's degrees in tourism in Brazil from January 2013 to December 2016. The specific objectives define a quantitative and qualitative exam that (re)know the academic structure of these programs, from the know-how of their professors. The selected corpus was the set of data published in the curricula of the permanent professor, inactives and collaborators of nine programs of master's and doctor's degrees in tourism in Brazil: Universidade Federal do Paraná-UFPR, Universidade de São Paulo - USP, Universidade Anhembi Morumbi-UAM, Universidade Caxias do Sul -UCS, Universidade do Rio Grande do Norte-UFRN, Universidade Estadual do Ceará-UECE, Universidade do Vale do Itajaí-UNIVALI, Universidade de Brasília-UNB, Universidade Federal FluminenseUFF. These data were collected through the Lattes platform. The selected temporal scope was chosen because this period was used by the Coordenação de Aperfeiçoamento de Pessoal de Nível Superior (CAPES) to evaluate graduate programs in the last four years. The methodology used for the interpretation of the data was the Content Analysis (AC), proposed by Bardin (1977) and Krippendorff (1990). This theoretical perspective is a procedure that understands the data as symbolic phenomena of underlying structures, qualitatively and quantitatively. Considering the data collected and analyzed, it was verified that the internationalization of the research produced by the analyzed professors increased, because there was an increase in the indexation number of the national journals and the number of publication in international journals. Regarding the scientific articles, it was observed that the institutions that stood out quantitatively were: UFRN, UFPR and UAM, and qualitatively UNIVALI, USP and UFPR. Considering the keywords of the papers, books and chapters of books, it was verified that there is a developmental perspective in the tourism area. Despite all the co-authorship benefits, the data show that, of the 157 professors analyzed, 59 do not publish in co-authorship. In relation to the $\mathrm{H}$ index, it was noticed that it is necessary to improve the analysis variables, because sticking in only one or two productivity variables does not guarantee the validity of the analysis in its qualitative and quantitative criteria. We attempted to make the interpretation of the data, from the perspective of content analysis (BADIN, 1977), correlate different and diverse indicators of academic productivity. As one of the contributions of this research, it was verified that the time factor is not defining for the highest or the 
lowest index of teacher production in a program. This study, therefore, represents a contemporary portrait of the scenario of the research done by the teachers in tourism in Brazil in the programs of master's and doctor's degrees.

KEYWORDS: Tourism. Brazil. Professor. Programs of master's and doctor's degrees. Bibliographic production. 


\section{LISTA DE TABELAS}

Tabela 1- Total de Pós-Graduação Stricto Sensu em turismo no Brasil

Tabela 2- Total de cursos de Pós-Graduação Stricto Sensu em turismo no Brasil

Tabela 3- Dados gerais dos Programas de Pós-Graduação Stricto Sensu em turismo no Brasil

Tabela 4- Produção bibliográfica dos docentes (2013-2016) artigos em periódicos

Tabela 5- Qualis dos artigos em periódico de produção docente em turismo (20132016)

Tabela 6- Porcentagens gerais da produção docente em turismo (2013-2016): quantidade e qualidade

Tabela 7- Artigos em periódicos de alto impacto da produção docente em turismo (2013-2016): qualidade e quantidade

Tabela 8- Porcentagens gerais da produção em turismo (2013-2016) em periódicos de alto impacto (A1, A2 e B1): quantidade e qualidade

Tabela 9- Publicações por instituição da área do turismo dos periódicos internacionais mais frequentes no período de 2013-2016

Tabela 10- Publicações por instituição da área do turismo dos periódicos nacionais mais frequentes no período de 2013-2016

Tabela 11- Presença do índice $\mathrm{H}$ e do i10 nos currículos dos docentes dos programas relacionados a área do turismo 


\section{LISTA DE QUADROS}

Quadro 1- Proposta de Análise

Quadro 2- Pontuação da Qualis

Quadro 3- Categorização das palavras-chaves por frequência dos artigos científicos das instituições selecionadas.

Quadro 4- Categorização das palavras por frequência dos titutlos dos artigos científicos das instituições selecionadas.

Quadro 5- Categorização das palavras por frequência dos títulos dos livros

Quadro 6- Categorização das palavras por frequência dos títulos dos Capitulo de livros

Quadro 7- PageRank da UNIVALI: 2013-2016

Quadro 8- PageRank da UFPR: 2013-2016

Quadro 9- PageRank da UAM: 2013-2016

Quadro 10-PageRank da UECE: 2013-2016

Quadro 11- PageRank da UCS: 2013-2016

Quadro 12-PageRank da USP: 2013-2016

Quadro 13- PageRank da UFRN: 2013-2016

Quadro 14- PageRank da UNB: 2013-2016

Quadro 15- PageRank da UFF: 2013-2016

Quadro 16- Os três primeiros colocados de cada instituição no índice $H$ 


\section{LISTA DE FIGURAS}

Figura 1- Distribuição dos Programas de Pós-Graduação Stricto Sensu conforme a nota Capes (quadriênio 2014-2017) e respectivo status jurídico

Figura 2- Distribuição dos Programas de Pós-Graduação Stricto Sensu em Turismo no território da República Federativa do Brasil

Figura 3- Desenvolvimento das três fases de uma análise de conteúdo

Figura 4- Áreas de avaliação da Revista Turismo em Análise

Figura 5- Nuvem de palavras: Palavras-chave mais frequentes nos artigos científicos dos docentes da área do turismo

Figura 6 - Nuvem de palavras: palavras-chave mais frequentes nos títulos dos artigos científicos dos docentes da área de turismo

Figura 7 -Nuvem de palavras: palavras-chave mais frequentes nos livros dos docentes da área de turismo

Figura 8-Nuvem de palavras: palavras-chave mais frequentes nos Capítulos de livros dos docentes da área de turismo

Figura 9- Diagrama de exemplo dos tipos de grafos do software scripLattes

Figura 10- Grafo de Colaboração da UNIVALI: 2013-2016

Figura 11- Grafo de Colaboração da UFPR: 2013-2016

Figura 12- Grafo de Colaboração da UAM: 2013-2016

Figura 13- Grafo de Colaboração da UECE: 2013-2016

Figura 14- Grafo de Colaboração da UCS: 2013-2016

Figura 15- Grafo de Colaboração da USP: 2013-2016

Figura 16- Grafo de Colaboração da UFRN: 2013-2016

Figura 17- Grafo de Colaboração da UNB: 2013-2016

Figura 18- Grafo de Colaboração da UFF: 2013-2016

Figura 19. Exemplo de Relações Unívocas e Biunívocas 


\section{LISTA DE GRÁFICOS}

Gráfico 1- Projeção dos alunos matriculados em Programas de Pós-graduação stricto sensu no Brasil entre 2011 e 2020: doutorado, mestrado acadêmico e mestrado profissional.

Gráfico 2- Distribuição de Programas de Pós-Graduação Stricto Sensu por grau: mestrado/doutorado, mestrado acadêmico, mestrado profissional, doutorado.

Gráfico 3- Distribuição dos Programas de Pós-Graduação Stricto Sensu conforme o status jurídico: federal, estadual, particular e municipal. 


\section{LISTA DE ABREVIATURAS E SIGLAS}

CNPQ: Conselho Nacional de Desenvolvimento Científico e Tecnológico

CAPES: Coordenação de Aperfeiçoamento de Pessoal de Nível Superior CFE: Conselho Federal de Educação

FAPESP: Fundação de Amparo à Pesquisa do Estado de São Paulo

FAPERJ: Fundação de Amparo à Pesquisa do Estado do Rio de Janeiro FAPMIG : Fundação de Amparo à Pesquisa do Estado de Minas Gerais IES: Instituição Superior de Ensino

SENAC: Serviço Nacional de Aprendizagem e Comércio

MEC: Mistério da Educação

ECA: Escola de Comunicações e Artes da Universidade de São Paulo

EMBRATUR: Instituto Brasileiro de Turismo

EACH: Escola de Artes, Ciências e Humanidades da Universidade de São Paulo IBGE: Instituto Brasileiro de Geografia e Estatística

UNIVALI: Universidade de Vale do Itajaí

USP: Universidade de São Paulo

UECE: Universidade Estadual do Ceará

UNB: Universidade de Brasília

UFF: Universidade de Fluminense

UCS: Universidade Caxias do Sul

UAM: Universidade Anhembi Morumbi

UFRN: Universidade Federal do Rio Grande do Norte

UFPR: Universidade Federal do Paraná

UFPE: Universidade Federal de Pernambuco 
IFS: Instituto Federal de Sergipe

UNESP: Universidade Estadual Paulista

UFMS: Universidade Federal do Mato Grosso do Sul

UNEB: Universidade do Estado da Bahia

IFBA: Instituto Federal da Bahia

PL: Plataforma Lattes

ANPTUR: Associação Nacional de Pesquisa e Pós-Graduação em Turismo

DOAJ- Directory Of Acess Journals

IBICT- Instituto Brasileiro de Informação em Ciência e Tecnologia

SEER- Sistema de Eletrônico de Editoração de Revistas

SPELL- Scientific Periodicals Electronic Library

EBSCO- Information Services

SCIELO - Scientific Electronic Library Online

CIRET- International Center for Research and Study in Tourism

LATINDEX Regional Information System for Online Scientific Journals from Latin America, the Caribbean, Spain and Portugal

SIBI: Sistema integrado de bibliotecas da UFPR

ULRICHS WEB: Global Serials Directory

DIADORIM: Diretório de Políticas de Acesso Aberto das Revistas Científicas Brasileiras

E-REVISTA: Open Access Platform for Electronic Scientific Journals Spanish and Latin American. 


\section{SUMÁRIO}

INTRODUÇÃO 15

2 PÓS-GRADUAÇÃO STRICTO SENSU EM TURISMO NO BRASIL: ASPECTOS HISTÓRICOS E INTRODUTÓRIOS. 22

2.1 PÓS-GRADUAÇÃO NO BRASIL .23

2.2 PANORAMA DA PÓS-GRADUAÇÃO STRICTO SENSUEM TURISMO NO BRASIL 33

2.3 PROGRAMAS DE PÓS-GRADUAÇÃO STRICTO SENSU EM TURISMO NO BRASIL .48

METODOLOGIA 55

4 ANÁLISE DA PRODUÇÃO CIENTÍFICA BIBLIOGRÁFICA DOS DOCENTES .75

4.1 ANÁLISE DOS ARTIGOS .76

4.2 DADOS GERAIS .78

4.3 QUALIS DA PRODUÇÃO BIBLIOGRÁFICA DAS IES .79

4.4 PERIÓDICOS INTERNACIONAIS E NACIONAIS MAIS FREQUENTES NA PRODUÇÃO DAS IES . .90

4.5 PALAVRAS-CHAVE MAIS FREQUENTES DOS ARTIGOS CIENTÍFICOS SELECIONADOS 101

4.6 CATEGORIZAČ̃̃O DAS PALAVRAS-CHAVE DOS ARTIGOS ...........106

4.7 CATEGORIZAÇÃO DAS PALAVRAS-CHAVE DOS TíTULOS DOS ARTIGOS

4.8 CATEGORIZAÇÃO DAS PALAVRAS-CHAVE DOS LIVROS 110

4.9 CATEGORIZAÇÃO DAS PALAVRAS-CHAVE DOS CAPÍTULOS DE LIVROS

5 REDE DE COLABORAÇÃO DOS DOCENTES

5.1 A COLABORAÇÃO DOS DOCENTES DA PÓS-GRADUAÇÃO STRICTO SENSU EM TURISMO NO BRASIL...........................................................122

5.2 ANÁLISE DAS PRODUÇÕES ACADÊMICAS DOS DOCENTES SELECIONADOS.

5.3 ANÁLISE DO ÍNDICE H I10 DOS DOCENTES SELECIONADOS.

REFERÊNCIAS

ANEXOS A

ANEXOS B. 
1 INTRODUÇÃO 
O ensino superior na área do turismo é um tema que vem ganhando notoriedade no século XXI, seja pelo desenvolvimento social das cidades, seja pela necessidade de construir um intercâmbio sustentável e economicamente viável entre culturas, nações e povos em geral. A formação para o mercado e para a própria academia está se especializando cada vez mais, por isso a pósgraduação sctrito sensu na área do turismo é uma pauta importante na agenda das universidades brasileiras e também nas estrangeiras. Para estudar essa área, este trabalho aborda a produção docente, como um meio de desvelar os avanços e os desafios da pós-graduação stricto sensu em turismo no Brasil.

Ressalta-se que o processo de crescimento está acelerado na área do turismo. Em 2013, havia seis programas que ofereciam o diploma de mestrado e apenas dois o de doutorado; já em 2018, existem onze mestrados, incluídos os de caráter profissional e os acadêmicos, e quatro doutorados. Diante dessa oferta, este estudo questiona: como está estruturada a pós-graduação stricto sensu em turismo no Brasil a partir da análise da produção docente?

Antes de apresentar propostas para a resolução dessa indagação, faz-se necessário entender o porquê do crescimento desses programas no território nacional. Além disso, em uma sociedade complexa, diversificada e dotada de diversas culturas, é importante que a formação dos docentes seja discutida a partir do rigor científico, do processo metodológico, da crítica à formação profissional e da prospecção de suas possibilidades sociais, culturais e mercadológicas, conforme sugerem diversos estudiosos (COSTA, 2016; TOMAZZONI, 2016; KOEBSCH, 2017). Assim, de um lado, há o contexto sociocultural que estimula os processos de estruturação de cada fenômeno, e de outro, existem as coerções institucionais e políticas que cerceiam ou alavancam esses mesmos processos.

O caso da expansão da pós-graduação no Brasil, em especial o do turismo, não se isenta dessas condições socioculturais, nem das institucionais e políticas. Como objeto de investigação na pós-graduação, o turismo no mundo contemporâneo constitui uma nova área, principalmente no Brasil, pois começou a se desenvolver institucionalmente, como graduação, em 1971 na Universidade Anhembi Morumbi, localizada em São Paulo-SP, e, como pós-graduação stricto sensu, em 1999, na Universidade Vale do Itajaí, (UNIVALI) situada em Santa Catarina. 
Diante dessa recente institucionalização, não há um consenso sobre a abrangência epistemológica do fenômeno turístico. Para alguns estudiosos, entre eles, Leiper (1981), Jafari (1994), Ritchie e Jafari (1981), Guimarães

(2008), Bomfim (2009) e Castillo Nechar (2010), os estudos do turismo constituem uma disciplina. Já para outros pesquisadores, como Tribe (1997), Moraes e Vilar (2010), esse campo não passa de uma atividade multidisciplinar.

Embora existam dificuldades epistemológicas, a área do turismo no Brasil deixou de ser apenas uma profissão e se firmou como campo de pesquisa (PANOSSO NETTO, et al. 2017). Foi explorando essas diversas faces do turismo que a realização de seminários nacionais e internacionais proporcionou avanços dentro desse âmbito. Em 2002, foi criada a Associação Nacional de Pesquisa e

Pós-Graduação em Turismo (ANPTUR) que resultou desse processo de institucionalização da área, mas também do amplo debate sobre a qualidade das pesquisas dos programas de pós-graduação stricto sensu em turismo.

Observando esse contexto sociocultural e essas institucionais que perpassam a criação e, atualmente, o crescimento da pós-graduação stricto sensu em turismo no Brasil, pode-se dizer que esse é um momento bastante oportuno para uma revisão crítica da produção do conhecimento nesse campo de estudo (PANOSSO NETTO e NECHAR, 2016), pois a análise da produção acadêmica é uma ferramenta para criação de indicadores de acompanhamento da divulgação científica, e uma estratégica para fortalecer as ações de colaboração entre os docentes. Soares e Cunha (2010) ressaltam ainda que são poucos os trabalhos sobre a formação de docentes universitários em programas de stricto sensu. Elas afirmam que a formação nesse assunto é de grande relevância, apesar da evidente insuficiência de iniciativas. Milagres (2014), por sua vez, explicita que, embora haja dissertações de mestrado ou teses de doutorado sobre o turismo, o estudo sobre a pós-graduação em turismo stricto sensu brasileira parece ser inovador, pois poucas pesquisas relacionadas à produção docente são realizadas no território nacional.

A partir desse panorama, observa-se que a estrutura da pós-graduação stricto sensu em turismo pode ser analisada a partir da produção científica de seus docentes. É uma proposta de investigação necessária porque a produção docente, além de resultar em um impacto significativo para os programas, amplia as discussões científicas em sua área de conhecimento. Desse modo, a 
produção docente é pertinente como um objeto de estudo. Além disso, esta pesquisa fomenta a bibliografia sobre o tema, porque traz dados quantitativos e qualitativos.

Para fazer um exame de como está a pós-graduação stricto sensu em turismo nas universidades brasileiras, este estudo tem como objetivo geral, analisar a produção bibliográfica dos docentes dos programas de pósgraduação stricto sensu em turismo no Brasil no período de janeiro de 2013 a dezembro 2016 e em 2018 o índice H, que embora essa análise apresente aspectos mais específicos e coletados em outro momento do que do período analisado, temos uma análise complementar. Enquanto analisamos a colaboração entre os docentes, nesse caso do índice $\mathrm{H}$ e i10, observamos a pertinência da jornada de cada docente em sua instituição. Isso se faz pertinente, porque (a) existem poucos estudos sobre o tema; (b) o turismo permite diversas abordagens dado seu perfil (multidisciplinar), pois ele participa de várias áreas do saber, dialogando, assim, com outras disciplinas (interdisciplinar) e podendo até dialogar com outros campos de estudo (transdisciplinar); (c) embora tenha ocorrido a institucionalização do turismo, o contexto sociocultural é bastante diverso nos diferentes programas de pós-graduação stricto sensu. Portanto, como objetivo específico, busca-se analisar quantitativa e qualitativamente a produção científica de artigos, livros e capítulos de livros dos docentes dos programas de pós-graduação stricto sensu em turismo.

Para se fazer essa análise, o corpus selecionado foi o conjunto dos currículos Lattes dos professores permanentes, colaboradores e inativos aos programas de pós-graduação stricto sensu em turismo no Brasil. O escopo temporal das contribuições científicas coletadas e analisadas foi de janeiro de 2013 a dezembro de 2016, e o indíce em 2018 como já mencionados. O período utilizado pelo órgão de fomento nacional para avaliar os respectivos programas de pós-graduação no último quadriênio a Coordenação de Aperfeiçoamento de Pessoal de Nível Superior - CAPES). A metodologia utilizada para a interpretação dos dados foi a análise do conteúdo, proposta por proposta por Bardin, (1977); Krippendorff, (1990). Análise do Conteúdo (AC) é um procedimento que "procura compreender os dados, não como um conjunto de acontecimentos físicos, mas como fenômenos simbólicos e abordar sua análise direta" (BARDIN, 1997). 
Como arcabouço teórico, partimos de uma posição interdisciplinar, uma vez que são acolhidos estudos do campo do turismo (ANSARAH, 2002; COSTA, 2016; TRIBE, 2006a; LEAL, TRIBE, HOLANDA, 2013) e os da educação (NAVAS, Ca, et al. 2017; MARQUES, 2017; VELOSO, 2014). Esses referenciais teóricos são pertinentes para esta pesquisa porque eles, cada um a seu modo, discutem o fenômeno do turismo de forma crítica e projetada para o futuro, contribuindo, assim, para a formação do docente. A partir dos dados coletados, essa fundamentação teórica auxilia na sistematização dos conteúdos, bem como na orientação epistemológica da argumentação desenvolvida.

Metodologicamente, dividiu este trabalho em três capítulos. No Capítulo 1, é contextualizado o ensino superior em turismo no Brasil, desde a criação do primeiro curso até o atual momento de expansão dos programas de pósgraduação stricto sensu em turismo no Brasil. Sobre estes programas existe um avanço quantitativo e qualitativo. No que concerne aos programas de pósgraduação stricto sensu em turismo, eles são concentrados em algumas regiões. Embora os programas stricto sensu tenham se ampliado de forma significativa, particularmente os mestrados e doutorados, duas marcantes atributos merecem destaque: a desigualdade na distribuição regional dos programas, com a forte concentração nas regiões mais ricas do país ainda forte, como por exemplo na região Sul e a Sudeste, as quais contam com a presença atuante da UCS, da UFPR, da UNIVALI, da UAM, da USP e da UFF. O Nordeste aumentou significativamente, com a UECE, IFS, UFRN e a UFPE. A região Centro-Oeste ganhou participação ainda pequena. A região Norte não possui programa na área.

Quanto aos resultados sobre o número de programas, advertir-se um aumento significativo desse indicador na pós-graduação stricto sensu em turismo, com indicações de que o setor público tende a ter um papel cada vez maior no cenário do ensino em turismo, uma vez que ele domina $81,4 \%$ de todo o setor da pós-graduação no País. De fato, os resultados mostraram que o sistema público é hoje um ator protagonista relevante pelo crescimento no campo do turismo, uma vez que grande parte dos cursos está concentrada no setor público. Porém a distribuição dos programas ainda é irregular, principalmente quando se trata dos programas de pós-graduação stricto sensu em turismo. 
Em específico dos programas de pós-graduação stricto sensu em turismo, podemos dizer que existem duas vertentes para a área do turismo no Brasil: uma teórica e a outra descritiva. Do lado teórico, discutido principalmente por Leal (2012), Ansarah (2002), Holanda et al. (2014) e Tribe (1997a), essa perspectiva traça uma revisão da literatura sobre o tema, o conhecimento, com destaque para sua dimensão científica e tecnológica. Já na perspectiva descritiva, baseada pelos estudos de Panosso Netto et al (2017), Leal (2012) e Tribe (1997).

No Capítulo 2, foi apresentada a análise da produção científica bibliográfica dos docentes; incluindo, também nessa segunda parte, o exame específico dos artigos nos periódicos nacionais e internacionais e as palavraschaves mais frequentes dos artigos científicos, dos livros e dos capítulos de livros

selecionados. Verificou que todos os programas publicaram artigos, livros e capítulo de livros em 2013 e 2016, e as universidades que mais publicaram artigos foram UFRN, UFPR e a UAM, os programas que tem mais qualidade são UNIVALI, USP e a UFPR. Observou-se que nesse período de 2013 a 2016 aumentou a internacionalização da pesquisa produzida pelos docentes dos programas sctrito sensu em turismo no Brasil, as Universidades que publicaram mais em periódicos internacionais e nacionais foram A USP, a UAM e a UFPR.

Haja vista o acréscimo do número de indexação dos periódicos nacionais e o número de publicação em periódicos nacionais. Outro dado importante na análise dos periódicos internacionais e nacionais foi a variância irregular entre os fatores de tempo, indexação e classificação no Sistema Sucupira/Qualis entre os fatores de tempo, indexação e classificação Qualis. Sobre as revistas nacionais, salientamos que possa existir endogenia, porque existe uma concentração de docentes-autores da própria UCS, UAM, UFPR e UNB fomentando as revistas ao invés de abrir espaço para outros estudiosos de outras regiões e/ou instituições. Isso, portanto, restringe o acesso à publicação, porque o espaço de divulgação fica concentrado em determinada instituição que coincide a instituição que acolhe, revisa e lança o periódico. É um contrassenso do que é previsto e disseminado internacionalmente. Segundo Meneghini (2012), atualmente, os cientistas que compõem os conselhos de alta qualidade dos periódicos estrangeiros têm compromisso de orientar as revistas a diversificar as áreas de pesquisa e os locais de divulgação geograficamente emergentes e/ou 
produtivos, sem com isso concentrar em apenas uma organização - menos ainda, naquela que publica o próprio periódico.

No Capítulo 3, são verificadas, a partir de um exame das redes de colaboração dos docentes juntamente com o pageRank das produções dos docentes e o índice $\mathrm{Hi10}$ atual desses professores-pesquisadores. Neste trabalho, foi utilizado, como recurso metodológico, o software scriptLattes. O scriptLattes é uma ferramenta de código livre desenvolvido por Jesús Pascual Mena-Chalco e Roberto Marcondes Cesar Junior criadores de forma independente do CNPq. Por isso, este sistema pode ser utilizado para diversas finalidades acadêmicas e institucionais. O programa tem como objetivo extrair e compilar automaticamente informações contidas no currículo Lattes de um determinado conjunto de pesquisadores e auxiliar na difusão das informações sobre as produções acadêmicas no país. Destaca-se que a rede de colaboração de vários departamentos de Pós-graduação permite a identificação de uma série de itens relacionados ao processo de colaboração científica. Dentre outros itens, ressaltamos: nível de colaboração da comunidade envolvida, distância média entre os colaboradores, autores que mais colaboram, grupos que colaboram com mais intensidade.

O grafo de colaboração e o pageRank, de nove universidades selecionadas a partir de sua produção docente, a saber: UNIVALI, UFPR, UAM, UECE, UCS, USP, UFRN, UNB e UFF. O índice H e o i10 foi analisado separadamente. Escolhemos essa metodologia, porque os dados coletados dos indicadores do grafo de colaboração e o pageRank se referem ao período de 2013 a 2016, já o índice H compreende os dados coletados em julho de 2018. Uma vez que são períodos diferentes - de um lado, 2013 a 2016, e de outro, 2018 -, esses índices foram analisados separadamente. Os dados do índice $\mathrm{H}$ podem reforçar ou não as análises obtidas com os indicadores dos grafos e do pageRank. Portanto, essa metodologia é pertinente, porque acolhe duas análises de índices diferentes em dois períodos distintos com os mesmos grupos de docentes selecionados para relativizar os resultados para além dos indicadores adotados. 
2 A PÓS-GRADUAÇÃO EM TURISMO NO BRASIL: ASPECTOS HISTÓRICOS E INTRODUTÓRIOS 


\subsection{Pós-graduação no Brasil}

Conforme Navas, Ca, et al. (2017), os sucessos alcançados pelo Brasil na pós-graduação nos últimos anos têm sido motivo de satisfação tanto para a comunidade científica como para as autoridades públicas que se empenharam para conquistar esses resultados. A ampliação do sistema de pós-graduação foi fundamental na formação de docentes e na geração de conhecimento científico no país. Atualmente, existem parcerias entre universidades e empresas que enriquecem os projetos acadêmicos e, ao mesmo tempo, contribuem para a inovação e tecnologia. Podemos verificar isso a partir do aumento crescente das matrículas na pós-graduação no Brasil, conforme relatório recente da Coordenação de Aperfeiçoamento de Pessoal de Nível Superior - (CAPES). (Gráfico 1).

Gráfico 1 - Projeção dos alunos matriculados em programas de pós-graduação stricto sensu no Brasil entre 2011 e 2020: doutorado, mestrado acadêmico e mestrado profissional

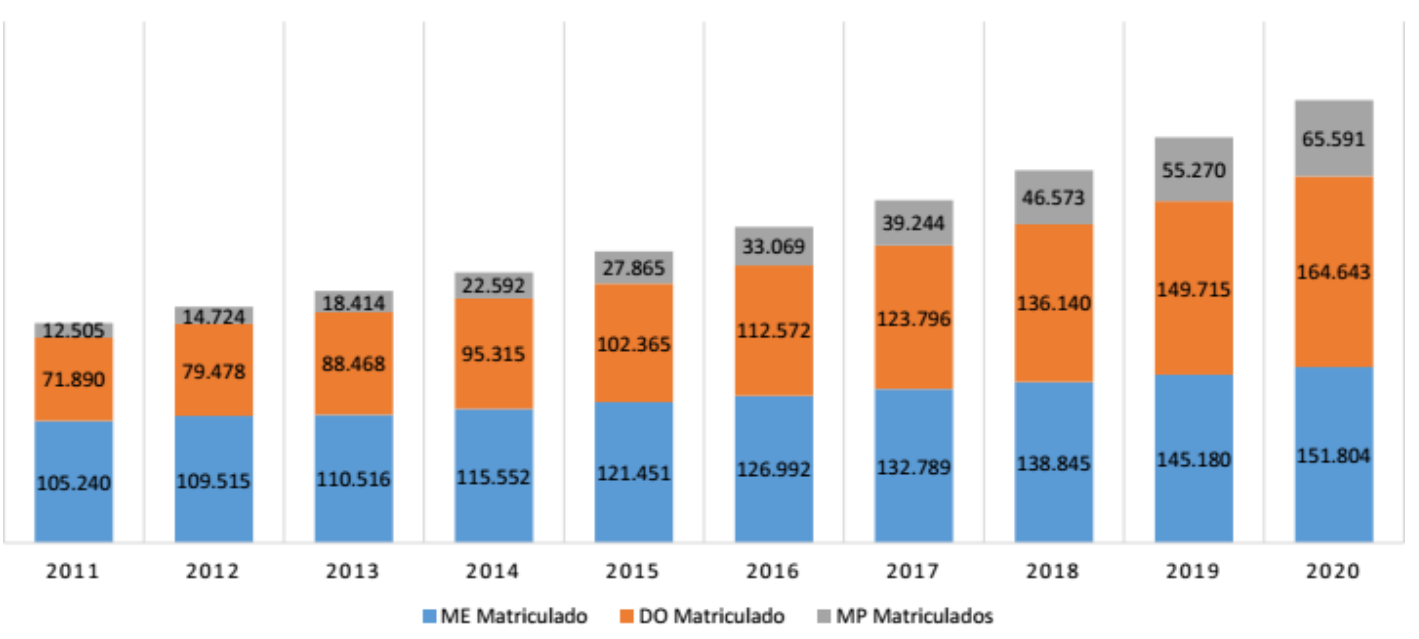

Fonte: CAPES (2017).

Esses dados do gráfico acima apontam que a pós-graduação está se expandindo numericamente, como se pode apreender pelo aumento constante das matrículas. Isso é evidente tanto no mestrado acadêmico e no doutorado quanto na modalidade recente do mestrado profissional. A projeção para 2020, 
segundo o relatório da Capes de 2016/2017, é que teremos 65.551 no mestrado profissional, 151.804 no mestrado acadêmico e 164.643 no doutorado.

Por outro lado, a pós-graduação enfrenta vários desafios importantes à medida que avança: falta de infraestrutura adequada, corte nos investimentos, desvalorização da remuneração dos funcionários e docentes, e até a perda da autonomia universitária. Isso evidencia que é importante crescer com qualidade, não crescer a qualquer custo. Nota-se que se faz necessário adotar tanto parâmetros globais fundamentais ao desenvolvimento da tecnologia e da ciência no Brasil, mas também o conhecimento local para que haja a distribuição regional dos conhecimentos e a defesa dos bens culturais imateriais, uma vez que o país tem proporções continentais.

Outro fator importante da cultura acadêmica no território nacional é que a pós-graduação acolhe em seu seio diferentes e diversas áreas e subáreas. Os grandes campos do saber instituídos politicamente nas agências de fomento nacionais (principalmente CNPq e CAPES) são: ciências agrárias, ciências da saúde, ciências humanas, ciências da linguagem, ciências da tecnologia, ciências exatas e ciências biológicas. Dentro dessas grandes áreas, estão segmentadas as mais diversas e distintas perspectivas teórico-metodológicas adotadas e desenvolvidas no Brasil. Além disso, nos últimos anos, tem se destacado o campo dos estudos inter, multi e transdisciplinares que, subvertendo as fronteiras das disciplinas, acolhe, multiplica e faz dialogar esses diversos e distintos campos do conhecimento.

Essa conjuntura política e sociocultural, atualmente em expansão, foi sendo construída historicamente e de forma paulatina no país, não sendo, desse modo, caótica ou casual. Um fenômeno recente que trouxe resultados positivos, por exemplo, foi a ampliação de cursos interdisciplinares tanto na graduação, quanto na pós-graduação, em suas diversas modalidades conforme explica Velloso (2014). Isso se evidencia nos relatórios dos últimos anos da Capes (2017).

Segundo Velloso (2014), a introdução formal dos cursos de pósgraduação no Brasil se deu entre os anos de 1960 e 1970 - para sermos exatos, a partir do parecer ํำ 977, publicado em 3 de dezembro de 1965 do Conselho 
Federal de Educação (CFE), que ficou conhecido como Parecer Sucupira ${ }^{1}$. Esse parecer estabeleceu a pós-graduação como um escalão dos estudos avançados na estrutura educacional brasileira em sentido amplo. Ele possibilitava uma gama de habilitações em cursos stricto sensu e trazia, ainda, informações pertinentes à análise dos programas de pós-graduação.

É relevante salientar que, de acordo com Bomeny (2001, p. 59), a presença de Newton Sucupira nesse processo foi essencial. Isso se deve por diversos motivos. O principal deles é que esse estudioso "modificou a própria estrutura de pensamento do Conselho Federal de Educação (CFE), de uma atitude prático-especulativa da Filosofia da Educação para uma perspectiva mais prática das implicações dos processos educacionais" ( BOMENY, 2001, P. 59). Partindo desse princípio, Velloso (2014) enfatizou que a pós-graduação deveria trazer contribuições para a educação, a pesquisa, a cultura e o aperfeiçoamento profissional do povo brasileiro, de forma geral e abrangente.

Velloso (2014) também relatou que a definição dos cursos de pósgraduação e as suas características estavam difusas. Desses questionamentos, surgiu a distinção entre a pós-graduação stricto sensu e a lato sensu:

Os cursos de pós-graduação lato sensu assumem formas de aperfeiçoamento e especialização, esses cursos visam uma formação básica. A pós-graduação stricto sensu, organizada sob as formas de mestrado e doutorado, é voltada para a formação do pesquisador, o elemento definidor da pós-graduação stricto sensu é a pesquisa, com objetivo da pesquisa ser requisito para o desenvolvimento do país. (SAVIANI, 2002, p. 14).

O curso de pós-graduação lato sensu é voltado a uma formação básica, já o stricto sensu é uma formação especializada, dirigida a pesquisadores. De acordo com Prates (1997, p. 22), esta última tem características bastante peculiares, a saber:

[...] não é umamera ação programada como é a graduação voltada às profissões regulamentadas por lei. Universalmente a pós-graduação [stricto sensu] tem caráter solidamente livre, exatamente para permitir a experimentação e a formação do espírito de investigação criativa e de crítica intelectual, é o que se observa de maneira clara nos países mais civilizados, onde não se admitem organismos estatais

\footnotetext{
${ }^{1}$ O parecer foi emitido por Newton Lins Buarque Sucupira (1920-2007), pesquisador formado em História e Filosofia da Ciência, que participou durante 16 anos do CFE e ficou conhecido como o "pai da pós-graduação" por causa da importância na regulamentação deste nível de ensino no Brasil.
} 
centralizados e normalizadores da atividade de pós-graduação que é privativa da necessária autonomia universitária.

Para Saviani (2002), o termo curso está ligado ao ensino e o seu centro é o elenco de disciplinas frequentadas pelos alunos. Já o termo programa abarca tanto as atividades de ensino como as de pesquisa, nas quais o aluno desenvolverá uma dissertação ou tese. Logo, esse processo tem o papel de garantir a assimilação dos procedimentos e resultados do desenvolvimento do conhecimento. Nesse contexto a CAPES é o órgão responsável por coordenar esse processo.

Criada em 1951, a CAPES, órgão do Ministério da Educação, regulamenta a pós-graduação no Brasil, desempenhando um papel importante para o avanço das pesquisas brasileiras. Além da CAPES, existem, como já mencionamos, outros órgãos federais que também auxiliam no progresso científico e tecnológico do Brasil. Sendo eles: o CNPq, as Fundações de Amparo à Pesquisa dos Estados (e.g. Fundação de Amparo à Pesquisa do Estado de São Paulo - FAPESP; Fundação de Amparo à Pesquisa do Estado do Rio de Janeiro - FAPERJ; Fundação de Amparo à Pesquisa do Estado de Minas Gerais - FAPMIG, - dentre outras). Todas essas agências apoiam o sistema de pósgraduação e a pesquisa por meio de editais, bolsas e outros programas de fomento.

Gaeta (2007) explica, que o desenvolvimento da pós-graduação lato sensu e stricto sensu, a partir de sua implantação e da sua institucionalização, enfrentou vários problemas e ajustes. Nas décadas de 1970 e 1980, como descreve a autora, a pós-graduação apresentou grande evasão, o ensino pouco se relacionou com a pesquisa e, por isso, poucos alunos permaneciam na universidade como pesquisadores. Uma exceção dentro desse contexto era o caso dos cursos de educação que se preocupavam com a formação de seus alunos, futuros professores. No restante dos cursos de pós-graduação, notavase um certo descaso com a formação do alunado.

Diante desses desafios entre a evasão e a formação, foi preciso criar critérios de avaliação para os programas de pós-graduação no país. Por isso, a implementação dos critérios do sistema de avaliação da CAPES foi importante para o desenvolvimento da pós-graduação. Balbachevsy (2005, p. 274) afirma 
que a avaliação da pós-graduação se iniciou por volta de 1976, e consolidou-se na década seguinte.

Ressalta-se que o início básico do sistema foi a produção de critérios de avaliação por pares indicados pela comunidade científica. A avaliação começou sendo anual, passando depois a ser bienal, trienal, e hoje, é feita por quadriênio. Ela consiste em uma avaliação constante que faz acompanhamentos intermediários ano a ano, no qual a cada período os programas de pósgraduação pertencentes a um conjunto de áreas do conhecimento são avaliados. Em termos do detalhamento dos critérios do sistema de avaliação, a CAPES tem como objetivos, segundo Sguissardi:

\begin{abstract}
Estabelecer o padrão de qualidade exigido dos cursos de mestrado e doutorado; identificar os cursos que atendem a tal padrão; fundamentar nos termos da legislação em vigor os pareceres do Conselho Nacional de Educação sobre a autorização, reconhecimento dos cursos de mestrado e doutorado brasileiros, exigência legal para que estes possam expedir diplomas com validade nacional reconhecida pelo Ministério da Educação (MEC), impulsionar a evolução de todo o Sistema Nacional de Pós-Graduação (SNPG) e de cada programa em particular, antepondo-Ihes metas e desafios que expressam os avanços da ciência e da tecnologia na atualidade, bem como o aumento da competência nacional nesse campo (SGUISSARDI, 2008, p. 137-164)
\end{abstract}

A avaliação dos programas de pós-graduação no Brasil, de acordo com Sguissardi (2008), possui um caráter abrangente e indutor das práticas científicas. A excessiva centralidade que envolve a avaliação que a CAPES faz dos cursos de pós-graduação não deixa de sofrer restrições e críticas, gerando nesse âmbito alguns prejuízos para a autonomia dos programas. Segundo esse estudioso, esse panorama acaba por criar uma espécie de "cultura do conformismo", porque essa avaliação engessa a estrutura e a gestão das instituições, beneficiando, assim, alguns programas em detrimento de outros. Essa situação pouco mudou nos últimos 10 anos, conforme alertam os estudos de Halffman et al. (2017) e Marques (2017).

De acordo com Lima (2012, p. 176), o cunho produtivista foi incorporado ao Plano Nacional de Pós-graduação concernente ao período de 2005-2010. Nesse momento, ao invés de avaliar os programas com base na sua potencialidade e relevância institucional e regional como ocorria anteriormente, concentrou-se nos indicadores dos docentes credenciados para atuarem nos 
programas de pós-graduação. Foi exigido, então, um padrão produtivista dentro de um campo restrito de periódicos qualificados e indicados pela própria CAPES.

É preciso referenciar a tese da pesquisadora Vogel (2015). Ela indica que a avaliação da pós-graduação é pauta acadêmica de professores, pesquisadores, estudantes. Logo, deve existir a conviç̧ão de que há a necessidade de se fazer uma revisão nos critérios e na forma que essa avaliação vem sendo processada nos últimos anos.

$\mathrm{Na}$ perspectiva de Vogel (2015), deve haver uma avaliação dos programas de pós-graduação no Brasil. A pesquisa explora os dois lados distintos da problemática da avaliação: o do sistema de avaliação da CAPES e o da comunidade científica. Vogel (2015) salienta que a comparação do sistema brasileiro de avaliação dos programas de pós-graduação com os sistemas de outros países pode trazer importantes contribuições para o aprimoramento do sistema da CAPES. Apesar de haver obstáculos, como, por exemplo, a morosidade na atualização dos critérios da CAPES em relação ao processo contínuo e acelerado dos modos de se fazer ciência no Brasil: antes se publicavam muitos livros e manuais científicos; hoje, são editados artigos científicos, teses e dissertações.

Outra questão que a autora ressalta é o problema do acesso às informações para pesquisadores. Ainda não existe um canal de informações para quem deseja estudar os dados de avaliação armazenados no sistema da CAPES (VOGEL, 2015). O que há é a Plataforma Sucupira (https://sucupira.capes.gov.br) que armazena as informações sobre os programas de pós-graduação, os periódicos credenciados, grupos de pesquisa, dentre outras. Todavia, esse sistema não expõe todos os critérios, nem todos os dados coletados anualmente, apenas alguns deles são apresentados ao grande público. Isso evidencia que existe uma seleção de dados.

Diante dessas dificuldades de acesso à informação, torna-se fundamental um acompanhamento contínuo da educação e da pesquisa brasileira para que os pesquisadores possam sugerir melhorias ao sistema e este possa se atualizar com maior rapidez. Também é preciso repensar o momento pelo qual a pesquisa brasileira está passando: já foi consolidada uma rede consistente de programas de pós-graduação em todo o território nacional, é preciso, agora, integrar e gerir melhor essa rede. No atual momento político do país, Vogel (2015) alerta que 
existe a preocupação do retrocesso das áreas de educação, de ciência e de tecnologia. Isso pode ocorrer e, caso aconteça, dificultará as boas propostas e alterará o curso da história científica brasileira de forma catastrófica.

Mesmo diante das críticas e dos desafios, o Brasil tem a maior estrutura de pós-graduação da América Latina. O gráfico 2 apresenta o número de programas e cursos de pós-graduação no Brasil. Nela, os programas e cursos são distribuídos com relação aos tipos (mestrado acadêmico/mestrado profissional e doutorado) e também conforme os conceitos da CAPES (de 1 a 7 ).

Gráfico 2 - Distribuição de Programas de Pós-Graduação stricto sensu por Grau: Mestrado/Doutorado, Mestrado acadêmico, Mestrado profissional, Doutorado



Fonte: Sucupira (2018)².

Evidenciado no gráfico 2, na distribuição de programas de pós-graduação por grau, o maior número é os de programas possuem tanto o grau de doutorado quanto o de mestrado, os quais, juntos, somam 2.106. Em seguida, vem os programas que possuem apenas o grau de mestrado acadêmico que equivalem a 1.292. Em terceiro lugar, vem os programas com grau de mestrado profissional que são um total de 703. E, por fim, os programas de pós-graduação que oferecem apenas o grau de doutorado que são 76 . Esses dados foram divulgados em 2018 com referência da avaliação de 2017. Que avaliou o período 2013-2016.

Sobre a distribuição dos programas de pós-graduação por status jurídico, podemos observar a seguinte configuração conforme o Gráfico 3:

\footnotetext{
${ }^{2}$ Disponível em: < https://geocapes.capes.gov.br/geocapes/>. Acessado em: 13 mar. 2018.
} 
Gráfico 3 - Distribuição dos programas de pós-graduação stricto sensu conforme o status jurídico: federal, estadual, particular e municipal

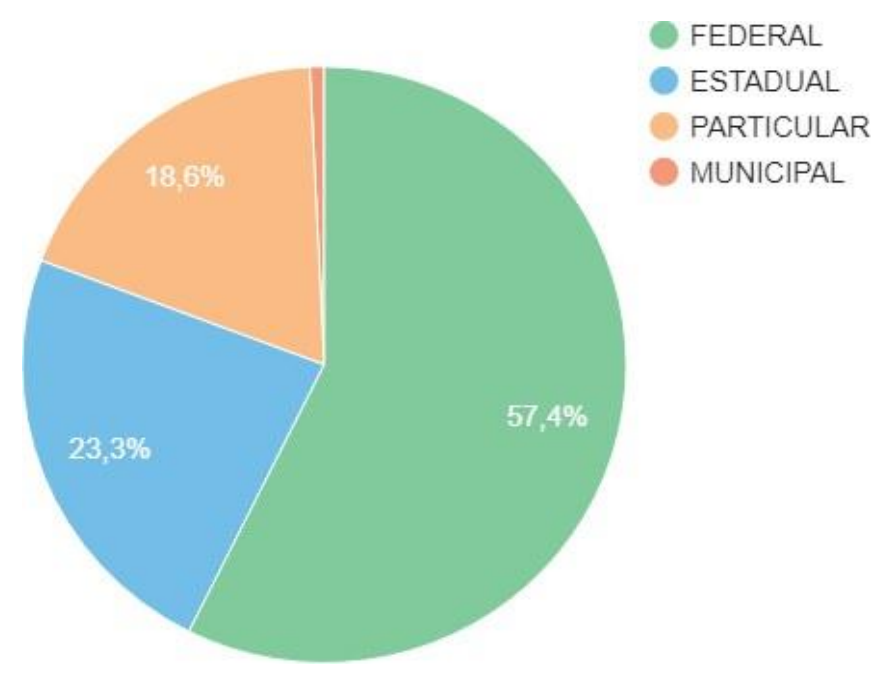

Fonte: Sucupira (2018) ${ }^{3}$.

Conforme o status jurídico, podemos perceber que a maior parcela é de jurisdição federal, com $57,4 \%$. Em seguida, vem o status estadual, com $23,3 \%$. Em terceiro, está o particular com 18,6\%. O municipal tem apenas $0,7 \%(\mathrm{O}$ ensino superior não é competência do executivo municipal). Somando esses dados, a esfera pública domina $81,4 \%$ da jurisdição da pós-graduação no Brasil, enquanto que a esfera privada concentra somente $18,6 \%$. Observa-se que se a análise fosse pela graduação, a concentração seria nas Instituições de ensino superior (IES) privadas.

Outro fator que influencia na escolha dos programas de pós-graduação e também nos repasses de verbas públicas é a nota CAPES. Essa nota é atribuída, conforme os dispositivos legais vigentes, a cada quadriênio. Seguindo essa nota e observando sua distribuição no mapa do Brasil, a plataforma Sucupira disponibiliza os dados da Figura 1. Esses dados foram atualizados em 16 de janeiro de 2018 com a referência dos relatórios de 2017.

${ }^{3}$ Disponível em:< https://geocapes.capes.gov.br/geocapes/>. Acessado em: 13 mar. 2018. 
Figura 1 - Distribuição dos programas de pós-graduação stricto sensu conforme a nota CAPES (quadriênio 2014-2017) e respectivo status jurídico

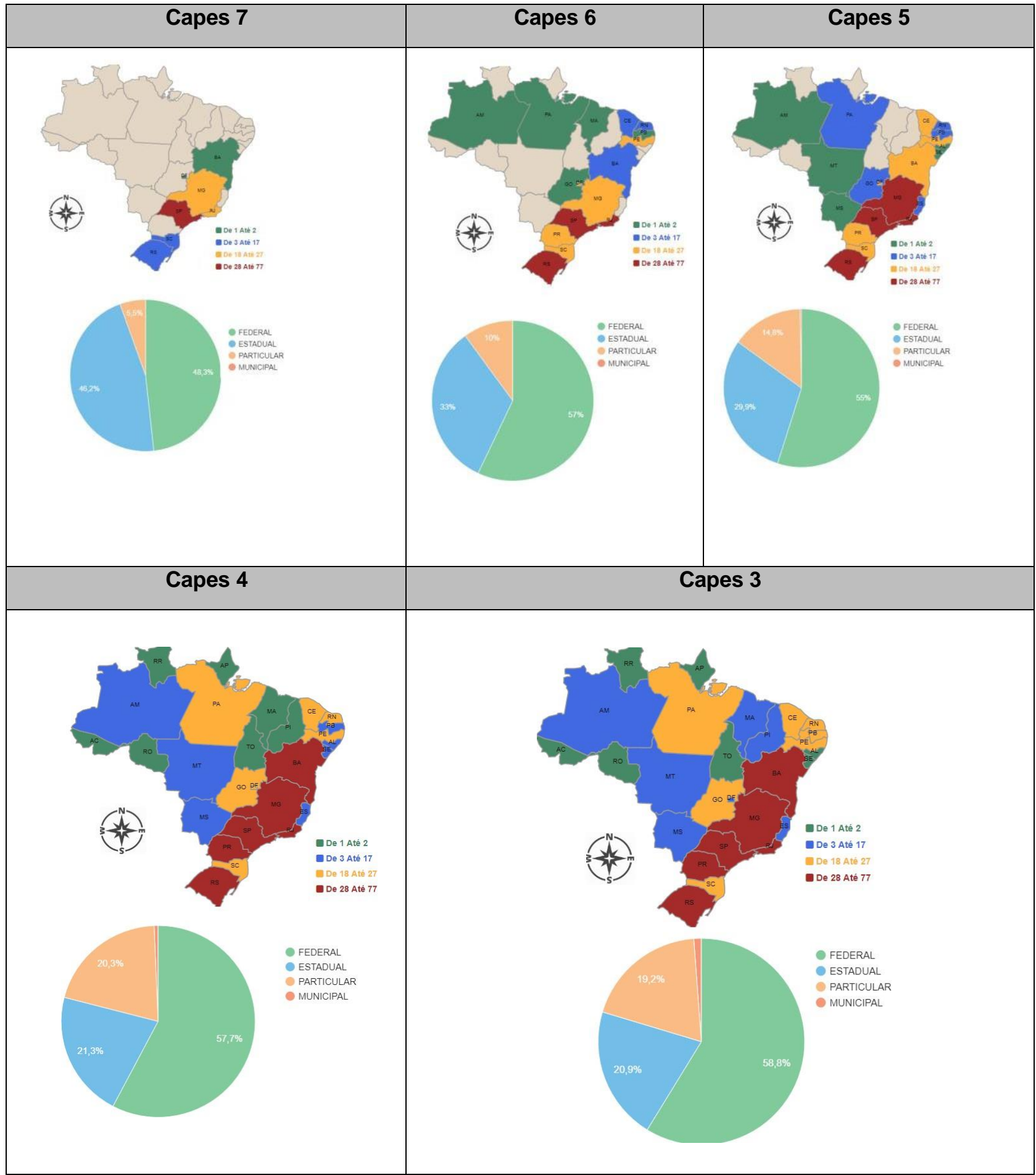

Fonte: Sucupira $(2018)^{4}$.

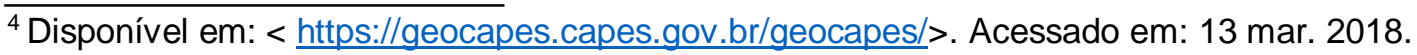


Atualmente, a pós-graduação está presente em todas as regiões brasileiras, como mostra a Figura 1 a partir dos diferentes quadros de avaliação. A nota CAPES dos programas de pós-graduação é um dos principais indicadores de desenvolvimento regional do Ensino Superior. Pelo quadros da Figura 1, pode-se observar que há a necessidade de aumento do número de Programas nas regiões Norte, Centro Oeste e Nordeste com avaliações superiores a nota 5. Outro indicador que foi notado é que os estados das regiões Sudeste e Sul possuem melhores notas - isto é, 7 e 6 - do que as demais regiões país.

É importante ressaltar que a nota 7 , a nota máxima da CAPES, se concentra em apenas seis estados, a saber: São Paulo, Bahia, Rio de Janeiro, Santa Catarina, Rio Grande do Sul e Minas Gerais. Com a nota CAPES 6, temos dezesseis estados e o Distrito Federal nos quais possuem programas pósgraduação com essa nota, a saber: Amazonas, Pará, Maranhão, Goiás, Paraíba, Ceará, Rio Grande do Norte, Bahia, Pernambuco, Minas Gerais, Paraná, Santa Catarina, São Paulo, Rio de Janeiro e Rio Grande do Sul. Com nota 5, temos 21 estados e o Distrito Federal. Com notas 4 e 5, temos todos os estados e o Distrito Federal.

Observa-se que conforme a nota CAPES vai diminuindo a proporção da particular vai aumentando. Em outras palavras, proporcionalmente, o status jurídico da particular aumenta conforme a nota CAPES diminui. Outro aspecto relevante é que o status jurídico municipal só tem programas de pós-graduação com nota CAPES 3 e 4 . O status jurídico da Federal, por sua vez, possui em todas as avaliações uma proporção igual ou superior a $48,3 \%$.

Em relação às notas, elas são atribuídas aos programas numa escala que vai de 1 a 7 , levando em consideração quesitos como proposta do programa, corpo docente, corpo discente, teses e dissertações, produção intelectual, inserção social e infraestrutura de ensino e pesquisa. Cada um desses quesitos é subdividido em itens que possuem pesos numa escala de 10,00 a 100,00 e avaliação que varia entre fraco, regular, bom, muito bom e excelente. As notas 1 e 2 descredenciam os programas. A nota 3 significa desempenho regular e atendimento aos padrões mínimos de qualidade, as notas 4 e 5 significam um desempenho entre bom e muito bom, sendo que 6 e 7 indicam desempenho equivalente a padrões internacionais de excelência para os programas de mestrado e doutorado (CAPES, 2017). 


\subsection{Panorama da pós-graduação stricto sensu em turismo no Brasil}

Segundo Trigo (2000, p. 243), na década de 1950, os primeiros empresários do turismo iniciaram suas atividades no Brasil. Para eles, o turismo era algo que poderia ser inserido como um trabalho diário e lucrativo. A princípio, as universidades brasileiras não estavam preparadas para ensinar nessa área, nem havia docentes habilitados para tal exercício.

O Serviço Nacional de Aprendizagem e Comércio de São Paulo (SENACSP) lançou em 1950 uma oferta de educação profissional na área do turismo e hotelaria. Essa oferta, inicialmente apresentada devido à demanda regional, teve forte desenvolvimento nas regiões Sudeste e Sul do país. Conforme explica Fonseca Filho (2007), esses cursos do SENAC-SP atendiam a qualificação de quadros operacionais de base para hotéis e restaurantes. Silva (2007) explica, ainda, que os cursos ofertados eram direcionados para garçons e cozinheiros, não sendo, nesse primeiro momento, um curso de ensino superior, era apenas e somente de caráter profissionalizante. Mesmo assim, o estudo em turismo no Brasil teve grande adesão devido à essa crescente demanda.

Entre as décadas de 1950 e 1970, fatores históricos, como a mobilidade social, a industrialização, os meios de comunicação, dentre outros, contribuíram na procura dos cursos superiores. Juntamente com isso, no final da década de 1960, a crescente atividade turística e a procura por profissionais qualificados para trabalharem na área possibilitaram a criação de cursos técnicos e de graduação em turismo para atender a formação desses profissionais em diferentes níveis (HALLAL et al. 2010).

A institucionalização do turismo no âmbito do ensino superior se deu a partir de 1971, quando houve a criação do primeiro curso de turismo, com ele, surgiu a definição do currículo mínimo para essa área pelo Ministério da Educação (MEC). A justificativa para a formação em nível superior em turismo no Brasil foi a existência de múltiplas possibilidades do setor turístico para 0 desenvolvimento socioeconômico nacional (PANOSSO NETTO, et al. 2017).

Sobre esse momento de institucionalização, é importante destacar que o curso superior na área de turismo no Brasil, de acordo com Ansarah (2002), 
começou a existir a partir do parecer n. 35/71 do Ministério da Educação. Ele foi feito pelo relator Conselheiro Roberto Siqueira Santos e aprovado em 28 de janeiro de 1971. Esse parecer deu base a uma resolução sem número, de 29 de janeiro de 1971, do Conselho Federal de Educação, que fixou o conteúdo e a duração do curso superior de turismo de, no mínimo, 1.700 horas e com disciplinas obrigatórias, como, por exemplo, Sociologia, História do Brasil, Geografia, dentre outras.

Segundo Rejowski (1996, p. 59), na década de 1970, no Brasil, assim como em outros países, existia uma expectativa e credibilidade sobre o turismo como uma das "chaves que abririam as portas" do desenvolvimento econômico. Isso surge em função da difusão do turismo massivo e a consequente movimentação e circulação de capital, cuja importância econômica já era reconhecida em todo o mundo. Informações eram veiculadas tanto em meios de comunicação especializados (revistas e boletins técnico-científicos), como em meios de comunicação de massa (jornais diários, programas de rádio e televisão), divulgando os aspectos positivos do turismo em sua plenitude.

Segundo Ansarah (2017) ${ }^{5}$, foi o antigo reitor da faculdade de Turismo Morumbi que detectou que as mulheres com filhos que já estavam cursando o antigo primário tinham o tempo ocioso, então, ele fez uma pesquisa com esse grupo nas redondezas da universidade. Esse estudo preliminar desvelou que o período vespertino desse grupo era ocioso e, dentro da gama de opções de cursos, a escolha mais frequente das senhoras foi pelo curso de turismo. Diante dessa demanda e com a expectativa de adesão do grupo pesquisado, foi aberto o primeiro curso de graduação em turismo no Brasil, na atual Universidade Anhembi Morumbi (UAM), situada na cidade de São Paulo (SP) em 1971.

Com o sucesso do curso na (UAM) e a institucionalização da área no ensino superior no âmbito da graduação, outras instituições passam a ofertar a referida formação. Conforme destaca Ansarah (2002, p. 104) a Escola de Comunicações e Artes da Universidade de São Paulo (ECA/USP) foi a segunda instituição a oferecer o curso de graduação em turismo no Brasil. O início da oferta se deu em 1972, sendo o professor doutor Mario Carlos Beni o idealizador e também o primeiro docente de turismo reconhecido pelo MEC.

\footnotetext{
$\overline{{ }^{5} \text { Observação da autora durante }}$ o processo de qualificação desta pesquisa.
} 
Em 1978, a pedido da Empresa Brasileira de Turismo (EMBRATUR atual Instituto Brasileiro de Turismo), foi realizado pela Escola de Comunicações e Artes (ECA) da Universidade de São Paulo (USP) um seminário com a finalidade de se estabelecer um currículo mínimo para os cursos de turismo no Brasil. Foram constituídas duas vertentes educacionais: a primeira, da ECAUSP, "que preconizava uma linha filosófica mais acadêmica, voltada à epistemologia, à pesquisa e ao planejamento do turismo". A outra, liderada pela Universidade Anhembi Morumbi, "que orientava o conjunto de disciplinas da estrutura curricular para o mercado. Destas vertentes surgiram os demais cursos que se seguiram até a década de 1980" (ANSARAH, 2002, p. 49).

Segundo Trigo (1998, p. 221), o primeiro currículo de curso superior em turismo foi elaborado pelo professor Domingo Hernandez Peña, após um levantamento da área nas escolas europeias, seguido de uma adaptação à realidade brasileira. Os primeiros cursos de turismo foram inseridos em unidades universitárias autônomas ou ligados aos igualmente novos cursos de artes e comunicações no país. Chegou-se a discutir a possibilidade de implantar os cursos de turismo nas faculdades de administração de empresas ou de educação física, mas, em vista da realidade do turismo no Brasil, esse projeto foi abandonado, mantendo apenas o curso em unidades independentes ligadas à área de comunicação.

De acordo com Ruschmann (1991, p. 94), antigamente as estruturas curriculares plenas dos cursos superiores em turismo, regulamentadas de acordo com a instituição de ensino, tinham duração de três, quatro ou cinco anos, e baseavam-se no currículo mínimo estabelecido pelo Conselho Federal de Educação-CFE. Hoje, as estruturas curriculares dos cursos técnicos têm duração mínima de 800 horas. Já os cursos de graduação plena com fundamentação humanística têm duração mínima de 2.400 horas e duram em média dois anos e meio (FREIRE, 2015).

Os currículos dos cursos de bacharelado preveem a realização de estágio curricular de pesquisa, disciplinas optativas e estágio supervisionado. É válido acrescentar que os currículos no Brasil são elaborados a partir das orientações das Diretrizes Curriculares, do MEC. Com base nessas diretrizes, cada IES desenvolve o seu próprio currículo, levando em consideração a realidade da região onde o programa é oferecido (PEQUENO, 2012). 
Em consulta realizada ao site do $E-m e c^{6}$, no dia 3 março de 2018, foi verificado que existem 614 cursos de turismo, sendo que 263 estão em plena atividade e 151 foram extintos ou estão em processo de extinção. Dentre os cursos em atividade, existe 331 bacharelados, 129 tecnológicos, 2 licenciaturas e 1 sequencial. Também podemos dividi-los em cursos presenciais e a distância cujos respectivos números são 441 e 22. É importante ressaltar que esses dados podem estar desatualizados, uma vez que o sistema do MEC, embora faça coletas regulares, nem sempre são precisas e conseguem retratar todas as condições de produção, circulação e recepção do conhecimento no território brasileiro.

De acordo com Brusadin (2007), existiam no Brasil centenas de cursos de turismo, mas por serem deficitários, não atingiram o objetivo de propiciar uma formação profissional consistente, na qual poderia contribuir para o desenvolvimento do turismo em diversas regiões do país. Ansarah (2002) destacou que a abertura indiscriminada de novos cursos superiores não conseguiu formar mão-de-obra capacitada, e que só seria possível com a melhoria da qualidade do ensino.

Diante dessa contingência entre o que era esperado e o que foi realizado, é necessário refletir sobre o tipo de formação oferecida na graduação e na pósgraduação em turismo. Como já salientamos, há duas vertentes: uma que privilegia a formação profissional e a outra, a formação humanística. Em outras palavras, uma vê o mercado (da universidade para o campo de trabalho) e a outra observa o campo do conhecimento (do meio socialcultural para a pesquisa). Se as universidades privilegiarem um dos lados, com certeza, o alunado será prejudicado em alguma instância, porque se só forem atendidas as necessidades dos meios de trabalho, o ensino fica tecnicista e pouco contribui para o desenvolvimento tecnológico e cientifico do campo de saber. De outro ponto de vista, se apenas forem concentrados os esforços na pesquisa e nada

\footnotetext{
${ }^{6}$ Disponível em: - E-MEC: base de dados oficial e única de informações relativas às Instituições de Educação Superior- IES e cursos de graduação do Sistema Federal de Ensino. Disponível em: <http://e-mec.gov.br>. Acesso em: 13 mar. 2018.
} 
retribuir, de forma prática e sustentáve à sociedade, se construirá um campo de saber limitado e de pouca valia às demandas da comunidade.

Para Mota (2005), o sucesso de uma formação adequada ao turismólogo é a integração entre uma formação humanística e uma formação profissional. Em sua tese de doutorado, Mota (2005) aborda a qualificação de recursos humanos em turismo e hotelaria na sociedade pós-industrial, discutindo a identidade do turismólogo e sua empregabilidade. A autora ressalta que a qualidade e a quantidade da oferta de cursos superiores de turismo e hotelaria devem se equiparar a integração multidisciplinar e a sustentabilidade na sociedade atual e futura, isto é, melhorar o curso de turismo conforme as demandas econômicas, socioculturais, profissionais de cada momento histórico.

Na mesma direção de Mota (2005), Trigo (1998) argumenta a favor da formação de recursos humanos associada ao perfil profissional do turismólogo, sem com isso deixar de diferenciar formação profissional e qualificação profissional:

\begin{abstract}
no nível superior, o processo de formação profissional deve ser centrado na educação e não em simples treinamento, desse modo, quando houver referência ao termo "formação profissional" entenda-se que se refere ao conhecimento profissional constituído e acumulado, e, quando houver referência ao termo "qualificação profissional" entenda-se que se referem as habilitações ou qualidades que permitem um indivíduos estar apto ao exercício profissional em questão (TRIGO, 1998, p. 199).
\end{abstract}

Compreendemos, assim, que opor uma formação humanística a uma formação profissional na área de turismo é contraproducente, porque, de um lado, pode tornar o ensino tecnicista e, de outro, pode enfraquecer o campo de conhecimento dessa formação. O mais adequado é integrar características dos recursos humanos à formação profissional do turismólogo. Isso proporciona uma maior abrangência de saberes, unindo a teoria à prática, pois hoje as universidades se associam às indústrias, em busca de investimento e trocas de conhecimentos, bem como para proporcionar os estágios, optativos ou obrigatórios. Apesar que a abordagem humanística não necessariamente se relaciona com o desenvolvimento tecnológico e científico, por exemplo a filosofia que faz parte de uma formação humanística, mas não é ciência. 
Discutida a problemática da formação do turismólogo, observemos a trajetória dos cursos superiores de turismo no Brasil, depois de sua implementação. De acordo com Teixeira (2007), para compreender essa trajetória bem como seu contexto histórico-social, é necessário considerar as condicionantes que levaram um curso sem tradição acadêmica a se espalhar e a se consolidar em nível universitário. São consideradas seis fases para estudar a história do curso de turismo no Brasil (PANOSSO NETTO, et al. 2017). A primeira foi a criação, em 1966, da EMBRATUR, que, a partir daí, estimulou os investimentos em redes hoteleiras, meios de transportes e infraestrutura básica e turística. Isso, consequentemente, gerou a necessidade de formar profissionais para atuar nesse locais.

Destaca-se, ainda, que essa primeira fase foi marcada pela criação do curso de turismo em 1971, na Universidade Anhembi Morumbi, depois na USP, em 1972, e em 1978 com os cursos tecnológicos iniciados pela Universidade de Caxias do Sul-RS,(ANSARAH, 2002). Esse foi o período conhecido como Milagre Brasileiro, no qual grandes obras de infraestrutura foram financiadas e apoiadas pelo governo militar no poder.

Segundo Ansarah (2002), a segunda fase se inicia na década de 1980. Ela se caracterizou pela estagnação da oferta de cursos, devido a um cenário de crise econômica conhecida como A Década Perdida. Não há dados sobre quantas formações de turismo foram ofertadas até o final da década de 1980 no país (PANOSSO NETTO, et al. 2017).

Isso se deve a diversos fatores, o principal deles é a atuação do regime militar que dificultava e censurava a divulgação de registros e dados nacionais ao grande público. Além disso, Panosso Netto e Trigo (2009) salientam que o crescimento quantitativo dos cursos de graduação em turismo no Brasil não foi acompanhado de uma evolução qualitativa. Esse contexto também justifica o motivo de muitos desses cursos na época atravessarem uma crise e terem sido fechados, em especial aqueles ofertados nas instituições privadas.

A terceira fase ocorre na década seguinte, que é a de 1990. Ela marca a fase de desenvolvimento do ensino do turismo no Brasil. Ela é caracterizada pela valorização dos cursos no âmbito acadêmico, tendo novamente o aumento dos cursos de turismo e hotelaria (ANSARAH, p. 74, 2002). Em 1991, havia 28 cursos de graduação em turismo no Brasil (PANOSSO NETTO; TRIGO, 2009, p.118), 
aumentando para 32 cursos de turismo e hospitalidade em 1994 e 225 em 2000 (TEIXEIRA, 2007).

Em relação à quarta fase, Ansarah (2002) destaca:

[...] que deverá estabelecer o equilíbrio "quantidade versusqualidade", com o aumento quantitativo de propostas diferenciadas de cursos e uma tendência de cursos de turismo com ênfases direcionadas para a flexibilização e a regionalização, como a LDB, 1996. Alguns exemplos são eventos, lazer, hotelaria e planejamento, já para os cursos de administração, observa-se habilitação diversificada. Primeiramente, uma concentração em turismo com habilitações em gestão de serviços turísticos, gestão em turismo, empreendimentos turísticos. Outra concentração é direcionada à hotelaria, com habilitações voltadas para administração hoteleira, empresas hoteleiras, gestão em hotelaria e restaurantes; e ainda as habilitações para a formação em turismo e hotelaria (ANSARAH, 2002, p. 74).

Por sua vez, Panosso Netto et al. (2017) elenca a quarta fase como a consolidação e a internacionalização (2000-2010), destacando que o número de cursos cresceu até meados de 2000. Em 2005, havia 834 graduados (LEAL, 2011) e 1.084 em 2010 (595 bacharelados, 450 de dois anos tecnológicos, 38 sequenciais e um de licenciatura). Posteriormente, o número de cursos de educação superior começou a diminuir. Saturação do mercado de trabalho e cursos com desequilíbrio (mais teóricos e menos práticos) contribuíram para esse declínio, conforme os mesmos autores.

Por causa do grande número de faculdades e pelo fechamento de muitas delas, por não terem uma evolução qualitativa, ocorreu uma expansão dos cursos de graduação em turismo nas universidades públicas, como o curso de Lazer e Turismo, da Escola de Artes, Ciências e Humanidades da Universidade de São Paulo (EACH/USP), da Universidade Estadual Paulista (UNESP), Campus de Rosana, os cursos de Turismo, da Universidade Federal do Mato Grosso do Sul (UFMS), Universidade do Estado da Bahia (UNEB), Instituto Federal da Bahia (IFBA), dentre outras universidades (PANOSSO NETTO; TRIGO, 2009, p.175).

Panosso Netto et al. (2017) identificaram uma quinta fase na educação superior do turismo depois de 2010. Ela é marcada por uma busca por internacionalização, fortalecimento e criação de novos programas de pósgraduação. Busca-se, ainda, a criação de novas revistas científicas e há um maior estímulo para o fortalecimento de associações de pesquisa. 
Com relação à sexta fase, ela está associada às pressões econômicas e sociais que criaram novos caminhos para as relações de trabalho no Brasil e no mundo. As crises globais de 2008 a 2009 afetaram o país entre 2014 e 2016, gerando inflação, desemprego, índices negativos na balança comercial e uma diminuição geral no número de estudantes no ensino superior, particularmente, no setor de educação privada (PANOSSO NETTO et al. 2017).

A indústria transformadora sofreu a queda mais acentuada, mas também houve perdas no setor de serviços, incluindo o turismo. A maior quantidade de empregos retidos foi entre os setores mais tradicionais, que normalmente recebiam trabalhadores com conhecimento oriundos de faculdades $e$ universidades (PANOSSO NETTO et al. 2017).

O aumento dos cursos de pós-graduação criou uma nova oportunidade para a promoção de conhecimentos. Nas últimas décadas, o ensino superior do turismo não se consolidou como uma profissão, mas, pelo contrário, firmou-se como uma área de estudo, aprofundando teorias que, outrora, separavam as universidades do setor comercial (PANOSSO NETTO, et al. 2017). Atualmente, as universidades se filiam às empresas, em busca de investimento, bem como para proporcionar os estágios, optativos ou obrigatórios.

Em relação aos programas de pós-graduação stricto sensu, Gaeta (2007) afirma que são cursos voltados à formação científica e acadêmica, ou seja, associados à pesquisa. Existem nos níveis do mestrado acadêmico, profissional e doutorado e, em 2008, surgiu o doutorado profissional. O curso de mestrado tem a duração de dois anos a dois anos e meio, durante os quais o aluno desenvolve uma dissertação e cursa as disciplinas relativas à sua pesquisa. Os doutorados têm a duração média de quatro anos, para o cumprimento das disciplinas, realização da pesquisa e para a elaboração da tese. Todas essas modalidades conferem diplomas.

No entanto, a história da pós-graduação brasileira em turismo é fruto da institucionalização da atividade no país, da ascensão do ensino superior na área e da demanda por profissionais preparados para pesquisar, ensinar e produzir conhecimento sobre uma atividade relativamente nova e em franca expansão no mundo (MILAGRES, 2014). Todos esses são fatores que elevaram os níveis de exigência tanto no ambito educacional, quanto no profissional. Da universidade 
para a sociedade, quanto desta para aquela, é a via de mão dupla que fortaleceu a consolidação da pós-graduação stricto sensu em turismo no Brasil.

Conforme Rejowski (2010), é nesse cenário que o ensino de pósgraduação iniciou suas atividades com a sua criação em 1993. Segundo ela, o primeiro programa de pós-graduação stricto sensu em turismo no Brasil foi realizado na Universidade de São Paulo (USP), na Escola de Comunicações e Artes (ECA). O programa foi extinto em 1996, passando a ser uma das linhas de pesquisa da pós-graduação em Ciências da Comunicação, também da ECA/USP, já que a demanda por profissionais qualificados para o planejamento e a organização da atividade turística no país ainda é necessária.

Apesar de Rejowski (2010) afirmar que em 1993 teria se iniciado a pósgraduação em turismo na (USP), de acordo com Ansarah (2002, p. 105), o primeiro curso de mestrado na área de turismo foi oferecido pela Universidade do Vale do Itajaí (UNIVALI) em turismo e hotelaria, sendo recomendado pela CAPES, em dezembro de 1999, em administração/turismo, tendo a professora doutora Doris Ruschmann como idealizadora dos cursos de pós-graduação.

A plataforma Sucupira informa que foi a UNIVALI, a primeira instituição a oferecer o primeiro mestrado em turismo no Brasil. Temos, assim, um dissenso na literatura sobre a criação da pós-graduação stricto sensu em turismo no país, todavia nosso posicionamento é que o primeiro curso stricto sensu de turismo, efetivamente, realizado e recomendado pela CAPES foi o ofertado pela UNIVALI, pois o programa da USP era uma linha de pesquisa dentro do programa de Ciências da Comunicação.

A pós-graduação stricto sensu no Brasil representa uma alternativa de formação para profissionais atuarem no campo do turismo sob o escopo da qualificação de docentes e pesquisadores. Tem-se, assim, finalidade de formar profissionais motivados em aprofundar conhecimentos teóricos e práticos sobre as diversas temáticas do turismo seja em pesquisa ou ensino (GOMES et al. 2008). Como se nota, houve uma mudança paulatina das demandas socioculturais: outrora, buscava-se a formação básica (por exemplo, os primeiros cursos oferecidos pelo (SENAC-SP), agora, pretende-se obter uma formação mais teórica e prática (como os cursos da UNIVALI), dentre outros.

Segundo Gaeta (2007), os programas de pós-graduação stricto sensu vêm consagrando o princípio da indissociabilidade entre ensino e pesquisa. Essa 
perspectiva privilegia a formação do pesquisador especialista em determinada área de estudos e reforçando o princípio da racionalidade técnica. Com isso, o profissional possui certo conhecimento formal e se propõe a ensiná-lo.

É necessário desenvolver a produção acadêmica, devendo passar pelo processo de divulgação e facilitar o acesso da comunidade universitária ao conhecimento, a fim de gerar bibliografia e base teórico-metodológica para 0 campo de conhecimento. A produção bibliográfica dos docentes deve levar a um novo pensar sobre o efeito prático do conhecimento produzido na academia, exercendo assim um discurso maduro e colocando-se em constante reflexão sobre seu fazer-saber. Em outras palavras, a universidade precisa ser um espaço por excelência da crítica, mas para que isso aconteça, deve-se estimular que os programas de pesquisas e ensino atuem na sociedade de forma prática e não somente teórica (PANOSSO NETTO e NECHAR, 2016).

Voltando à problemática da avaliação dos programas de pós-graduação, como já expusemos, existem inúmeras discussões entre os acadêmicos da área do turismo sobre esse tema e seus critérios (KOEBSCK, 2017). Dentre os requisitos de avaliação, está a produção científica dos pesquisadores, professores e alunos. Essa avaliação considera a publicação de artigos em periódicos avaliados regularmente pela CAPES e isso tem sido alvo de questionamentos pela comunidade científica da área do turismo, como as que, por exemplo, se tem visto nas discussões dos congressos da Associação Nacional de Pesquisa e Pós-Graduação em Turismo (ANPTUR).

Dentro das dificuldades e limitações de uma pesquisa em turismo realizada nas universidades, Panosso Netto e Nechar (2016) enfatizaram que o modelo de avaliação baseado em informações obrigatoriamente lançadas na Plataforma Sucupira (https://sucupira.capes.gov.br/sucupira) vicia os programas de pós-graduação a trabalharem para cumprir os interesses da própria CAPES. Segundo esses autores, essa atuação não necessariamente atende a essência da pós-graduação que seria fazer ciência de qualidade e formar recursos humanos nas mais diversas áreas do conhecimento.

Koebsck (2017) destaca o papel das agências de fomento, em especial o sistema de avaliação da CAPES, que está relacionado à pesquisa científica e tecnológica no país. Ele tem o objetivo de assegurar e manter a qualidade dos cursos de mestrado e doutorado por meio de uma avaliação realizada 
quadrienalmente, como já explicado. Por intermédio dessa agência, os cursos de mestrado e doutorado em turismo foram avaliados conforme a tabela 1 :

Tabela 1- Total de Programas de Pós-Graduação stricto sensu em Turismo no Brasil

\begin{tabular}{|c|c|c|c|c|c|c|c|}
\hline \multirow[b]{2}{*}{ Nome da IES } & \multirow{2}{*}{$\begin{array}{l}\text { Sigla da } \\
\text { IES }\end{array}$} & \multirow[b]{2}{*}{ UF } & \multicolumn{5}{|c|}{\begin{tabular}{|c} 
Total de Programas de pós- \\
graduação stricto sensu em turismo
\end{tabular}} \\
\hline & & & \begin{tabular}{|l|} 
Total \\
\end{tabular} & ME & $\mathrm{DO}$ & MF & ME/DO \\
\hline \begin{tabular}{|l|} 
INSTITUTO FEDERAL DE EDUCAÇÃO, \\
CIÊNCIA E TECNOLOGIA DE SERGIPE
\end{tabular} & IFS & SE & 1 & 0 & 0 & 1 & 0 \\
\hline \begin{tabular}{|l} 
UNIVERSIDADE ANHEMBI MORUMBI \\
\end{tabular} & UAM & SP & 1 & 0 & 0 & 0 & 1 \\
\hline UNIVERSIDADE DE BRASÍLIA & UNB & $\mathrm{DF}$ & 1 & 0 & 0 & 1 & 0 \\
\hline UNIVERSIDADE DE CAXIAS DO SUL & UCS & RS & 1 & 0 & 0 & 0 & 1 \\
\hline \begin{tabular}{|l} 
UNIVERSIDADE DE SĀO PAULO \\
\end{tabular} & USP & SP & 1 & 1 & 0 & 0 & 0 \\
\hline UNIVERSIDADE DO VALE DO ITAJAÍ & UNIVALI & SC & 1 & 0 & 0 & 0 & 1 \\
\hline UNIVERSIDADE ESTADUAL DO CEARÁ & UECE & CE & 1 & 0 & 0 & 1 & 0 \\
\hline $\begin{array}{l}\text { UNIVERSIDADE FEDERAL DE } \\
\text { PERNAMBUCO }\end{array}$ & UFPE & PE & 1 & 1 & 0 & 0 & 0 \\
\hline UNIVERSIDADE FEDERAL DO PARANÁ & UFPR & PR & 1 & 1 & 0 & 0 & 0 \\
\hline $\begin{array}{l}\text { UNIVERSIDADE FEDERAL DO RIO GRANDE } \\
\text { DO NORTE }\end{array}$ & UFRN & RN & 1 & 0 & 0 & 0 & 1 \\
\hline UNIVERSIDADE FEDERAL FLUMINENSE & UFF & RJ & 1 & 1 & 0 & 0 & 0 \\
\hline $\begin{array}{r}\text { ME: Mestrado Acadêmico } \\
\text { DO: Doutorado } \\
\text { MF: Mestrado Profissional } \\
\text { ME/DO: Mestrado e Doutorado }\end{array}$ & & Totais & 11 & 4 & 0 & 3 & 4 \\
\hline
\end{tabular}

Fonte: dados coletados da Plataforma Sucupira (acesso em 21 abr. 2018).

A CAPES registra atualmente 11 programas de pós-graduação dedicados diretamente à área de turismo e que dispõem, no total, de 11 cursos em nível de Mestrado Acadêmico são 8, Mestrado Profissional 3 e Doutorado 4.

Todos os programas estão recomendados e/ou reconhecidos pela agência. Entre eles, o mais antigo é o da Universidade Vale do Itajaí (UNIVALI), em nível de mestrado, criado em 1999. O mais recente é o Programa de Mestrado em Turismo da Universidade Federal de Pernambuco (UFPE), criado em 2017. Nota-se, assim, um descompasso entre o ritmo da graduação em turismo e a pós-graduação stricto sensu em turismo, visto que, atualmente, a primeira está em fase de declínio de cursos e a segunda, por sua vez, está em ascensão. Existe uma preocupação para harmonizar essas duas modalidades 
do ensino superior que não podem se dissociar uma da outra, já que uma se nutre da outra.

O programa de mestrado profissional do IFS e o do mestrado acadêmico da UFPE também foram retirados do escopo de nossa análise. Isso se deve porque a recomendação do primeiro programa foi recentemente homologado em 2015 e por isso tem pouca produtividade docente na área. Já o segundo programa teve sua homologação em 2017 e, como o espaço-tempo coberto por este estudo vai de 2013 a 2016, ele também foi excluído de nossa seleção. No total, foram selecionados nove programas stricto sensu em turismo a saber: UAM, UECE, UNIVALI, UFPR, UFRN, UCS, UFF, UCS e a USP, mas vamos expor todos os programas na tabela.

Tabela 2 - Total de cursos de Pós-graduação stricto sensu em turismo no Brasil.

\begin{tabular}{|c|c|c|c|c|c|c|}
\hline \multirow[b]{2}{*}{ Nome da IES } & \multirow{2}{*}{$\begin{array}{l}\text { Sigla da } \\
\text { IES }\end{array}$} & \multirow[b]{2}{*}{ UF } & \multicolumn{4}{|c|}{$\begin{array}{l}\text { Totais de Cursos de pós- } \\
\text { graduação stricto sensu em } \\
\text { turismo }\end{array}$} \\
\hline & & & Total & $\mathrm{ME}$ & DO & MF \\
\hline $\begin{array}{l}\text { INSTITUTO FEDERAL DE EDUCAÇÃO, CIÊNCIA E } \\
\text { TECNOLOGIA DE SERGIPE }\end{array}$ & IFS & SE & 1 & 0 & 0 & 1 \\
\hline UNIVERSIDADE ANHEMBI MORUMBI & UAM & SP & 2 & 1 & 1 & 0 \\
\hline UNIVERSIDADE DE BRASILIA & UNB & DF & 1 & 0 & 0 & 1 \\
\hline UNIVERSIDADE DE CAXIAS DO SUL & UCS & RS & 2 & 1 & 1 & 0 \\
\hline UNIVERSIDADE DE SÃO PAULO & USP & SP & 1 & 1 & 0 & 0 \\
\hline UNIVERSIDADE DO VALE DO ITAJAÍ & UNIVALI & SC & 2 & 1 & 1 & 0 \\
\hline UNIVERSIDADE ESTADUAL DO CEARÁ & UECE & CE & 1 & 0 & 0 & 1 \\
\hline UNIVERSIDADE FEDERAL DE PERNAMBUCO & UFPE & $\mathrm{PE}$ & 1 & 1 & 0 & 0 \\
\hline UNIVERSIDADE FEDERAL DO PARANÁ & UFPR & PR & 1 & 1 & 0 & 0 \\
\hline $\begin{array}{l}\text { UNIVERSIDADE FEDERAL DO RIO GRANDE DO } \\
\text { NORTE }\end{array}$ & UFRN & RN & 2 & 1 & 1 & 0 \\
\hline UNIVERSIDADE FEDERAL FLUMINENSE & UFF & RJ & 1 & 1 & 0 & 0 \\
\hline Totais & & & 16 & 8 & 4 & 3 \\
\hline
\end{tabular}

Fonte: dados coletados da Plataforma Sucupira (acesso em 21 abr. 2018).

Após destacar a Tabela 2 que apresenta o total de cursos de pósgraduação stricto sensu na área turismo reconhecidos pelo Conselho Nacional de Educação (CNE). Ainda que existam as limitações dos estudos relacionados à pós-graduação stricto sensu em turismo, podemos verificar pelo mapa a seguir a distribuição dos programas stricto sensu em turismo conforme as regiões do 
país. Com isso, podemos verificar pelo mapa, como a pós-graduação stricto sensu em turismo está atualmente distribuída e/ou concentrada no território nacional.

Figura 2 - Distribuição dos programas de pós-graduação stricto sensu em Turismo no território da República Federativa do Brasil

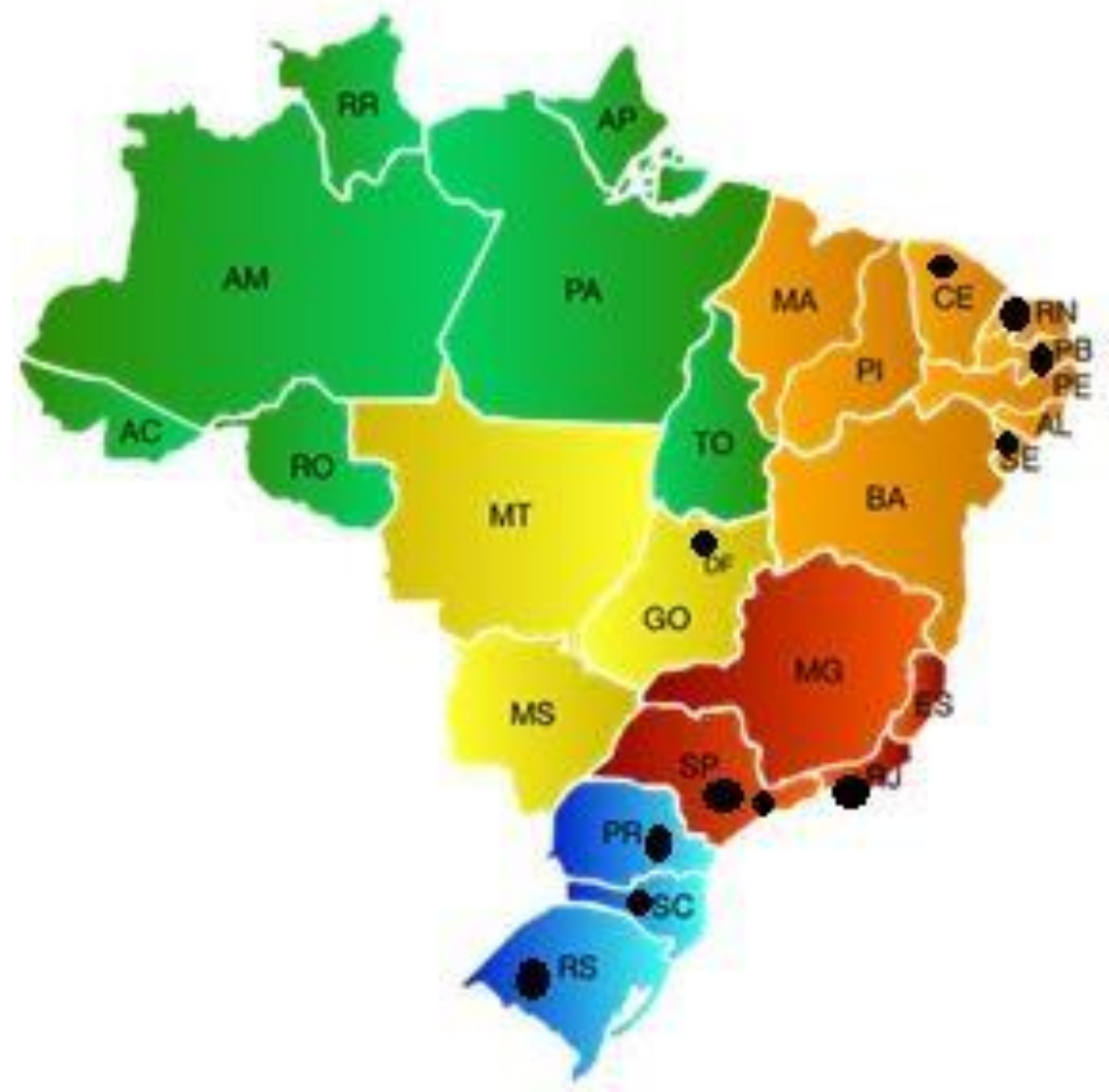

Fonte: IBGE (2018)

Conforme se pode notar pelo mapa, há um avanço quantitativo e qualitativo dos programas de pós-graduação. No que se refere aos programas de pós-graduação stricto sensu em turismo, eles são concentrados em alguns estados da Federação. Embora os programas stricto sensu tenham se ampliado de forma significativa, particularmente os mestrados e doutorados, duas marcantes características merecem destaque: a desigualdade na distribuição regional dos programas, com a forte concentração nas regiões mais ricas do país

\footnotetext{
${ }^{7}$ Disponível em: < https://www.ibge.gov.br/>. Acessado em: 13 mar. 2018.
} 
ainda forte, como por exemplo na região Sul e a Sudeste, as quais contam com a presença atuante da UCS, da UFPR, da UNIVALI, da UAM, da USP e da UFF. O Nordeste aumentou significativamente, com a UECE, IFS, UFRN e a UFPE. A região Centro-Oeste ganhou participação ainda pequena. A região Norte não possui programa na área.

Quanto aos resultados sobre o número de programas, ressalta-se um aumento significativo desse indicador na pós-graduação stricto sensu em turismo, com indicações de que o setor público tende a ter um papel cada vez maior no cenário do ensino em turismo, uma vez que ele domina $81,4 \%$ de todo o setor da pós-graduação no País. De fato, os resultados mostraram que o sistema público é hoje um ator protagonista relevante pelo crescimento no campo do turismo, uma vez que grande parte dos cursos está concentrada no setor público. Porém a distribuição dos programas ainda é irregular, principalmente quando se trata dos programas de pós-graduação stricto sensu em turismo (cf. Figura 2).

Tratando, agora, em específico dos programas de pós-graduação stricto sensu em turismo, podemos dizer que existem duas vertentes relevantes para o estudo da pós-graduação stricto sensu em turismo no Brasil: uma teórica e a outra descritiva. Do lado teórico, discutido principalmente por Leal (2012), Ansarah (2002), Holanda et al. (2014) e Tribe (1997a), essa perspectiva traça uma revisão da literatura sobre o tema, o conhecimento, com destaque para sua dimensão científica e tecnológica. Já na perspectiva descritiva, baseada pelos estudos de Panosso Netto et al (2017), Leal (2012) e Tribe (1997). Os programas de pós-graduação em turismo são descritos a partir de suas características e peculiaridades. Em outras palavras, em um prisma, busca-se os fatores mais gerais e constantes; em outro, investigam-se as características e as singularidades.

Abordando o aspecto dos títulos, podemos apreender que o doutorado e o mestrado em turismo mostram um crescimento forte. Um exemplo disso é o projeto de doutorado em turismo na USP que está tramitando pela CAPES 8 . Observa-se, no entanto, que, no panorama geral, é o mestrado acadêmico que vem apresentando um crescimento muito expressivo, com projetos para abertura

${ }^{8} \mathrm{O}$ PPTUR EACH-USP submeteu à CAPES o projeto de doutorado em outubro de 2017 e no momento ( agosto de 2018) espera o resultado da avaliação. 
de novos programas em diversas universidades - em específico, podemos citar: Universidade Federal Juiz de Fora (UFJF) Universidade Federal do Pará (UFPA) e a Universidade Federal Estadual do Rio de Janeiro (UNIRIO).

Dessa forma, a pós-graduação stricto sensu em turismo no Brasil está propondo ações efetivas de ensino e pesquisa que possam impulsionar o desenvolvimento do turismo. Com isso, contribui-se na formação de profissionais qualificados para a geração e a disseminação de conhecimento científico, estabelecendo relações teórico-metodológicas e práticas a fim de propiciar a formação de um pesquisador autônomo intelectualmente, crítico e comprometido com as transformações sociais (cf. PANOSSO, 2017) ${ }^{9}$.

O avanço desse processo está também no Seminário Nacional de Pesquisa e Pós-Graduação em Turismo, respondendo aos objetivos da Associação de Pesquisa e Pós-Graduação em Turismo - ANPTUR ${ }^{10}$. Esse evento constitui um fórum de debate que promovem reflexões e propostas de pesquisadores, docentes e estudiosos. Esse grupo de colaboradores resgata um espírito de integração para a área, discutindo ideias e propondo soluções para as problemáticas que afetam aos campos do turismo, da hospitalidade, do lazer e de outras áreas afins.

Esse seminário também contribui para o crescimento e o avanço da produção científica na área, pois permite a construção de quadros teóricoconceituais e de bases empíricas para balizar as atividades de pesquisa, de ensino e extensão. Os temas propostos nas últimas edições do evento reportamse à multidimensionalidade, à complexidade e à dinamicidade, aspectos estes que envolvem todo o fenômeno do turismo.

Outro fator relevante desse evento é que o acesso aos trabalhos apresentados que estão disponíveis a partir das publicações dos Anais. Isso amplia e potencializa o diálogo entre os membros da comunidade acadêmica do turismo e de áreas afins. Esse evento é um dos mais relevantes para os profissionais e estudiosos da área no Brasil, dando, inclusive, coesão ao campo de estudos e de suas práticas.

\footnotetext{
${ }^{9}$ Informação verbal do orientador coletada em orientação.

${ }^{10}$ Os dados referentes a esse evento estão disponíveis no seguinte endereço: < https://www.anptur.org.br/seminario/2018>. Acessado em: 13 mar. 2018.
} 
Um aspecto da pós-graduação stricto sensu em turismo no Brasil é a quantidade de matrículas anuais que esse campo recebe. A partir da plataforma Sucupira, podemos dizer que houve crescimento da quantidade de alunos no mestrado e doutorado, com 932 inscritos no período de 2013 e 2016. A área possui, em torno, de 176 docentes, contando ativos e inativos. Ressalta-se que professores ativos nos programas de pós-graduação stricto sensu em turismo no Brasil, atualmente, temos apenas $127^{11}$. Comparando esses dados, percebe-se que há uma mobilidade entre docentes na área do turismo, pois eles estão saindo e/ou migrando de área, bem como se aposentando. Isso explica porque houve uma diminuição dos docentes no período de 2013 a 2016. Observados esses aspectos mais gerais, no próximo tópico, vamos tratar, com maior especificidade, dos programas de pós-graduação stricto sensu em turismo no Brasil.

\subsection{Programas de pós-graduação stricto sensu em turismo no Brasil}

Neste tópico, vamos abordar do contexto de criação e desenvolvimento dos programas de pós-graduação em turismo no Brasil. A seguir, temos elencado todos os programas de pós-graduação stricto sensu em turismo reconhecidos pela Capes. Serão apresentados dados básicos de cada um desses programas, com destaque para o ano de criação e a nota Capes.

\section{Universidade de Caxias do Sul (UCS)}

O curso de mestrado em turismo e hospitalidade, recomendado em 2000 com início no mesmo ano, já o Doutorado foi criado em 2014 com início em 2015, possuem nota 4 concedida pela CAPES, segundo avaliação quadrienal. Esse programa tem como área de concentração Desenvolvimento Regional do Turismo. Ele Conta com 16 docentes.

Outro dado sobre esse programa é que edita o periódico científico Revista Rosa dos Ventos, ISSN 2178-9061. Esse periódico foi iniciado em 2009 e está

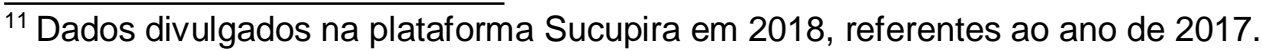


avaliado pela CAPES com QUALIS B2 para a área de Administração, Ciências Contábeis e Turismo. Além disso, o programa possui duas linhas de pesquisas, intituladas Turismo, Organizações e Sustentabilidade, e Turismo, Cultura e Educação.

\section{Universidade de São Paulo (USP)}

O Programa de Pós-Graduação em Turismo da Universidade de São Paulo está situado na Escola de Artes, Ciências e Humanidades (EACH). Atua no nível de mestrado acadêmico, recomendado em 2013 com início em 2014, com nota CAPES 4, em 2017. Sua área de concentração está voltada para o Desenvolvimento do Turismo e conta com 14 docentes.

O periódico científico Turismo em Análise, ISSN 1984-4867, iniciado em 1990 na ECA. Este foi vinculado ao programa com QUALIS B1 para a área Administração, Ciências Contábeis e Turismo. Outro fato sobre este programa é que está com o projeto de doutorado em turismo tramitando pela Capes. Além disso o programa possui duas linhas de pesquisas a primeira relaciona-se a Turismo: Conhecimentos e Tendências a segunda Turismo: processos e Inovação.

\section{Universidade Federal do Paraná (UFPR)}

Com um Programa de Pós-Graduação em Turismo, criado em 2012, atua no nível mestrado acadêmico, com início em 2013, e nota 3 concedida segundo a Avaliação quadrienal. Sua área de concentração é Turismo e Desenvolvimento e conta com 18 docentes.

O periódico científico Turismo e Sociedade, ISSN 1983-5442, iniciado em 2008. Foi vinculado ao programa com QUALIS B4 para a área Administração, Ciências Contábeis e Turismo. Além disso, o programa possui duas linhas de pesquisas, a primeira intitulada: Turismo, Sociedade e Meio ambiente. A segunda relaciona-se a Organizações Públicas e Privadas. 
A Universidade tem um Programa de Pós-Graduação em Turismo. Atua no nível de mestrado profissional, recomendado em 2005 e reconhecido em 2007. Sua área de concentração é Cultura e Desenvolvimento e conta com 22 docentes. Edita o periódico científico Revista Cenário, com QUALIS B4.

Atualmente, encontra-se com a nota 2 concedida segundo a Avaliação quadrienal 2017 da CAPES. Comeste resultado, é provável que esse programa seja desativado nos próximos anos. Além disso, o programa possui duas linhas de pesquisas, intituladas Cultura e Desenvolvimento Regional. E Cultura e Sustentabilidade no Turismo.

\section{Universidade Anhembi Morumbi (UAM)}

O Programa de Pós-Graduação em hospitalidade, atua no nível mestrado acadêmico e doutorado, recomendado em 2001 com início em 2002, ambos nota 4 concedida segundo a avaliação quadrienal. Esse programa tem umquadro de 19 docentes e edita o periódico científico Revista Hospitalidade, INSS 1807975X, com QUALIS B3. Além disso, o programa possui duas linhas de pesquisas, a primeira intitulada: Dimensões e Contextos da Hospitalidade. A segunda a Hospitalidade na Competitividade em Serviços.

\section{Universidade Estadual do Ceará (UECE)}

O Programa de Pós-Graduação em Gestão de Negócios Turísticos, atua no nível mestrado profissional, sendo recomendado em 2011 com início em 2012. Tem, atualmente, a nota 3, que foi concedida pela Capes, na avaliação quadrienal. Sua área de concentração é Gestão dos Negócios e dos Territórios Turísticos. O programa conta com 19 docentes. Além disso, o programa possui duas linhas de pesquisas, a primeira intitulada: Política, Estratégia e Gestão de Negócios, e a segunda ao Turismo, Território e Desenvolvimento Local.

\section{Universidade Vale do Itajaí (UNIVALI)}


O Programa de Pós-Graduação em Turismo e Hotelaria, atua em dois níveis, no mestrado e doutorado, com recomendação para o mestrado no ano de 1997, com início em 1999. Já o doutorado foi recomendado em 2012 com início em 2013, ambos com nota 5, de acordo com a Avaliação quadrienal.

Sua área de concentração está voltada para Planejamento e Gestão do Turismo e da Hotelaria. O programa conta com 17 docentes. Edita o periódico científico, a Revista Turismo: visão e ação, com um ISSN para a edição impressa (14156393) e outro para a edição digital (19837151), ambos vinculados à área Administração, Ciências Contábeis e Turismo. Além disso, o programa possui duas linhas de pesquisas, a primeira intitulada: Planejamento do Destino Turístico. A segunda com o título de Gestão das Empresas em Turismo

\section{Universidade Federal Fluminense (UFF)}

O Programa de Pós Graduação em Turismo, está vinculado à Faculdade de Turismo e Hotelaria da UFF. Foi recomendado em 2015 e teve início no mesmo ano, com nota 3, de acordo com a avaliação quadrienal. Sua área de atuação é Turismo e sociedade e conta com 10 docentes. O programa possui duas linhas de pesquisas, a primeira intitulada: Turismo, Planejamento e Gestão. A segunda tendo como título Turismo, Cultura e Ambiente.

\section{Universidade Federal do Rio Grande do Norte (UFRN)}

O Programa de Pós-graduação Stricto Sensu em Turismo foi reconhecido o seu mestrado em 2008 e o seu doutorado em 2014 ambos com nota 4, de acordo com a Avaliação quadrienal. Sua área de concentração é Turismo, desenvolvimento e Gestão. Atualmente, conta com 22 docentes. O programa edita o periódico científico Revista Turismo Contemporâneo, INSS 23578211, com QUALIS B4. Além disso, o programa possui duas linhas de pesquisas, a primeira intitulada: Turismo e Desenvolvimento Regional. A segunda intitulada: Gestão em Turismo. 


\section{Instituto Federal de Sergipe (IFS)}

Em 2015 foi recomendado o Programa de Mestrado Profissional em Turismo, com início em 2016. Nota 3 concedida pela CAPES. Sua área de concentração é Gestão de turismo e o quadro de profissionais é composto por 08 docentes permanentes no programa. Além disso, o programa possui duas linhas de pesquisas, a primeira intitulada: Gestão de Destinos Turísticos: Sistemas, Processos e Inovação, a segunda intitulada: Gestão de Turismo de Base Comunitária.

\section{Universidade Federal de Pernambuco (UFPE)}

O Programa de Pós-graduação Stricto Sensu em Hotelaria e Turismo (PPHTUR), recomendado em 2016 com início em 2017, tem nota 3, de acordo com a CAPES. Sua área de concentração está relacionada à Hotelaria e ao Turismo, conta com 11 docentes. Além disso o programa possui duas linhas de pesquisa, a primeira intitulada Gestão de Empresas Hoteleiras e Turísticas, e a segunda com o título Turismo, Cultura e Sociedade.

Esses dados sistematizamos na tabela 3. Nessa tabela, apresentamos os seguintes componentes de todas as instituições selecionadas: nome da instituição, grau do título, nota Capes, fundação, revista do programa de pósgraduação, Qualis, número de docentes, quantidade de linhas de pesquisa. Com isso, podemos verificar um panorama geral dos programas de pós-graduação em turismo no Brasil

Tabela 3- Dados gerais dos programas de pós-graduação stricto sensu em turismo no Brasil

\begin{tabular}{|c|c|c|c|c|c|c|c|}
\hline 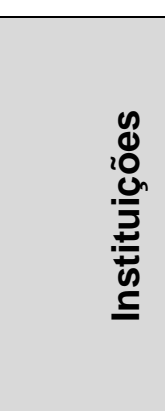 & 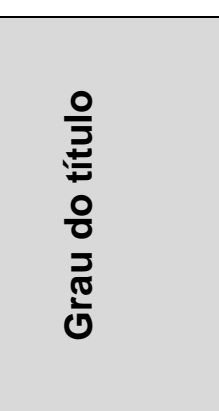 & $\begin{array}{l}\text { \& } \\
\text { 융 } \\
0 \\
\text { o } \\
\text { z }\end{array}$ & 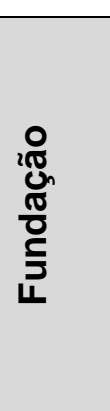 & 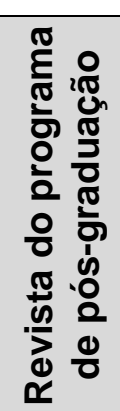 & $\begin{array}{l}\frac{\infty}{\bar{T}} \\
\frac{\widetilde{J}}{0}\end{array}$ & 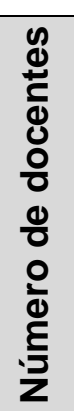 & 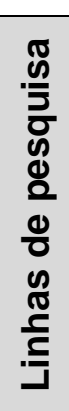 \\
\hline UECE & $\begin{array}{l}\text { Mestrado } \\
\text { Profissional }\end{array}$ & 3 & 2012 & & & 19 & 2 \\
\hline UFF & Mestrado & 3 & 2015 & & & 10 & 2 \\
\hline
\end{tabular}




\begin{tabular}{|c|c|c|c|c|c|c|c|}
\hline UCS & $\begin{array}{l}\text { Mestrado } \\
\text { Doutorado }\end{array}$ & 4 & $\begin{array}{l}2001 \\
2015\end{array}$ & Rosa dos Ventos & B2 & 16 & 2 \\
\hline UAM & $\begin{array}{l}\text { Mestrado } \\
\text { Doutorado }\end{array}$ & 4 & $\begin{array}{l}2002 \\
2002\end{array}$ & $\begin{array}{l}\text { Revista } \\
\text { Hospitalidade }\end{array}$ & B3 & 19 & 2 \\
\hline UNIVALI & $\begin{array}{l}\text { Mestrado } \\
\text { Doutorado }\end{array}$ & 5 & $\begin{array}{l}1999 \\
2013\end{array}$ & $\begin{array}{l}\text { Turismo: Visão e } \\
\text { Acão }\end{array}$ & $\mathrm{B} 2$ & 17 & 2 \\
\hline USP & Mestrado & 4 & 2014 & $\begin{array}{ll}\text { Turismo } & \text { em } \\
\text { Análise } & \end{array}$ & $\mathrm{B} 1$ & 14 & 2 \\
\hline $\begin{array}{l}\text { UFPR } \\
\end{array}$ & Mestrado & 3 & 2013 & $\begin{array}{ll}\text { Turismo } & \mathrm{e} \\
\text { Sociedade } & \end{array}$ & B4 & 18 & 2 \\
\hline UFRN & $\begin{array}{l}\text { Mestrado } \\
\text { Doutorado }\end{array}$ & 4 & $\begin{array}{l}2008 \\
2014\end{array}$ & $\begin{array}{l}\text { Turismo } \\
\text { Contemporâneo }\end{array}$ & B4 & 22 & 2 \\
\hline UNB & $\begin{array}{l}\text { Mestrado } \\
\text { Profissional }\end{array}$ & 2 & 2007 & Cenário & B4 & 22 & 2 \\
\hline IFS & $\begin{array}{l}\text { Mestrado } \\
\text { Profissional }\end{array}$ & 3 & 2016 & & & 08 & 2 \\
\hline UFPE & Mestrado & 3 & 2017 & & & 11 & 2 \\
\hline Total & $\begin{array}{l}3 \text { Mestrados } \\
\text { profissionais } \\
8 \text { Mestrados } \\
\text { acadêmicos } \\
4 \text { doutorados }\end{array}$ & & & 7 & & 176 & 22 \\
\hline
\end{tabular}

Fonte: Plataforma Sucupira (acesso em 21 abr. 2018). ${ }^{12}$

A partir da Tabela 3, podemos apreender que existem 11 programas de pós-graduação stricto sensu em turismo analisados. Esses programas, juntos, possuem o efetivo de 176 docentes. Esses mesmos programas tem 7 revistas credenciadas no sistema Qualis. Existem, atualmente, 22 linhas de pesquisa promovidas nesses programas. Esse é o panorama geral da área, de acordo com as instituições, e os dados divulgados na plataforma Sucupira - lembrando que a IFS e a UFPE não foram analisadas.

Outro aspecto pertinente para se abordar é presença da Plataforma Lattes na vida acadêmica dos docentes e de seus respectivos programas de pósgraduação. Como parte para a evolução da pesquisa científica em turismo, a Plataforma Lattes tem despertado interesse de pesquisadores nas mais diversas áreas do conhecimento. Baseadas nos dados do Currículo Lattes, Barata,

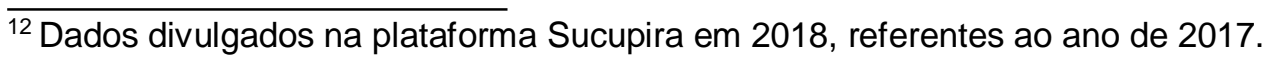


Goldbaun (2003), Santos et al. (2013), e Mendes et al. (2010) analisaram os perfis dos pesquisadores que possuem bolsa de produtividade em pesquisa do CNPq. Além desses estudiosos, os trabalhos de Digiampietri et al. (2012a) também tratam do tema. Mena-Chalco, Digiampietri e Cesar-Júnior (2012a) analisaram 176.114 currículos da plataforma Lattes de pesquisadores que integram os grupos de pesquisa da área das Ciências Exatas e da Terra, com o objetivo de identificar automaticamente as coautorias, mediante a produção científica e a caracterização topológica das redes de coautoria. Ainda com base nos dados dos currículos presentes na plataforma Lattes, foram apontadas resultados relevantes em algumas pesquisas relacionadas às áreas da Ciência da Informação, da Bibliometria e da cientometria (cf. ANDRETTA; SILVA; RAMOS, 2012; SILVA et al. 2012b; DANUELLO e OLIVEIRA, 2012). Com base nesses autores, percebemos a importância de se estudar a coautoria juntamente com os pageRanks (conforme explicado na metodologia) e o índice $\mathrm{H}$ atual dos docentes dos programas em turismo. Por isso, no próximo capítulo, é explicada a metodologia que sustentará a análise da rede de colaboração dos docentes selecionados para esta pesquisa. 


\title{
3.1 METODOLOGIA
}

Para este estudo, utilizamos a Análise de Conteúdo. Ela foi descrita por Laurence Bardin, professora da Universidade de Paris V, na década de 1970. Segundo a autora, essa metodologia se define como:

\begin{abstract}
Um conjunto de técnicas de análise das comunicações visando obter por procedimentos sistemáticos e objetivos de descrição do conteúdo das mensagens indicadores (quantitativos ou não) que permitam a inferência de conhecimentos relativos às condições de produção/recepção (variáveis inferidas) dessas mensagens (BARDIN, 1977, p. 48).
\end{abstract}

Nessa definição, entende-se comunicação em um sentido amplo, sendo ela verbal ou não, isto é, como qualquer enunciado passível de descrição e análise. Para Camprubí e Coromina (2016), é inconteste que análise do conteúdo deve ser utilizada para a coleta e/ou análise de comunicações como prevê Bardin (1977). Todavia, nenhum dos autores se aprofundaram nas especificidades do tipo dessas comunicações, deixando sua definição aberta. Camprubí e Coromina (2016) tentam exemplificar algumas fontes de dados suscetíveis à análise nas investigações turísticas, mas seu estudo não é exaustivo. Bardin (1977).

Essa metodologia prevê um rigor na aplicação de seus métodos para, com isso, não se perder na heterogeneidade de seu objeto de análise. Para tanto, sua principal pretensão é fornecer técnicas precisas e objetivas para garantir a inferência de dados sobre o objeto de análise, os quais à primeira vista estão ocultos ou, pelo menos, implícitos Bardin (1977).

Desse modo, neste estudo, nossa metodologia apresenta uma proposta de aplicação do método da análise de conteúdo, em específico com o material coletado. Algumas investigações científicas já lançaram mão desse método nesse campo de estudos, como, por exemplo, Hannam e Knox (2005), Stepchenkova, Kirilenko e Morrison (2009) e Camprubí e Coromina (2016). Retomando as principais ideias dos autores Hannam e Knox (2005), esses estudiosos investigam a diferença entre a análise de conteúdo, a análise textual 
simples, a análise semiótica e as formas pós-estruturalistas de análise do discurso, a fim de fornecer uma estrutura para outros pesquisadores da área do turismo. Stepchenkova, Kirilenko e Morrison (2009) propõem uma nova abordagem metodológica para facilitar a análise de conteúdo de dados textuais eletrônicos de maneira eficiente e transparente. Já Camprubí e Coromina (2016) tratam da análise de conteúdo, aplicando-a ao campo do turismo para detectar problemas críticos apresentados em periódicos.

De acordo com Krippendorff (1990), a análise de conteúdo pode ser de três tipos: pragmática, semântica e de veículos-signos. Cada um desses tipo possui suas próprias características e procedimentos de análise, mesmo, assim, um não exclui o outro; nenhum deles é melhor ou pior que o outro. As diferenças entre esses tipos é a maneira como eles definem seus conteúdos, coletam seus dados e os sistematizam.

A análise pragmática classifica os conteúdos segundo sua causa ou efeito provável. Por exemplo, esse tipo ocorre quando se efetua uma coleta de dados da quantidade de vezes que se pode dizer algo a um grupo determinado enunciado e, depois, se analisa como esse fenômeno é capaz de produzir uma atitude favorável ou não para os participantes do referido grupo. Como se observa, nesse tipo é muito relevante a relação causa/efeito. (KRIPPENDORFF 1990).

O tipo de análise semântica possui procedimentos que classificam os conteúdos de acordo com seus significados. Como a significação é uma seara bastante complexa, esse tipo de análise pode ocorrer em, pelo menos, três dimensões, a saber: a das designações, a das atribuições e a das afirmações. Discriminemos cada um desses subtipos: (KRIPPENDORFF 1990).

- análise de designações: ela proporciona a frequência com que se faz a referência a determinados objetos, como pessoas, coisas, grupos ou conceitos. Nesse tipo, faz-se uma análise temática do ato de nomear os dados coletados (substantivos).

- análise de atribuições: ela pesquisa a frequência com que se remete a certas caracterizações de um objeto, isto é, referências a qualidade ou atribuídos. Nesse outro tipo, realiza-se uma análise temática do ato de caracterizar os dados coletados (adjetivos). 
- análise de afirmações: ela estuda a frequência com que certos objetos são caracterizados de um modo particular. Nesse caso, há uma análise que, apropriando-se da temática das caracterizações, investiga o modo particular de dizer (construção argumentativa).

O tipo de análise de veículos-signos compreende procedimentos que classificam o conteúdo de acordo com as propriedades psicofísicas dos conteúdos, por exemplo, a quantidade de vezes que a palavra aparece no corpus selecionado. Desse modo, a análise de veículos-signos propõe depreender pela recorrência de conteúdos e de determinadas características as propriedades desses conteúdos Krippendorff (1990).

Nesta pesquisa, optou-se por se fazer uma análise de veículos-signos e análise de afirmações. Essa escolha se justifica por diversos fatores. Primeiramente, não poderia ser uma análise do tipo pragmático porque o objeto em análise, a produção docente da pós-graduação stricto sensu em turismo no Brasil, é mais complexo do que se pode supor em uma relação causa/efeito - a qual, ressaltamos, não consegue abarcar os aspectos socioculturais desse objeto. Em segundo lugar, não poderia ser uma análise do tipo semântica, uma vez que o corpus é extenso e possui diversos e diferentes feixes temáticos, o que torna insustentável qualquer análise pormenorizada de todos os conteúdos. Em outros termos, mesmo se optássemos por fazer uma análise de designação, ela não seria suficiente, o mesmo se pode dizer da análise de atribuições Krippendorff (1990).

De outro lado, a análise de afirmações exige a construção argumentativa de cada conteúdo, e o terceiro argumento, a análise de veículos-signos nos permite analisar um corpus bastante extenso sem perder a objetividade do fazer científico, porque é a recorrência de fenômenos e análise de afirmações que auxilia a determinar aspectos a partir da inferência baseada na frequência dos dados (KRIPPENDORFF, 1990).

Como fonte para a pesquisa quantitativa, foi escolhida a Plataforma Lattes (doravante, PL). Essa plataforma foi utilizada como fonte de informação, porque ela possui uma grande quantidade de dados disponíveis de forma gratuita, de fácil acesso e com grande adesão dos docentes universitários na esfera nacional. Uma das funcionalidades da PL é gerar currículos que se tornam 
públicos, disponibilizando à sociedade referências a outros documentos (alguns públicos e outros privados) do arquivo pessoal ou institucional dos pesquisadores brasileiros (DIGIAMPIETRI et al. 2012b). Desse modo, essa plataforma cria os Currículos Lattes. Semelhante aos curriculum vitae, esses documentos possuem uma formatação padrão que o usuário preenche com 0 histórico das suas atividades científicas, acadêmicas e profissionais. Esses dados são cadastrados no sistema da $\mathrm{PL}$, sendo utilizados, posteriormente, pelo CNPq e pela CAPES para avaliar os programas de pós-graduação e graduação no território nacional para efeito de manutenção do credenciamento ou argumento para o descredenciamento. Esse, portanto, é o veículo de informação que foi escolhido nesta pesquisa

Uma vez escolhida o tipo de análise a ser aplicada aos dados e a principal fonte de informação para a pesquisa quantitativa, deve-se discriminar as fases dessa análise. Para tanto, adota-se a proposta de Bardin (1977) que organiza a análise do conteúdo em três as fases, a saber:

1) Pré-análise, composta de:

a) Leitura flutuante;

b) Escolha dos documentos;

c) Preparação do material;

d) Referenciação dos índices e a elaboração de indicadores;

2) Exploração do material;

3) Tratamento dos resultados, a inferência e a interpretação (BARDIN, 1994, p. 85).

Para apresentar cada uma dessas fases e as relações entre elas, a autora faz um fluxograma em que apresenta de forma didática as inter-relações dessas fases. É importante salientar que a fase (1), a pré-análise, dá as condições de base para se realizar a pesquisa; a fase (2), a exploração do material, realiza, de fato, a análise dos dados e, por fim, a fase (3), tratamento dos resultado, a inferência e a interpretação, concretiza os objetivos de uma análise de conteúdo a depreensão da(s) inferência(s), em seguida, a interpretação desses resultados à luz da(s) inferência(s). Compreendidas essas três fases, reproduzimos a seguir o referido fluxograma (Figura 3), de Bardin (1977, p. 102), o qual norteia o desenvolvimento deste estudo.

Figura 3- Desenvolvimento das três fases de uma análise de conteúdo 


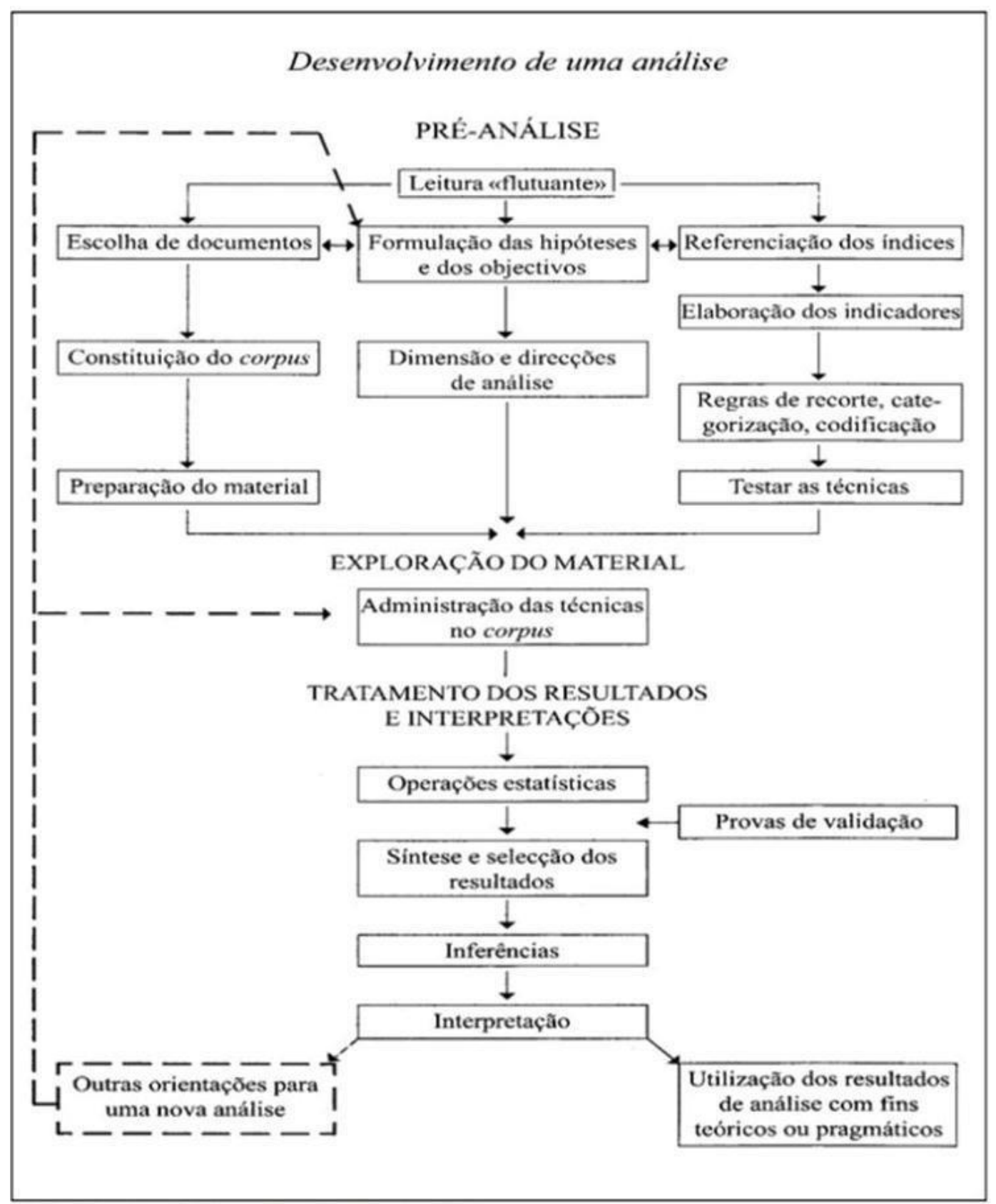

Fonte: Reprodução do fluxograma de Bardin (1977, p. 102).

Nesta pesquisa, adotamos três fases: (1) pré-análise, (2) exploração do material e (3) tratamento dos resultados. Na fase da pré-análise, realizamos a seguintes operações: preparação, codificação e categorização. $\mathrm{Na}$ fase da exploração do material, executamos a descrição dos dados sistematizados. $\mathrm{Na}$ fase da tratamento dos resultados, efetuamos, de fato, a interpretação dos dados à luz das inferências alcançadas com os resultados de análise conseguidos nas fases anteriores. Expliquemos essas fases da pesquisa. 
A primeira fase, nomeada pré-análise, consiste na organização da pesquisa e na sistematização dos dados, realizada ou não por meios informatizados. Trata-se, portanto, de tornar operacional e sistematizável as ideias iniciais de forma a orientar um esquema preciso para o plano de análise. Esse esquema tem que ser flexível, isto é, permitir a introdução de novos procedimentos durante a análise. Os principais procedimentos adotados nessa fase foram: preparação, codificação e categorização.

O primeiro procedimento da fase da pré-análise consistiu em uma preparação material. "Antes da análise propriamente dita, o material reunido deve ser preparado. Trata-se de uma preparação material e, eventualmente, de uma preparação formal (edição)" (BARDIN, 1977, p.100). Em outras palavras, quando foi escolhido, como objeto de estudo, a produção docente da pósgraduação stricto sensu em turismo no Brasil a análise dos docentes no período de 2013 a 2016, teve que se excluir da coleta de dados qualquer produção científica que não fosse proveniente de docentes em programas de pósgraduação stricto sensu em turismo. Em nossa seleção, permaneceram nove programas stricto sensu em turismo.

Outro dado relevante de nossa metodologia é que foram inseridos nesta pesquisa dados que respeitassem concomitantemente os seguintes critérios: (i) produção bibliográfica de docente; (ii) produção bibliográfica de caráter científico; (iii) autoria de docente que permaneceram no programa no período analisado (2013 a 2016) e (iv) os docentes cadastrados atualmente na Plataforma Sucupira em programa de pós-graduação stricto sensu em turismo de instituição brasileira.

Nesta preparação, a amostra de material foi coletado na Plataforma Sucupira, o montante de 157 currículos dos docentes permanentes/colaboradores e inativos nas IES. Para a identificação dos pesquisadores atuantes no programa de pós-graduação stricto sensu em turismo no Brasil, foi acessada a interface de busca avançada no campo de docentes doutores na Plataforma Sucupira. Todos esses currículos foram coletados como material bruto desta pesquisa.

$\mathrm{Na}$ fase de codificação, os materiais coletados depois de efetuado o procedimento de preparação são transformados em dados. "A codificação corresponde a uma transformação - efetuada segundo regras precisas - dos 
dados brutos em texto, transformação esta que, por recorte, agregação e enumeração, permite atingir uma representação do conteúdo" (BARDIN, 1977, p. 103, grifo da autora). Para a efetuar a codificação do material, foram escolhidas as seguintes unidades de registros:

- artigos completos em periódicos;

- livros;

- capítulos de livro.

Bardin (1977, p. 104) define, desse modo, que uma unidade de registro: "é unidade de significação a codificar e corresponde ao segmento de conteúdo a considerar como unidade de base, visando a categorização e a contagem frequencial". Como critério de escolha e constituição das unidades de registro, foram selecionados apenas os elementos que são relevantes nas avaliações dos órgãos de fomento no país (em especial CNPq e CAPES).

Uma vez escolhidas as unidades de registro, esta pesquisa fez uso de um programa de computador, especializado em análise de currículos, nomeado scriptlattes. Esse software é gratuito e de livre acesso ${ }^{13}$. Sua principal funcionalidade é extrair informações de currículos, em especial os da PL. Essa ferramenta analisa as publicações em pares e individual de uma determinada área do conhecimento. Ela é, então, útil porque evidencia o grau de colaboração entre si e o pageRank ${ }^{14}$ dos docentes. Um dado interpretativo relevante nas tabelas de análise é que uma mesma referência bibliográfica pode ser contada mais de uma vez, no qual as publicações são emparelhadas, isto é, em que os docentes publicam em coautoria. Por isso, é importante dizer que as publicações quando são em coautoria elas contam pelo menos duas vezes caso os professores sejam de programas diferentes. Daí a atenção ao fazer a análise para evitar duplicidade na somatória dos dados. Exemplificaremos com mais detalhe o conceito de scriptLattes e o Pagerank

Nesta pesquisa, foi utilizado, como recurso metodológico, o software scriptlattes. Por isso se faz necessário descrever as principais características desse suporte de coleta e estruturação de dados retirados dos currículos acadêmicos presentes na Plataforma Lattes (disponível em: www.lattes.cnpq.br),

\footnotetext{
${ }^{13}$ Disponível em: <https://bitbucket.org/vlab4u>. Acessado em: 13 jul. 2017.

${ }^{14} \mathrm{O}$ Pagerank é o algoritmo que vai de zero a dez, desenvolvido pelo Larry Page e Sergey Brin, fundadores do Google, em 1998. Caracteriza-se como uma métrica de prestígio.
} 
do CNPq. Observa-se, assim, é um recurso metodológico que é depende de outro sistema, que o alimenta com dados, no caso a Plataforma Lattes.

Destaca-se que a rede de colaboração de vários departamentos de Pósgraduação permite a identificação de uma série de itens relacionados ao processo de colaboração científica. Dentre outros itens, ressaltamos: nível de colaboração da comunidade envolvida, distância média entre os colaboradores, autores que mais colaboram, grupos que colaboram com mais intensidade. Esses são alguns dos fatores que influenciaram os criadores do software scriptLattes, os matemáticos Jesús Pascual Mena-Chalco e Roberto Marcondes Cesar Junior, a fazerem o programa, em meados de 2010.

Embora correlata à Plataforma Lattes, o software não está vinculado a ou assessorado pela CNPq, conforme ressaltam em nota seus criadores:

\footnotetext{
O scriptLattes não está vinculado ao CNPq. A ferramenta é o resultado de um esforço independente realizado com o único intuito de auxiliar as tarefas mecânicas de compilação ou coleta de informações publicamente cadastradas nos Currículos Lattes. Portanto, o CNPq não é responsável por nenhuma assessoria técnica sobre esta ferramenta. (MENA-CHALCO; CESAR JUNIOR, 2013, 128).
}

Por meio da produção bibliográfica informada ao sistema na Coleta de Dados da CAPES, referente ao período de 2013-2016, pudemos, nesta pesquisa, depreender as redes de coautoria que analisamos no tópico 4.5. Essas redes de colaboração indicam métricas de avaliação, conforme o sistema scriptLattes indica.

Dessa forma, o scriptLattes é uma ferramenta de código livre desenvolvido por criadores de forma independente do CNPq. Por isso, ela pode ser utilizada para diversas finalidades acadêmicas e institucionais. O objetivo do programa é extrair e compilar automaticamente informações contidas no currículo Lattes de um determinado conjunto de pesquisadores e auxiliar na difusão das informações sobre as produções acadêmicas no país.

Conforme contam os autores supracitados, o programa foi desenvolvido na linguagem de programação que era menos acessível. Atualmente, é um software mais prático para o público leigo à linguagem de programação. A versão mais recente - e aquela utilizada neste trabalho - foi inteiramente reprogramada em phython13, e realiza as seguintes funções: 


\begin{abstract}
O scriptLattes baixa automaticamente os currículos Lattes (em formato HTML) de um grupo de pessoas de interesse, compila as listas de produções, tratando apropriadamente as produções duplicadas e similares. Em seguida, são gerados relatórios, em formato HTML, com listas de produções e orientações separadas por tipo e colocadas em ordem cronológica invertida. Adicionalmente, a ferramenta permite a criação automática de grafos (redes) de coautoria entre os membros do grupo e um mapa de geolocalização dos membros e alunos (de pós•doutorado, doutorado e mestrado) com orientação concluída (MENA-CHALCO; CESAR JUNIOR, 2013, p. 110).
\end{abstract}

Como explicitado acima, o programa também calcula a colaboração entre os docentes do grupo e, depois, representa essa colaboração por três tipos de grafos de colaboração, baseados na produção bibliográfica, técnica e/ou artística de cada um dos membros. Os três grafos gerados são:

- Grafos de colaboração não direcionados sem pesos: são mostrados apenas os dados das ligações de trabalho colaborativo;

- Grafos de colaboração não direcionados com pesos: nesse caso, existem pesos, os quais indicam o número de produções acadêmicas elaboradas em coautoria entre os dois nós (membros);

- Grafos de colaboração direcionados com pesos normalizados: nesses também existem pesos, mas esses são direcionados pelo programa para calcular o grau de colaboração e o pagerank do docente (nó) dentro do programa.

Os autores explicam que cada docente "é representado por um nó se e somente se uma produção acadêmica em comum dos membros é detectada como produção redundante no módulo de tratamento de redundâncias" (MENACHALCO; CESAR JUNIOR, 2013, p. 110). Em outras palavras, os criadores afirmam que um mesmo trabalho não é contado duas ou mais vezes pelo software, porque há um controle das redundância efetuado pelo sistema. Todavia, em nossa análise, apreendemos que o sistema, embora tenha esse recurso de não-redundância dos dados, tem pontualmente a contagem duplicada de uma mesma publicação por conta dos docentes. Por isso, alertamos, neste trabalho, que todos os dados analisados foram contados manualmente para conferência e coerência das tabelas e demais informações trazidas à luz em nossas discussões. 
Para entender esses três tipos de grafos, os autores trazem o seguinte exemplo, formatado em diagrama, o qual reproduzimos a seguir:

Produções elaboradas em colaboração

$\begin{array}{ll}\text { Artigo 1: Elaborado pelos autores M1 e M2. } & \text { Autor M1: Participa em } 3 \text { artigos. } \\ \text { Artigo 2: Elaborado pelos autores M1, M2 e M3. } & \text { Autor M2: Participa em } 2 \text { artigos. } \\ \text { Artigo 3: Elaborado pelos autores M1 e M4. } & \text { Autor M3: Participa em } 1 \text { artigo. } \\ & \end{array}$

Grafos de colaborações

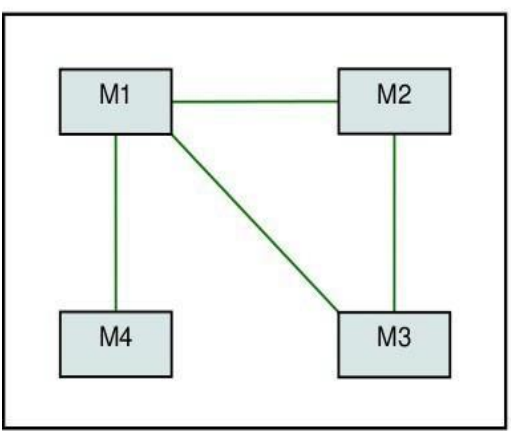

sem pesos



com pesos

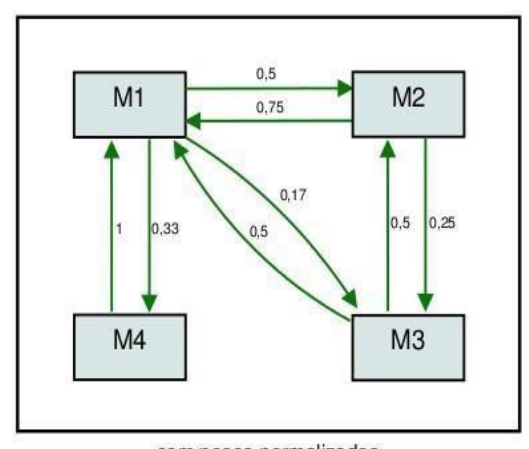

com pesos normalizados

Figura 9. Diagrama de exemplo dos tipos de grafos do software scriptLattes

Fonte: Mena-Chalco e Cesar Junior (2013, p. 115).

Essa normalização do scriptLattes permite atribuir maior peso para autores que coproduziram mais publicações em conjunto. Veja abaixo como os criadores explicam essas inter-relações entre coautores e seus diferentes pesos a partir dos exemplos M1, M2, M3 e M4:

Os pesos normalizados intuitivamente dão uma ideia da 'importância' de um coautor na produção realizada em colaboração com outro. Por exemplo, para M2 o colaborador M1 participa em $75 \%$ da sua produção feita em colaboração, i.e. M2 é $75 \%$ importante para M1. Já para M1, M2 é apenas $50 \%$ importante para sua produção feita em colaboração. Por outro lado, para M4, M1 é $100 \%$ importante na sua produção (colaborativa) acadêmica, entretanto para M1, M4 é importante apenas $33 \%$. Note que este último comportamento é típico nas relações orientador-orientado (M1-M4) (MENA-CHALCO; CESAR JUNIOR, 2013, p. 114).

Os pesos do grafo direcionado que está presente no terceiro quadro acima da figura 9 mostra o prestígio de colaboração e a sua reciprocidade. "Entenda-se como grau de colaboração, um valor numérico que representa o impacto de um membro no grafo de colaborações [...] denominado AuthorRank" Esse é um tipo de adaptação do algoritmo PageRank utilizado no sistema de busca de páginas relevantes no buscador Google que explicaremos em tópico mais na frente. Para este estudo, utilizaremos o terceiro tipo de grafo porque ele evidencia as porcentagens dos membros de maior impacto 
colaborativo no próprio grupo de pesquisa, o que os outros dois grafos não demonstram. Com isso, poderemos inferir os maiores graus de colaboração das instituições selecionadas (MENA-CHALCO; CESAR JUNIOR, 2013, p. 115).

De forma geral, como explicam Mena-Chalco e Cesar Junior (2013) do scriptlattes, ele é um programa que está em ascensão entre as comunidades acadêmicas brasileiras:

O scriptLattes foi adotado recentemente por diversas instituições de ensino e pesquisa no Brasil e a sua utilização está motivada pela necessidade de exploração automática e uma grande quantidade de currículos cadastrados na Plataforma Lattes (veja uma lista atualizada com as organizações e instituições de ensino e pesquisa que usaram ou estão usando o scriptLattes em http://scriptlattes.sourceforge.net/links.html) (MENA-CHALCO; CESAR JUNIOR, 2013, p. 130).

Essas são algumas das características principais do programa scriptlattes. Como dissemos, utilizaremos em nossa análise o terceiro tipo de grafo. No próximo tópico, explicaremos o que é o PageRank.

De acordo com Page (1999), o Pagerank é o algoritmo que vai de zero a dez, desenvolvido pelo Larry Page e Sergey Brin, fundadores do Google, em 1998. Caracteriza-se como uma métrica de prestígio. Essa métrica atribui maior peso aos atores que se conectam com diferentes nós (isto é, um ponto de interrelação de pelo menos duas relações diferentes), e com nós que já estão bem conectados (ou seja, pontos de inter-relações com outros pontos também interrelacionados). Em outras palavras, os autores com Pagerank elevado estão associados a nós de redes que possuem audiência, isto é, uma maior rede de colaboração de membros que estão publicando em coautoria. O objetivo dessa métrica é avaliar a qualidade das conexões e não só a quantidade de acessos ou de nós.

A seguir, reproduzimos a fórmula matemática utilizada pelo Pagerank para deduzir o algoritmo de cada pesquisador de acordo com seus nós:

$$
P R\left(P_{1}\right)=(1-d)+d \times \sum_{i=1}^{n}\left(\frac{P R\left(P_{i}\right)}{N\left(P_{i}\right)}+\ldots+\frac{P R\left(P_{n}\right)}{N\left(P_{n}\right)}\right)
$$

Equação 1. Fórmula do PageRank

Fonte: Page et al. (1999, p.25). 
Os cientistas da computação Silva, Tirelo e Marques Neto (2013) explicam da seguinte maneira essa fórmula:

\begin{abstract}
Onde $\mathrm{PR}(\mathrm{P} 1)$ é o PageRank da página $\mathrm{P} 1$. $\mathrm{PR}(\mathrm{Pi})$ é o PageRank da página $\mathrm{Pi}$ que aponta para a página $\mathrm{P} 1 . \mathrm{N}(\mathrm{Pi})$ é o número de links que saem da página $\mathrm{Pi}$. Seja do damping factor no qual pode assumir valores entre 0 e 1 . $O$ damping factor $\mathrm{d}$ representa a probabilidade do usuário que está clicando em links aleatoriamente, interromper a sua ação e ir para outra página web. Estudos realizados por Page et al. (1999) testaram diferentes valores para o damping factor e é definido como padrão o valor 0,85 . Esse algoritmo trabalha recursivamente $\mathrm{e}$ em cada iteração todos os ranks são computados. O PageRank se encerra quando a diferença entre o rank atual e o rank anterior, ou seja, o fator de convergência, for um valor pouco significativo (SILVA; TIRELO; MARQUES NETO, 2013, p. 6).
\end{abstract}

Embora o índice pageRank se inicie com zero, o scripLattes não adota o mesmo ponto de partida, embora se utilize parcialmente da fórmula do pageRank para efetuar o seu authorRank. Para o sistema scriptLattes, os autores, mesmo quando não se citam ou têm publicação em coautoria, podem se conhecer, seja por meio de interação direta em eventos científicos e projetos, seja por mediação indireta de outros autores. Por isso, o ponto de partida adotado pelo scriptLattes é 0,15 e não o zero absoluto, como acontece na fórmula acima explicada por Silva, Tirelo e Marques Neto (2013).

Como vimos, o pageRank é um importante fator na análise de rede de colaboração. E ele é assimilado e reformulado na proposta do scriptLattes, a qual faremos uso em nossa análise. No próximo tópico, explicaremos o último parâmetro selecionado neste estudo: o índice H e o i10 diferente do período analisado, que foi de 2013 a 2016, resolvemos pesquisar o índice H pois o scriptLattes não nos oferece esse acesso.

Esse índice foi proposto pelo físico argentino Jorge Eduardo Hirsch, em 2005. Esse parâmetro foi utilizado, primeiramente, para a avaliação qualitativa de pesquisadores somente da área da física. Depois de apreendida a eficiência, a produtibilidade e reprodutibilidade, esse índice espraiou-se para outras disciplinas. Atualmente, é dos parâmetros quantitativo e qualitativo usado para mensurar o impacto de cada pesquisador. Como explicam Thomaz, Assad e Moreira (2011), esse é um índice que vem ganhando notoriedade graças as diversas possibilidades de aplicação: 
Muitos autores consideram-no [índice $\mathrm{H}$ ] não somente a forma mais segura de mensurar a qualidade científica do pesquisador, como também uma boa ferramenta de avaliação da regularidade da produção e previsão do desempenho científico futuro, pois combina produtividade com impacto14,15. O índice H de um pesquisador é definido com o número de artigos publicados pelo pesquisador, os quais obtenham citações maiores ou iguais a esse número. Por exemplo, quando dizemos que o índice $\mathrm{H}$ de um pesquisador é dez, significa que ele tem, pelo menos, dez artigos publicados, cada um deles com, pelo menos, dez citações. Quanto maior o número de artigos de grande interesse publicado pelo pesquisador, maior será o número de citações alcançadas, e maior será seu índice $\mathrm{H}$, refletindo a qualidade acadêmico-científica do pesquisador e sua capacidade produtiva. Entretanto, apenas o número total de artigos, por exemplo, pode mascarar a falta de relevância de cada texto, isoladamente. Podemos assim dizer que o índice $\mathrm{H}$ é o resultado do equilíbrio entre o número de publicações e o número de citações. Jorge Hirsch comparou o fator $\mathrm{H}$ com outros índices comumente usados para se analisar a produção científica de um pesquisador [...] (THOMAZ; ASSAD; MOREIRA, 2011, p. 91).

Como podemos apreender, o índice $\mathrm{H}$ calcula quantas vezes determinado artigo foi citado em determinado período. $\mathrm{O}$ índice $\mathrm{H} 10$ calcula quantas vezes determinado artigo foi citado pelo menos dez vezes. $\mathrm{O}$ indexadores $\mathrm{H}$ permitem que o docente verifique quem o citou, em que texto e onde está publicado, conforme salienta Martins (2017). Rego (2010) afirma que o índice $\mathrm{H}$, juntamente com outros fatores de impacto difundidos pelas diferentes comunidades acadêmicas, criou uma espécie de círculo vicioso, no qual quem tem maior visibilidade, tem maior prestígio:

É claro que os artigos de uma revista serão tanto mais citados quanto melhor for sua qualidade e, portanto, o fator de impacto e o índice $\mathrm{H}$ também refletem a qualidade desses artigos, mas não só. $O$ acesso à revista também é determinante. Ninguém pode citar o que não vê ou não entende. Dessa maneira, um círculo vicioso se instala (REGO, 2010, p. 190).

Esse círculo vicioso é apenas uma das críticas que estão ao redor do índice $\mathrm{H}$, bem como do pageRank e de qualquer outra forma de categorização da produção acadêmica, como explicam Thomas, Assad e Moreira (2011, p. 91):

O mesmo Hirsch argumenta que indivíduos com índices $\mathrm{H}$ similares são também comparáveis em termos de impacto científico, mesmo quando o número de artigos ou número total de citações de ambos for muito diverso. Diferentemente, quando comparamos dois indivíduos (de idade científica igual), com números iguais de publicações ou citações e com índices $\mathrm{H}$ muito díspares, aquele com maior índice H é 
provavelmente um pesquisador mais talentoso. Entretanto, como toda tentativa simplista de se categorizar ou classificar a produção de um pesquisador por um único número, o índice H está longe de ser perfeito e enfrenta várias críticas. Entre essas, além das usuais de que não se pode caracterizar um pesquisador por um número, estão: a autocitação, a indistinção entre cientistas ativos e inativos, a dependência da idade científica, as diferenças entre áreas, sexo etc. (THOMAZ; ASSAD; MOREIRA, 2011, p. 91).

De forma geral, tanto os índices $\mathrm{H}$ e i10 têm sido instrumentos de verificação da repercussão científica de diversos trabalhos em distintas áreas do conhecimento. (MARTINS, 2017). Eles auxiliam no reconhecimento da repercussão e da relevância dos estudos científicos nas diversas comunidades acadêmicas. Por isso, esses índices, juntamente aos dados do pagerank e aqueles fornecidos pelo sistema scriptLattes, mostram como a produção acadêmica está estruturada e estrutura, por sua vez, os programas de pósgraduação - em nosso caso, os programas de pós-graduação em turismo.

É importante ressaltar também que devido ao preenchimento incorreto dos Currículos Lattes (por parte de vários docentes), seja com preenchimento incorreto do ISSN (International Standard Serial Number) do periódico ou do nome do próprio periódico, foi necessário refazer a análise dos currículos manualmente. Existiram casos mais graves, em que dois ou mais autores do mesmo trabalho ( artigo, livro e capítulos de livros) preencheram os currículos Lattes de forma distintas (ISSN distintos, ausência do nome de coautores, etc.) gerando duplicidade de artigos, livros e capítulo de livros por isso o scriptLattes contou os mesmos duas ou mais vezes no próprio currículo gerando assim uma contagem incorreta do número de artigos publicados. Isso também foi corrigido na análise.

Para Krippendorf (2004), a análise do conteúdo de grande volume de dados é mais confiável com o auxílio de computadores, o que justifica o uso desse software nesta pesquisa, o qual, como estamos destacando, é bastante adequado ao que se propõe pesquisar neste estudo.

Com a entrada dos 157 currículos selecionados, foram obtidos 932 artigos, 112 livros e 339 capítulos de livros como produção docente dos programas de pós-graduação stricto sensu em turismo no Brasil. Com relação ao estudo desse material em 2013 e 2016, foram depreendidos os seguintes aspectos qualitativos: 
Local de publicação dos artigos

Veículo de publicação dos artigos

Qualidade da publicação dos artigos (tradução da editora/Web qualis

Rede de colaboração dos docentes (scripLattes)

PageRank (scripLattes)

Indice $\mathrm{H}$

Destaca-se, ainda, que, com referência aos artigos completos, livros e capítulos de livro publicados, foram analisados as palavras-chave mais frequentes como aspecto quantitativo e qualitativo de um fato temático. Para isso, foi utilizado o site, intitulado jasondavies, que também é gratuito e de livre acesso ${ }^{15}$. Esse aplicativo gera, a partir das palavras mais citadas no corpus inserido - em nosso caso, as unidades de registro selecionados - uma nuvem de palavras, isto é, uma espécie de rede interconectada de termos que mais se repetem. Identificadas as palavras-chave mais frequentes das unidades de análise, elas são utilizadas para a elaboração de um ranking das principais temáticas e tendências da área de turismo, desenvolvidas pelos docentes dos programas de pós-graduação stricto sensu.

Para a análise de livros, outro método de análise foi utilizado. Primeiramente, selecionamos as três palavras mais recorrentes dos títulos dos referidos livros. Em seguida, categorizamos essas palavras frequentes por universidade. Esse percurso vai, portanto, do particular (livros) para o geral (instituições).

Para a análise de capítulos de livros, esse método é também aplicado. Em um primeiro momento, são coletadas as três palavras-chave mais recorrentes dos títulos dos capítulos de livro no geral. Depois, são analisados as palavras-chave mais frequentes por instituição. Novamente, segue-se um caminho dedutivo.

Outro método aplicado é o da rede de colaboração dos docentes, dado possibilitado pelo software scritptLattes. Esse trajeto investigativo consiste, em um primeiro momento, no grafo de colaboração entre os 157 docentes na construção da produção em pares. Esse grafo correlaciona os dados de publicação entre os docentes, com isso, consegue-se depreender o grau de

${ }^{15}$ Disponível em: <http://www.jasondavies.com >. Acessado em: 13 jul. 2017. 
colaboração de cada docente que é o valor numérico que indica o impacto de um membro na produtividade científica de sua instituição. A partir dos dados do grau de cooperação, são selecionados, em um segundo momento, a análise dos três docentes de cada instituição e os correlacionamos entre si. Com isso, conseguimos depreender, na primeira análise, o grau de cooperação de cada membro de cada instituição e, na segunda análise, a rede de cooperação dos membros que possuem o pagerank entre os nove programas escolhidos. Em um terceiro momento, a partir dos dados docentes, busca-se analisar os fatores de impacto atual dos três docentes mais recorrentes dos programas analisado.

Esses fatores de impacto são os presentes no Google Scholar, a saber: as citações, o índice h e o índice i10. Na página de cada pesquisador cadastrado pelo Google Scholar, essas três informações aparecem no canto superior direito da página. As citação constituem o número total de citações dos artigos do pesquisador nos artigos e livros credenciados no site de busca do Google.

Compreendidas as unidades de registro e os aspectos qualitativos e quatitativos a serem depreendidos delas, executa-se o procedimento de categorização da fase de pré-análise. "A categorização é um operação de classificação de elementos constitutivos de um conjunto, por diferenciação e, seguidamente, por reagrupamento segundo gênero (analogia), com os critérios previamente definidos" (BARDIN, 1977, p. 117). A categorização que se faz neste estudo é a diferenciação das unidades de registro em gráficos distintos, os quais tem em comum o período de análise de 2013 a 2016 e como diferença a unidade de registro que é analisada ${ }^{16}$.

$\mathrm{Na}$ fase de exploração do material, realizam-se dois principais procedimentos: identificação e observação dos resultados da categorização. Se na categorização obtém-se a representação simplificada dos dados brutos, na exploração do material consegue-se depreender os resultados dessa categorização a partir da reconstituição desses dados representados no panorama geral da pesquisa. Tem-se, assim, uma via de mão dupla: do geral para o particular (dos 157 currículos da PL para as três unidades de registro, no

\footnotetext{
${ }^{16}$ Como explica Bardin (1977, p. 117), "as categorias são rubricas ou classes, as quais reúnem um grupo de elementos (unidades de registro, no caso da análise de conteúdo) sob um título genérico agrupamento esse efetuado em razão dos caracteres comuns destes elementos".
} 
procedimento de categorização) e, depois, do particular para o geral (dos gráficos das três unidades de registro para os resultados dessa categorização, no procedimento de identificação). Desse modo, como Bardin (1977, p. 101) explica, essa fase "não é mais do que a administração sistemática das decisões tomadas", por isso, essa fase é consequência das decisões e procedimentos já realizados na fase anterior.

$\mathrm{Na}$ fase do tratamento dos resultados, busca-se evidenciar os indicadores que permitam inferir dados quantitativos e qualitativos sobre os resultados alcançados nas fases anteriores os quais não estavam aparentes à primeira vista na superfície dos materiais brutos selecionados. Como Bardin (1977, p. 69) ressalta, nesta fase, "o objetivo é estabelecer uma correspondência entre o nível empírico e o teórico [...]". Em outras palavras, prevê-se estabelecer uma relação entre os dados dos 157 currículos selecionados e a produção docente da área do turismo, respondendo, assim, como está estruturada os programas da pósgraduação stricto sensu nesse campo. No quadro 1, faz-se uma retomada dos principais fases e procedimentos adotados nesta pesquisa:

Quadro 1 Proposta de análise

\begin{tabular}{|l|l|}
\hline \multicolumn{2}{|c|}{$\begin{array}{l}\text { Análise de conteúdo (tipo análise de veículos-signos e Análise de } \\
\text { afirmações) } \\
\text { Fase 1. Pré-análise }\end{array}$} \\
\hline Preparação & $\begin{array}{l}\text { Foram selecionados } 157 \text { currículos da } \\
\text { Plataforma Sucupira. }\end{array}$ \\
\hline Codificação & $\begin{array}{l}\text { Foram escolhidos três unidades de registro: } \\
\text { artigos completos em periódico, livros e } \\
\text { capítulos de livros, no escopo temporal de 2013 } \\
\text { a 2016 } \\
\text { - Foi utilizado o software jasondavies, para } \\
\text { encontrar as palavras-chave mais frequentes } \\
\text { dos artigos completos em periódico, livros e } \\
\text { capítulos de livro selecionados, }\end{array}$ \\
\hline
\end{tabular}




\begin{tabular}{|l|l|}
\hline Categorização & $\begin{array}{l}\text { Foi utilizado a plataforma scriptlattes para } \\
\text { extrair as informações dos currículos da PL } \\
\text { selecionados a partir das unidades de registro. }\end{array}$ \\
& $\begin{array}{l}\text { - Foram formulados distintos gráficos a partir da } \\
\text { diferenciação das unidades de registro; }\end{array}$ \\
& $\begin{array}{l}\text { Foram observados os seguintes aspectos } \\
\text { qualitativos: local de publicação; veículo da } \\
\text { publicação; qualidade da publicação; rede de } \\
\text { colaboração em coautoria, PageRank, Indíce H } \\
\text { e o i10 dos docentes. }\end{array}$ \\
\hline Fase 2. Exploração do material \\
\hline Fescrição dos dados & $\begin{array}{l}\text { Foram identificados e observados os resultados } \\
\text { da categorização (gráficos); }\end{array}$ \\
\hline Fase 3. Tratamento dos resultados
\end{tabular}

Fonte: Juliana Ferreira dos Santos, a partir dos dados da StrictoLattes, 2018.

A partir do quadro 1, pode-se compreender que, apoiada em uma análise do conteúdo indutiva, cujo corpus é constituído prioritariamente pelos 157 currículos selecionados da PL. As unidades de registros escolhidas foram: artigos completos em periódicos, livros e capítulos de livros, dentro do escopo temporal de 2013 a 2016, sendo que todos os dados foram baixados pelo Dr. Luciano Digiampietri. A categorização dos dados levou em conta, ainda, os seguintes aspectos qualitativos: local de publicação; nome da editora/periódico; qualidade da publicação; rede de colaboração dos docentes, PageRank e índice $\mathrm{H}$ atual dos docentes.

As inferências a serem depreendidas desses procedimentos permitem conceber as condições de produção dos docentes permanentes/colaboradores e inativos na área do turismo nos programas de pós-graduação stricto sensu. A interpretação, por sua vez, nasce da confrontação sistemática com o material (dados da Plataforma Sucupira, da Plataforma Lattes; do Google Scholar; dos títulos e das palavras-chave das três unidades de registro) e as inferências 
deduzidas ao longo da pesquisa, conforme assevera Bardin (1977, p. 101). Logo, de uma análise de conteúdo do tipo veículo-signo e de afirmações partindo dos currículos da PL selecionados, pretende-se inferir um retrato contemporâneo da produção docente dos programas de pós-graduação stricto sensu em turismo no Brasil. 


\subsection{ANÁLISE DOS ARTIGOS}

De acordo com Silva (2004), o desenvolvimento científico e tecnológico de um país é alcançado a partir da qualidade e da quantidade das pesquisas desenvolvidas, bem como da capacidade de transformar os avanços obtidos por meio dessas pesquisas em progresso econômico e social. Para Garvey et al. (1979), a comunicação científica é um conjunto de atividades associadas à produção, à disseminação e ao uso da informação. Essa comunicação está presente desde o momento em que o pesquisador concebe a ideia de seu estudo. Diversos meios de comunicação podem ser utilizados para transmitir as mensagens nesse contexto, incluindo meios formais e informais (MINOZZO; REJOWSKI, 2004).

Dentre esses diversos meios de comunicação, o conceito de publicação pode ser compreendido como o resultado de uma comunicação entre a razão individual e a coletiva, conforme Santos et al.(2003). Para isso ocorrer, há diversas condições e pré-requisitos. Por exemplo, pode-se exigir determinada titulação (doutorado, mestrado, especialização de forma geral, dentre outras possibilidades), ou ainda, um autor que ganha respeito e reconhecimento de seus pares consegue publicar mais em periódicos de qualidade de sua área do que outros que não possuem tal notoriedade. Esse jogo entre o individual e o coletivo permeia a produção científica e ele é perpetuado pela comunicação científica.

A produção técnica e científica é encontrada em periódicos científicos. Nesse meio de veiculação de informação, os artigos científicos são submetidos e avaliados às cegas, por pareceristas da área e, se aceitos, publicados. Dentro desse processo, o artigo científico se tornou a forma-padrão de disseminação dos resultados de pesquisa científica em todas as áreas do conhecimento. Essa tendência não é somente brasileira, ela é mundial, pois, em muitos outros centros científicos espalhados por todos os continentes, o artigo científico também é a principal ferramenta de difusão do conhecimento (MENEGHINI, 2012).

O periódico científico, bem como o artigo nele publicado, tem sido objeto de muitos estudos, motivados pelo papel que representa na construção do conhecimento científico (GARVEY, et al 1979; SILVA, 2004). Conforme Mueller (1999), eles são usados como: (a) apontadores do desenvolvimento científico do 
país; (b) medidores do estágio de desenvolvimento de uma área do conhecimento; (c) indicadores do desempenho individual de um cientista ou de uma instituição de pesquisa. Atualmente, o periódico científico é o principal modelo de canal formal de comunicação da ciência no Brasil e no mundo, como já dissemos, porque ele representa um espaço de divulgação dos resultados de pesquisa e elaborações teóricas que é controlável quantitativa e qualitativamente.

Embora ele seja controlável, os critérios de seleção dos artigos ainda são um ponto a ser debatido. Por isso, o periódico pode ser visto como um espaço de conflitos de interesses em que diversos grupos disputam chances de comunicar seus pensamentos, muitas vezes tendo como objetivo implícito a intenção da manutenção de seu status, conforme discute Alvarenga (2003). Nesse contexto, o desempenho de cargos docentes em instituições públicas ou privadas fica dependente da publicação em revistas, em especial aquelas denominadas de alto impacto.

Atualmente, no Brasil, os periódicos estão sendo avaliados pela CAPES. Eles determinam uma pontuação para cada tipo de publicação. Por exemplo, no caso da CAPES, em suas avaliações quadrienais, a publicação de artigo científico tem sua pontuação associada ao Qualis do periódico. Destaca-se que Qualis é "um conjunto de procedimentos adotados com intuito de estabelecer a qualidade dos artigos produzidos, a partir da determinação da qualidade dos periódicos científicos em que eles são publicados" (QUEIROZ, 2012).

Os periódicos são avaliados por diversos fatores. Um dos mais importantes é a sua indexação. Ser um periódico indexado quer dizer que o periódico está inserido em plataformas de difusão do conhecimento, como, por exemplo, Latex, Scielo e Web of Science. Cada uma dessas plataformas tem, por sua vez, determinadas regras e critérios para aceitar ou não a indexação do periódico. Como se vê, o artigo em periódico é uma publicação que está sendo constantemente (re)avalidada, o que evidencia a sua pertinência no universo acadêmico contemporâneo.

Uma vez entendido a importância da publicação de artigos científicos, é relevante destacar que a publicação de outros materiais técnico-científicos é também pertinente na avaliação do desempenho docente empregada 
quadrienalmente pelas agências de fomento, em específico pela CAPES e pelo CNPq.

\subsection{Dados gerais}

Para realizar o estudo desses três tipos de publicação, utilizamos 0 strictpLattes. Como já explicamos, essa ferramenta analisa as publicações em pares e individualmente de uma determinada área do conhecimento. Com ela é possível porque evidencia o grau de colaboração dos docentes entre si e entre outros docentes. Salientamos, mais uma vez, que as publicações, quando são em coautoria entre pesquisadores de diferentes instituições de ensino, contam pelo menos duas vezes. Por isso, tivemos a acuidade de, ao fazer a análise, excluir os dados que tinham duplicidade, evitando, assim, distorções na somatória dos dados.

Compreendendo a relevância da publicação de artigos científicos em periódicos indexados, livros e capítulos de livros, a plataforma utilizada e o critério de seleção, analisamos a seguir a produção docente na Tabela 4. Ela exibe o número de artigos publicados pelas nove instituições de ensino superior como também a quantidade de docentes e as porcentagem de artigos por docentes que compõe a área de turismo no quadriênio de 2013 a 2016.

Tabela 4 - Produção bibliográfica dos docentes (2013-2016):

Artigos em periódicos

\begin{tabular}{|l|c|c|c|}
\hline & Artigos & $\begin{array}{c}\text { Categoria } \\
\text { Quantidade } \\
\text { de docentes }\end{array}$ & $\begin{array}{c}\text { Média de } \\
\text { artigos por } \\
\text { docentes }\end{array}$ \\
\hline UAM & 144 & 19 & $7,75 \%$ \\
\hline UCS & 107 & 16 & $6,68 \%$ \\
\hline UECE & 103 & 19 & $5.42 \%$ \\
\hline UFF & 40 & 10 & $4 \%$ \\
\hline UFPR & 130 & 18 & $7,22 \%$ \\
\hline UFRN & 167 & 22 & $7,59 \%$ \\
\hline UNB & 61 & 22 & $2,77 \%$ \\
\hline UNIVALI & 112 & 17 & $6,58 \%$ \\
\hline USP & 128 & 14 & $9,14 \%$ \\
\hline Total & 932 & 157 & $5,93 \%$ \\
\hline
\end{tabular}

Fonte: Juliana Ferreira dos Santos, a partir dos dados da StrictoLattes, 2018. 
Analisando a Tabela 4, verifica-se que todos os programas de pósgraduação stricto sensu em turismo publicam artigos. Os programas de pósgraduação stricto sensu que publicaram mais artigos em 2013 a 2016, respectivamente, foram: UFRN, UFPR e a UAM. A UFF foi o programa que publicou menos artigos no mesmo período, com quarenta publicações, porém a UFF começou seu PPTUR em 2015.

Outra análise que podemos detectar com a análise de veículos-signos e a análise de afirmações é o resultado da soma de cada programa e com a divisão pelo número de docentes, permanentes e inativos que lecionaram ou lecionam no programa no período analisado. Uma vez que esse resultado representa a publicação média por docente em cada programa. Constatamos que a USP apresenta $9,14 \%$ produções por docente, possui quatorze docentes, a UNIVALI apresenta $6,58 \%$ produções por docente, tendo o número de docentes (dezessete docentes). A UFPR tem dezoito docentes e obteve 7,22\%.

Outro caso interessante é que a UAM e a UECE possuem o mesmo número de contingente de docente, dezenove professores. Todavia, o percentual de produção média por docente da UAM é de $7,75 \%$ itens enquanto a da UECE é $5,42 \%$. O mesmo acontece com a UFRN e a UNB que tem o mesmo número de docentes, vinte dois professores. Entretanto a produção média docente da UFRN é de $7,59 \%$, já a UNB com 2,77\%. Para uma relação de comparação, o programa que obteve o menor número de produção média por docente foi a UFF com 4 itens, que possui dez docentes. Através dessa análise, constata-se que o fator tempo não é definidor para o maior ou menor índice de produção docente em um programa.

\subsection{Qualis da produção bibliográfica das IES}

Aprofundemos a análise de conteúdo estudando a qualidade e a quantidade dos artigos publicados pelos programas de pós-graduação stricto sensu em turismo no Brasil. A qualidade do artigo é, assim, definida por meio do Qualis do periódico em que o artigo foi publicado. O sistema Qualis é um conjunto de procedimentos utilizados pela CAPES para estratificação da qualidade da produção intelectual dos programas de pós-graduação a partir de suas áreas de concentração (CAPES, 2017). Atualmente, o sistema Qualis 
possui as seguintes áreas de concentração: Administração Pública e de Empresas, Ciências Contábeis e Turismo; Antropologia/Arqueologia; Arquitetura, Urbanismo e Design, Artes, Astronomia/Física, Biotecnologia, Ciência da Computação, Ciência de Alimentos, Ciência Política e Relações Internacionais, Ciência Agrarias I, Ciências Ambientais, Ciências Biológicas I, Ciências Biológicas II, Ciências Biológicas III, Ciência da Religião e Teologia, Comunicação e Informação, Direito, Economia, Educação, Educação Física, Enfermagem, Engenharias I, Engenharias II, Engenharias III, Engenharias IV, Ensino, Farmácia, Filosofia, Geociências, Geografia, História, Interdisciplinar, Linguística e Literatura, Matemática/Probabilidade e Estatística, Materiais, Medicina I, Medicina II, Medicina III, Medicina Veterinária, Nutrição, Odontologia, Planejamento Urbano e Regional/Demografia, Psicologia, Química, Saúde Coletiva, Serviço Social, Sociologia, Zootecnia, Recursos Pesqueiros.

Cada periódico pode ser avaliado em mais de uma área e, por isso, a depender da qualidade dos artigos publicados nessas áreas, tem diferentes notas Qualis. Em outras palavras, um periódico, publica artigos de mais de uma área e recebe uma nota Qualis para cada uma delas. Cada nota Qualis possui uma nota na avaliação geral da produção docente das instituições feita pela Capes a cada quatro anos. Atualmente essa estratificação classifica-se da seguinte maneira, conforme tabela a seguir:

Quadro 2 Pontuação da Qualis

\begin{tabular}{|c|c|}
\hline Qualis & Pontuação \\
\hline A1 & 100 \\
\hline A2 & 80 \\
\hline B1 & 60 \\
\hline B2 & 50 \\
\hline B3 & 30 \\
\hline B4 & 20 \\
\hline B5 & 10 \\
\hline C & 0 \\
\hline
\end{tabular}

Fonte: Juliana Ferreira dos Santos, a partir do site oficial da CAPES, 2018. 
Podemos usar como exemplo a Revista Turismo em Análise, editada pelo Departamento de Relações Públicas, Propaganda e Turismo da Escola de Comunicações e Artes da Universidade de São Paulo (ECA), desde 1990. Essa revista, embora se relacione com a área do turismo desde o título, possui quatorze registros de áreas de concentração na Plataforma Sucupira. Podemos observar isso na reprodução da tela da referida plataforma a seguir:

Figura 5 - Áreas de avaliação da Revista Turismo em análise

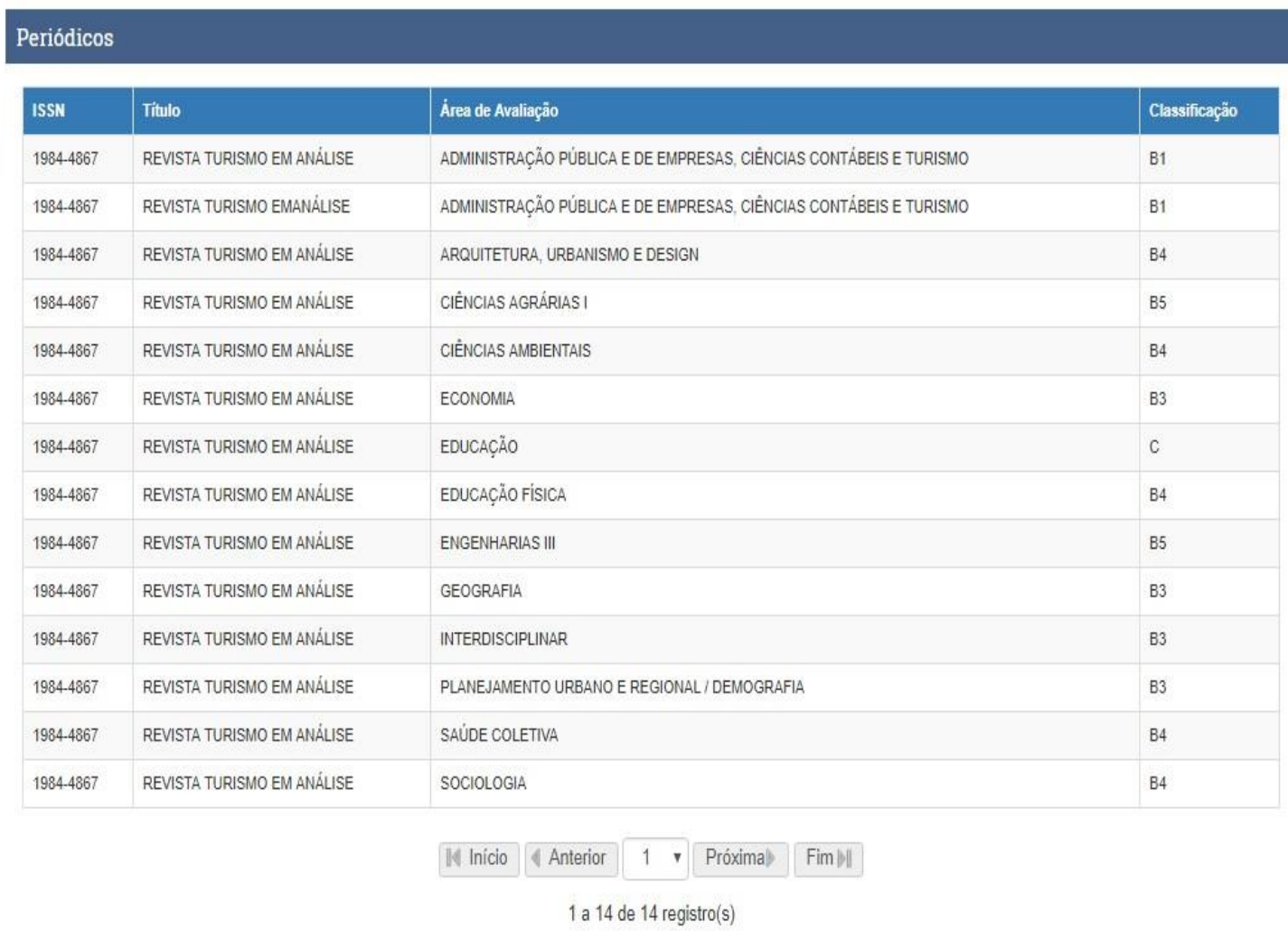

Fonte: Plataforma Sucupira, (2018)

Como se pode perceber Figura 5, a Revista Turismo em Análise possui um escopo bem diversificado de áreas de avaliação, indo de Administração pública e de empresas, ciências contábeis e turismo até ciências agrárias. Outro dado interessante a se observar é que a revista possui também diferentes notas qualis a depender da área de avaliação. Por exemplo, se o artigo se concentrar em administração pública e de empresas, ciências contábeis e turismo, ele recebera nota B1, obtendo na avaliação quadrienal CAPES 60 pontos. Todavia, se 0 artigo se concentrar em educação e for publicado nesse periódico, ele terá a nota $\mathrm{C}$, ficando, assim, zerada sua avaliação para este artigo na CAPES. 
Com isso, podemos depreender que a nota Qualis não é do periódico, mas do periódico em relação a área de avaliação. Por isso, quando é avaliada a produção docente dos professores universitários em revistas científicas, é analisada a pontuação que esses pesquisadores tiveram na área de concentração de seus programas. Desse modo, se o professor publicou em revistas de impacto em sua área, sua pontuação será maior do que se ele tiver publicado em diversas revistas que não se tenham registro em sua área de concentração ou tenham uma nota Qualis baixa nessa área.

A seguir, a Tabela 5 exibe o número de artigos publicados pelas nove instituições de ensino superior da área de turismo no período de 2013 a 2016, correlacionado o artigo ao Qualis do periódico em que ele foi publicado. Destacase que alguns artigos publicados não tiveram seu Qualis identificado, pois o Qualis é atribuído e/ou atualizado às revistas de quatro em quatro anos por isso algumas revistas novas, lançadas durante o período analisado, não possuíam Qualis atribuído. Na tabela 5 , a coluna com a letra $\mathrm{N}$ corresponde ao número total de artigos publicados segundo a categoria de cada linha e a coluna com a letra $\mathrm{P}$ representa a pontuação alcançada na categoria de cada linha.

Tabela 5 - Qualis dos artigos em periódico da produção docente em turismo $(2013-2016)^{17}$

\begin{tabular}{|c|c|c|c|r|r|r|c|}
\hline \multicolumn{2}{|c|}{ Qualis } & \multicolumn{2}{c|}{ UAM } & \multicolumn{2}{c|}{ UCS } & \multicolumn{2}{c|}{ UECE } \\
\hline Categoria & $\begin{array}{c}\text { Pontuação } \\
\text { (P) }\end{array}$ & № & P & № & P & № & P \\
\hline A1 & 100 & 0 & 0 & 0 & 0 & 0 & 0 \\
\hline A2 & 80 & 10 & 800 & 8 & 640 & 1 & 80 \\
\hline B1 & 60 & 16 & 960 & 17 & 1020 & 6 & 360 \\
\hline B2 & 50 & 25 & 1250 & 25 & 1250 & 8 & 400 \\
\hline B3 & 30 & 38 & 1140 & 24 & 720 & 35 & 1050 \\
\hline B4 & 20 & 25 & 500 & 18 & 360 & 40 & 400 \\
\hline B5 & 10 & 11 & 110 & 7 & 70 & 2 & 20 \\
\hline C & 0 & 1 & 0 & 0 & 0 & 1 & 0 \\
\hline $\begin{array}{l}\text { Qualis não } \\
\text { identificado }\end{array}$ & 0 & 18 & 0 & 08 & 0 & 10 & 0 \\
\hline \multicolumn{2}{|c|}{ Total por instituição } & 144 & 4760 & 107 & 4060 & 103 & 2310 \\
\hline
\end{tabular}

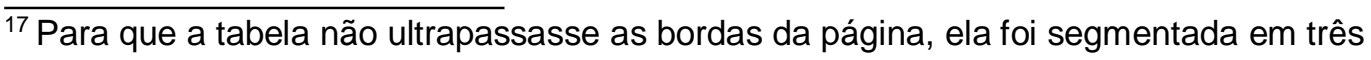
partes. 


\begin{tabular}{|c|c|r|r|r|r|r|r|}
\hline \multicolumn{2}{|c|}{ Universidade } & \multicolumn{2}{c|}{ UFF } & \multicolumn{2}{c|}{ UFPR } & \multicolumn{2}{c|}{ UFRN } \\
\hline Categoria & $\begin{array}{c}\text { Pontuação } \\
\text { (P) }\end{array}$ & № & P & No & P & № & P \\
\hline A1 & 100 & 0 & 0 & 1 & 100 & 2 & 200 \\
\hline A2 & 80 & 3 & 240 & 16 & 1280 & 13 & 1040 \\
\hline B1 & 60 & 10 & 600 & 22 & 1320 & 17 & 1020 \\
\hline B2 & 50 & 5 & 250 & 15 & 750 & 28 & 1400 \\
\hline B3 & 30 & 0 & 0 & 29 & 870 & 42 & 1260 \\
\hline B4 & 20 & 5 & 100 & 27 & 540 & 41 & 820 \\
\hline B5 & 10 & 7 & 70 & 11 & 110 & 12 & 120 \\
\hline C & 0 & 2 & 0 & 0 & 0 & 0 & 0 \\
\hline $\begin{array}{l}\text { Qualis não } \\
\text { identificado }\end{array}$ & 0 & 8 & 0 & 9 & 0 & 12 & 0 \\
\hline \multicolumn{2}{|c|}{ Total por instituição } & 40 & 1260 & 130 & 4970 & 167 & 5860 \\
\hline
\end{tabular}

\begin{tabular}{|c|c|c|c|c|c|c|c|c|c|}
\hline \multicolumn{2}{|c|}{$\begin{array}{l}\text { Universidade } \\
\text { Qualis }\end{array}$} & \multicolumn{2}{|c|}{ UNB } & \multicolumn{2}{|c|}{ UNIVALI } & \multicolumn{2}{|c|}{ USP } & \multicolumn{2}{|c|}{ GERAL } \\
\hline Categoria & $\begin{array}{c}\text { Pontuação } \\
\text { (P) }\end{array}$ & № & $\mathbf{P}$ & № & $\mathbf{P}$ & № & $\mathbf{P}$ & № & $\mathbf{P}$ \\
\hline $\mathrm{A} 1$ & 100 & 1 & 100 & 1 & 100 & 7 & 700 & 11 & 1100 \\
\hline A2 & 80 & 8 & 640 & 13 & 1040 & 14 & 1120 & 82 & 6560 \\
\hline B1 & 60 & 6 & 360 & 30 & 1800 & 15 & 900 & 137 & 8220 \\
\hline B2 & 50 & 0 & 0 & 14 & 840 & 10 & 500 & 128 & 6400 \\
\hline B3 & 30 & 12 & 360 & 22 & 660 & 38 & 1040 & 213 & 6390 \\
\hline B4 & 20 & 21 & 420 & 13 & 260 & 28 & 560 & 197 & 3940 \\
\hline B5 & 10 & 4 & 40 & 7 & 70 & 7 & 70 & 67 & 670 \\
\hline $\mathrm{C}$ & 0 & 0 & 0 & 0 & 0 & 2 & 0 & 6 & 0 \\
\hline $\begin{array}{l}\text { Qualis não } \\
\text { identificado }\end{array}$ & 0 & 9 & 0 & 12 & 0 & 7 & 0 & 91 & 0 \\
\hline \multicolumn{2}{|c|}{ Total por instituição } & 61 & 1920 & 112 & 4770 & 128 & 4890 & 932 & 33280 \\
\hline
\end{tabular}

Fonte: Juliana Ferreira dos Santos, a partir dos dados da StrictoLattes, 2018 
A partir dos dados da Tabela 5, conseguimos depreender que a área do turismo, entre 2013 a 2016, publicou 932 artigos em periódicos credenciados ou não no sistema da Qualis, obtendo, com isso, o total de 33280 pontos no referido sistema. As três instituições que mais publicaram e, consequentemente, tiveram a maior pontuação são: em primeiro lugar, a UFRN com 167 e um total de 5860 pontos; em segundo lugar, a UFPR com 130 artigos e um total de 4970 pontos. E em terceiro lugar, a USP e a UAM disputam essa colocação, porque, numericamente, a UAM possui 144 artigos publicados e a USP tem 128, todavia, a USP alcançou um total de 4890 pontos, enquanto a UAM teve 4760 pontos. Isso se deve, provavelmente, a ocorrência de que a UAM publicou 18 artigos em periódicos não registrados no sistema Qualis. Com o menor número de publicações e de pontuação no sistema Qualis, temos as seguintes instituições: a UFF, com 40 artigos e um total de 1260 pontos; a UNB, com 61 artigos e um total de 1920 pontos; e a UECE, com 103 artigos e um total de 2310 pontos.

A partir desses dados, fizemos uma leitura dos programas, atribuindo a cada instituição uma porcentagem conforme sua produção em quantidade (coluna N) e sua qualidade, conforme a pontuação obtida no sistema Qualis (coluna $\mathrm{P}$ ). Esses resultados da coluna $\mathrm{N}$ foram obtidos dividindo o número total de publicações alcançado no período de 2013 a 2016 pela instituição sobre o número total de publicações do campo do turismo (no caso, 932 artigos). Os resultados da coluna $\mathrm{P}$ foram adquiridos a partir da divisão da pontuação total, conforme tabela da Qualis, conseguida pela instituição no mesmo período, sobre o número total de pontuação da área (no caso, 33280 pontos). Estratificamos os resultados na seguinte Tabela 6 
Tabela 6 - Porcentagens gerais da produção docente em turismo (2013-2016): quantidade e qualidade ${ }^{18}$

\begin{tabular}{|c|c|c|c|c|c|c|c|c|c|c|}
\hline Universidade & \multicolumn{2}{|c|}{ UAM } & \multicolumn{2}{c|}{ UCS } & \multicolumn{2}{c|}{ UECE } & \multicolumn{2}{c|}{ UFF } & \multicolumn{2}{c|}{ UFPR } \\
Qualis & & Nategorias: \\
\hline $\begin{array}{c}\text { Número total de } \\
\text { publicações (№) e } \\
\text { Pontuação (P) }\end{array}$ & № & P & № & P & № & P & No & P & № & P \\
\hline Total por instituição & 144 & 4760 & 107 & 4060 & 103 & 2310 & 40 & 1260 & 130 & 4970 \\
\hline $\begin{array}{c}\text { Porcentagem } \\
\text { sobre o total de } \\
\text { cada instituição }\end{array}$ & $15,4 \%$ & $14,3 \%$ & $11,4 \%$ & $12,1 \%$ & $11 \%$ & $6,9 \%$ & $4,2 \%$ & $3,7 \%$ & $13,9 \%$ & $14,9 \%$ \\
\hline
\end{tabular}

\begin{tabular}{|c|c|c|c|c|c|c|c|c|c|c|}
\hline Universidade & \multicolumn{2}{|c|}{ UFRN } & \multicolumn{2}{|c|}{ UNB } & \multicolumn{2}{c|}{ UNIVALI } & \multicolumn{2}{c|}{ USP } & \multicolumn{2}{c|}{ GERAL } \\
Qualis & \multicolumn{2}{|c|}{} & & & & & & & & \\
\hline $\begin{array}{c}\text { Categorias: } \\
\text { Número total } \\
\text { de publicações } \\
\text { (№) } \\
\text { Pontuação (P) }\end{array}$ & № & $\mathbf{P}$ & № & $\mathbf{P}$ & № & $\mathbf{P}$ & № & $\mathbf{P}$ & № & P \\
\hline $\begin{array}{c}\text { Total por } \\
\text { instituição }\end{array}$ & 167 & 5860 & 61 & 1920 & 112 & 4770 & 128 & 4890 & 932 & 33280 \\
\hline $\begin{array}{c}\text { Porcentagem } \\
\text { sobre o total } \\
\text { de cada } \\
\text { instituição }\end{array}$ & $17,9 \%$ & $17,6 \%$ & $6,5 \%$ & $5,7 \%$ & $12 \%$ & $14,3 \%$ & $13,7 \%$ & $14,6 \%$ & $100 \%$ & $100 \%$ \\
\hline
\end{tabular}

Fonte: Juliana Ferreira dos Santos, a partir dos dados da StrictoLattes, 2018

Confrontando os dados obtidos na Tabela 5, conseguimos construir um panorama geral, por instituição, constatando a porcentagem de participação que cada universidade tem, seja numericamente (coluna $\mathrm{N}$ ), seja qualitativamente (coluna $\mathrm{P}$ ). As três instituições que possuem maior participação numérica e qualitativamente são: em primeiro lugar, a UFRN, com uma porcentagem de $17,9 \%$ com o total de publicações e $17,6 \%$ no total de pontuação da área; e em segundo lugar, a UFPR, com 13,9\% e 14,9\%, respectivamente. Em terceiro lugar, numericamente a UAM tem maior participação no campo do turismo, com $15,4 \%$, enquanto a USP possui $13,7 \%$. Já, quando consideramos a participação na pontuação dos programas, a USP tem $14,6 \%$ e a UAM possui $14,3 \%$, Isso se

\footnotetext{
${ }^{18}$ Para que a tabela não ultrapassasse as bordas da página, ela foi segmentada em três partes.
} 
explica, como já dissemos, pela ocorrência de a UAM ter publicado, no período examinado, dezoito artigos em periódicos não classificados dentro do sistema Qualis e, portanto, não pontuados.

Em relação aos programas que obtiveram os menores índices numericamente e qualitativamente no panorama geral da área, as três instituições já observadas se mantiveram. A UFF teve a participação de 4,2\% contando o seu total de artigos publicados e 3,7\% com a pontuação alcançada por seus artigos; a UNB teve 6,5\% e 5,7\%, respectivamente; e a UECE, $11 \%$ e $6,9 \%$. Com isso, pode-se depreender que os dados coletados com o total de publicações e a pontuação conseguida dessas publicações por cada programa se refletem no panorama geral do turismo, uma vez que os dados da Tabela 5 se confirmam nas porcentagens apresentadas na Tabela 6 .

Para verificar se esse panorama se mantém, quando se é considerada a qualidade da produção docente, retomamos os dados da Tabela 5 e só contabilizamos os números gerais e as pontuações das publicações com Qualis A1, A2 e B1 de todas as instituição selecionadas. Estratificamos esses dados na Tabela 7:

Tabela 7 - Artigos em periódico de alto impacto da produção docente em turismo (2013-2016): qualidade e quantidade ${ }^{19}$

\begin{tabular}{|c|c|c|c|c|c|r|r|r|r|r|r|r|}
\hline \multicolumn{2}{|c|}{ Universidade } & \multicolumn{2}{|c|}{ UAM } & \multicolumn{2}{c|}{ UCS } & \multicolumn{2}{c|}{ UECE } & \multicolumn{2}{c|}{ UFF } & \multicolumn{2}{c|}{ UFPR } \\
Qualis & №tegoria & $\begin{array}{c}\text { Pontuação } \\
\text { (P) }\end{array}$ & № & P & № & P & № & P & № & P & № & P \\
\hline A1 & 100 & 0 & 0 & 0 & 0 & 0 & 0 & 0 & 0 & 1 & 100 \\
\hline A2 & 80 & 10 & 800 & 8 & 640 & 1 & 80 & 3 & 240 & 16 & 1280 \\
\hline B1 & 60 & 16 & 960 & 17 & 1020 & 6 & 360 & 10 & 600 & 22 & 1320 \\
\hline \multicolumn{2}{|l|}{ Total por instituição } & 26 & 1760 & 25 & 1660 & 7 & 440 & 13 & 860 & 39 & 2700 \\
\hline
\end{tabular}

\begin{tabular}{|l|l|l|l|l|l|}
\hline Universidade & UFRN & UNB & UNIVALI & USP & GERAL \\
\hline
\end{tabular}

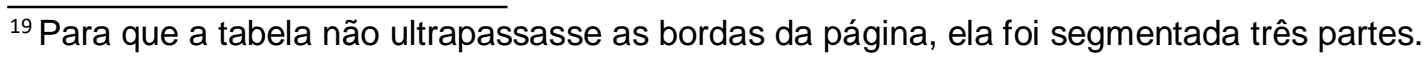




\begin{tabular}{|c|c|c|c|c|c|c|c|c|c|c|c|}
\hline \multicolumn{2}{|c|}{ Qualis } & \multirow[b]{2}{*}{ № } & \multirow[b]{2}{*}{$\mathbf{P}$} & \multirow[b]{2}{*}{ № } & \multirow[b]{2}{*}{$\mathbf{P}$} & \multirow[b]{2}{*}{ № } & \multirow[b]{2}{*}{$\mathbf{P}$} & \multirow[b]{2}{*}{ № } & \multirow[b]{2}{*}{$\mathbf{P}$} & \multirow[b]{2}{*}{ № } & \multirow[b]{2}{*}{$\mathbf{P}$} \\
\hline Categoria & $\begin{array}{c}\text { Pontuação } \\
\text { (P) }\end{array}$ & & & & & & & & & & \\
\hline $\mathrm{A} 1$ & 100 & 2 & 200 & 1 & 100 & 1 & 100 & 7 & 700 & 11 & 1100 \\
\hline A2 & 80 & 13 & 1040 & 8 & 640 & 13 & 1040 & 14 & 1120 & 82 & 6560 \\
\hline $\mathrm{B} 1$ & 60 & 17 & 1020 & 6 & 360 & 30 & 1800 & 15 & 900 & 137 & 8220 \\
\hline \multicolumn{2}{|c|}{ Total por instituição } & 32 & 2260 & 15 & 1100 & 44 & 2940 & 26 & 2720 & 230 & 15880 \\
\hline
\end{tabular}

Fonte: Juliana Ferreira dos Santos, com as contribuições da scriptLattes, 2018.

Reunindo os artigos publicados em periódicos com notas A1, A2 e B1, observamos que temos um total de 230 artigos os quais representam, apenas, $24,6 \%$ do total de artigos. De outro lado, esse conjunto de artigos alcança um total de 15880 pontos, o que equivale a $47,7 \%$ da pontuação geral dos programas de pós-graduação stricto sensu em turismo. Por isso, publicar nessa faixa da avaliação do Qualis corresponde a ter um artigo de alto impacto, seja pelo alcance da revista em número de leitores, seja pela pontuação obtida nas avaliações da CAPES. Observamos, então, os resultados das instituições, em especial aquelas que tiveram os maiores e os menores índices.

As instituições que alcançaram os três maiores índices em números de artigos nessa faixa de alto impacto foram: UNIVALI, com 44 artigos, UFPR, com 39 artigos e UFRN, com 32 artigos, respectivamente. Com relação a pontuação, o conjunto das três primeiras muda, porque a UNIVALI continua com a maior pontuação, tendo 2940 pontos, só que o segundo lugar é da USP que obteve 2720 pontos, com 26 artigos, e a UFPR fica em terceiro lugar com 2700 , embora tenha, como salientamos, 39 artigos. A UFRN fica em quarto lugar, com relação a pontuação, porque ela conseguiu 2260 pontos.

As três instituições que tiveram os menores índices em números e em pontuação foram, as seguintes: a UECE, com 7 artigos e 440 pontos; a UFF, com 13 artigos e um total de 860 pontos; e a UNB, com 15 artigos e total de 1100 pontos. Salienta-se que a UECE estava em antepenúltimo lugar no panorama geral e, com relação as publicações em alto impacto, ela foi para a última colocação. 
Os dados da Tabela 7 demonstram que o sistema Qualis tem sua importância como métrica de avaliação. Isso ocorre, porque as pontuações atribuída pelo sistema Qualis evidenciam, mesmo que com algumas falhas, a qualidade dos artigos publicados e isso influencia as avaliações da Capes e no próprio modo dos docentes publicarem. Como evidenciou, as instituições, com maior índice de avaliação na CAPES (por exemplo, USP; UFPR, UFRN), buscam as revistas de alto impacto, enquanto as instituições com avaliação mais baixa na CAPES (por exemplo, UFF, UNB e UECE) têm pouca publicação nessas revistas. Por isso, não se pode considerar casual a ascendência da USP ao segundo lugar comparada ao UFRN e a descendência da UECE à última colocação em cotejo com a UFF, na Tabela 7. Essas ocorrências demonstram uma tendência dos programas mais bem avaliados buscarem as melhores revistas, enquanto os programas com avaliação menor terem suas publicações em periódicos com baixa pontuação no sistema Qualis.

Para confirmar essas deduções, vamos observar na tabela a seguir as porcentagens da participação de cada instituição selecionada com relação à publicação em revistas de alto impacto. A coluna $\mathrm{N}$ representa o número total de artigos publicados na faixa de alto impacto (A1, A2 e B1) da instituição dividido pelo número total de artigos de alto impacto da área do turismo no período de 2013 a 2016, no caso 230 artigos. A coluna P designa o resultado da divisão da pontuação total obtida pela instituição no referido período com as publicações de alto impacto sobre o total da pontuação geral do turismo também no mesmo período, no caso 15880 pontos. A Tabela 8 apresentamos a seguir: 
Tabela 8 - Porcentagens gerais da produção docente em turismo (2013-2016) em periódicos de alta impacto (A1, A2 e B1): quantidade e qualidade ${ }^{20}$

\begin{tabular}{|c|c|c|c|c|c|c|c|c|c|c|}
\hline \multirow{2}{*}{\begin{tabular}{|c|} 
Universidade \\
Qualis \\
Categorias: \\
Número total \\
de \\
publicações \\
(No) e \\
Pontuação (P)
\end{tabular}} & \multicolumn{2}{|c|}{ UAM } & \multicolumn{2}{|c|}{ UCS } & \multicolumn{2}{|c|}{ UECE } & \multicolumn{2}{|c|}{ UFF } & \multicolumn{2}{|c|}{ UFPR } \\
\hline & № & $\mathbf{P}$ & № & $\mathbf{P}$ & № & $\mathbf{P}$ & № & $\mathbf{P}$ & № & $\mathbf{P}$ \\
\hline $\begin{array}{c}\text { Total por } \\
\text { instituição }\end{array}$ & 26 & 1760 & 25 & 1660 & 7 & 440 & 13 & 860 & 39 & 2700 \\
\hline $\begin{array}{c}\text { Porcentagem } \\
\text { sobre o total } \\
\text { de cada } \\
\text { instituição }\end{array}$ & $11,3 \%$ & $11 \%$ & $10,8 \%$ & $10,4 \%$ & $3 \%$ & $2,7 \%$ & $5,6 \%$ & $5,4 \%$ & $16,9 \%$ & $17 \%$ \\
\hline
\end{tabular}

\begin{tabular}{|c|c|c|c|c|c|c|c|c|c|c|}
\hline Universidade & \multicolumn{2}{|c|}{ UFRN } & \multicolumn{2}{c|}{ UNB } & \multicolumn{2}{c|}{ UNIVALI } & \multicolumn{2}{c|}{ USP } & \multicolumn{2}{c|}{ GERAL } \\
Qualis & & & & & & & & & \\
\hline $\begin{array}{c}\text { Categorias: } \\
\text { Número total } \\
\text { de publicações } \\
\text { (No) } \\
\text { Pontuação (P) }\end{array}$ & № & $\mathbf{P}$ & № & $\mathbf{P}$ & No & $\mathbf{P}$ & № & $\mathbf{P}$ & No & P \\
\hline $\begin{array}{c}\text { Total por } \\
\text { instituição }\end{array}$ & 32 & 2260 & 15 & 1110 & 44 & 2940 & 26 & 2720 & 230 & 15880 \\
\hline $\begin{array}{c}\text { Porcentagem } \\
\text { sobre o total } \\
\text { de cada } \\
\text { instituição }\end{array}$ & $13,9 \%$ & $14,2 \%$ & $6,5 \%$ & $6,9 \%$ & $19,1 \%$ & $18,5 \%$ & $11,3 \%$ & $17,1 \%$ & $100 \%$ & $100 \%$ \\
\hline
\end{tabular}

Fonte: Juliana Ferreira dos Santos, a partir dos dados da StrictoLattes, 2018

Os dados da Tabela 8 confirmam as inferências da Tabela 7. As porcentagens dos programas com maior índice de participação numericamente são: UNIVALI, com 19,1\%; UFPR, com 16,9\% e UFRN, com 13,9\%. As maiores porcentagens de participação na área com relação à pontuação geral do programa na faixa de revistas de alto impacto são as seguintes: a UNIVALI, com $18,5 \%$, a USP, com $17,1 \%$ e a UFPR, com $17 \%$. De novo, percebemos que, pela pontuação, a USP ultrapassa a UFPR, embora sua participação numericamente seja menor, com $11,3 \%$. A UFRN continua em quarto lugar com relação a pontuação, porque possui uma porcentagem de $14,2 \%$. Os menores índices são

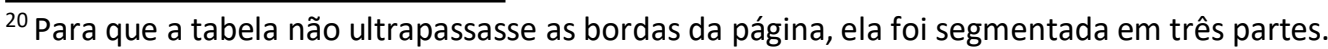


os das mesmas instituições já indicadas na Tabela 7, porque a UECE tem participação numérica de 3\% da área e de pontuação uma participação de 2,7\%, acompanhada pela UFF que tem $5,6 \%$ e $5,4 \%$, respectivamente, e pela UNB que possui $6,5 \%$ e $6,9 \%$, também respectivamente.

Observa-se que, embora os critérios de seleção de revistas de alto impacto sejam mais rigorosos na maioria das vezes, isso não garante seu grau de importância para área de conhecimento, uma vez que pode ocorrer que uma publicação em uma revista de baixo impacto ou mesmo não indexada no Qualis auxilie mais a comunidade local daquela área do que uma publicação em uma revista de alto impacto em inglês, por exemplo.

\subsection{Periódicos internacionais e nacionais mais frequentes na produção bibliográfica das IES}

De acordo com Mugnaini (2007) a importância das revistas científicas na comunicação científica foi vigorosa com a criação de bases de dados, que passam a exercer o papel não só de agrupá-las, mas também de avalia-las e seleciona-las. $O$ conceito de qualidade das revistas passa a ser representado pela estimativa do indicador de impacto dada a generalização do uso dessa medida de certa forma popularizada.

Dessa forma partir das análises de afirmações e veículos-signos, é possível compreender outras inferências nas recorrências dos fenômenos discriminados. No caso, foram selecionados todos os periódicos indexados mais frequentes na produção dos docentes, tanto em âmbito internacional, quanto no nacional. Porém para a análise somaram-se, somente, os mais recorrentes, que são: três internacionais e três nacionais. Os critérios de seleção foram, portanto, indexação, frequência e nacionalidade.

A partir desses critérios, foram selecionadas sete revistas internacionais mais recorrentes, porém três foram analisadas, tais como: Turydes, Estudios y Perspectivas en Turismo e Pasos. Os dados foram sistematizados no scriptLattes. Com isso, obtivemos a seguinte Tabela 9: 
Tabela 9 - Publicações por instituição e área do turismo dos periódicos internacionais mais frequentes no período de 2013-2016

\begin{tabular}{|c|c|c|c|c|c|c|c|c|c|c|c|}
\hline $\begin{array}{c}\text { Periódicos } \\
\text { internacionais }\end{array}$ & ISSN & UAM & UCS & JECE & UFF & UFPR & UFRN & UNB & UNIVALI & USP & \begin{tabular}{l|} 
Total da \\
área de \\
Turismo \\
\end{tabular} \\
\hline Turydes & 19885261 & 17 & 0 & 11 & 0 & 4 & 3 & 0 & 10 & 13 & 59 \\
\hline $\begin{array}{l}\text { Estudios y } \\
\text { Perspectivas } \\
\text { en Turismo } \\
\text { (em línea) }\end{array}$ & $\begin{array}{c}03275841 \\
18511732\end{array}$ & 2 & 5 & 3 & 3 & 14 & 6 & 4 & 6 & 8 & 50 \\
\hline Pasos & 16957121 & 2 & 6 & 2 & 0 & 3 & 5 & 0 & 1 & 3 & 20 \\
\hline $\begin{array}{c}\text { Tourism \& } \\
\text { Management } \\
\text { studios }\end{array}$ & $\begin{array}{c}2182845 \\
21828466 \\
\end{array}$ & 0 & 0 & 2 & 3 & 1 & 3 & 0 & 3 & 1 & 12 \\
\hline $\begin{array}{l}\text { Tourism And } \\
\text { Hospitalily } \\
\text { Internacional } \\
\text { Journal }\end{array}$ & 21830800 & 0 & 0 & 0 & 0 & 2 & 1 & 3 & 3 & 0 & 9 \\
\hline $\begin{array}{l}\text { Research In } \\
\text { Hospitality } \\
\text { Management }\end{array}$ & 22243534 & 4 & 0 & 0 & 0 & 0 & 0 & 0 & 0 & 3 & 6 \\
\hline $\begin{array}{c}\text { Tourism } \\
\text { Economics }\end{array}$ & 13548166 & 0 & 1 & 0 & 0 & 0 & 0 & 0 & 0 & 3 & 4 \\
\hline $\begin{array}{l}\text { Total por } \\
\text { instituição }\end{array}$ & & 25 & 12 & 18 & 6 & 24 & 18 & 7 & 23 & 31 & \\
\hline
\end{tabular}

Fonte:Juliana Ferreira dos Santos, com as contribuições da scriptLattes, 2018.

As três revistas internacionais com mais publicações, no período de 2013 a 2016 foram, Turydes (Revista Turismo y desarollo local) com 59 publicações, Estudios y Perspectivas en Turismo, com 50 publicações e Pasos (Revista de Turismo y patrimonio cultural) com 20 recorrências.

Sobre o local de publicação dessas revistas, elas são predominantemente de origem hispânica. A Turydes é editada em Mágala; a Estudios y Perspectivas en Turismo, em Buenos Aires e a Passos, em El Sauzal. Desse modo, percebese que o campo do turismo tem, como centro difusor de ideias científicas, as revistas de produção espanhola. Eis uma das inferências que a análise veículos- 
signos e análise de afirmações permetiram apreender que, superficialmente, não é aparente nas análises quantitativas.

Sobre a tradição dessas revistas, pode-se reconhecer o ano de fundação de sua primeira edição. A Turydes teve o seu primeiro número e volume 2008; a Estudios y Perspectivas en Turismo, em 1992 e a Pasos, em 2003. Com isso, depreende-se que são revistas relativamente recentes, com menos de trinta anos de existência

Sobre os dados gerais das instituições, pode-se apreender que as duas instituições que mais publicaram nessas três revistas foram a UAM com 25 a UFPR com 24 publicações, ficando em terceiro lugar a USP, com 24 publicação, ou seja, a USP foi a instituição que mais publicou nesses periódicos. Em quarto lugar a UNIVALI com 23 publicações e a UECE com 16 publicações. As duas instituições que menos publicaram nesses periódicos foram UFF e UNB, com 2 publicação cada. Esse dado confirma as inferências obtidas no tópico anterior, no qual ficou patente que essas duas instituições têm produtividade mais baixa. Em outras palavras, a produtividade baixa também se evidencia na escolha dos periódicos, ou seja, além de não publicarem com frequência nas referidas revistas, essas duas instituições não escolheram as mesmas que a maioria de sua área publicam - outra inferência a partir da análise veículos-signos e de análise de afirmações.

Observados esses dados gerais do campo, analisemos a distribuição da produção bibliográfica docente no caso particular de cada uma das revistas internacionais. Comecemos pela Turydes. Como podemos observar, a UAM com 17 publicações, a USP 13 publicações nessa revista; em terceiro, vem a UECE com 11 publicações. A instituição que teve menos publicações nessa revista foi a UFPR com 4 publicações e a UFRN com 3 recorrência, e as instituições que não publicaram nessa revista foram UCS, UFF e a UNB.

Retomando a historicidade dessa revista, salienta-se que Turydes é promovida pela Rede Acadêmica Ibero-Americana Local-Global, sendo editada

e mantida pelo Grupo de Investigação Eumed.net (Serviços Académicos Intercontinentales S. L.). A periodicidade é semestral. Os reservatórios digitais em que ela está indexada são os seguintes ${ }^{21}$ :

\footnotetext{
${ }^{21}$ http://www.eumed.net/rev/turydes/ acesso em 21. Mar.2018.
} 
- Research Papers in Economics;

- LATINDEX- Regional Information System for Online Scientific Journals from Latin America, the Caribbean, Spain and Portugal;

- CIRET-International Center for Research and Study on Tourism ;

- UNIVERSIA;

- DOAJ- Directory of Open Access Journals;

- E-REVISTAS- Open Access Platform for Electronic Scientific Journals Spanish and Latin American;

- EBSCO;

- Hospitality \& Tourism Index with Full Text ;

- LIBRARIES USA.

Embora a revista possua essas indexações e tenha quase dez anos de existência, seu Qualis é B3, isto é, uma qualificação intermediária. Já internacionalmente, a revista é relevante, porque, desde 2010, faz parte do banco de dados IN-Recs, que é um índice de impacto das revistas espanholas de projeto de Ciências Sociais da Avaliação Grupo de Pesquisa de Ciência e Comunicação Científica da Universidade de Granada - o qual é financiado pelo Ministério da Educação e Ciência da Espanha. Nesse indíce, a revista ocupa a posição 70 das 136 revistas intermediária na Espanha igual a do Brasil da área de ciências sociais mais consultadas. Apesar que muitos no Brasil não conhecem esse banco de dados, e não irão considerar como um critério de qualidade. Essa outra inferência obtida pela análise veículos-signos e análise de afirmações que nos faz ressignificar algumas das considerações tecidas no tópico anterior.

Em relação a revista Estudios y Perspectivas en Turismo, podemos depreender outras considerações. A instituição que mais publicou nesse periódico foi a UFPR, 14 vezes; em segundo lugar, foi a USP com 8 publicações e, em terceiro, ficou a UFRN e a UNIVALI com 6 recorrências. A UECE, a UFF e a UCS publicaram, nesse periódico, 3 vez cada uma. E a UAM teve 2 artigos nessa revista.

Dentre as três revistas selecionadas, a Estudios y Perspectivas en Turismo é a mais antiga, nasceu em 1992. Ela tem periodicidade bimestral, publicando, assim, o maior número de edição por ano dentre as três revistas, 
seis edições. Outro diferencial dessa revista é que ela tem dois ISSN, um para a edição impressa (ISSN 03275841) e a outra para a edição digital (ISSN 18511732). As outras duas revistas possuem um ISSN único porque só têm a edição digital.

Estudios y Perspectivas en Turismo é, atualmente, indexada nos seguintes reservatórios:

- LADINTEX - Regional Information System for Online Scientific Journals from Latin America, the Caribbean, Spain and Portugal;

- CIRET - International Center for Research and Study in Tourism;

- UNIRED - Nations Educational, Scientific and Cultural Organization;

- SCIELO - Scientific Electronic Library Online.

Comparada a revista Turydes, a Estudios y Perspectivas en Turismo possui um número menor de indexações. Todavia, diferentemente da Turydes, o Qualis dela é A2, ou seja, o segundo melhor da escala do Qualis. Ela é considerada assim, no território nacional, uma revista de alto impacto. Isso, contudo, não se confirma necessariamente no contexto internacional, uma vez que como se pode observar pelo número de indexações, essa revista não é um das mais referenciadas nos reservatórios de pesquisa internacionais. Essa é outra inferência depreendida a partir da análise veículos-signos e análise de afirmações.

A revista Pasos possui outras configurações. A instituição que mais publicou nesse periódico foi a UCS com 6 publicações, e a UFRN 5 recorrência. A instituição que menos publicou foi a UNIVALI com 1 publicação. As organizações que não publicaram nesse periódico foram: UFF e UNB.

Comparando às outras duas revistas já evidenciadas, pode-se apreender que a Pasos é mais antiga do que Turydes e mais recente do que a Estudios y Perspectivas en Turismo. No entanto, ela publica semestralmente, como a Turydes. Sobre a indexação, ela possui mais indexações do que Turydes e a Estudios y Perspectivas en Turismo. Suas indexações são as seguintes:

- REDALYC-Network of Scientific Journals from Latin America and the Caribbean, Spain and Portugal Scientific Information System;

- LATINDEX-Regional Information System for Online Scientific Journals from Latin America, the Caribbean, Spain and Portugal;

- DOAJ- Directory of Open Access Journals; 
- ISOC - Bibliographich databases CSIC;

- CAB ABSTRACTS (CABI PUBLISHING);

- CIRET- Centre for International Research on Economic Tendency Surveys

- REBIUM- Network of University Libraries

- E-Revistas - Open Access Platform for Electronic Scientific Journals Spanish and Latin American;

- SUNCAT - Database of library catalogs UK;

- JISC - Journal Archives Selection of Journals with Perpetual Access;

- COPAC - Specialized database.

Sobre a avalição da Pasos no Qualis, a sua última nota foi B2. Desse modo, ela é considerada uma revista de impacto médio. Com isso, ela é, seguindo o critério do Qualis, uma revista melhor do que a Turydes e inferior se comparada á Estudios y Perspectivas en Turismo. Todavia, se observarmos a avaliação internacional, a partir do critério da indexação em repositórios internacionais, ela é a melhor das três. Com isso, pode-se relativizar as ponderações acerca do uso do Qualis como índice de avaliação da produção bibliográfica docente, porque, como se pode notar por esse cotejo, a depender do critério adotado (o nacional, a partir do Qualis, ou o internacional, a partir da indexação), os resultados mudam expressivamente.

Compreendido isso, partimos, agora, para análise dos periódicos nacionais mais frequentes na produção bibliográfica docente das instituições que compõe a área do turismo no Brasil. Os periódicos que os docentes mais publicaram artigos foram no total de 18, porém foi analisado os três mais recorrentes. Utilizamos os mesmos três critérios para sistematizar os dados: a indexação, a frequência e a nacionalidade. Os dados apresentam-se na seguinte tabela 10. 
Tabela 10- Publicações por instituição e área do turismo dos periódicos nacionais mais frequentes

\begin{tabular}{|c|c|c|c|c|c|c|c|c|c|c|c|}
\hline $\begin{array}{l}\text { Periódicos } \\
\text { Nacionais }\end{array}$ & ISSN & UFF & UECE & UNB & UFPR & UFRN & UNIVALI & USP & UAM & UCS & \begin{tabular}{|l} 
otal da \\
área de \\
Turismo \\
\end{tabular} \\
\hline Rosa dos Ventos & 21789061 & 3 & 0 & 0 & 9 & 4 & 7 & 5 & 12 & 15 & 53 \\
\hline $\begin{array}{c}\text { Revista Brasileira } \\
\text { de Pesquisa em } \\
\text { Turismo }\end{array}$ & 19826125 & 0 & 0 & 4 & 5 & 8 & 10 & 7 & 8 & 6 & 48 \\
\hline $\begin{array}{l}\text { Turismo e } \\
\text { Sociedade } \\
\end{array}$ & 19835442 & 1 & 1 & 0 & 10 & 9 & 3 & 6 & 6 & 0 & 35 \\
\hline $\begin{array}{c}\text { Caderno Virtual } \\
\text { do Turismo }\end{array}$ & 16776976 & 4 & 1 & 1 & 10 & 4 & 3 & 3 & 3 & 6 & 34 \\
\hline $\begin{array}{l}\text { Revista Turismo } \\
\text { e Cultura-Cultur }\end{array}$ & 19825838 & 3 & 0 & 0 & 6 & 6 & 1 & 2 & 3 & 4 & 25 \\
\hline $\begin{array}{c}\text { Revista Turismo } \\
\text { em Análise }\end{array}$ & 19844867 & 0 & 1 & 2 & 7 & 2 & 4 & 4 & 5 & 3 & 25 \\
\hline $\begin{array}{c}\text { Hospitalidade } \\
\text { Revista da } \\
\text { Universidade } \\
\text { Anhembi }\end{array}$ & 21799164 & 0 & 1 & 0 & 7 & 1 & 1 & 5 & 7 & 3 & 24 \\
\hline $\begin{array}{c}\text { Revista Brasileira } \\
\text { de Ecoturismo }\end{array}$ & 19839391 & 0 & 1 & 3 & 5 & 6 & 1 & 3 & 1 & 4 & 23 \\
\hline $\begin{array}{c}\text { Revista Turismo } \\
\text { Visão e Ação }\end{array}$ & 19837151 & 1 & 0 & 1 & 2 & 2 & 5 & 4 & 2 & 5 & 21 \\
\hline $\begin{array}{c}\text { Revista Turismo } \\
\& \\
\text { Desenvolvimento }\end{array}$ & 16459261 & 3 & 0 & 2 & 3 & 2 & 2 & 1 & 6 & 0 & 18 \\
\hline $\begin{array}{c}\text { Revista } \\
\text { Iberoamericana } \\
\text { e Turismo }\end{array}$ & 22366040 & 0 & 2 & 0 & 5 & 8 & 0 & 1 & 2 & 2 & 18 \\
\hline $\begin{array}{c}\text { Revista } \\
\text { Hospitalidade }\end{array}$ & $1807975 \mathrm{X}$ & 0 & 1 & 1 & 1 & 4 & 1 & 9 & 0 & 4 & 18 \\
\hline Revista Cenário & 23188561 & 0 & 1 & 13 & 1 & 0 & 1 & 0 & 1 & 1 & 18 \\
\hline $\begin{array}{c}\text { Anais Brasileiros } \\
\text { e Estudos } \\
\text { Turísticos } \\
\end{array}$ & 22382925 & 0 & 1 & 0 & 3 & 1 & 0 & 3 & 1 & 0 & 9 \\
\hline $\begin{array}{l}\text { Revista Turismo } \\
\text { Contemporâneo }\end{array}$ & $2357821 X$ & 0 & 1 & 2 & 0 & 0 & 0 & 2 & 2 & 1 & 8 \\
\hline $\begin{array}{l}\text { Centro de } \\
\text { Estudos de } \\
\text { Lazer e } \\
\text { Recreação- } \\
\text { Licere }\end{array}$ & 19806183 & 0 & 1 & 0 & 0 & 1 & 0 & 6 & 0 & 0 & 8 \\
\hline $\begin{array}{c}\text { Revista Brasileira } \\
\text { de Estudos do } \\
\text { Lazer }\end{array}$ & 3581239 & 0 & 1 & 0 & 0 & 0 & 0 & 5 & 0 & 1 & 7 \\
\hline $\begin{array}{c}\text { Revista Turismo } \\
\text { Estudos e } \\
\text { Práticas }\end{array}$ & 23161493 & 0 & 3 & 0 & 0 & 0 & 0 & 1 & 0 & 0 & 4 \\
\hline $\begin{array}{l}\text { Total por } \\
\text { instituição }\end{array}$ & & 14 & 16 & 39 & 74 & 58 & 39 & 67 & 59 & 55 & \\
\hline
\end{tabular}

Fonte: Juliana Ferreira dos Santos, com as contribuições da scriptLattes, 2018.

A revista nacional em que os docentes mais publicaram no período de 2013 a 2016 foi a Rosa dos Ventos, com 53 artigos da área do turismo. A segunda com mais publicações foi a Revista Brasileira de Pesquisa em Turismo 
(RBTUR) com 48 artigos, e, em terceiro lugar, a revista Turismo e Sociedade, com 35 artigos.

Sobre o local de publicação dessas revistas, elas são predominantemente localizadas nas regiões Sul do Brasil. A revista Rosas dos Ventos é editada em Caxias do Sul-RS. Esse periódico faz parte do programa de pós-graduação em Turismo e Hospitalidade da (UCS). Já a Revista Brasileira de Pesquisa em Turismo (RBTUR) está sediada em Santa Catarina-SC e é editada pela Associação Nacional de Pesquisa e Pós-Graduação em Turismo ANPTUR. Turismo e Sociedade, por sua vez, é publicada no Paraná (Curitiba) e faz parte do programa de Pós-Graduação stricto sensu em Turismo, da UFPR.

Em relação à historicidade e à tradição dessas revistas, pode-se destacar que o ano da primeira edição da RBTUR, em 2007; Turismo e Sociedade em 2008 e a Rosa dos Ventos, em 2009. Com isso, compreende-se que são revistas com pouco tempo de veiculação. Outro diferencial dessas revistas é que a periodicidade delas não são distintas. A RBTUR têm periodicidade quadrimestral, a Rosa dos Ventos é trimestral e a Turismo e Sociedade é semestral.

Sobre os dados gerais das instituições, pode-se apreender que as três instituições que mais publicaram nessas três revistas foram UFPR (24 artigos); UFRN (21 artigos) e a UAM (26 artigos). A UNB, UECE e a UFF foram a instituição cujos docentes menos publicaram nesses periódicos no período de 2013 a 2016. Isso corrobora os outros dados que apontam a baixa produtividade dos programas UFF e UNB também nos periódicos nacionais se comparados aos outros programas da área.

Examinemos, agora, caso a caso as revistas, isto é, investigar a distribuição da produção bibliográfica docente no caso particular de cada uma das revistas nacionais selecionadas.

Comecemos pela Rosa dos Ventos. Como podemos verificar, a UCS com 15 publicações, a UAM com 12 artigos nessa revista, e a UFPR com 9 recorrências. Sobre as demais que publicaram nessa revista, pode-se verificar que, UNIVALI publicou 7 artigos, USP publicou 5 vezes, e a UFRN teve 4 recorrência, Já UECE e UNB não tiveram nenhuma publicação nessa revista. Esses números podem sugerir que a concentração de publicações de docentes pertencentes à UCS talvez possa caracterizar endogenia, não só na referida 
UCS, como também pode-se observar na tabela 10 que nas revistas das Universidades UAM, (Revista Hospitalidade Revista da Universidade Anhembi ) com o número de sete publicações, a UNB (Revista cenário) com treze recorrência, a UNIVALI (Revista Turismo Visão e Ação), com cinco artigos e a UFPR (Revista Turismo e Sociedade) com dez publicações.

Conforme explica Sales (2013, p. 37):

\begin{abstract}
Entende-se por endogenia a concentração institucional ou geográfica por meio da afiliação declarada do conselho editorial dos revisores e dos autores com membros oriundos de uma mesma instituição, cidade ou região. O editor do periódico é responsável por divulga-lo, e portanto, deve cuidar para que não haja concentração, o que pode restringir o acesso a informação para uma determinada área ou região.
\end{abstract}

Dessa forma, a distribuição pode estar comprometida no caso dessas revistas, porque existe uma concentração de docentes-autores da própria UCS, UAM, UFPR e a UNB fomentando as revistas ao invés de abrir espaço para outros estudiosos de outras regiões e/ou instituições. Isso, portanto, restringe 0 acesso à publicação, porque o espaço de divulgação fica concentrado em determinada instituição que coincide a instituição que acolhe, revisa e lança o periódico. É um contrassenso do que é previsto e disseminado internacionalmente. Segundo Meneghini (2012), atualmente, os cientistas que compõem os conselhos de alta qualidade dos periódicos estrangeiros têm compromisso de orientar as revistas a diversificar as áreas de pesquisa e os locais de divulgação geograficamente emergentes e/ou produtivos, sem com isso concentrar em apenas uma organização - menos ainda, naquela que publica o próprio periódico.

Como um fator de comparação simples, a grosso modo, pode-se destacar o caso da revista Turismo em Análise que é da USP e que possui também, semelhante a três revistas em análise, uma alta aderência de publicação dos docentes da área do turismo. Ao contrário do caso acima, nessa revista, existem apenas quatro publicações de autoria dos docentes do programa. Esse cotejo demonstra que pode ocorrer a difusão de conhecimento sem necessariamente haver endogenia. Apesar que na área (qualis) da história, o documento de avaliação do programa exige que pelo menos $75 \%$ dos artigos 
de uma revista deva estar em pelo menos em 5 instituições. Esse é só um exemplo da exigência de outras áreas.

Os reservatórios digitais em que a Rosa dos Ventos está indexada são os seguintes:

- DOAJ - Directory of Open Access Journals;

- ULRICHS WEB Global serials directory;

- DIADORIM Diretório de políticas de acesso aberto das revistas científicas brasileiras;

- LANTINDEX - Regional Information System for Online Scientific Journals from Latin America, the Caribbean, Spain and Portugal;

- CIRET- International Center for Research and Study in Tourism;

- IBICT- Instituto Brasileiro de informação em Ciência e tecnologia;

- SEER- Sistema de Eletrônico de Editoração de Revistas;

- SPELL- Scientific Periodicals Electronic Library;

- E-REVISTA- Open Access Platform for Electronic Scientific Journals Spanish and Latin American.

Como se pode verificar, são muitos os diretórios em que essa revista esta inserida, confirmando sua pertinência no cenário internacional. No nacional, o Qualis dessa revista é B2, o quarto mais elevado no sistema Qualis. É um impacto intermediário.

Em relação à revista $R B T U R$, podemos depreender outras considerações. As instituições que mais publicaram nesse periódico foram a UNIVALI, com 8 publicações; a USP e a UAM com 6 artigos e, em terceiro lugar, a UFRN com 5 publicações. A instituição que publicou menos nesse periódico foi a UECE, com apenas uma referência. E o programa que não publicou nesse periódico foi a UFF.

Como já enfatizamos, a RBTUR foi criada em atendimento à demanda de representantes da comunidade científica em Turismo no Brasil, amparados pela ANPTUR. Por isso, ela tem o compromisso de disseminar pesquisas e estudos originais, com alto rigor teórico e metodológico, promovendo a sua análise, discussão e reflexão no cenário nacional e internacional. Nos reservatórios digitais em que ela está indexada, ela faz parte das seguintes bases: 
- DOAJ- Directory of acess journals

- IBICT- Instituto Brasileiro de informação em Ciência e tecnologia;

- SEER- Sistema de Eletrônico de Editoração de Revistas;

- SPELL- Scientific Periodicals Electronic Library;

- EBSCO- Information Services;

- SCIELO - Scientific Electronic Library Online;

- CIRET- International Center for Research and Study in Tourism.

Comparada com a Rosa dos Ventos, a RBTUR possui menos indexações. Todavia, o Qualis da revista é A2, sendo, portanto, maior do que o da Rosa dos Ventos que é, como foi dito, B2. Ressalta que A2 é o segundo mais elevado nível do sistema Qualis. É um nível reservado aos periódicos de alto impacto. Mais uma vez, compreende-se que a indexação e o sistema Qualis nos periódicos nacionais não se equiparam no sentido de que não atribuem a mesma qualidade/validade ao periódico em exame - como também foi observado na análise de veículos-signos dos periódicos internacionais.

Com relação à Turismo e Sociedade a instituição que mais publicou nesse periódico foi a UFPR, com 10 artigos; em segundo lugar, a UFRN com 9 publicações, em terceiro lugar, a USP e a UAM, com 6 artigos cada. O programa que menos publicou nessa revista foi a UECE e a UFF que teve um artigocada. A UNB convalida, mais uma vez, a sua pouca representatividade na produção docente nos periódicos preferidos dos docentes dos programas sctrito sensu em turismo no Brasil.

Outro dado relevante é que talvez a prática da endogenia pode ser evidenciada. A revista Turismo e Sociedade é publicada pela Editora da UFPR e está, portanto, vinculada ao mestrado acadêmico de turismo da própria instituição, como já salientamos. Logo, o fato de ela publicar dez vezes nessa revista é relevante. Isso porque é o próprio programa da UFPR que seleciona, revisa e edita os artigos, logo, se há mais artigos dessa revista do que de outras durante o período de 2013 a 2016, isso pode caracterizar também um caso de endogenia.

Esse periódico, é datado no ano 2008 um ano depois que a RBTUR, e possui as seguintes indexações: 
- SPELL Scientific Periodicals Electronic Library;

- LATINDEX Regional Information System for Online Scientific Journals from Latin America, the Caribbean, Spain and Portugal;

- CIRET International Center for Research and Study in Tourism;

- SIBI Sistema integrado de bibliotecas da UFPR;

- Google Acadêmico.

O Qualis da Turismo e Sociedade é B4, enquanto o da primeira é A2 e o da Rosa dos ventos é B2. Salienta-se que B4 é o nível baixo do sistema Qualis.

Observa-se que nesse período de 2013 a 2016 aumentou a internacionalização da pesquisa produzida pelos docentes dos programas sctrito sensu em turismo no Brasil, as Universidades que publicaram mais em periódicos internacionais e nacionais foram A USP, a UAM e a UFPR. Haja vista o acréscimo do número de indexação dos periódicos nacionais e o número de

publicação em periódicos nacionais. Outro dado importante na análise dos periódicos internacionais e nacionais foi a variância irregular entre os fatores de tempo, indexação e classificação no Sistema Sucupira/Qualis entre os fatores de tempo, indexação e classificação Qualis.

Cotejando a revista Turydes e Estudios y Perspectivas en Turismo, entende-se, por exemplo, que a primeira possui mais indexação do que a segunda, mas esta tem uma maior Qualis do que aquela. Isso contrasta pela análise metodologica que não há necessariamente uma proporcionalidade como salientamos, entre tempo, indexação e classificação Qualis nos períodos no que diz respeito a produção bibliográfica docente dos programas de pós-graduação stricto sensu em turismo no período de 2013 a 2016.

\section{Palavras-chave mais frequentes dos artigos científicos selecionados}

Conforme explica Spolon (2015) uma nuvem de palavras é uma imagem que contém todas as palavras de um texto de modo que o tamanho de cada palavra é proporcional a sua frequência no texto. A nuvem de palavras é uma 
ferramenta gráfica relevante para se analisar textos, pois ela permite captar de forma direcionada as palavras e/ou ideias principais de um conjunto de textos, livros, sites etc. Nesta pesquisa, essa ferramenta foi utilizada para identificar quais palavras/temas são mais frequentes nas pesquisas produzidas pelos docentes da área de turismo no Brasil nas instituições selecionadas.

Para a construção das nuvens de palavras da produção docente dos programas de pós-graduação stricto sensu em turismo, foram utilizadas as palavras-chave dos artigos científicos das respectivas instituições, publicados no período entre 2013 e 2016. A ferramenta utilizada para a criação das nuvens de palavras foi obtida no site jasondavies. Em relação às palavras-chave, destacase que os artigos selecionados têm de três a cinco.

Sobre as dificuldades de construir essa nuvem de palavras, ressalta-se que nem todo artigo científico possui necessariamente palavras-chave, porque, em algumas revistas, esse item não é obrigatório dentro das normas de submissão. Por conseguinte, do montante total de 932 artigos pesquisados, 43 exemplares não continham em sua estrutura composicional.

Além disso, a consulta a todos esses artigos foi realizada a partir do link presente na indicação bibliográfica da pesquisa realizada no sistema scriptLattes. Por isso, devido às falhas e às inconsistências nos preenchimentos dos currículos Lattes, fonte do supracitado sistema, essa consulta teve que ser manual e personalizada. Em outras palavras, foi conferido item a item, exemplar por exemplar de cada um dos artigos considerados nesta pesquisa.

Para a análise de conteúdo, utiliza-se o tipo e análise de afirmações e veículos-signos que traz interpretações na particulariedade de cada conteúdo e a segunda na recorrência de palavras. Esse tipo de análise mostra, por exemplo, que a repetição pode ser um indicador de uma estratégia de desenvolvimento local, regional e nacional para delimitar determinado fenômeno. Isso decorre do fato de que a frequência de qualquer ocorrência depende de pré-condições naturais, sociais, culturais, econômicas, organizacionais, infraestruturais, da qualificação, da responsabilidade e de políticas públicas, tanto na perspectiva da oferta como da demanda ( Bardin 1977).

Compreendidas as dificuldades da metodologia aplicada e as orientações teóricas norteadoras do fazer científico deste estudo, a nuvem de palavras gerada a partir dos artigos científicos considerados, total de 932, está 
reproduzida a seguir. Nesta Figura 5, as palavras com maior destaque são: turismo, desenvolvimento e hospitalidade. Observa-se isso na reprodução abaixo:

Figura 5 - Nuvem de palavras: palavras-chave mais frequentes nos artigos científicos dos docentes da área de turismo

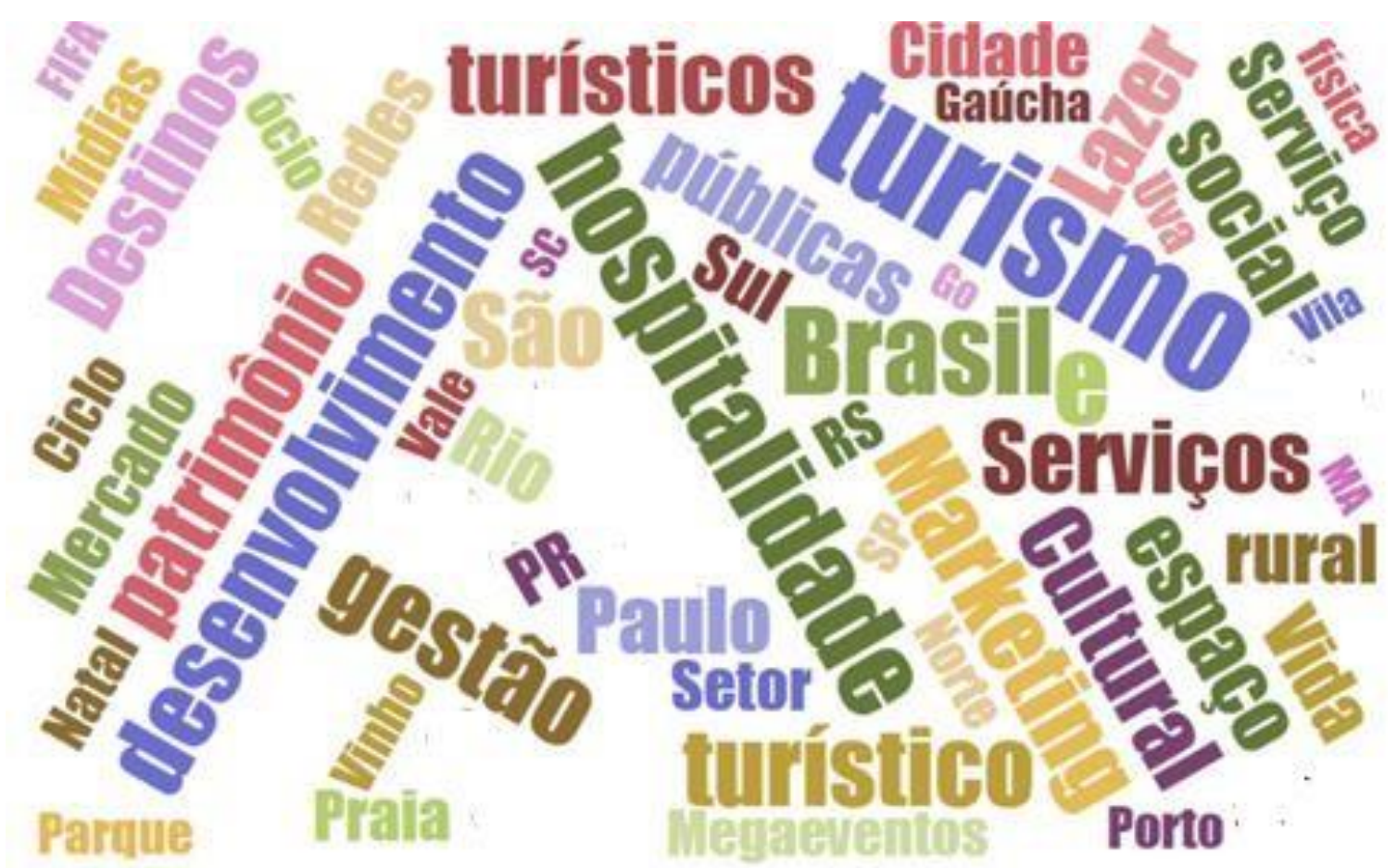

Fonte: Juliana Ferreira dos Santos, com as contribuições da scriptLattes e site jasondavies, 2018.

Analisando as palavras mais evidenciadas na nuvem, pode-se dizer que há uma coerência lógica entre elas. Primeiramente, a palavra turismo se relaciona com hospitalidade e desenvolvimento de forma estrutural, principalmente no mercado e na universidade, guardadas as diferenças de interesse social e financeiro de cada um desses setores. Principalmente nos últimos anos, um viés desenvolvimentista tem acompanhado a área do turismo, seja nacional ou internacionalmente. Isso é promovido, dentro do cenário brasileiro, a partir do senso cultural e histórico de hospitalidade. Desse modo, a 
área de turismo é retroalimentada tanto pelo viés teórico-metodológico do desenvolvimento, quanto da conjuntura prática da hospitalidade.

Outro fator interessante para se notar nessa figura é que a palavra turismo é a que está mais destacada. Isso traz diversos significados para além da frequência e recorrência do termo entre as palavras-chave dos artigos dos docentes dos programas. Esse fenômeno também pode indicar que as pesquisas realizadas e publicadas vêm contribuindo para a consolidação do turismo, por isso o termo turismo é enfatizado.

Podemos então perceber que a produção do conhecimento turístico possui múltiplas facetas temáticas e interpretativas. Essa análise pode depreender à luz de teorias pertinentes que permitem um debate sobre a epistemologia do turismo, ponderando elementos da complexidade que envolve formulações. Desse modo, é relevante ressaltar que a presença do termo turismo é um forte indicador de que a área está em processo de maduração. Por isso, as palavras-chave refletem e refratam o statu quo do sentimento de identidade e de identificação de cada disciplina/teoria/área de atuação.

Sobre a segunda palavra mais frequente, compreende-se que o termo desenvolvimento é bastante utilizado em distintos contextos de uso, seja dentro da área de turismo, seja fora dela. O que se pode dizer é que, atualmente, é um imperativo no meio universitário desenvolver metodologias para estudos e pesquisas de competitividade de destinos e empreendimentos turísticos, bem como apontar mecanismos de contribuição ao desenvolvimento turístico local e regional sustentável. Assim, a presença frequente desse termo faz muito sentido na conjuntura nacional e global.

Outro indicador que demonstra que o termo desenvolvimento é bastante característico da área é a sua presença nos nomes da área de concentração dos programas de pós-graduação em turismo de diversas universidades. Alguns exemplos são:

- UCS - Desenvolvimento regional do turismo;

- USP - Desenvolvimento do turismo;

- UFPR - Turismo e desenvolvimento;

- UNB - Cultura e desenvolvimento;

- UFRN - Turismo, Desenvolvimento e Gestão. 
Em relação ao termo da hospitalidade, pode-se depreender algumas considerações de acordo com Spolon (2015). Segundo essa autora, a hospitalidade, como área de conhecimento, ganha novos contornos e rompe as fronteiras dos estudos turísticos tradicionais. Isso ocorre, porque caracteriza uma mudança de paradigma temático.

É uma mudança de paradigma temático por diversos motivos. Dentre eles, abandona-se uma abordagem instrumental para uma perspectiva mais ampla. Desse modo, observa-se o tema da hotelaria, por exemplo, a partir de um viés social-antropológico, como um fenômeno de acolhimento do outro em diversas situações. Com isso, depreende-se que as publicações em periódicos científicos dos docentes vêm registrando estudos que abordam aspectos de gestão de pessoas, planejamento, administração, dentre outros.

Esse conceito de hospitalidade é tão forte dentro da área do turismo nos últimos anos que até compõe nome de área de concentração nos programas de pós-graduação em turismo. É caso do programa da UAM que fora criado em 2002. Desde essa data, existe a área de concentração intitulada: hospitalidade. Outro dado que precisa ser ressaltado é que o nome do programa da UCS consta a palavra hospitalidade.

$\mathrm{Na}$ lateralidade da imagem percebe-se outras palavras-chave que são importantes de serem observadas na análise, a saber: uva, vinho, fifa e parques. Essas palavras definem o campo semântico específico do fazer-saber da atratividade turística de um determinado nicho. Isso define que os docentes não analisam apenas aspectos gerais como por exemplo infraestrutura e desenvolvimento, mais também aspectos específicos, como a uva e o vinho, que está associado a região do Rio Grande de Sul, especificamente Caxias do Sul que é ressaltada nas pesquisas de análise de determinados docentes. E com isso, percebe-se tanto a influência especifica de um termo dentro do turismo quanto a importância da publicação de um pesquisador para ratificar um marco dentro do turismo.

Retornando, as três palavras-chave mais salientes na nuvem de palavras, observa-se que são fruto das condições sócio-históricas que permeiam a conjuntura atual, mas não só isso. Turismo, desenvolvimento e hospitalidade são termos que ecoam na produção docente não somente porque são frequentes, mas também porque são direções teórico-metodológicas tomadas 
por esses docentes em seu fazer científico, seja pelas condições da área, seja pelos seus próprios posicionamentos. Destarte, não é a área de turismo que está se consolidando per se, é também os docentes que, como se pode notar, começam a adotar propostas teórico-metodológicas que, embora sejam distintas em vários momentos, dialogam entre si.

\section{6- Categoria das três palavras-chave dos artigos em cada} programa

Apresentamos um detalhamento sistemático das palavras mais frequentes nos artigos. Para tanto, partimos de uma proposta metodológica da análise de afirmações e veículos-signos para sua categorização. Essa

categorização se firma a partir da repetição, isto é, quantas vezes a mesma palavra esteve presente no artigo, de forma geral. E em seguida, faremos a mesma categorização a partir da frequência das palavras nos títulos dos artigos. Nas duas categorizações, são selecionadas as três palavras mais frequentes que destacadas e depreendidas a partir das contribuições da scriptLattes e do site jasondavies.

Quadro 3 - Categorização das palavras-chave por frequência dos artigos científicos das instituições selecionadas

\begin{tabular}{|l|l|l|l|}
\hline Instituição & Três palavras mais frequentes dos artigos \\
\hline USP & Turismo & Lazer & Desenvolvimento \\
\hline UECE & Turismo & Parnaíba & Ocio \\
\hline UAM & Turismo & Hospitalidade & Stakeholders \\
\hline UNB & Turismo & Acessibilidade & Patrimônio \\
\hline UNIVALI & Turismo & Marketing & Destinos \\
\hline UCS & Turismo & Contabilidade & Desenvolvimento \\
\hline UFPR & Turismo & Competitividade & Curitiba \\
\hline UFRN & Turismo & Gestão & Geoturismo \\
\hline UFF & Turismo & Gestão & Rio de Janeiro \\
\hline
\end{tabular}

Fonte: Juliana Ferreira dos Santos com as contribuições da scriptLattes e site jasondavies, 2018.

Do ponto de vista do turismo em geral, os periódicos científicos vêm registrando textos que abordam aspectos operacionais e de gestão de estabelecimentos de hospedagem, desde a vertente da administração, do marketing, destinos, gestão de pessoas entre outros (SPOLON, 2015). Observase que a palavra turismo teve recorrência frequente em todas as instituições 
analisadas, fato esperado, uma vez que estamos trabalhando com programas de turismo.

Outro dado relevante da tabela é a variedade de campos que são correlacionados ao turismo. Isso aponta, por um lado, a riqueza de atuação desse campo de estudo que, como se pôde notar, reclama as palavras-chave, respeitando a especificidade das outras áreas do saber e suas respectivas epistemologias: patrimônio, contabilidade, acessibilidade, gestão dentre outras. Essa gama diversificada de palavras-chave demonstra que o turismo é inter, trans e multidisciplinar, como evidenciamos no Capítulo 1.

Nota-se também que as palavras-chave mais frequentes dizem respeito aos aspectos do tempo e do espaço físico. Isso indica que há uma maior tendência para o lado prático do que para o teórico da epistemologia do turismo. Com essa dedução, pode-se depreender que, por prático, entende-se estudos mais concretos, empíricos e com vistas à aplicação profissional imediata e, por teórico, compreende-se revisões bibliográficas, estudos de opinião, tendências e esquematizações mais abstratas. As duas Instituições que possuem essas junções que envolvema teoria e a prática nesse primeiro momento é a UCS e a USP com a palavra desenvolvimento.

Como forma de apresentar novas possibilidades para a área do turismo, os estudos e suas respectivas palavras-chave sustentam um olhar mais prático do que teórico. Cabe reforçar que a metodologia de um trabalho científico é orientada pelos pressupostos epistemológicos que dão base à construção do conhecimento que se quer investigar. Portanto, à primeira vista, previa-se que os estudos iriam pender para o lado das considerações teóricas, conforme já prediz os autores (Silva et al. 2018) mas, como salientamos, não foi o que aconteceu porque os estudos sustentavam mais aspectos práticos da área do que perfaziam contextualizações e esquematizações teóricas.

O turismo como teoria, do ponto de vista metodológico, é uma via a ser explorada com mais afinco no futuro. Isso é necessário tanto para que a área se fortaleça, quanto é preciso para que as suas ramificações internas dialoguem entre si a partir de um mínimo de consenso teórico. Em outras palavras, mesmo sendo um campo inter, trans e multidisciplinar, é imprescindível sustentarmos uma matriz teórica consistente, clara e, minimamente, comum a todos. Sem isso, o risco é que possa ocorrer a dissolução da própria área do 
turismo, a meio ou a longo prazo, em uma subárea da administração, da geografia, do marketing ou de outro campo já sedimentado ou emergente.

Observado essas considerações sobre as palavras mais frequentes nos artigos, como um todo, atentemo-nos para os termos que são mais frequentes nos títulos. É pertinente dizer que escolhemos os títulos porque eles são os enunciados que convocam e provocam a leitura dos referidos artigos, trazendo, não raras vezes, os principais conceitos tratados ao longo do texto. Por isso, é um dos enunciados mais importantes para se refletir e investigar em uma análise mais detalhada sobre os conteúdos. A seguir, apresentamos todas as palavraschave na figura 6 das universidades pesquisadas, para depois categorizarmos as três palavras-chave mais frequência dos títulos dos artigos científicos, diferenciando-os, ainda, por instituição, isto é, a filiação dos autores entre as instituições destacadas. 
Figura 6 - Nuvem de palavras: palavras-chave mais frequentes nos títulos dos artigos científicos dos docentes da área de turismo

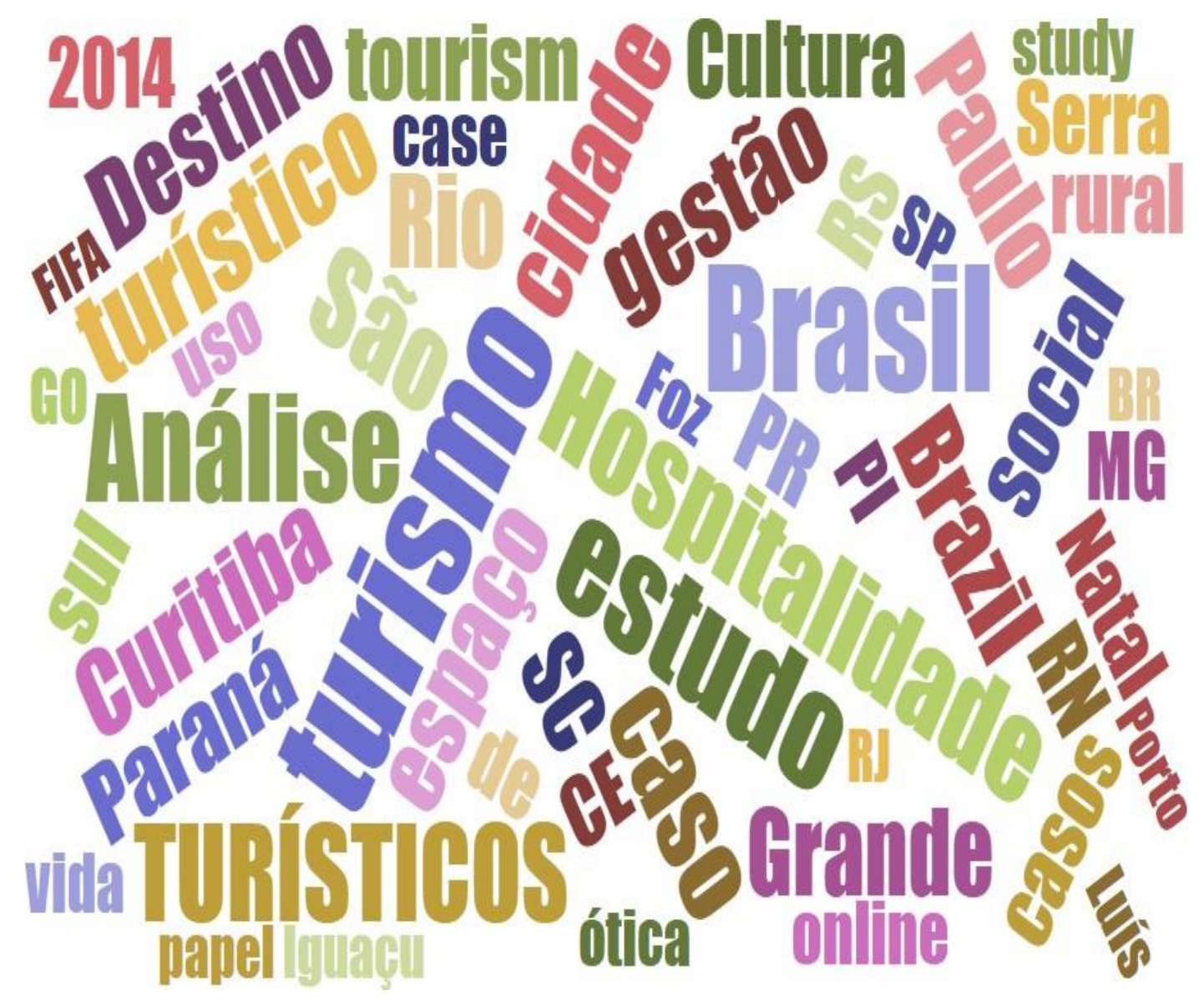

Fonte: Juliana Ferreira dos Santos, com as contribuições da scriptLattes e site jasondavies, 2018 


\section{7- Categorização das palavras dos títulos dos artigos científicos}

Quadro 4 - Categorização das palavras por frequência dos títulos dos artigos científicos das instituições selecionadas

\begin{tabular}{|c|l|l|l|}
\hline \multirow{2}{*}{$\begin{array}{c}\text { Instituição } \\
\text { USP }\end{array}$} & \multicolumn{3}{|c|}{ Três palavras mais frequentes nos títulos dos } \\
artigos científicos
\end{tabular}

Fonte: Juliana Ferreira dos Santos, com as contribuições da scriptLattes e site jasondavies, 2018.

As palavras mais frequentes de uma instituição para outra mudam, embora existam concomitância, como por exemplo, a palavra turismo. Isso pode revelar que as palavras de cada artigo são utilizadas como indexadores para identificar a produção e a investigação sobre um tema. Logo, temos uma diversidade de temas sendo tratados, ao mesmo tempo, pela área, apontando, assim, a riqueza temática da área.

Afirma-se, com isso, que o turismo vem apresentando-se como uma das alternativas promissoras para o desenvolvimento sociocultural, ambiental e histórico de uma comunidade, seja ela nacional, seja ela internacional. Exemplo disso é que as palavras mais frequentes cobrem temas regionais como nos casos da UECE que traz o termo frequente Fortaleza; da UCS, que retoma Serra Gaúcha pois a área de concentração é desenvolvimento regional. E da UFPR, que sustenta Curitiba. Já temos instituições que tratam de temas mais gerais e abstratos e com interesse nacional, como a UNIVALI que sustenta o termo Brasil e a UFF que assevera a expressão políticas públicas. A USP, por sua vez, apresenta a palavra turismo, mas invês de destacar a "cidade de São Paulo", destaca apenas o conceito cidade evidenciando uma perspectiva ampla sobre o conceito, e não somente focada num destino em específico. 
A UAM tem como palavras frequentes hospitalidade e gastronomia, a UFPR tem destinos e Curitiba; a UECE traz comunicação e Fortaleza, a UNIVALI sustenta marketing e Brasil e UFRN a palavra análise com duplo sentido em relação a "destinos turísticos", "gastos públicos" e "empresa" no total de 20 artigos. Todas essas palavras evidenciam um enfoque mercadológico e comercial. De todo modo, acreditamos que esse quadro mostra os aportes para o avanço da reflexão e da práxis, seja na comunicação, seja na integração das políticas públicas e para a consolidação de uma comunidade científica comprometida com o hibridismo do pensamento e com uma crescente institucionalização dos debates nessa área.

Por outro lado, também existe uma tendência teórica dentro da área. Afirma-se isso primeiro, porque, como se pode averiguar no Quadro 4, a palavra turismo é frequente nos títulos dos artigos de todas as instituições selecionadas. Como se pode apreender a USP e a UFRN, apresentam palavras de caráter prioritariamente teórico e prático como Desenvolvimento. Segue abaixo:

\begin{abstract}
O conceito de desenvolvimento do turismo é inerente ao conceito de desenvolvimento nos campos social, humanístico, cultural, político, econômico e científico. A multiplicação e a expansão das atividades turísticas sustentáveis devem constituir ciclos virtuosos de desenvolvimento, em razão da melhoria da qualidade de vida, do bem estar e da inclusão social, proporcionados pelas oportunidades de atuação profissional e empresarial no setor. Para a atuação inovadora e empreendedora dos atores do desenvolvimento turístico, é fundamental a contribuição da academia na criação de condições ambientais favoráveis, com base na produção de conhecimentos, que proporcionem visões e competências de transformação positiva da realidade. EACH, (2018).
\end{abstract}

Destaca-se que esse termo se relaciona ao viés teórico-prático metodológico desenvolvimentista, amplamente divulgado no Brasil nas últimas décadas.

\title{
4.8 Categorização das palavras por frequência dos títulos dos livros
}

Neste tópico, é discutida a categorização das palavras por frequência de livros e capítulos de livros. Essa análise foi realizado, como nas anteriores, a partir das contribuições da scriptLattes e site Jasondavies. Ressalta-se que as publicações em turismo contribuem para a criação de um arcabouço teórico significativo para e na área, tanto no sentido de consolidação do campo de estudos entre as outras disciplinas e saberes, quanto para demarcar os avanços 
dos conhecimentos nas diversas especialidades existentes dentro do próprio campo de saber do turismo. Na figura 7, mostraremos todas as palavras-chave dos livros das nove universidades, para depois, no Quadro 5, delimitar as três palavras-chave, na qual essa área tem um acervo de palavras bastante diversificado:

Figura 7 - Nuvem de palavras: palavras-chave mais frequentes nos livros dos docentes da área de turismo

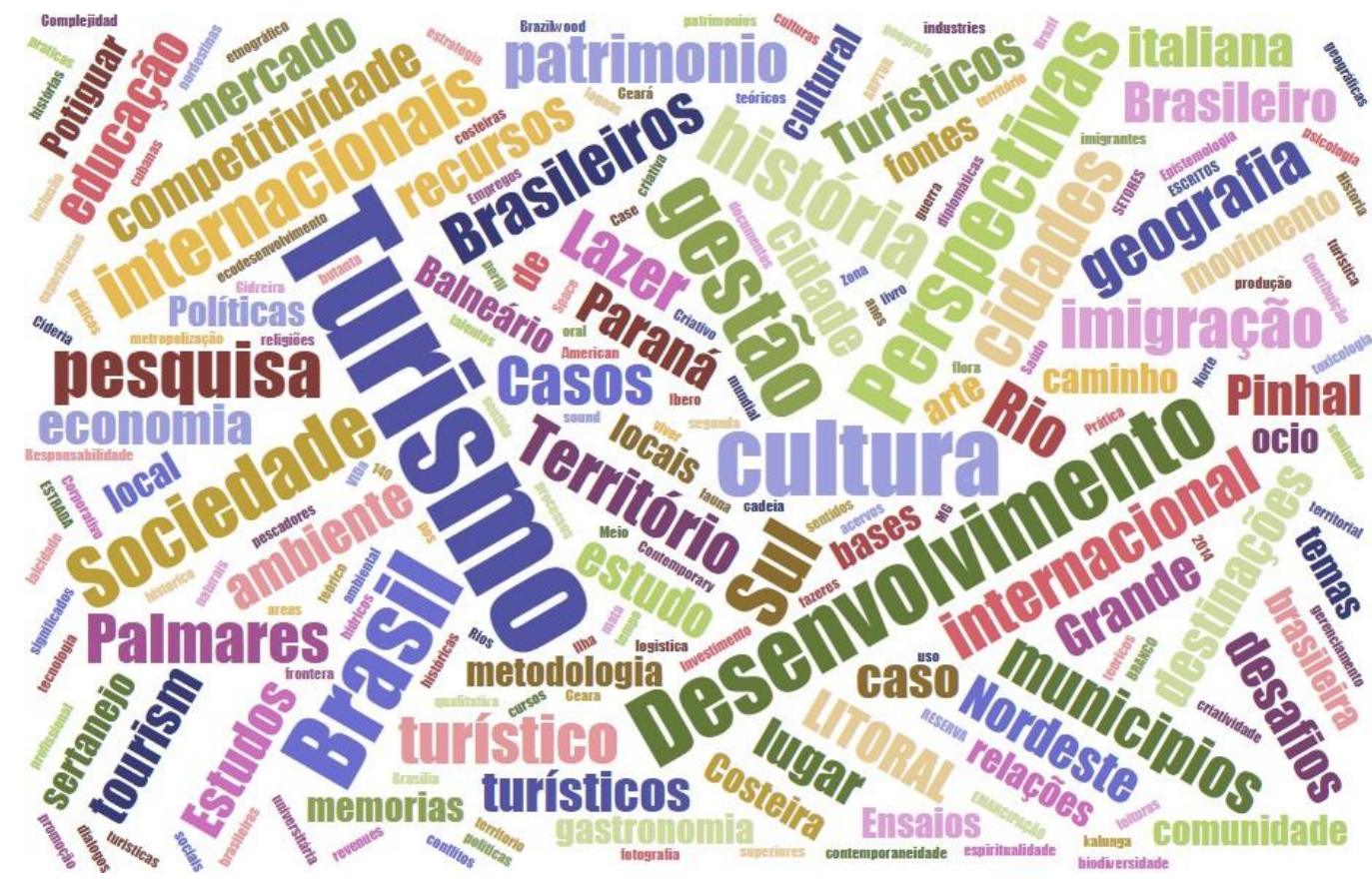

Fonte: Juliana Ferreira dos Santoa, com as contribuições da scriptLattes e site jasondavies, 2018. 
Quadro 5 - Categorização das palavras por frequência dos títulos dos livros

\begin{tabular}{|l|l|l|l|}
\hline Instituição & Três palavras mais frequentes dos livros \\
\hline USP & Turismo & Internacional & Paradiplomacia \\
\hline UFPR & Educação Ambiental & Paraná & Litoral \\
\hline UECE & Turismo & Cultura & Nordeste \\
\hline UFRN & Turismo & Sociedade & Análise \\
\hline UNB & Turismo & Saberes & História \\
\hline UNIVALI & Turismo & Gestão & Interdisciplinares \\
\hline UAM & Turismo & Gestão & Imigrantes \\
\hline UCS & Municípios & Imigração & Palmares \\
\hline UFF & Turismo & História & Brasil \\
\hline
\end{tabular}

Fonte: Juliana Ferreira dos Santos, com as contribuições da scriptLattes e site jasondavies, 2018.

Para se obter esse quadro, foram analisados 112 livros por meio do site Jasondavies. As palavras presentes em cada linha são as mais frequentes encontradas nos títulos dos livros das instituições selecionadas, as quais são descriminadas linha a linha. Compreendendo esse contexto, discutiremos cada uma dessas instituições e os resultados obtidos em seus livros.

Antes disso, nota-se que a palavra mais frequente em quase todos os livros das instituições selecionadas foi "turismo". Essa observação faz se constatar que a área se reconhece como um campo de estudo relevante e, também, uma disciplina de investigação. Essa é mais uma evidência de que a área de turismo está se consolidando frente às demais áreas do fazer-saber. $\mathrm{E}$ somente a UCS e a UFPR não tiveram a palavra turismo, uma vez que optaram por palavras de caráter regionalistas como Palmares, e Parána.

Na primeira linha, temos as palavras mais frequentes na USP. Observase que a palavra "internacional" traz uma expectativa institucional emse difundir os conhecimentos no exterior. Compreende-se, assim, que essa instituição entende o turismo em um viés mundial como um fenômeno complexo que envolve uma rede de atividades de âmbito econômico, social, cultural, ambiental, antropológico, histórico e político. Isso se reflete na própria organização da instituição em que os docentes estabelecem parcerias, acordos e contatos internacionais. 
Discutindo esse dado em um patamar mais geral, pode-se dizer que é o programa de Pós-Graduação scrito sensu em turismo avançou no conhecimento da área, abordando paradigmas do pensamento crítico. Em relação identificação de problemáticas sistêmicas, bem como alternativas que apontam soluções, essa perspectiva internacional auxilia a se consolidar um prisma teórico-científico baseado no desenvolvimento turístico sustentável. Para isso, a presença do termo paradiplomacia está associado a internacional, retroalimentando o anterior, uma vez que para se promover um processo de internacionalização é necessária uma base diplomática forte e eficiente entre os países.

A UFPR, por sua vez, concentra seus livros na análise da atividade turística a partir das palavras frequentes como: educação ambiental, Paraná e litoral. Ou seja relaciona-se com o que está ao redor, próximo da região na qual está inserida. Compreende-se, com isso, que as dinâmicas sociais, produtivas, culturais, políticas e ambientais são apreendidas a partir da maior proximidade com o espaço físico da localidade em que a universidade está situada.

A UECE têm como entradas as palavras turismo, cultura e nordeste. Essa instituição está localizada na região Nordeste, na qual tem um acervo cultural que está sendo explorado de forma sistêmica e orgânica nos últimos ano. Ressalta-se que esse fenômeno se relaciona quanto as características da instituição como as da própria região Nordeste.

No que concerne a UFRN, as palavras em destaque são: turismo, sociedade e análise a palavra sociedade têm vários acepções, dentre elas o de apurar os processos da produção social que envolvem turistas e residentes nos territórios, espaços e lugares turísticos. O fenômeno do turismo é compreendido a partir das possibilidades de encontros da interação entre os sujeitos e a comunidade. Outro termo destacado é análise que enfatiza a perspectiva teórico científica da área. Com base nos livros da UFRN duas são as acepções mais frequentes do termo análise, para as palavras-chave dos artigos, ela aparece em dois sentidos a saber: uma hora, ela está relacionada com prática; e outra hora, ela está associada a teoria. Quando se diz prática se quer enfatizar os destinos turísticos, despesas sociais do governo e infraestrutura dentre outros; quando se diz teórico ressalta a base epistemológica. 
A UNB, tem como palavras mais frequentes em seus livros turismo, saberes e história. A partir desse dados, verifica-se que a instituição privilegia conteúdos mais teórico que práticos. Dentre esses saberes são privilegiados aqueles relacionados ao de patrimônio histórico. Como se constata pelos seguintes títulos: Cidades da 'patrimonialização global; Ensaios sobre a Antropologia da Alimentação: saberes, dinâmicas e patrimônios e A cidade do Rio de Janeiro na obra literária.

A UNIVALI, tem como entradas as palavras: turismo, gestão e interdisciplinares. Em relação ao termo interdisciplinares, estão envolvidas as propostas teóricas metodológicas que enfocam o turismo como um sistema complexo. Resguardadas as especificidades, busca-se, com isso, ampliar as formas de articulação com outros domínios de fazer-saber da produção acadêmica. Essa é a perspectiva da UNIVALI que por ser uma das instituições mais antigas da área, busca integrar o domínio do turismo a outras disciplinas.

Gestão é outra palavra destacada pela UNIVALI. Ressalta-se que a UAM também tem gestão como um da palavras mais frequentes. Esse termo remete aos sistemas turísticos de planejamento, como por exemplo as formas de apropriação das localidades na elaboração de produtos turísticos pelas políticas públicas de mercado, compreensão da capacidade criadora de inovação na organização e formatação dos destinos turísticos nos processos de produção de programas e de produtos turísticos públicos e /ou privados.

Compartilhando com essas ideias, A UAM contém as palavras turismo, gestão, que já foi mencionada, e imigrantes. $\mathrm{O}$ termo imigrantes, Na versão dessa instituição está relacionada com a migração internacional no período PósSegunda Guerra Mundial. Destaque que esse tema tem merecido estudos de sistematização e tratamento dos dados referentes à entrada de imigrantes de diferentes nacionalidades chegados no Brasil entre 1947 e 1980.

Por outro lado, a UCS, embora tenha a palavra imigração, ela não dá o mesmo tratamento teórico ao tema. Ela contextualiza, e traz outra perspectiva interpretativa. Na versão da UCS, o termo imigração, está relacionado com a produção econômica na região, as práticas culturais, a força religiosa dentre outros.

Com essa observação, destaca-se outros fenômenos, como as palavras da UCS Palmares e Municípios. A cidade Palmares está localizada a tanto 
quilometos de 137,30 km da UCS. E municípios é a única base em que se pode realizar um programa de médio a longo prazo em turismo. Esse é um caso de regionalismo exacerbado dentro do corpus coletado nessa pesquisa.

A UFF no período de 2013 a 2016 só teve um livro publicado, porque é um programa recente que iniciou sua primeira turma em 2015. Por isso os seus dados refletem um maior nível de generalização nas palavras escolhidas turismo, história e Brasil. Em outros termos, essas palavras não refletem uma maior ou menor frequência porque só possui 1 exemplar. Esses dados não foram destacados porque eles apontam que mesmo sendo um exemplar ele seguiu a tendência da área. Com por exemplo destacar o termo turismo.

No geral, esses termos mostram que a pós-graduação sctrico sensu em turismo vem evoluindo. Isso também demostra que não há grande disparidade entre as instituições selecionadas. Portanto, temos sim um domínio do conhecimento estruturado na área do turismo.

\subsection{Categorização das palavras por frequência nos capítulos de} livros

Ao analisar e interpretar as palavras presentes pelos títulos dos capítulos dos livros, verifica-se a existência de uma determinada frequência de algumas palavras. Salienta-se que a trajetória analítico-interpretativa não é excludente, nem sequencial, pois pode haver uma interpenetração dos dados. Por isso, este é um recorte interpretativo da produção docente de um grupo seleto de instituições de ensino de turismo que sugere determinados posicionamentos da atual situação da pós-graduação sctrico sensu em turismo no Brasil - o mesmo se aplica nas análises feitas dos artigos e dos livros. Para isso demostramos abaixo todas as palavras-chave dos capítulos de livros de cada universidade na figura 8. Para depois categorizar a de cada universidade escolhida para este estudo conforme a categorização das palavras por frequência nos capítulos de livros. 
Figura 8 - Nuvem de palavras: palavras-chave mais frequentes nos Capítulos de livros dos docentes da área de turismo

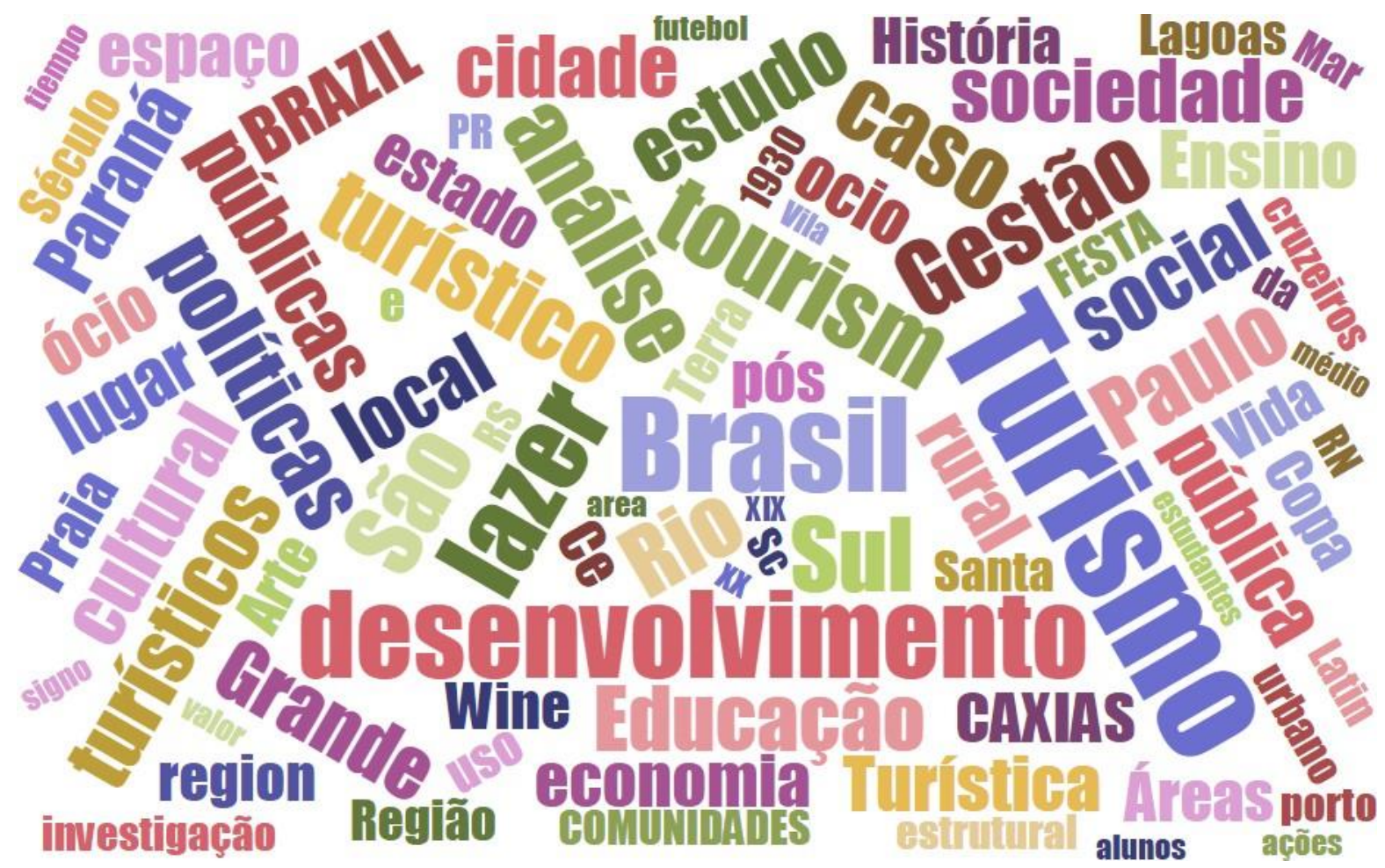

Fonte: Juliana Ferreira dos Santos, com as contribuições da scriptLattes e site jasondavies, 2018.

Quadro 6 - Categorização das palavras por frequência dos títulos dos capítulos de livros

\begin{tabular}{|l|l|l|l|}
\hline Instituição & \multicolumn{3}{|l|}{$\begin{array}{l}\text { Três palavras mais frequentes dos } \\
\text { Capítulos }\end{array}$} \\
\hline USP & Turismo & Lazer & Desenvolvimento \\
\hline UECE & Turismo & Desenvolvimento & Ócio \\
\hline UFRN & Turismo & Desenvolvimento & Políticas \\
\hline UAM & Turismo & Imigração & Hospitalidade \\
\hline UCS & Turismo & Hospitalidade & $\begin{array}{l}\text { Rio Grande do } \\
\text { Sul }\end{array}$ \\
\hline UNB & Turismo & Desigualdades & Patrimônio \\
\hline UFPR & Turismo & Paraná & Brasil \\
\hline UFF & Turismo & História & Brasil \\
\hline UNIVALI & Turismo & Destinos & Brasil \\
\hline
\end{tabular}

Fonte: Própria autoria com as contribuições da scriptLattes e site Jasondavies.

Dos 332 capítulos de livro, depreendemos que a palavra mais frequente foi novamente o termo turismo, o que confirma, mais uma vez, que a área está se consolidando e, prova disso, é a sua consciência como campo de estudo. As palavras mais frequentes na USP foram: turismo, lazer e desenvolvimento. No 
que consta às palavras desenvolvimento e turismo, a sua relação nesta instituição se estabelece porque a área de concentração da pós-graduação stricto sensu em turismo na USP se intitula "Turismo e Desenvolvimento". Logo, a aparição dessas duas palavras faz jus ao direcionamento já previsto pelo referido programa de pós-graduação. Já a presença do termo lazer se deve a um fator particular, uma vez que dois dos docentes-pesquisadores mais produtivos do programa estão afiliados à linha teórico-epistemológica que investiga o lazer e, como a produção bibliográfica deles foi elevada, essa palavra tornou-se mais presente no computo geral do programa de turismo na USP. Além disso, o programa de mestrado da USP tem sua origem no curso de Lazer e Turismo da própria instituição.

Acompanhando as palavras da USP, a UECE tem como palavras frequentes turismo, desenvolvimento e ócio. O termo desenvolvimento nas publicações dos capítulos está associado, majoritariamente, ao desenvolvimento local, favorecendo uma investigação sobre o turismo regional. Nessa linha o estudo do desenvolvimento promovido nas pesquisas da UECE se afasta do desenvolvimento investigado nos estudos da USP, porque a USP tem uma pósgraduação de linha acadêmica e a UECE de caráter profissional.

A frequência do termo ócio nos corpus da UECE é mais alto do que média das demais universidades. Uma possível explicação para esse fato decorre da existência de um pós-doutor que pesquisa o termo ócio no corpo docente dessa instituição.

Já na UFRN, as entradas turismo, desenvolvimento e políticas enfatizam a relação com a teoria e a prática. Pois a palavra desenvolvimento é utilizada pela IES não só nos aspectos locais e regionais, mas também nacional. A palavra política, a qual é referida nos capítulos de livro, está relacionada com políticas públicas, uma área mais voltada para a questão da gestão e do planejamento. Projeta-se dessa forma que a área de concentração da Universidade é turismo, desenvolvimento e gestão, ou seja, ela também tem o mesmo comprometimento como a USP com a interligação das áreas de estudo. A UAM tem como palavras mais frequentes turismo, imigração e hospitalidade. Verifica-se que a palavra imigração está mais presente em textos voltados para o tópico do pós-segunda-guerra mundial em São Paulo. Já a palavra hospitalidade envolve o aspecto imigratório do município de São Paulo, 
como por exemplo a hospitalidade urbana, especialmente nos lugares ou localidades.

A UCS tem como entrada as palavras turismo, hospitalidade e Rio Grande do Sul. O termo hospitalidade está intrinsecamente ligada ao ser humano e é muito mais do que atender com qualidade e presteza. A análise dos textos da IES aponta que o termo hospitalidade não está associada apenas ao tópico acolhimento, e sim a uma perspectiva epistemologia do termo relacionado ao coletivo. A UCS analisa o entorno no qual está instalado a instituição, numa forma mais restrita com a palavra Rio Grande do Sul.

A UNB tem como palavras turismo, desigualdades e patrimônio. Nos capítulos selecionados a palavra desigualdade está relacionada a gênero, raça, a desigualdade das mulheres no trabalho dentre outros. Já a patrimônio referese a reflexão e o questionamento sobre como se configuram os lugares turísticos, como se legitimam ou não a partir da memória, da materialidade e imaterialidade do patrimônio artístico ou cultural e de como se (re)inventam suas tradições.

Já a UFPR tem como frequência a palavra turismo, Paraná e Brasil ou seja engloba estudos relacionados ao entorno da IES, e a palavra Brasil tem recorrência por causa do tipo ser (Paraná-Brasil). Ainda em outro contexto, temos a UFF tem como palavras turismo, história e Brasil, a palavra história está relacionado com a história do turismo no Brasil, e a palavra Brasil, mesmo tendo uma conotação maior, os estudos da IES estão relacionados a cidade do Rio de Janeiro.

A UNIVALI teve como entrada as palavras turismo, destinos e Brasil. Estão presentes nos capítulos de livro a palavra destinos, que aponta para gestão. Já a palavra Brasil está inserida no contexto amplo do termo, diferente da UFF. Na UNIVALI os títulos dos capítulos da palavra Brasil aparece em várias conotações, não só restrito a localidade da universidade, por exemplo a cidade Balneário Camboriú, como também todo território nacional, a saber: turismo de natureza no Brasil, reflexão Sobre o Ensino da Gastronomia no Brasil, e a promoção do produto turístico do destino Roraima/Brasil.

Compreendemos que a partir da produção docente é possível uma infinidade de possibilidades metodológicas de investigação. Essas possibilidades são capazes de gerar frutos e contributos significativos para o 
"fazer-saber". Isso permite a inovação científica necessária para o desenvolvimento social e a transformação humana a partir de novas ações metodológicas. 
Nenhum indicador isolado é capaz de sintetizar a qualidade do desempenho científico de um pesquisador. Neste contexto, o uso de um conjunto de métricas permite que se obtenha uma avaliação mais precisa sobre seu impacto científico (HADDAD, MENA-CHALCO, SIDONE, 2017, p. 620).

A partir do que observamos nas análises das palavras-chave dos artigos, livros e capítulos de livros, abordamos a colaboração dos docentes em turismo no Brasil a partir da análise de afirmações e veículos-signos. Essa investigação teve como universo de pesquisa a pós-graduação stricto sensu em turismo no Brasil no período de 2013 a 2016, considerando a produção cientifica de 157 docentes permanentes, colaboradores e inativos dos nove diferentes programas. Além disso, utilizamos o mesmo processo explicitado no Capítulo 2, que foi o de detectar recorrências nas produções de livros, artigos e capítulos de livros.

No próximo tópico, realizaremos uma contextualização sobre a Rede de Colaboração dos Docentes e outro aspecto que observamos foram os grafos de colaboração dos docentes, proporcionado pelo scriptLattes. Eis os próximos passos que daremos em nossa análise da produção docente.

\section{1- A colaboração dos docentes da pós-graduação stricto sensu em turismo no Brasil}

As instituições de fomento à pesquisa no Brasil, como a CAPES, têm cada vez mais incentivado e valorizado a coautoria, ou seja, a colaboração científica entre pesquisadores de universidades (cf. MENA-CHALCO; CESAR JUNIOR, 2013). De acordo com Gomes, Cavalcante e Lins (2012), o trabalho em conjunto se torna mais eficiente, pois envolve um processo de interação social que impulsiona o intercâmbio de ideias, o aumento do conhecimento nas áreas e o compartilhamento de custos. Esses autores afirmam que essa tendência está alinhada às "recomendações de melhoria da produção científica e cooperação entre pesquisadores, que a CAPES utiliza no acompanhamento anual e na avaliação quadrienal dos cursos de Pós-Graduação" (GOMES; CAVALCANTE; LINS, 2012, p. 3).

Como consequência, o interesse pela análise de redes de coautoria tem aumentado no país, conforme sustentam Maia e Caregnato (2008). Concomitantemente a isso, está em ascendência a bibliometria, como se 
observa nos parâmetros analíticos aplicados na Plataforma Lattes e no Google Acadêmico para a "coleta de dados sobre a produção nacional" (BALANCIERI et al., 2005, p. 72). Mais recentemente, os estudos de Digiampietri (2015), MenaChalco- Cesar-Junior (2013) e Mugnaini (2006) reafirmam essa tendência e a do scripLattes.

Em uma análise mais aprofundada dessas redes, é possível compreender o processo de pesquisa dos docentes, identificar suas relações, entender como a troca de informações influencia o trabalho acadêmico e atestar desde o grau de envolvimento entre os autores até a organização estrutural criada dentro desse ambiente, como a centralização ou não do trabalho de pesquisa acadêmica. Todos esses aspectos auxiliam a construção de um conhecimento coletivo (MAIA; COREGNATO, 2012). Ressalta-se que estudar a dinâmica das colaborações científicas também pode auxiliar no desenvolvimento de plataformas ou outras tecnologias, que, por sua vez, poderão facilitar e otimizar a comunicação entre docentes.

Para compreender a atual preferência, tanto de instituições como dos próprios docentes, pela autoria compartilhada, foram feitas análises evolutivas e estudos, como os de Hagstrom (1965), Price (1963) e Crane (1972), sobre a origem desse tipo de cooperação, inclusive foi cunhado o conceito dos colégios invisíveis. Este último termo é usado para nomear as redes informais de profissionais com interesses em comum e que não envolvem uma instituição formal (cf. PRICE, 1963). Assim, de acordo com Price e Beaver (1966, p. 6), os autores podem trocar informações e muitas vezes publicar formalmente, "transcendendo o local de pesquisa, o departamento, a universidade e até o país".

De acordo com Mena-Chalco; Cesar Junior (2013), as primeiras cooperações tiveram início de maneira informal nos primeiros anos de formação científica dos pesquisadores, ou mesmo na relação orientador-orientando, como provou a partir de estudos comparativos de grafos de colaboração - mais à frente explicaremos como funciona esse recurso de grafos. Depreende-se que a interação social ao redor de um tema de interesse comum pode fomentar 0 interesse pela pesquisa e, posteriormente, levar a uma publicação acadêmica, principalmente quando existe uma relação entre orientando-orientador. 
Segundo Casado et al. (2004), "há uma maior complexidade na prática de pesquisa devido a novas conexões entre disciplinas tradicionais e mesmo [com a] geração de novas disciplinas". A cada nova tecnologia, novas áreas de interesse vão surgindo, que podem ser complementadas com conhecimentos de outros campos. Essa inter-relação entre conteúdos novos/inovadores/pioneiros e temas já tradicionais nas leituras acadêmicas também promovem a colaboração de autores e, consequentemente, a autoria compartilhada.

"A interdisciplinaridade vem se afirmando nas publicações de diferentes áreas de pesquisa, com impacto sobre o cenário geral das redes de colaboração" (CASADO et al. 2004, on-line). Além disso, como sugerem Mangante, Araújo e Schulz (2014), a cooperação expande as fronteiras teóricas, bem como as nacionais. De acordo com esses pesquisadores, os "docentes que mantiveram uma colaboração alta com instituições internacionais tenderam a aumentar a média de citações de seus artigos" (MANGANTE; ARAÚJO; SCHULZ, 2014, online).

Como mencionado anteriormente, entre os pontos positivos para a coautoria estão os custos mais baixos, a valorização do intercâmbio de ideias e o estímulo à interdisciplinaridade. Além disso, a preferência por essa forma de trabalho também pode ser explicada "pelas possibilidades de acesso a novas pesquisas e de prestígio acadêmico" (GOMES; CAVALCANTE; LINS, 2012, p. 2). Isso ocorre, porque, fazendo trabalhos em coautoria, é possível que autores mais novos, mais inexperientes ou menos conhecidos no meio alcancem mais visibilidade acadêmica e maior financiamento para suas pesquisas (cf. GOMES; CAVALVANTE; LINS, 2012).

Os estudos de Gomes, Cavalcante e Lins (2012) ressaltam, ainda, que a estrutura das redes de coautoria faz com que virtualmente todos nela estejam ao alcance uns dos outros. Conforme esses estudiosos, os "indivíduos em uma rede estão separados por até seis graus" (GOMES; CAVALCANTE; LINS, 2012, p. 3. Em outras palavras, os autores podem se inter-relacionar e estabelecerem contato de diversas maneiras, em suas publicações: ora sendo citados, ora publicando junto a outros autores. Todos "estão relacionados de alguma forma e podem, portanto, estabelecer um contato" (GOMES; CAVALCANTE; LINS, 2012, p. 3). Esse fenômeno foi estudado também anteriormente por Milgram (1967) e Barabási et al. (2002). 
Observados essas aspectos gerais da rede de colaboração, nos próximos tópicos, vamos descrever três diferentes recursos metodológicos de análise dessas redes. No tópico 5.2, utilizamos os três recursos ( scriptLattes, Pagerank, e o índice $\mathrm{H}$ para analisar as produções acadêmicas de docentes selecionados e suas respectivas redes de colaboração.

\section{2- Análise das produções acadêmicas dos docentes selecionados}

Neste tópico, foi analisado os dois índices, o grafo de colaboração e o pageRank, de nove universidades selecionadas a partir de sua produção docente, a saber: UNIVALI, UFPR, UAM, UECE, UCS, USP, UFRN, UNB e UFF. $\mathrm{O}$ índice H e o i10 será analisado separadamente no próximo tópico. Escolhemos essa metodologia, porque os dados coletados dos indicadores do grafo de colaboração e o pageRank se referem ao período de 2013 a 2016, já o índice H compreende os dados coletados em julho de 2018.

Uma vez que são períodos diferentes - de um lado, 2013 a 2016, e de outro, 2018 -, esses índices são analisados separadamente. Os dados do índice $\mathrm{H}$ podem reforçar ou não as análises obtidas com os indicadores dos grafos $\mathrm{e}$ do pageRank. Portanto, essa metodologia é pertinente, porque acolhe duas análises de índices diferentes em dois períodos distintos com os mesmos grupos de docentes selecionados para relativizar os resultados para além dos indicadores adotados.

Neste tópico, apresentamos cada universidade a partir da explicitação do número de docentes acolhidos em nossa análise. Em seguida, apresentamos a figura representativa do grafo de colaboração e também um quadro com o índice do pageRank de cada um dos docentes, ambos obtidos a partir do scriptLattes. Embora os dados trazidos pela figura e pelo quadro sejam de todos os docentes, optamos, como critério de comparação entre as universidades, por analisar apenas e somente os três docentes mais produtivos, isto é, aqueles que possuem, conforme a figura e a tabela de cada instituição, os maiores índices.

Foram escolhidos os três primeiros, porque, a partir dos níveis mais altos de produtividade, é possível verificar, em hipótese, os maiores índices de colaboração. Em outras palavras, quando o docente publica mais, maior é a chance dele ter publicado em coautoria, embora existam exceções. Como este 
capítulo se propõe a entender a rede de colaboração, ter a maior probabilidade de coautoria é um requisito pertinente à esta pesquisa.

A figura de cada grafo obtida pelo scriptlattes possui algumas especificações. O número descrito entre parêntese ao lado de cada docente concebe o quantitativo de publicações desenvolvidas em colaboração com membros do programa. As setas direcionais representam o grau de intensidade de colaboração de um docente para o outro de acordo com a quantidade de publicações desenvolvidas. As porcentagens que aparecem junto às setas são resultantes da proporcionalidade entre 0 número total de produções bibliográficas e o número total de coautores.

Por exemplo, um autor $X$ pode ter duas publicações e outro autor $Y$ pode também ter duas publicações. No parênteses de ambos aparecerá o número dois. As porcentagens de suas setas poderá ser diferente a depender do número de coautoria de cada autor. Se o autor X publicou com dois outros, cada seta terá a porcentagem de 0.5 , porque cada autor tem metade da produção. Se o autor $Y$ publicou com apenas um outro, a seta terá a porcentagem 1, porque cada autor tem $100 \%$ da coautoria naquela dupla.

Outra probabilidade é as setas entre os coautores terem valores distintos. Isso ocorre, porque pode acontecer de um autor ter mais coautoria com um determinado colega de programa do que com outro. Por exemplo, o autor $Z$ tem o número 3 entre os parênteses, significando que ele possui três publicações em coautoria. $O$ autor $Z$ possui duas setas, uma indicando 0,67 e outra, 033. Isso quer dizer que o primeiro coautor, possui dois terços da coautoria com o autor $Z$; e, com o segundo coautor, um terço.

Destacamos que nem sempre os primeiros colocados no grafo de colaboração são também os primeiros colocados no pageRank. A correspondência não é direta. Isso não ocorre, porque o grafo de colaboração relaciona a quantidade de coautoria dos docentes. Já o pageRank analisa a quantidade e a qualidade da coautoria, ou seja, se os coautores também produzem artigos em coautoria com outros docentes do mesmo programa. Nesse segundo caso, quanto maior for a rede de colaboração maior será o índice; já no caso do grafo, importa somente o número de coautoria. A partir desses dois dados, é possível distinguir o desempenho colaborativo dos 
docentes influentes no programa: com o grafo de colaboração, de forma quantitativa; com o pageRank, de maneira qualitativa e por suavez quantitativa. Começamos a análise com os dados coletados da UNIVALI. O grafo e o quadro que apresentaremos a seguir trazem a colaboração dos dezessete docentes permanentes/ colaboradores/inativos no programa no período de 2013 a 2016.

Desse grupo, como poderemos verificar, quinze docentes desenvolveram atividades de colaboração por meio de coautoria de trabalhos no período analisado com os membros do grupo. Ou seja, dois docentes não realizaram produções em coautoria, recebendo indicado 0 no grafo e 0,15 no pageRank. Desses quinze que produziram, analisaremos os três primeiros colocados, seguindo a metodologia já explicitada. A seguir, reproduzimos o grafo e o quadro obtidos pelo scriptlattes:

Figura 10. Grafo de colaboração da UNIVALI: 2013 a 2016 


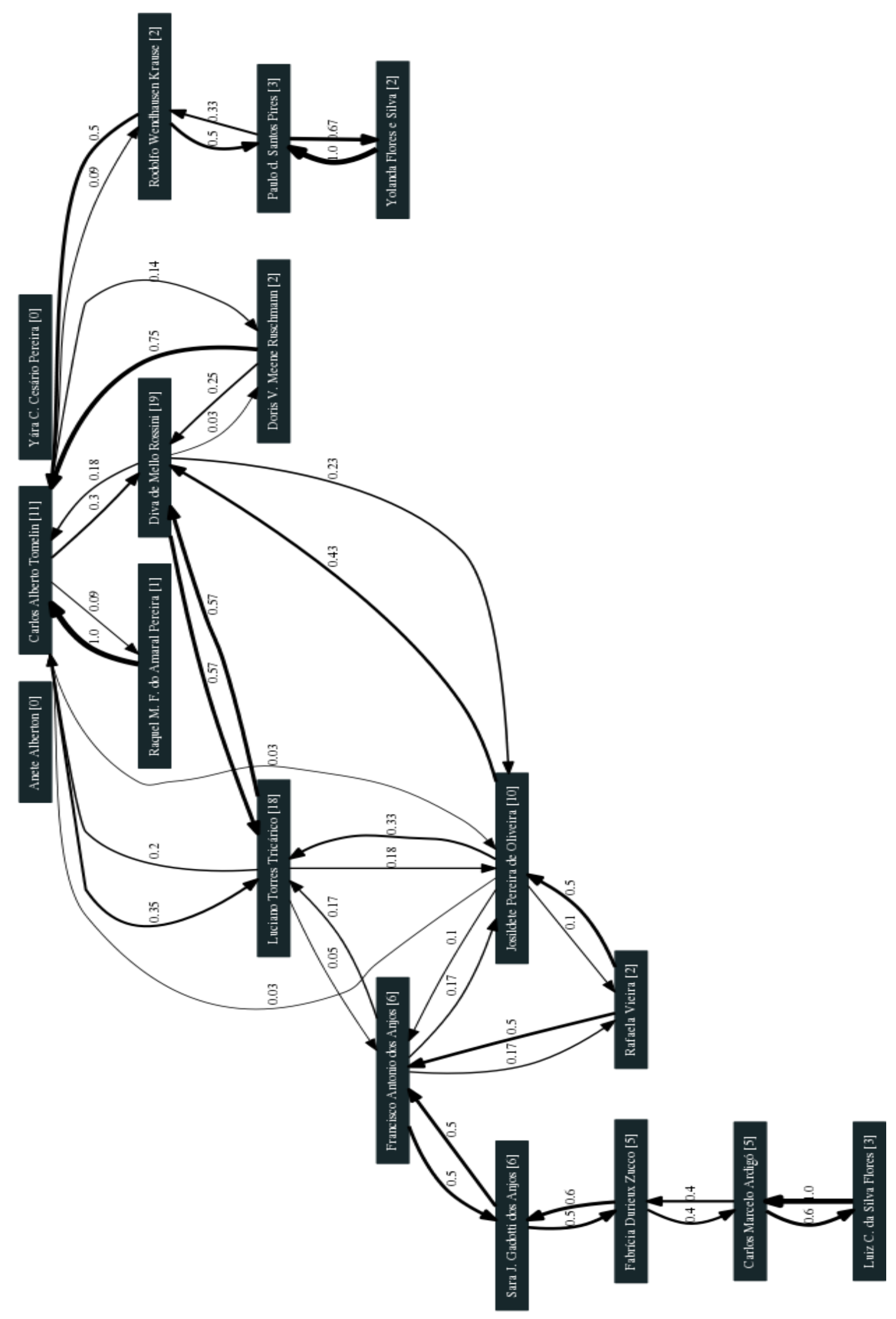

Fonte: scriptlattes (2018). 
Quadro 7. PageRank da UNIVALI: 2013 a 2016

\begin{tabular}{|c|l}
\hline Rank de Colaboração & \multicolumn{1}{|c}{ Membro } \\
\hline 2.12 & Luciano Torres Tricário \\
\hline 2.11 & Diva de Mello Rossini \\
\hline 1.57 & Carlos Alberto Tomelin \\
\hline 1.21 & Josildete Pereira de Oliveira \\
\hline 1.06 & Carlos Marcelo Ardigão \\
\hline 1.04 & Sara Joana Gadotti dos Anjos \\
\hline 0.99 & Paulo dos Santos Pires \\
\hline 0.96 & Francisco Antonio dos Anjos \\
\hline 0.95 & Fabricia Durieux Zucco \\
\hline 0.71 & Yolanda Flores e Silva \\
\hline 0.69 & Luiz Carlos da Silva Flores \\
\hline 0.55 & Rodolfo Wendhausen Krause \\
\hline 0.39 & Rafaela Vieira \\
\hline 0.38 & Doris Van Meene Ruschmann \\
\hline 0.27 & Raquel Maria Fontes do Amaral Pereira \\
\hline 0.15 & Yara Christina Cesario Pereira \\
\hline 0.15 & Anete Alberton \\
\hline 2018. & \\
\hline
\end{tabular}

Fonte: Scriptlattes (2018).

Depreende-se que a UNIVALI possui como os três primeiros colocados no grafo os seguintes docente: Diva de Mello Rossini (19), Luciano Torres Tricário (18) e Carlos Alberto Tomelin (11). No pageRank, mantém-se os mesmos autores só que a ordem muda: (1) Luciano Torres Tricário obteve 2.12; (2) Diva de Mello Rossini, 2.11; (3) Carlos Alberto Tomelin, 1.57. Observemos como cada um desses professores alcançou esses índices.

A docente Diva de Mello Rossini exibe a maior colaboração no grupo no grafo e é a segunda colocada no pageRank. Vê-se, no grafo, que ela desenvolveu pesquisas em coautoria com quatro membros: Luciano Torres 
Tricário, Carlos Alberto Tomelin, Doris Van Meene Ruschmann e Josildete Pereira de Oliveira. Essas coautorias têm diferentes graus de colaboração. $O$ grau de colaboração da docente Diva de Mello Rossini com Luciano Torres Tricário é de 0,57. A colaboração da docente Diva Rossini com Carlos Tomelin tem um grau de 0,18 . Já o grau de colaboração da docente Diva Rossini com a docente Doris Ruschmann é de 0,03. Por último, a docente Diva Rossini com Josildete Oliveira tem um grau de 0,23.

O docente Luciano Torres Tricário é o segundo no grafo e o primeiro no pageRank. Ele desenvolveu pesquisas em coautoria também com quatro docentes: Francisco Antonio dos Anjos, Carlos Alberto Tomelin, Josildete Pereira de Oliveira e Diva de Mello Rossini. Essas coautorias também possuem diferentes graus de colaboração. Com a docente Diva Rossini, o índice é 0,57. Com Josildete Oliveira, foi de 0,18. Com Francisco dos Anjos, foi de 0,05. Com Carlos Tomelin, foi 0,2.

O professor Carlos Alberto Tomelin é o terceiro colocado tanto no grafo quanto no pageRank. Ele fez parcerias com seis docentes, a saber: Rodolfo Wendhausen Krause, Luciano Torres Tricário, Raquel Maria Fontes do Amaral Pereira, Doris Van Meene Ruschmann, Josildete Pereira de Oliveira e Diva de Mello Rossini. As coautorias novamente obtiveram diferentes graus de colaboração. Com a docente Raquel Maria Fontes do Amaral Pereira, teve 0,09. Com Diva Rossini, foi de 0,3. Com Doris Ruschmann, foi de 0,14. Com Rodolfo Krause, foi de 0,09. Com Luciano Torres Tricário, foi de 0,35. Com Josildete Oliveira, teve 0,03 .

Notamos, com esses dados, que, embora o docente Carlos Alberto Tomelin tenha uma rede maior de coautores (seis coautores) frente aos outros dois professores, Diva de Mello Rossini (quatro coautores) e Luciano Torres Tricário (coautores), ele permaneceu na terceira colocação. Isso decorreu do fato de suas parcerias serem mais fracas do que a dos outros dois docentes, além de seu número de publicações ser menor. Constata-se, assim, a relevância de se verificar o grau de intensidade de cada seta no grafo da figura 11.

Comparando os dois primeiros colocados, podemos identificar, como já salientamos, que, no grafo de colaboração, a docente Diva Rossini é a que tem mais colaboração, mas, em contrapartida, é o docente Luciano Tricário que tem o pagerank maior. Esse contraste ocorre, porque o docente publica com outros 
professores que também publicam em coautoria, formando, assim, uma rede maior de colaboração.

Partimos, então, para os dados coletados da UFPR. O grafo e o quadro que apresentaremos a seguir trazem a colaboração dos dezoitos docentes permanentes/ colaboradores/ inativos no programa no período de 2013 a 2016. Desse grupo, como poderemos verificar, apenas quatorze docentes desenvolveram atividades de colaboração por meio de coautoria de trabalhos no período analisado com os membros do grupo. Ou seja, quatro docentes não realizaram produções em coautoria. Desses quatorze que produziram, analisaremos os três primeiros colocados. A seguir, reproduzimos o grafo e 0 quadro obtidos pelo scriptLattes na Figura 11: 
Figura 11. Grafo de colaboração da UFPR: 2013 a 2016

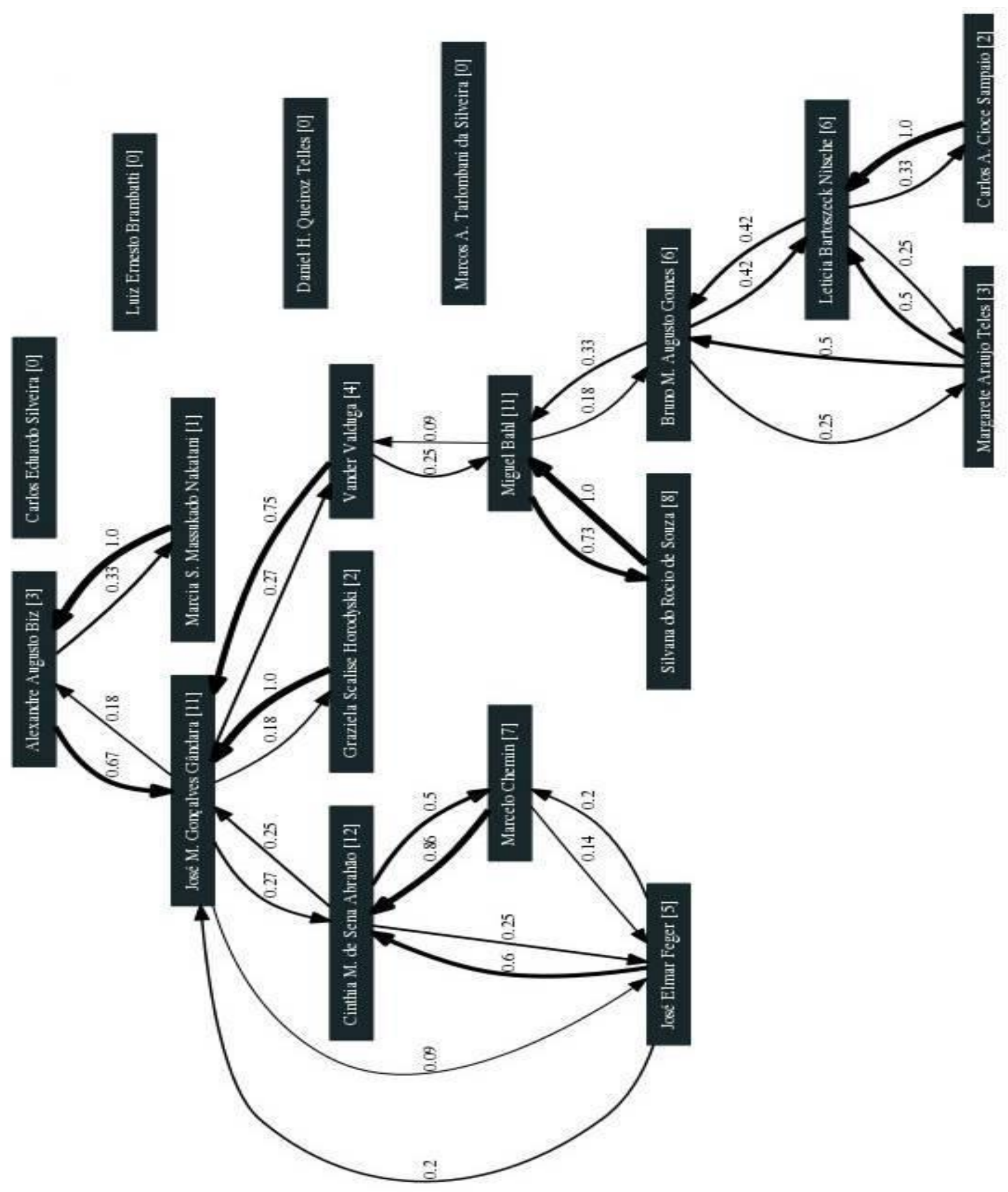

Fonte: scriptlattes (2018). 
Quadro 8. PageRank da UFPR: 2013 a 2016

\begin{tabular}{|l|l|}
\hline Rank de Colaboração & \multicolumn{1}{c}{ Membro } \\
\hline 1.92 & José Manoel Gonçalves Gândara \\
\hline 1.75 & Cinthia Maria de Sena Abrahão \\
\hline 1.57 & Miguel Bahl \\
\hline 1.25 & Leticia Bartoszeck Nitsche \\
\hline 1.12 & Silvana do Rocio de Souza \\
\hline 1.11 & Bruno Martins Augusto Gomes \\
\hline 1.03 & Marcelo Chemin \\
\hline 0.8 & José Elmar Feger \\
\hline 0.76 & Alexandre Augusto Biz \\
\hline 0.72 & Vander Valduga \\
\hline 0.65 & Margarete Araujo Teles \\
\hline 0.5 & Carlos Alberto Cioce Sampaio \\
\hline 0.45 & Graziela Scalise Horodyski \\
\hline 0.36 & Marcia Shizue Massukado Nakatani \\
\hline 0.15 & Marcos Aurelio Tarlombani da Silveira \\
\hline 0.15 & Luiz Ernesto Brambatti \\
\hline 0.15 & Daniel Hauer Queiroz Telles \\
\hline 0.15 & Carlos Eduardo Silveira \\
\hline
\end{tabular}

Fonte: Scriptlattes (2018)

Nota-se que a UFPR possui como os três primeiros colocados no grafo os seguintes docentes: Cinthia Maria de Sena Abrahão (12), José Manoel Gonçalves Gândara (11) e Miguel Bahl (11). No pageRank, mantém-se os mesmos autores só que a ordem se modifica: (1) José Manoel Gonçalves Gândara obteve 1.92; (2) Cinthia Maria de Sena Abrahão, 1.75; (3) Miguel Bahl, 1.57. Observemos como cada um desses professores atingiu esses índices.

A docente Cinthia Maria de Sena Abrahão exibe a maior colaboração no grupo no grafo e é a segunda colocada no pageRank. Observa-se, no grafo, que ela desenvolveu pesquisas em coautoria com três membros: José Manoel Gonçalves Gândara, Marcelo Chemin e João Elmar Feger, com diferentes graus de colaboração. O grau de colaboração da docente Cinthia Maria de Sena Abrahão com José Manoel Gonçalves Gândara é de 0,25. Com Marcelo Chemin, teve um grau de 0,5. Com o docente João Elmar Feger, é de 0,25. 
O docente José Manoel Gonçalves Gândara é o segundo no grafo e o primeiro no pageRank. Ele pesquisou em coautoria com cinco docentes: Alexandre Augusto Biz, João Elmar Feger, Vander Valduga, Cinthia Maria de Sena Abrahão e Graziela Scalise Horodyski; obtendo diferentes graus de colaboração com esses magistrados. Com o docente Alexandre Biz, teve o grau de colaboração 0,18. Com João Feger, foi de 0,09. Com Vander Valduga, foi de 0,27 . Com Cinthia Abrahão, teve o mesmo percentual 0,27. Com a docente Graziela Horodyski, teve 0,18.

O professor Miguel Bahl é o terceiro colocado tanto no grafo quanto no pageRank. Ele fez parcerias com os três docentes, a saber: Vander Valduga, Bruno Martins Augusto Gomes e Silvana do Rocio de Souza; tendo diferentes graus de colaboração com estes. Com o docente Vander Valduga, teve 0,09. Com Bruno Gomes, foi de 0,18. Com Silvana Souza, foi de 0,73.

Observamos, com estes dados, que, embora o docente José Manoel Gonçalves Gândara seja o segundo no grafo com maior número em coautoria (cinco docentes), ele é o primeiro no pageRank, demonstrando, assim, que a depender do que é adotado como critério pelo indicador o resultado se modifica.

Também observamos que esse fenômeno ocorreu porque esse docente é um dos que mais publicou artigos nesse período com docentes do departamento de geografia da UFPR, como também professores da Universidade de Sergipe, Universidade Positivo (UP) e com alunos de outros mestrados e orientandos do programa e que este fenômeno quando observado na totalidade da vida acadêmica do docente fica ainda mais patente. Gândara, até julho de 2016, tem um montante de cinquenta nove publicações, sendo 11 em coautoria com seus colegas do programa.

Encontramos outra análise nos dados coletados da UAM. O grafo e o quadro que apresentaremos a seguir trazem a colaboração dos dezenove docentes permanentes/colaboradores/ inativos no programa no período de 2013 a 2016. Desse grupo, como poderemos verificar, dezesseis docentes realizaram atividades de colaboração por meio de coautoria de trabalhos no período analisado com os membros do grupo. Ou seja, três docentes não realizaram produções em coautoria. Desses dezesseis que produziram, analisaremos os três primeiros colocados, A seguir, mostramos o grafo e o quadro obtidos pelo scriptLattes: 
Figura 12. Grafo de colaboração da UAM: 2013 a 2016 


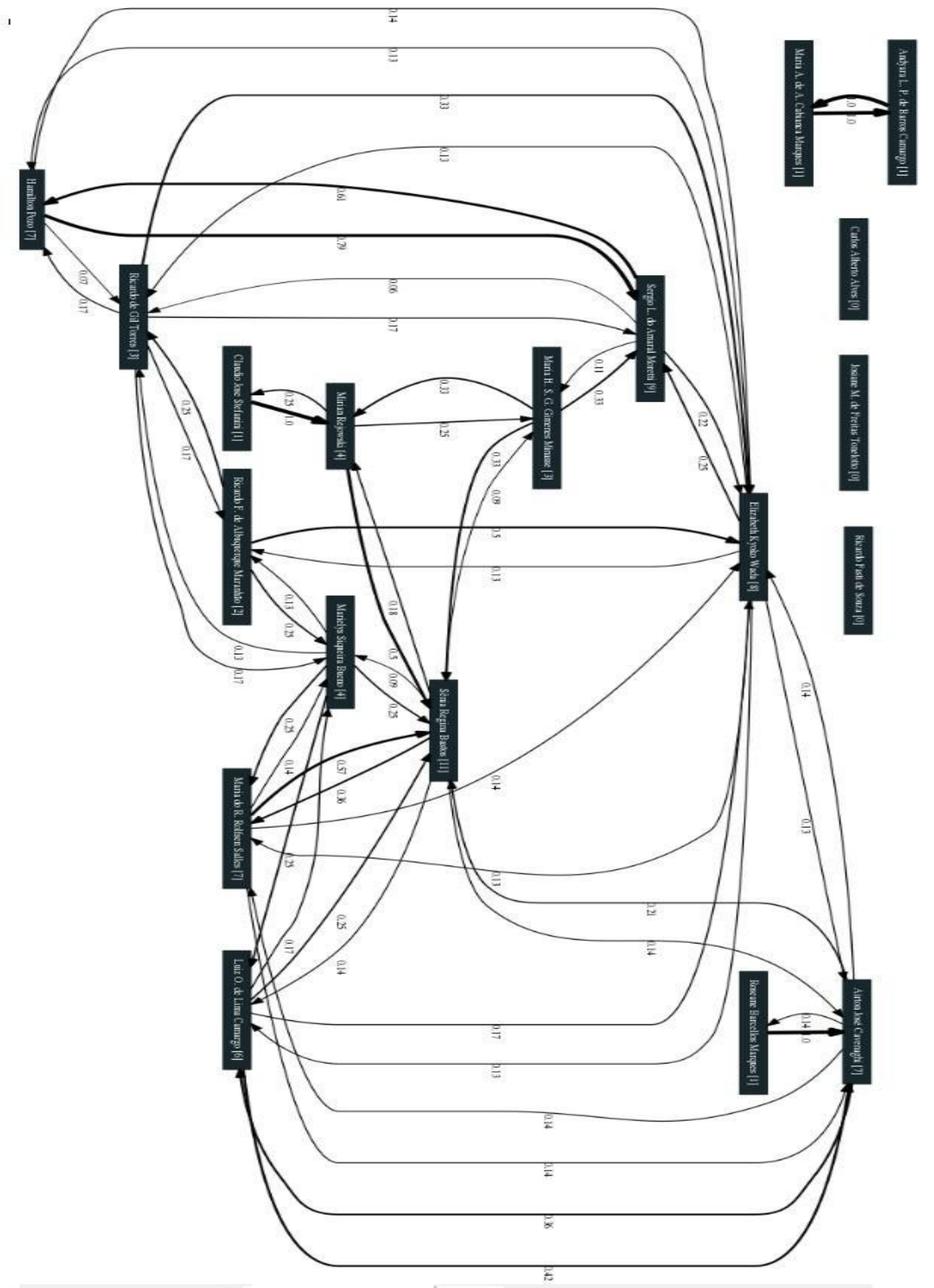

Fonte: scripLattes, 2018

Quadro 9. PageRank da UAM: 2013 a 2016 


\begin{tabular}{|l|l|}
\hline Rank de Colaboração & \multicolumn{1}{c}{ Membro } \\
\hline 1.99 & Senia Regina Bastos \\
\hline 1.52 & Sergio Luiz do Amaral Moretti \\
\hline 1.44 & Elizabeth Kyoko Wada \\
\hline 1.35 & Airton José Cavenaghi \\
\hline 1.25 & Maria do Rosario Rolfsen Salles \\
\hline 1.18 & Hamilton Pozo \\
\hline 1.11 & Luiz Octávio de Lima Camargo \\
\hline 1.0 & Maria Angela de Abreu Cabianca Marques \\
\hline 1.0 & Andyara Lena Paiva de Barros Camargo \\
\hline 0.94 & Mirian Rejowski \\
\hline 0.81 & Marielys Siqueira Bueno \\
\hline 0.65 & Maria Henriqueta Sperandio Garcia Gimenes Minasse \\
\hline 0.63 & Ricardo de Gil Torres \\
\hline 0.48 & Ricardo Frota de Albuquerque Maranhão \\
\hline 0.35 & Claudio Jose Stefanini \\
\hline 0.31 & Roseane Barcellos Marques \\
\hline 0.15 & Ricardo Fasti de Souza \\
\hline 0.15 & Josiane Maria de Freitas Tonelotto \\
\hline 0.15 & Carlos Alberto Alves \\
\hline
\end{tabular}

Fonte: ScripLattes (2018).

Nota-se que a UAM possui como os três primeiros colocados no grafo os seguintes docente: Senia Regina Bastos (11), Sergio Luiz do Amaral Moretti (9) e Elizabeth Kyoko Wada (8). No pageRank, mantém-se os mesmos autores: (1) Senia Regina Bastos alcançou 1.99; (2) Sergio Luiz do Amaral Moretti, 1.52; (3) Elizabeth Kyoko Wada, 1.44. Observemos como cada um desses professores atingiu esses índices. 
A docente Senia Regina Bastos exibiu a maior colaboração no grupo no grafo e no pageRank. Nota-se que, no grafo, ela desenvolveu pesquisas em coautoria com seis membros: Luiz Octávio de Lima Camargo, Airton José Cavenaghi, Maria do Rosario Rolfsen Salles, Marielys Siqueira Bueno, Mirian Rejoskwi e Maria Henriqueta Sperandio Garcia Gimenes Minasse; obtendo diferentes graus de colaboração. O grau de colaboração da docente Senia Bastos com Luiz Camargo é de 0,14. Com Airton Cavenaghi, tem o mesmo grau de 0,14. Já com a docente Maria Sales, tem mais que o dobro dessa colaboração: 0,36. De outro lado, com a docente Marielys Bueno, a colaboração é de 0,09. Com a Mirian Rejoswki, teve 0,18. Com Maria Henriqueta Minasse, teve 0,09 .

O docente Sergio Luiz do Amaral Moretti é o segundo no grafo de colaboração e no pageRank. Ele desenvolveu pesquisas em coautoria com 4 docentes, a saber: Hamilton Pozo, Ricardo de Gil Torres, Elizabeth Kyoko Wada e Maria Henriqueta Sperandio Garcia Minasse; tendo diferentes graus de colaboração. Com o docente Hamilton Pozo, teve 0,61. Com Ricardo Torres, foi de 0,06. Com Elizabeth Wada, foi de 0,22. Com Maria Henriqueta Minasse, foi de 0,11 . Esse docente além de publicar em coautoria com seus colegas, ele publica com os docentes da universidade (UNIVALI), no total de nove produções bibliográficas.

A docente Elizabeth Kyoko Wada foi a terceira no grafo de colaboração e no pageRank. Ela executou suas pesquisas em coautoria com sete docentes, a saber: Airton José Cavenaghi, Sergio Luiz do Amaral Moretti, Luiz Octávio de Lima Camargo, Ricardo de Gil Torres, Hamilton Pozo, Ricardo Frota de Albuquerque Maranhão e a Maria do Rosario Rolfsen Salles. Com os docentes Airton Cavenaghi, Luiz Camargo, Ricardo Torres, Hamilton Pozo e Ricardo Maranhão, a docente Elizabeth Kyoko Wada teve os mesmos graus de colaboração: 0,13. Já com Sergio Luiz Moretti e Maria Salles, o grau de colaboração foi de 0,25 .

Comparando os dados, compreendemos que, embora a docente Elizabeth Wada tenha uma rede maior de coautores (sete coautores) frente aos outros dois professores, Senia Bastos (seis coautores), Sergio Moretti (quatro coautores), ela permaneceu na terceira colocação. Isso decorreu do fato de suas parcerias serem mais fracas do que a dos outros dois docentes, além de seu 
número de publicações ser menor. Constata-se, assim, a relevância de se verificar o grau de intensidade de cada seta no grafo da figura 13, semelhantemente ao que observamos no caso dos três docentes selecionados da UNIVALI.

Os dados de UECE trazem outros resultados. O grafo e o quadro que apresentaremos a seguir trazem a colaboração dos dezenove docentes permanentes/ colaboradores/ e pesquisadores que permaneceram no programa no período de 2013 a 2016. Desse grupo, como podemos verificar, sete docentes desenvolveram atividades de colaboração por meio de coautoria de trabalhos no período analisado com os membros do grupo. Em outros termos, doze não realizaram produções em coautoria. Desses sete que produziram, analisaremos os três primeiros colocados. A seguir, reproduzimos o grafo e o quadro obtidos pelo scriptLattes: 
Figura 13. Grafo de colaboração da UECE: 2013 a 2016

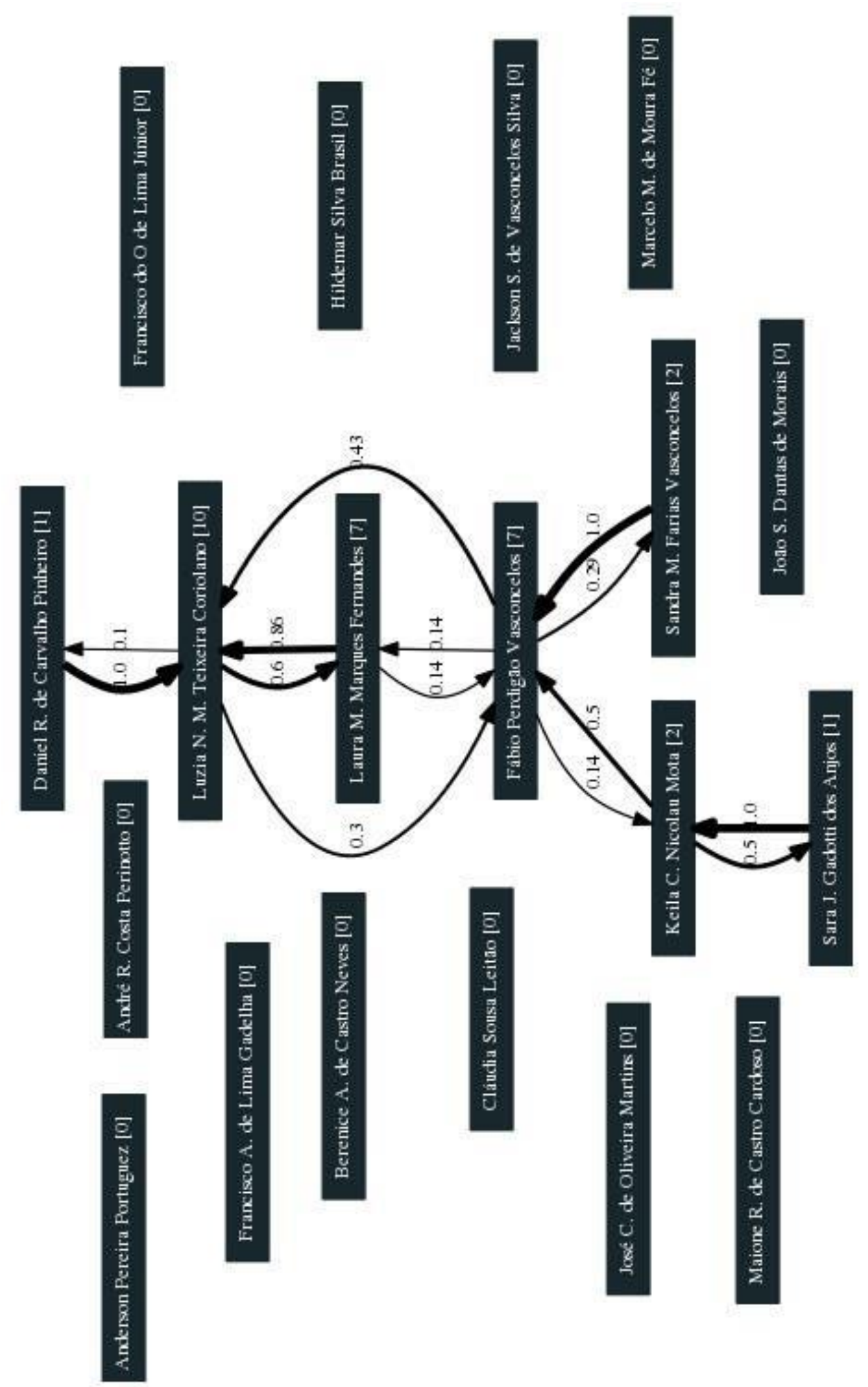

Fonte: ScripLattes (2018). 
Quadro 10. PageRank da UECE: 2013 a 2016

\begin{tabular}{l|l}
\hline Rank de Colaboração & \multicolumn{1}{c}{ Membro } \\
\hline 1.99 & Luzia Neide Menezes Teixeira Coriolano \\
\hline 1.59 & Fábio Perdigão Vasconcelos \\
\hline 1.36 & Laura Mary Marques Fernandes \\
\hline 0.74 & Keila Cristina Nicolau Mota \\
\hline 0.54 & Sandra Maia Farias Vasconcelos \\
\hline 0.46 & Sara Joana Gadotti dos Anjos \\
\hline 0.32 & Daniel Rodriguez de Carvalho Pinheiro \\
\hline 0.15 & Marcelo Martins de Moura Fe \\
\hline 0.15 & Maione Rocha de Castro Cardoso \\
\hline 0.15 & João Silvio Dantas de Morais \\
\hline 0.15 & José Clerton de Oliveira Martins \\
\hline 0.15 & Jackson Savio de Vasconcelos Silva \\
\hline 0.15 & Hildemar Silva Brasil \\
\hline 0.15 & Francisco do O de Lima Júnior \\
\hline 0.15 & Francisco Agileu de Lima Gadelha \\
\hline 0.15 & Claudia Sousa Leitão \\
\hline 0.15 & Berenice Abreu de Castro Neves \\
\hline 0.15 & André Riani Costa Perinotto \\
\hline 0.15 & Anderson Pereira Portuguez \\
\hline
\end{tabular}

Fonte: scripLattes (2018).

A UECE possui como os três primeiros colocados no grafo os seguintes docentes: Luzia Neide Menezes Teixeira Coriolano (10), Laura Fernandes (07) e Fábio Perdigão Vasconcelos (07). No pageRank, mantém os mesmos docentes, mas muda-se a ordem: (1) Luzia Neide Menezes Teixeira Coriolano obteve 1.99; (2) Fábio Perdigão Vasconcelos, 1.59; (3) Laura Fernandes, 1.36. Observemos como cada um desses professores galgou esses índices. 
A docente Luzia Neide Menezes Teixeira Coriolano exibe a maior colaboração no grupo no grafo e é também a primeira colocada no pageRank. Nota-se, no grafo, que ela desenvolveu pesquisas em coautoria com três docentes: Daniel Rodriguez de Carvalho Pinheiro, Fábio Perdigão Vasconcelos e Laura Mary Marques Fernandes, tendo diferentes grau de colaboração. Com Daniel Pinheiro, teve um grau de colaboração de 0,6. Com Fábio Vasconcelos, foi de 0,3. Com Laura Fernandes, foi de 0,1. Essa autora além de publicar em coautoria com seus colegas, ela também publica com os docentes das universidades (UCS, UFPR, UFRN, UNIVALI), no total de dez produções bibliográficas.

A docente Laura Fernandes é a segunda no grafo de colaboração e a terceira no pageRank. Ela desenvolveu pesquisas em coautoria com dois docentes a saber: Luzia Neide Menezes Teixeira Coriolano e Fábio Perdigão Vasconcelos; tendo diferentes graus de colaboração com esses parceiros. Com a docente Luzia Coriolano, seu grau de colaboração é bastante estabelecido, alcançando 0,86. Já com com Fábio Vasconcelos, o grau foi de apenas 0,14.

O docente Fábio Perdigão Vasconcelos é o terceiro no grafo de colaboração e o segundo no pageRank. Ele desenvolveu pesquisas em coautoria com quatro docentes a saber: Luzia Neide Menezes Teixeira Coriolano, Laura Mary Marques Fernandes, Keila Cristina Nicolau Mota e Sandra Maia Farias Vasconcelos, tendo diferentes graus de colaboração. Com a docente Luzia Coriolano, teve grau de colaboração 0,43. Com Laura Fernandes e Keila Mota, obteve o mesmo índice: 0,14. Com Sandra Vasconcelos, foi de 0,29 .

Esses dados demonstram que o grafo e o pageRank levantam diferentes requisitos para avaliar a colaboração. Exemplo disso é o caso de Laura Fernandes e Fábio Perdigão Vasconcelos que possuem a mesma quantidade de produção bibliográfica em regime de colaboração: sete publicações. No entanto, no grafo, Laura Fernandes está em segundo lugar, porque tem um grau de colaboração mais fortalecido com um de seus colaboradores: com a docente Luzia Coriolano, atingiu 0,86; enquanto que Fábio Vasconcelos com a mesma docente, Luzia Coriolano, teve grau de colaboração máximo de 0,43 . Já no pageRank, Fábio Vasconcelos está à frente de Laura Fernandes, porque sua 
rede colaboradores é maior e estes têm colaborações também mais extensas do que as redes dos colaboradores de Laura Fernandes.

Observa-se que os dados de UCS tem outra configuração. O grafo e o quadro que apresentaremos a seguir trazem a colaboração dos dezesseis docentes permanentes/colaboradores/ inativos no programa no período de 2013 a 2016. Desse grupo, como poderemos verificar, nove docentes desenvolveram atividades de colaboração por meio de coautoria de trabalhos no período analisado com os membros do grupo. Ou seja, sete não realizaram produções em coautoria. Desses nove que produziram, analisaremos os três primeiros colocados. A seguir, reproduzimos o grafo e o quadro obtidos pelo scriptlattes na Figura 14: 
Figura 14. Grafo de colaboração da UCS: 2013 a 2016

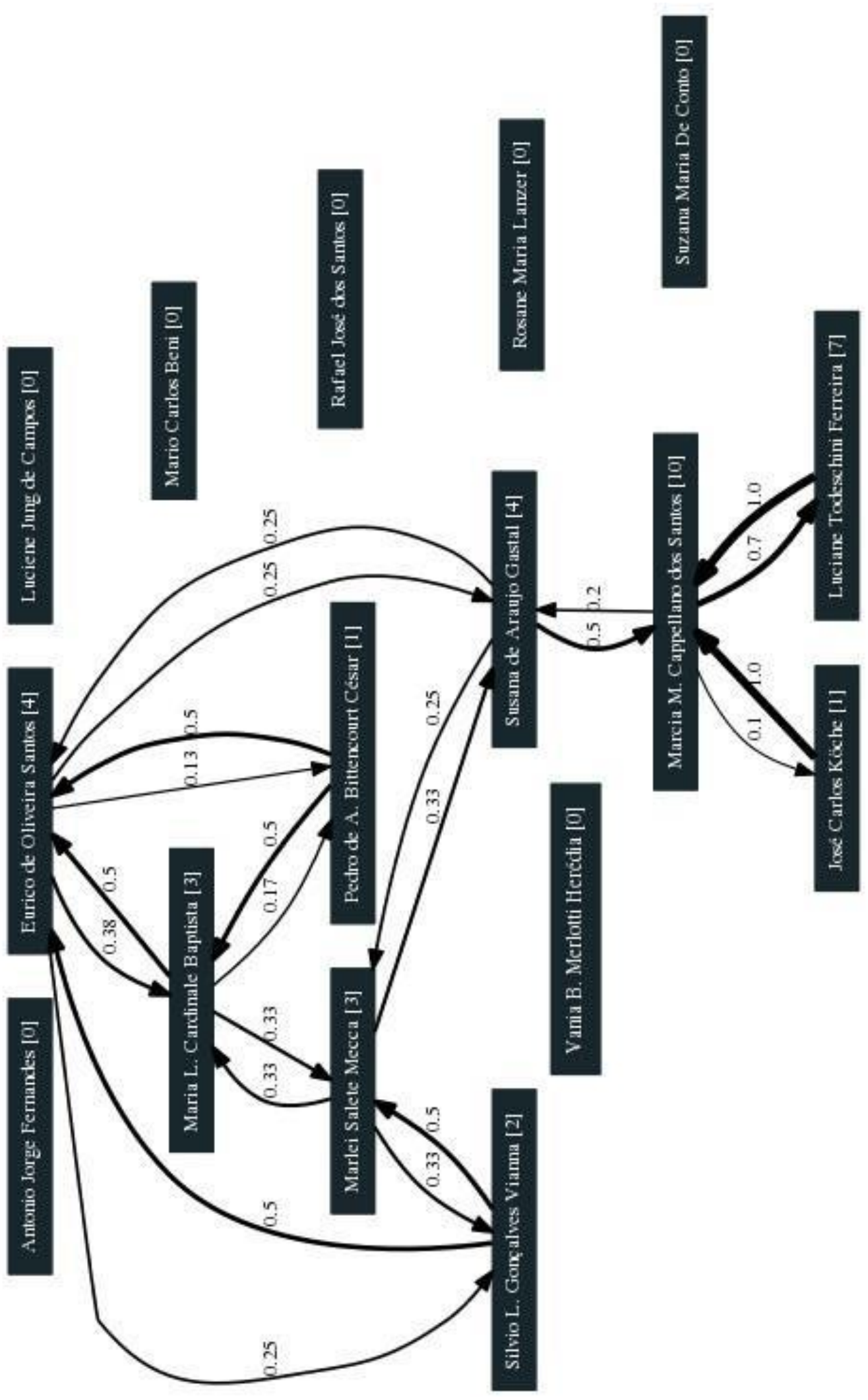

Fonte: scripLattes (2018). 
Quadro 11. PageRank da UCS: 2013 a 2016

\begin{tabular}{|l|l|}
\hline Rank de Colaboração & \multicolumn{1}{c|}{ Membro } \\
\hline 1.99 & Marcia Maria Cappellano dos Santos \\
\hline 1.34 & Luciane Todeschini Ferreira \\
\hline 1.27 & Eurico de Oliveira Santos \\
\hline 1.03 & Susana de Araujo Gastal \\
\hline 1.0 & Maria Luiza Cardinale Baptista \\
\hline 0.94 & Marlei Salete Mecca \\
\hline 0.69 & Silvio Luiz Gonçalves Vianna \\
\hline 0.43 & Pedro de Alcântara Bittencourt César \\
\hline 0.32 & José Carlos Koche \\
\hline 0.15 & Vania Beatriz Merlotti Heradia \\
\hline 0.15 & Suzana Maria De Conto \\
\hline 0.15 & Rosane Maria Lanzer \\
\hline 0.15 & Rafael José dos Santos \\
\hline 0.15 & Mario Carlos Beni \\
\hline 0.15 & Luciene Jung de Campos \\
\hline 0.15 & Antonio Jorge Fernandes \\
\hline \hline
\end{tabular}

Fonte: ScripLattes (2018).

A UCS possui como os três primeiros colocados no grafo os seguintes docente: Marcia Maria Cappellano dos Santos (10), Luciane Todeschini Ferreira (7) e Eurico de Oliveira Santos (4). No pageRank, mantém-se os mesmos autores na mesma ordem: (1) Marcia Maria Cappellano dos Santos obteve 1.99; (2) Luciane Todeschini Ferreira, 1.34; (3) Eurico de Oliveira Santos, 1.27. Observemos como cada um desses professores chegou até esses índices.

A docente Marcia Maria Cappellano dos Santos demonstra ter a maior colaboração no grupo no grafo e é ainda a primeira colocada no pageRank. Observa-se que, no grafo, ela desenvolveu pesquisas em coautoria com três docentes: José Carlos Koche, Susana de Araujo Gastal e Luciane Todeschini 
Ferreira; obtendo diferentes grau de colaboração com estes. Em coautoria com José Carlos Koche, teve 0,1. Com Susana Gastal, esse grau de colaboração foi de 0,2. Com Luciane Ferreira, foi de 0,7.

A docente Luciane Todeschini Ferreira é a segunda no grafo de colaboração e no pagerank. Ela desenvolveu pesquisas em coautoria com uma única docente, a saber: Márcia Maria Cappellano dos Santos. Isso equivale a dizer que o grau de colaboração que ela criou com essa docente foi de 1,0, ou seja, de $100 \%$.

O docente Eurico de Oliveira Santos é o terceiro colocado tanto no grafo quanto no pageRank. Ele desenvolveu pesquisas em coautoria com quatro docentes, a saber: Pedro de Alcântara Bittencourt César, Silvio Luiz Gonçalves Viana, Susana de Araújo Gastal e Maria Luiza Cardinale Baptista, tendo, com eles, diferentes graus de colaboração. Com o docente Pedro César, teve o grau de colaboração de 0,13. Com a docente Susana Gastal e Silvio Vianna, tiveram o mesmo grau de colaboração: 0,25. Com Maria Luiza Baptista, teve 0,38.

Notamos, com esses dados, que, embora a docente Luciane Ferreira tenha uma rede menor de coautores (coautor único) frente aos outros dois professores, Marcia dos Santos (três coautores) e Erico Santos (quatro coautores), ela permaneceu na segunda colocação no grafo de colaboração e no pagerank. Isso decorreu do fato de sua parceria ser mais forte e também mais produtiva do que a soma das parceiras e publicações do terceiro colocado, Erico Santos. Outra inferência é que o Erico Santos possui quatro docentes e a Suzana Gastal também, só que esta tem menos setas do que a do docente Eurico Santos, por isso ela ficou em quarto lugar no grafo e Eurico Santos em terceiro. Os indicadores do pageRank também atribuíram para Suzana Gastal o quarto lugar, mostrando que sua rede de colaboradores é menor do que a de Eurico Santos. Nesses casos, observamos que os dois indicadores entraram em acordo em suas análises.

Verifica-se outro contexto com os dados de USP. O grafo e o quadro que apresentaremos a seguir trazem a colaboração dos quatorze docentes permanentes/ colaboradores/ inativos no programa no período de 2013 a 2016. Desse grupo, como poderemos verificar, dez docentes desenvolveram atividades de colaboração por meio de coautoria de trabalhos no período analisado com os membros do grupo. Ressalta-se, assim, que quatro não 
realizaram produções em coautoria. Desses dez que produziram, analisaremos os três primeiros colocados. A seguir, reproduzimos o grafo e o quadro obtidos pelo scriptLattes:

Figura 15. Grafo de colaboração da USP: 2013 a 2016

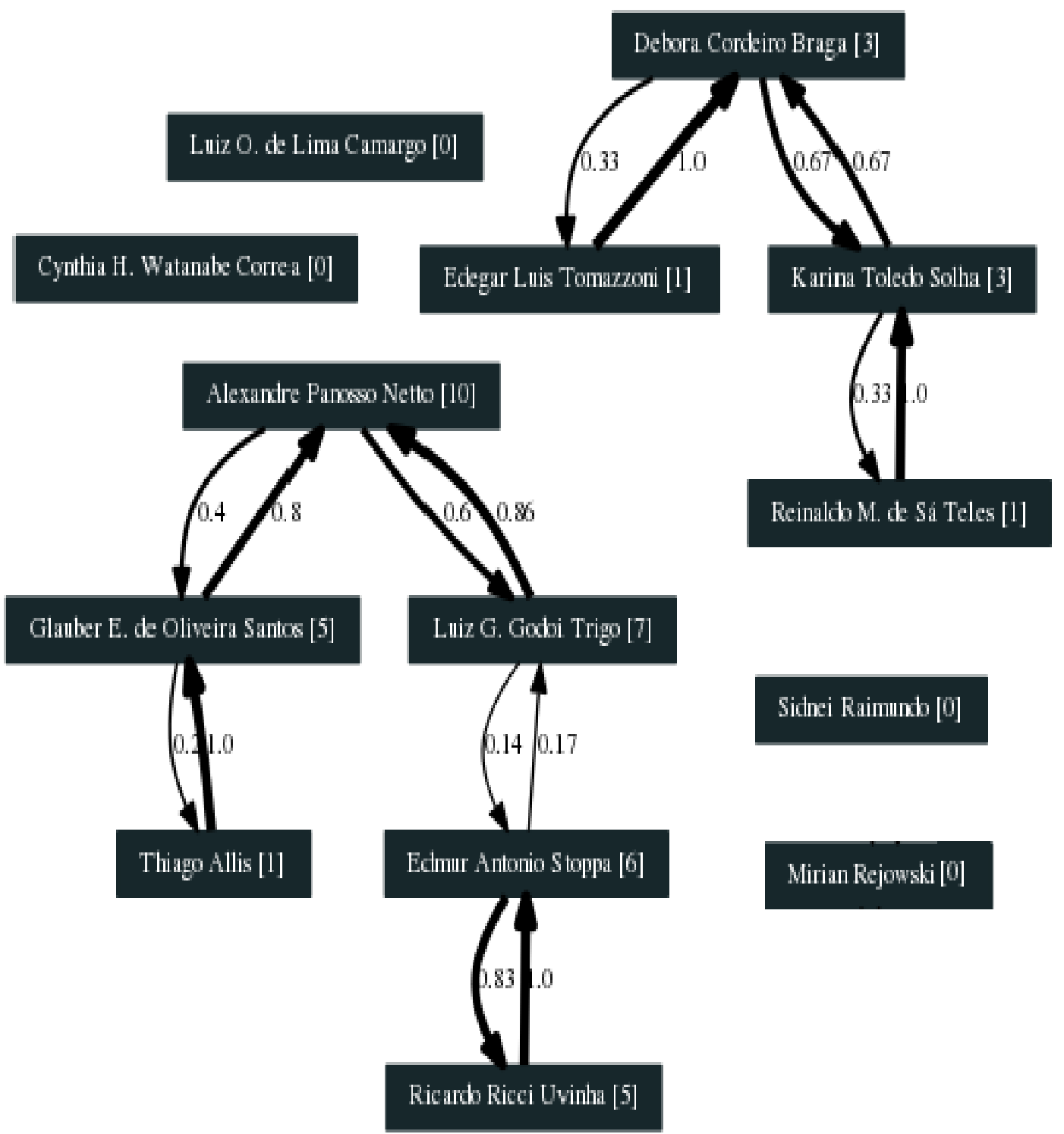

Fonte: scripLattes (2018).

Quadro 12. PageRank da USP: 2013 a 2016 


\begin{tabular}{ll}
\hline Rank de Colaboração & \multicolumn{1}{c}{ Membro } \\
\hline 1.78 & Alexandre Panosso Netto \\
\hline 1.53 & Luiz Gonzaga Godoi Trigo \\
\hline 1.32 & Edmur Antonio Stoppa \\
\hline 1.22 & Glauber Eduardo de Oliveira Santos \\
\hline 1.21 & Debora Cordeiro Braga \\
\hline 1.00 & Karina Toledo Solha \\
\hline 0.98 & Ricardo Ricci Uvinha \\
\hline 0.91 & Edegar Luiz Tomazzonni \\
\hline 0.47 & Reinaldo Miranda de Sá Teles \\
\hline 0.32 & Thiago Allis \\
\hline 0.15 & Sidnei Raimundo \\
\hline 0.15 & Cinthia Harumy Watanabe Corrêa \\
\hline 0.15 & Luiz Octávio de Lima Camargo \\
\hline 0.15 & Mirian Rejowski \\
\hline
\end{tabular}

Fonte: ScripLattes (2018).

A USP possui como os três primeiros colocados no grafo os seguintes docentes: Alexandre Panosso Netto (10), Luiz Gonzaga Godoi Trigo (7) e Edmur Antonio Stoppa (6). No pageRank, mantém-se os mesmos autores na mesma ordem: (1) Alexandre Panosso Netto obteve 1.78; (2) Luiz Gonzaga Godoi Trigo, 1.53; (3) Edmur Antonio Stoppa, 1.32. Observemos como cada um desses professores galgou esses índices.

O docente Alexandre Panosso atingiu a maior colaboração no grupo no grafo e no pageRank. Observa-se, no grafo, que ele desenvolveu pesquisas em coautoria com dois docentes, a saber: Glauber Eduardo de Oliveira Santos e Luiz Gonzaga Godoi Trigo, estabelecendo diferentes graus de colaboração. Com Luiz Trigo, o grau de colaboração é de 0,6. Com Glauber Oliveira, é de 0,4.

O docente Luiz Trigo é o segundo no grafo de colaboração e no pageRank. Ele construiu pesquisas em coautoria também com dois docentes: 
Alexandre Panosso e Edmur Stopa, tendo, com estes, diferentes graus de colaboração. Com o docente Alexandre Panosso, o grau de colaboração é fortalecido: 0,86. Com Edmur Stopa, por outro lado, o grau de colaboração é 0,14 .

O docente Edmur Stoppa é o terceiro no grafo de colaboração e no pageRank. Ele fez pesquisas em coautoria com Ricardo Uvinha e Luiz Trigo, tendo diferentes graus de colaboração com esses pesquisadores. Com o docente Ricardo Uvinha, o grau de colaboração foi de 0,83; em contrapartida, com o Luiz Trigo, o grau foi de apenas 0,17.

Esses dados apontam que existe uma centralidade das parcerias nesse programa. Comparando essas parcerias com as outras analisadas, nota-se que o número de coautores é menor, embora se tenha um maior número de publicações. Além disso, notamos que, mesmo sendo poucos coautores, uma determinada dupla de coautores se sobressai em relação as demais, atingindo elevados índices, como, por exemplo, o grau de colaboração de Alexandre Panosso e Luiz Trigo $(0,6)$; de Luiz Trigo e Alexandre Panosso $(0,86)$; e de Edmur Stoppa e Ricardo Uvinha $(0,83)$.

Outra dado que não está explícito no grafo de colaboração, mas com a inferência depreendida, pode-se destacar o docente Edegar Tomazzoni, Esse autor publica em coautoria com a docente Debora Braga no qual equivale a importância de $100 \%$. Ele é o docente que mais publica com os outros docentes das universidades analisadas. Como por exemplo: A UFPR e UFRN. No total de nove produções bibliográficas.

Os dados de UFRN apontam outra dimensão dos indicadores e seus respectivos resultados. O grafo e o quadro que apresentaremos a seguir trazem a colaboração dos 22 docentes permanentes/ colaboradores/ inativos no programa no período de 2013 a 2016. Desse grupo, como poderemos verificar, dezesseis docentes desenvolveram atividades de colaboração por meio de coautoria de trabalhos no período analisado com os membros do grupo. Ou seja, seis não realizaram produções em coautoria. Desses dezesseis que produziram, analisaremos os três primeiros colocados. A seguir, reproduzimos o grafo e o quadro obtidos pelo scriptLattes: 
Figura 16. Grafo de colaboração da UFRN: 2013 a 2016

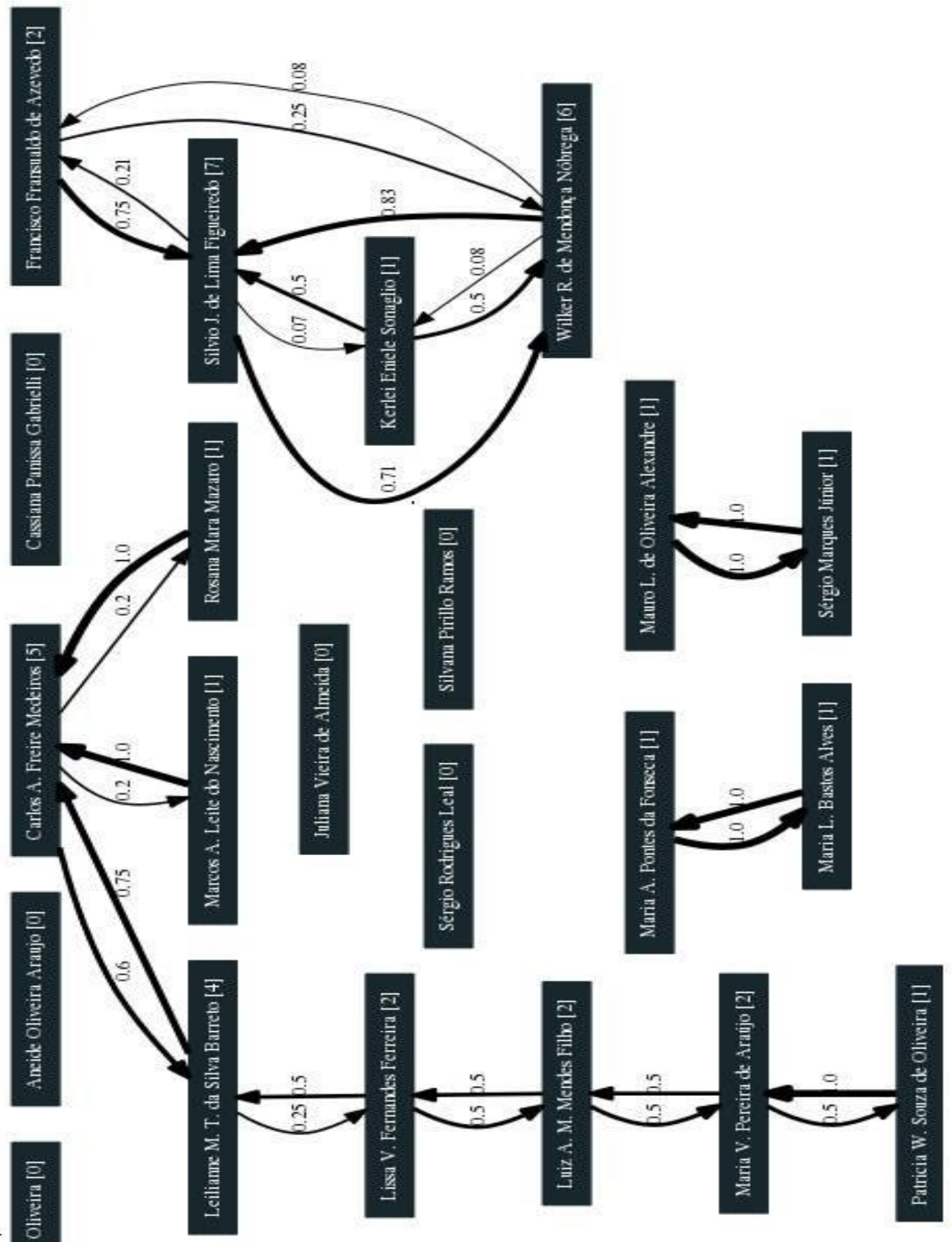

Fonte: scripLattes (2018).

Quadro 13. PageRank da UFRN: 2013 a 2016

Rank de Colaboração Membro 


\begin{tabular}{l|l}
\hline 1.66 & Silvio José de Lima Figueiredo \\
\hline 1.51 & Leilianne Michelle Trindade da Silva Barreto \\
\hline 1.43 & Wilker Ricardo de Mendonça Nobrega \\
\hline 1.1 & Maria Valéria Pereira de Araújo \\
\hline 1.0 & Sérgio Marques Júnior \\
\hline 1.0 & Mauro Lemuel de Oliveira Alexandre \\
\hline 1.0 & Maria Lúcia Bastos Alves \\
\hline 1.0 & Maria Aparecida Pontes da Fonseca \\
\hline 1.0 & Luiz Augusto Machado Mendes Filho \\
\hline 0.9 & Lissa Valéria Fernandes Ferreira \\
\hline 0.62 & Patricia Whebber Souza de Oliveira \\
\hline 0.55 & Francisco Fransualdo de Azevedo \\
\hline 0.48 & Rosana Mara Mazaro \\
\hline 0.48 & Marcos Antonio Leite do Nascimento \\
\hline 0.35 & Kerlei Eniele Sonaglio \\
\hline 0.15 & Sergio Rodrigues Leal \\
\hline 0.15 & Silvana Pirillo Ramos \\
\hline 0.15 & Juliana Vieira de Almeida \\
\hline 0.15 & Cassiana Panissa Gabrielli \\
\hline 0.15 & Aneide Oliveira Araujo \\
\hline 0.15 & Almir Felix Batista de Oliveira \\
\hline Fon & \\
\hline 0.0 &
\end{tabular}

Fonte: scripLattes (2018).

A UFRN possui como os três primeiros colocados no grafo os seguintes docentes: Silvio José de Lima Figueiredo (7), Wilker Ricardo de Mendonça Nobrega (6) e Carlos Alberto Freire Medeiros (5). No pageRank, os autores mudam e também temos outra ordem, (1) o Carlos Alberto Freire Medeiros obtém 1.93, (2) Silvio José de Lima Figueiredo com o pageRank, 1.66; (3) 
Leilianne Michelle Trindade da Silva Barreto, 1.51. Observemos como cada um desses professores atingiu esses índices.

O docente Silvio José de Lima Figueiredo teve a maior colaboração no grupo no grafo e foi o segundo no pageRank. Observa-se que ele desenvolveu pesquisas em coautoria com três membros: Francisco Fransualdo de Azevedo, Kerlei Eniele Sonaglio e Wilker Ricardo de Mendonça Nóbrega; tendo diferentes graus de colaboração. Com o docente Francisco Azevedo, teve o grau de colaboraçao 0,21. Já com Kerlei Sonaglio, teve 0,07. Com Wilker Nobrega, teve 0,71 .

O professor Wilker Ricardo de Mendonça Nóbrega é o segundo no grafo de colaboração, porém é o quarto no pageRank. Ele desenvolveu suas pesquisas com três docentes, a saber: Francisco Fransualdo de Azevedo, Silvio José de Lima Figueiredo e Kerlei Eniele Sonaglio. Os graus de colaboração com Francisco Azevedo e com Kerlei Sonaglio é de 0,08. Já com o docente Silvio Figueiredo, o grau é de 0,83 , sendo essa a parceria mais forte.

O docente Carlos Alberto Freire Medeiros é o terceiro no grafo de colaboração e o primeiro no pageRank. Ele realizou pesquisas em coautoria com três docentes, a saber: Marcos Antonio Leite do Nascimento, Rosana Mara Mazaro e Leilianne Michelle Trindade da Silva Barreto. O grau de colaboração do docente Carlos Alberto Medeiros com os pesquisadores Marcos Nascimento e a Rosana Mazaro tiveram o mesmo grau de colaboração: 0,2. Já com Leilianne Barreto, é de 0,6.

Analisando esses dados, compreendemos que, embora a docente Leilianne Michelle Trindade da Silva Barreto não tenha uma rede maior de coautores (quatro coautores) frente aos outros três professores, Silvio José de Lima Figueiredo (sete coautores), Wilker Ricardo de Mendonça Nobrega (seis coautores) e Carlos Alberto Freire Medeiros (cinco coautores), ela permaneceu na terceira colocação do pageRank, ultrapassando o docente Wilker Ricardo de Mendonça Nobrega. Isso decorreu devido a suas parcerias serem mais fortes do que as do docente Wilker Ricardo de Mendonça Nobrega, embora seu número de publicações ser menor. Constata-se, assim, a relevância da autora publicar com docentes que escrevem com outros docentes do programa, formando assim, uma rede de colaboração mais extensa. 
Os dados de UNB possuem uma dimensão distinta. O grafo e o quadro que apresentaremos a seguir trazem a colaboração dos 22 docentes permanentes/ colaboradores/ inativos no programa no período de 2013 a 2016. Desse grupo, como poderemos verificar, seis docentes desenvolveram atividades de colaboração por meio de coautoria de trabalhos no período analisado com os membros do grupo. Ou seja, dezesseis não realizaram produções em coautoria. Desses seis que produziram, analisaremos os três primeiros colocados. A seguir, reproduzimos o grafo e o quadro obtidos pelo scriptLattes:

Figura 17. Grafo de colaboração da UNB: 2013 a 2016 




Fonte: ScripLattes (2018).

Quadro 14. PageRank da UNB: 2013 a 2016 


\begin{tabular}{|l|l|}
\hline Rank de Colaboração & \multicolumn{1}{|c}{ Membro } \\
\hline 1.34 & Luiz Carlos Spiller Pena \\
\hline 1.26 & Marutschka Martini Moesch \\
\hline 1.06 & João Paulo Faria Tasso \\
\hline 1.0 & Gilson Zehetmeyer Borda \\
\hline 1.0 & Donaria Coelho Duarte \\
\hline 0.34 & lara Lucia Gomes Brasileiro \\
\hline 0.15 & Othon Henry Leonardos \\
\hline 0.15 & Neuza de Farias Araújo \\
\hline 0.15 & Neio Lucio de Oliveira Campos \\
\hline 0.15 & Mozart Fazito Rezende Filho \\
\hline 0.15 & Mario Carlos Beni \\
\hline 0.15 & Maria de Lourdes Rollemberg Mollo \\
\hline 0.15 & Maria Elenita Menezes Nascimento \\
\hline 0.15 & Lana Magaly Pires \\
\hline 0.15 & Karina e Silva Dias \\
\hline 0.15 & Jose Aroudo Mota \\
\hline 0.15 & Helena Araújo Costa \\
\hline 0.15 & Everaldo Batista da Costa \\
\hline 0.15 & Eloisa Pereira Barroso \\
\hline 0.15 & Ellen Fensterseifer Woortmann \\
\hline 0.15 & Biagio Mauricio Avena \\
\hline 0.15 & André de Almeida Cunha \\
\hline Fon & \\
\hline 0.15 &
\end{tabular}

Fonte: scripLattes (2018).

A UNB possui como os três primeiros colocados no grafo os seguintes docentes: na primeira colocação, estão empatados Donaria Coelho Duarte (7) e Gilson Zehetmeyer Borda (7); em segundo lugar, Luiz Carlos Spiller Pena (6); e em terceiro, Marutschka Martini Moesch (6). No pageRank, mudam-se alguns 
docentes e suas respectivas ordens: (1) Luiz Carlos Spiller Pena obteve 1.34;

(2) Marutschka Martini Moesch, 1.26; (3) João Paulo Faria Tasso, 1.06. Observemos como cada um desses professores alcançou esses índices.

A docente Donaria Coelho Duarte e o docente Gilson Borda exibem o maior número de colaborações no grupo no grafo com também o maior grau de colaboração: 1,0, o que corresponde a 100\%. Em contrapartida, no pageRank, o docente Gilson Borda é o quarto e a Donaria Coelho Duarte é a quinta colocados. Essa discrepância ocorre, porque a colaboração entre esses docentes é biunívocas, isto é, eles só produzem juntos e com mais nenhum outro docente do programa. Esse tipo de colaboração é contabilizado, sem restrições, no grafo de colaboração, já no pageRank, essa colaboração não é examinada da mesma forma, uma vez que diferentemente do grafo, o pageRank observa também a rede de colaboração de cada coautor. Essas relações de colaboração biunívocas ocorreram também, como vimos, na UCS.

O docente Luiz Carlos Spiller Pena é o terceiro no grafo de colaboração, mas é o primeiro colocado no pageRank. Nota-se que esse professor desenvolveu pesquisas em coautoria com três docentes: João Paulo Faria Tasso, Marutschka Martini Moesch e lara Lucia Gomes Brasileiro, obtendo diferentes graus de colaboração. $\mathrm{O}$ grau de colaboração do docente Luiz Carlos Pena com João Tasso é de 0,33. Com Marutschka Moesch, teve grau de colaboração de 0,5 . Já o grau de colaboração com a docente lara Brasileiro, foi de apenas 0,17 .

A docente Marutschka Moesch é a quarta no grafo de colaboração e a segunda colada no pageRank. Ela realizou pesquisas em coautoria com dois docentes: Luiz Spiller Pena e João Tasso, com graus de colaboração semelhantes. A docente Marutschka Moesch com os docentes supracitados teve o grau de 0,5 , o que equivale dizer que, com cada um, publicou $50 \%$ de sua produção bibliográfica em coautoria.

O docente João Tasso é o quinto no grafo de colaboração e o terceiro no pageRank. Ele escreveu em coautoria com dois docentes, a saber: Luiz Pena e Marutschka Moesch, tendo diferentes graus de colaboração. Com o docente Pena, obteve 0,4. Com Marutschka Moesch, teve 0,6. Isso quer dizer que publicou mais na dupla com Marutschka Moesch do que com a de Luiz Pena. 
Notamos várias inferências com esses dados da UNB. Os docentes Donaria Coelho Duarte e o docente Gilson Borda possuem o mesmo grau de colaboração, só que esses dois docentes publicam somente entre si e isso foi verificado desfavoravelmente no pageRank, o que não foi observado como negativo no grafo de colaboração. Isso quer dizer que, a depender dos critérios do indicador adotado, a colaboração biunívoca pode ser bem ou mal avaliadas. Por isso, é interessante diversificar os indicadores, adotando mais de um, para não tornar os resultados obtidos absolutos, uma vez que os dados avaliados são relativos a depender dos critérios de análise assumidos por cada indicador.

Tem-se, também, os dados de UFF que possuem uma dimensão peculiar. O grafo e o quadro que apresentaremos a seguir trazem a colaboração dos dez docentes permanentes/ colaboradores/ inativos no programa no período de 2013 a 2016. Desse grupo, como poderemos verificar, nove docentes desenvolveram atividades de colaboração por meio de coautoria de trabalhos no período analisado com os membros do grupo. Ou seja, somente um docente não realizou produção em coautoria. Desses nove que produziram, analisaremos os três primeiros colocados. A seguir, reproduzimos o grafo e o quadro obtidos pelo scriptLattes:

Figura 18. Grafo de colaboração da UFF: 2013 a 2016

Adonai T. de Siqueira e Sousa [0]

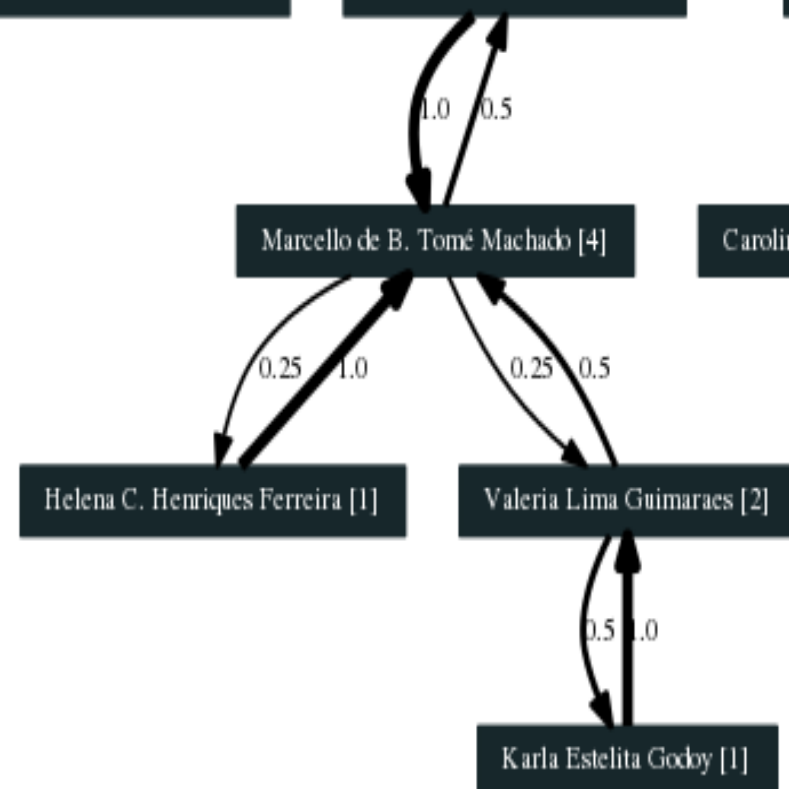

Fonte: scripLattes (2018). 
Quadro 15. PageRank da UFF: 2013 a 2016

\begin{tabular}{|l|l|}
\hline Rank de Colaboração & \multicolumn{1}{c|}{ Membro } \\
\hline 1.86 & Marcello de Barros T. Machado \\
\hline 1.05 & Valeria Lima Guimaraes \\
\hline 1.0 & Aguinaldo Cesar Fratucci \\
\hline 1.0 & Osiris Ricardo Bezerra Marques \\
\hline 1.0 & Carolina Lescura de Carvalho Castro \\
\hline 1.0 & Bernardo Lazary Cheibub \\
\hline 0.94 & Verônica Feder Mayer \\
\hline 0.6 & Karla Estelita Godoy \\
\hline 0.55 & Helena C. Henriques Ferreira \\
\hline 0.15 & Adonai Teles de Siqueira e Sousa \\
\hline
\end{tabular}

Fonte: scripLattes (2018).

A UFF possui como os três primeiros colocados no grafo os seguintes docente: em primeiro lugar, ficou Marcello de Barros Tome Machado (4); em segundo lugar, Aguinaldo Cesar Fratucci (2); em terceiro lugar, ficaram empatados Osiris Marques (2) e Verônica Feder (2). No pageRank, mudam-se os autores também suas respectivas ordens: (1) Marcello de Barros T. Machado obteve 1.86; (2) Valeria Lima Guimaraes, 1.05; (3) Aguinaldo Cesar Fratucci, 1.0. Observemos como cada um desses professores alcançou esses índices.

O docente Marcello de Barros Tome Machado teve a maior colaboração no grupo no grafo e é o primeiro colocado no pageRank. Ele desenvolveu pesquisas em coautoria com três docentes: Aguinaldo Cesar Frattuci, Helena Catão Henriques Ferreira e Valeria Lima Guimarães. O grau de colaboração do docente Marcelo Machado com Aguinaldo Frattuci é de 0,5, correspondendo a $50 \%$ de suas publicações em coautoria. Com Helena Ferreira e Valeria Guimarães, o grau de colaboração é o mesmo: 0,25 para cada. Nota-se, assim, que Marcelo Machado produz mais em coautoria com Aguinaldo Frattuci, mas sua colaboração não é biunívoca, uma vez que ele também se associa com Helena Ferreira e Valeria Guimarães. 
O docente Aguinaldo Cesar Frattuci é o segundo no grafo de colaboração e o terceiro no pageRank. Ele desenvolveu pesquisas em coautoria com apenas um docente, a saber: Marcello de Barros Tome Machado. O grau de colaboração foi esse docente foi 1,0, correspondendo a $100 \%$ de sua colaboração. Essa é uma relação unívoca por parte de Aguinaldo Frattuci, porque, embora este só produza com Marcelo Machado; Marcelo Machado produz, como vimos, com mais duas docentes: Helena Ferreira e Valeria Guimarães. Desse modo, depreendemos que as relações unívocas são melhor avaliadas no grafo de colaboração do que as biunívocas, uma vez que aquelas geram uma rede de colaboração maior do que estas, Conforme Figura 20.

Figura 19. Exemplos de Relações Unívocas e Biunívocas

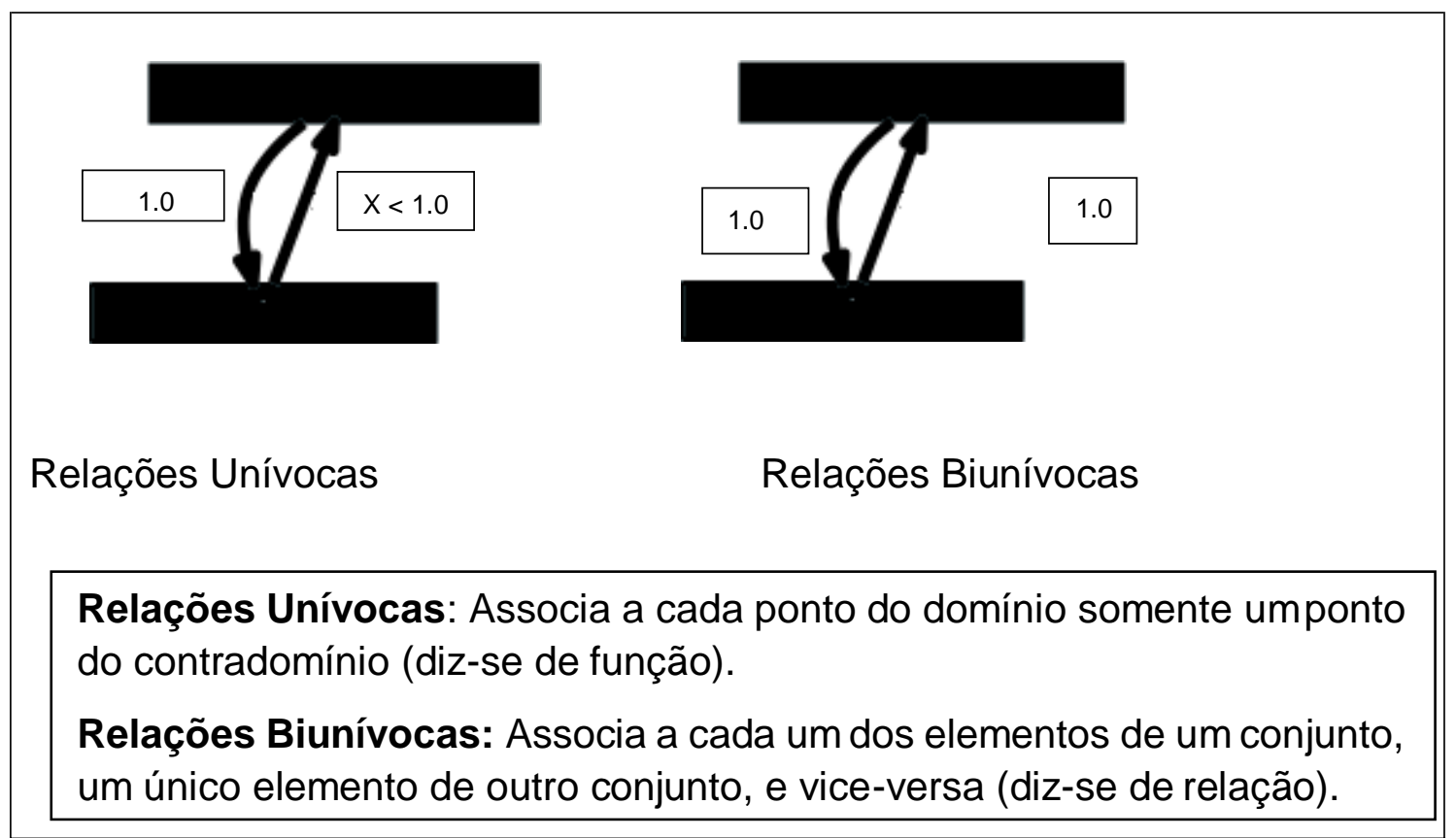

Fonte: Juliana Ferreira dos Santos, 2018

A docente Valéria Lima Guimarães é a segunda no pageRank e a quarta no grafo de colaboração. Ela desenvolveu pesquisas em coautoria com dois docentes: Marcelo de Barros Tome Machado e Karla Estelita Godoy, tendo, com eles, graus de colaboração semelhantes. Com os docentes Marcelo Machado e Karla Godoy, o grau de colaboração foi de 0,5 , o equivalente a dizer $50 \%$ da produção bibliográfica com cada coautor. Ela ficou em quarto lugar no grafo de colaboração, porque o grau de suas colaborações são mais fracos do que os de Aguinaldo Frattuci, Osiris Marques e Verônica Feder, embora todos eles tenham o mesmo número de publicações em coautoria: duas produções bibliográficas. 
Os docentes Osiris Marques e Verônica Feder ficaram empatados em terceiro lugar no grafo de colaboração, em contrapartida ficaram, no pageRank, quarto e quinto lugar, respectivamente. Essa diferença ocorreu, porque a colaboração entre esses docentes é biunívoca, ou seja, eles só produzem juntos e com mais nenhum outro docente do seu programa. Esse tipo de colaboração é negativamente marcado no pageRank que privilegia uma rede de coautoria mais extensa, já no grafo de colaboração, vale o grau de colaboração. Nas relações biunívocas de colaboração, como os dois autores são produzem em coautoria entre si, eles possuem o maior grau de colaboração: 1,0, que corresponde a $100 \%$ da produção bibliográfica em coautoria. Como vimos, essa relações de colaboração biunívocas ocorreram também na UCS e na UNB.

Apesar de todos os benefícios da coautoria, os trabalhos feitos em colaboração científica entre os docentes da área de turismo no Brasil mostra que dos 157 docentes, 59 cinquenta nove não publicam em coautoria. Segundo Pan et al. (2012), para tornar este tipo de pesquisa ainda mais eficiente, é possível otimizar seu impacto e visibilidade com uma escolha inteligente de parceiros colaboradores. Deve-se adotar "além da análise das redes de coautorias para condução de políticas públicas" também "a alocação de recursos que viabilizem a realização de projetos colaborativos" (PAN et al. 2012, p. 26). O processo de comunicação científica está pautado na ideia de comunicação e a ampliação do perfil colaborativo é uma característica preponderante da ciência nos moldes do contemporâneo. Na área do turismo, esse aspecto precisa ser explorado. É fundamental ressaltar que $o$ incremento de parcerias com outras universidades também pode repercutir na produtividade do docente, implicando em benefícios individuais e coletivos aos membros do grupo de cada programa.

O grafo de colaboração dos docentes em turismo apresentado propõe um cenário para os avanços na disponibilização de dados e acesso às informações e publicações. O panorama que observamos é que existem ainda relações biunívocas e unívocas que, embora instaurem colaborações, restringem a rede de colaboração, porque centram as publicações em duplas, quando se poderia ampliar a rede. Uma observação que deve ser salientada é que o grafo de colaboração e o pageRank não concordaram na maioria das listagens dos primeiros colocados, porque eles adotam critérios diferentes. A diferença mais recorrente foi que o pageRank analisava negativamente as relações biunívocas, 
enquanto que o grafo de colaboração só as diferenciava quando comparadas com as relações unívocas. O grau de colaboração do grafo também foi um índice passível de melhoramento, porque notamos que, embora o grau seja maior, isso não significa uma rede mais forte de colaboração. Prova disso são as relações biunívocas que possuem grau máximo de colaboração, mas não se ramificam.

Vale ressaltar que Vanz e Stumpf (2010) argumentam que quando o grau de colaboração de um grupo é pequeno, o motivo varia entre problemas na organização social em que o pesquisador está vinculado e particularidades existentes nas comunidades de investigação. Considerando a insuficiência de dados na literatura para fins de comparação, recomenda-se a realização de outros estudos como o presente, partindo de outros alunos dos programas de doutorado e mestrado. No próximo tópico, vamos analisar o índice H e o i10.

\section{3- ÍNDICE H E O I10 DOS DOCENTES SELECIONADOS}

Como já abordado anteriormente, o índice $\mathrm{H}$ é uma sugestão para quantificar a produtividade e o impacto de docentes, pautando-se nos seus artigos mais citados. $\mathrm{O}$ índice $\mathrm{H}$ é o número de artigos com mais citações nos periódicos cadastrados no Google Acadêmico, tendo como marco de seu início o ano de 2005. É também um instrumento de auxílio para avaliação da produção científica dos pesquisadores. Enquanto que o índice i10, constitui o número de publicações com pelo menos 10 citações, conforme explica Marques (2017).

De acordo Pereira e Bronhara (2011), o índice H possui limitações que advêm da base do Google Acadêmico para a interpretação crítica sobre a produção científica de um pesquisador. Exemplo disso é a dependência desse índice do banco de dados do Google Acadêmico, ou seja, caso não exista a inscrição da publicação acadêmica nesse banco de dados, essa publicação não será contabilizada por esse índice. Essa limitação compromete, principalmente, os pesquisadores seniores que, não raramente, colocaram suas produções mais antigas no Google, uma vez que só recentemente as revistas acadêmicas tornaram-se, majoritariamente, digitais, outrora a maioria era publicada de forma impressa, dificultando o acesso a públicos externos à instituição.

Outra limitação é o uso excessivo de autocitações. Estas são contabilizadas pelo sistema do índice He i10. Elas não necessariamente indicam 
que a publicação citada pelo(s) próprio(s) autor(es) está sendo lida por outros públicos.

Embora $\mathrm{o}$ índice $\mathrm{H}$ tenha a finalidade de evidenciar a produtividade e a relevância do trabalho do pesquisador, esse objetivo não é plenamente cumprido. Como questionam Martins (2017), Santos et al. (2017) e Rego (2010), apesar da quantidade de citações recebidas ser um indicador relevante da produção acadêmica dos docentes, essa avaliação quantitativa não valoriza a regularidade de publicações. Um docente com uma única publicação muito citada pode até ter oferecido uma grande contribuição para o desenvolvimento do conhecimento, mas, se observarmos por outra perspectiva, esse mesmo pesquisador pode não ser considerado um profissional altamente produtivo porque ele não produziu outros trabalhos relevantes. Ou seja, um docente não pode ser avaliado por apenas uma ou duas produções acadêmicas bem sucedidas, mas deve ser avaliado por toda sua obra, como argumenta Santos et al. (2017).

Compreendendo todas essas limitações desses dois índices e que eles foram coletados em um período diferente dos dois indicadores anteriores, chegamos aos seguintes dados. Dentre os docentes citados nos grafos de colaboração, que foram no total 157 docentes, 69 pesquisadores apresentam no Google Acadêmico o seu índice $\mathrm{H}$ e o i10. A partir das nossas análises, verificamos que os resultados foram parciais, uma vez que os docentes deixam sua conta do Google Acadêmico fechada (ou não a possuem), impossibilitando uma interpretação dos dados. Nesta pesquisa, evitamos fazer comparações extensas no que concerne ao estágio de carreira dos docentes e ao desempenho de pesquisadores em outras áreas diferentes da do turismo, utilizando apenas dois critérios: a faixa etária e o ano de ingresso na instituição em que o docente encontra-se atualmente vinculado.

Dos 69 docentes que possuem índice $\mathrm{H}$ e i10, tivemos uma distribuição bastante irregular. Na UFPR e na USP, todos os docentes possuem os dois índices supracitados: a primeira, com dezoito docentes, e a segunda, com quatorze. A UAM tem dezenove docentes no programa de pós-graduação stricto sensu em Hospitalidade e nove pesquisadores têm Google acadêmico, no qual constam esses parâmetros. A UCS é composta por dezesseis docentes no programa de pós-graduação stricto sensu em turismo e, destes, oito possuem 
esses indicadores. A UFRN, por sua vez, têm vinte dois docentes na área do turismo e, destes, sete são detentores dos dois índices em análise. A UECE, com dezenove docentes na mesma área, cinco deles têm índice $\mathrm{H}$ e i10. A UNIVALI, por sua vez, têm dezessete docentes que trabalham na área de turismo e, entre eles, somente quatro possuem o índice $\mathrm{H}$ e i10. A UNB, com vinte dois docentes nesse campo de estudo, tem três docentes apresentam esses indicadores. A UFF, com dez docentes, tem apenas um docente com o índice $\mathrm{H}$ e i10. Os docentes que possuem a conta no google acadêmico estão no anexo 1, juntamente com os três docentes produtivos que possuem o índice $\mathrm{H}$ de forma decrescente no anexo 2. Abaixo podemos comparar os docentes que possuem o índice $\mathrm{H}$ no seguinte quadro:

Tabela 11 - Presença do índice H e do 110 nos currículos dos docentes dos programas relacionados à área do turismo

\begin{tabular}{|c|c|c|c|}
\hline Dados & $\begin{array}{c}\text { Número de } \\
\text { docentes nos } \\
\text { programas de pós- } \\
\text { graduação em } \\
\text { turismo }\end{array}$ & $\begin{array}{c}\text { Número de } \\
\text { docentes que } \\
\text { possuem índice H e } \\
\mathbf{i 1 0}\end{array}$ & $\begin{array}{c}\text { Porcentagem de } \\
\text { docentes que } \\
\text { possuem os } \\
\text { indicadores nos } \\
\text { programas de pós- } \\
\text { graduação em } \\
\text { turismo }\end{array}$ \\
\hline UFPR & 18 & 18 & $100 \%$ \\
\hline USP & 14 & 14 & $100 \%$ \\
\hline UAM & 19 & 9 & $47,3 \%$ \\
\hline UCS & 16 & 8 & $50 \%$ \\
\hline UFRN & 22 & 7 & $26,3 \%$ \\
\hline UECE & 19 & 4 & $23,5 \%$ \\
\hline UNIVALI & 17 & 3 & $13,6 \%$ \\
\hline UNB & 22 & 1 & $10 \%$ \\
\hline UFF & 10 & 69 & $43,9 \%$ \\
\hline TOTAL & $157^{22}$ & & \\
\hline
\end{tabular}

22 Foram retirados da contagem dois docentes, a saber: Mirian Rejowski e Luiz Octávio de Lima Camargo. Estes docentes estavam presentes na contagem dos dois índices anteriormente examinados, grafo de colaboração e pageRank, porque eles faziam parte da colaboração do Programa de Pós-graduação em Turismo da USP. No caso dos índices $\mathrm{H}$ e i10 em que a contagem é individual, estes dois docentes não pontuam para a USP. No caso da docente Miriam Rejokiw, ela foi desvinculada da USP, onde atuava como professora visitante, e, atualmente, encontra-se somente na UAM. No caso do professor Otávio Camargo, ele possui, atualmente, dois vínculos: um com a UAM, como professor titular, e outro, com a USP, como professor 
Fonte: Juliana Ferreira dos Santos a partir do Google Acadêmico dos docentes, 2018

Como podemos constatar pela tabela 11, menos da metade dos docentes vinculados aos programas de pós-graduação relacionados à área de turismo, 43,9\%, possui suas publicações cadastradas no Google acadêmico, registrando os índices $\mathrm{H}$ e i10. Isso demonstra que esses índices não acolhem majoritariamente as produções dos professores, uma vez que nem toda publicação acadêmica é inserida no banco de dados do Google Acadêmico, como já alertamos.

Para analisar os dados dos índices H e i10, utilizamos o mesmo critério aplicado nas análises anteriores: escolhemos os três docentes que possuem a maior pontuação nos parâmetros em exames. Como a comparação entre os que possuem mais e os que possuem menos não é viável uma vez que mais da metade do total de docentes dos programas analisados não têm esses indicadores, adicionamos dois outros critérios de análise: a faixa etária e o ano de ingresso no programa ao qual o docente está atualmente vinculado.

Esses dois outros critérios foram escolhidos por três razões. A primeira razão é que a faixa etária do docente pode indicar se há ou não uma correlação entre a idade do docente e o indicadores $\mathrm{H}$ e i10, uma vez que esses dois parâmetros são recentes e exigem certo conhecimento técnico e tecnológico para a indexação das publicações, podendo ser essa habilidade uma dificuldade para aqueles que não são nativos digitais, isto é, nascidos anteriormente à revolução das mídias digitais, conforme Navas, Ca et al. (2017).

A segunda razão é que o ano de ingresso do docente no programa pósgraduação em que ele está vinculado atualmente pode dizer se há ou não uma correlação entre a influência do programa de pós-graduação e a prática individual do docente. Essa correlação decorre das seguintes possíveis deduções: se o docente é novo no programa e tem um alto índice $\mathrm{H}$ e i10, isso se deve ao esforço e a própria prática individual do pesquisador de indexar seus publicações no Google Acadêmico; de outro lado, se o docente é mais antigo na instituição e possui índices H e i10 elevados, isso pode decorrer tanto de um

colaborador. Para não haver duplicidade nos dados, pontuamos os índices de Otávio Camargo para a instituição em que ele possui a maior carga horária de trabalho que é, em seu caso, a UAM. Por outro lado, foi acrescentado os docentes da USP Heros Augusto Santos Lobo e George Beninelli Rossi por estarmos analisando os índices atuais dos docentes. 
esforço pessoal, quanto de um estímulo institucional que será comprovado no cotejo com os outros dois docentes que também possuem altos índices. Como se nota, relacionar 0 ano de ingresso no programa de pós-graduação e os índices H e 110 é uma proposta produtora de sentidos para entendermos as práticas vigentes nos programas de pós-graduação stricto sensu em turismo no Brasil.

A terceira razão é que isoladamente os índices $\mathrm{H}$ e $\mathrm{i} 10$ não permitem comparações entre os docentes, porque, como já dissemos, eles não capturam as publicações de todos os docentes, como acontece nos grafos de colaboração e nos índices do pageRank. Todavia, os índices $\mathrm{H}$ e i10, quando relacionados às faixas etárias e ao ano de ingresso, podem revelar práticas docentes. Eles revelam o esforço do docente em tornar público seu trabalho para o maior número possível de leitores, bem como sua maior afinidade com as mídias digitais. São fatores que não são acolhidos no pageRank, nem no grafo de colaboração, uma vez que todas as publicações de todos os docentes são coletadas, independentemente se o pesquisador quis ou não divulgar sua publicação acadêmica.

Já no Google Acadêmico, a situação é outra. O meio digital em que a publicação acadêmica se efetivou deve ter vínculo com o Google Acadêmico ou o próprio pesquisador deve manualmente cadastrar sua publicação. Além disso, o pesquisador pode deixar público ou não sua página no Google Acadêmico, sabendo, também, que o currículo no Google Acadêmico não é automático.

Compreendida a pertinência de se adotar os dois critérios supracitados, discutamos, agora, quais serão as faixas etárias consideradas. Observados as idades mínimas dos currículos dos docentes e a média ponderada de suas idades, optamos por três faixas, a saber: faixa $1=$ de 31 a 44 anos; faixa 2 = de 45 a 55 anos; e faixa $3=$ de 58 anos ou mais. No quadro que proporemos, a faixa etária do docente será apresentada numericamente conforme a sequência: 1, 2 e 3, seguindo a correspondência acima descrita.

Nos casos de empate entre o número total do índice $\mathrm{H}$ ou do número total do índice i10 entre dois pesquisadores ou mais, o desempate ocorrerá a partir do maior número de citações. Escolhemos as citações, uma vez que elas demonstram mais publicações divulgando os trabalhos científicos do pesquisador, logo sua maior colaboração - mesmo que esse número seja 
composto por autocitações. O fator tempo de indexação das publicações no Google Acadêmico é variável entre os dados, por isso não o utilizamos como característica de desempate.

A seguir, apresentamos os dados computados dos três primeiros colocados de cada instituição considerando o número total do índice $\mathrm{H}$. E o segundo tem os três primeiros colocados do índice i10. No quadro 16, apresentamos o nome dos docentes, a sua faixa etária, o ano de ingresso no programa de pós-graduação no qual está vinculado, o número total de seu índice, seja o H ou o i10, e, por fim, o número total de citações.

Quadro 16- Os três primeiros colocados de cada instituição no índice H e i10

\begin{tabular}{|c|c|c|c|c|c|c|c|}
\hline Instituição & Ordem & Professor & $\begin{array}{l}\text { Faixa } \\
\text { etária }\end{array}$ & $\begin{array}{c}\text { Ano de } \\
\text { ingresso }\end{array}$ & Índice H & Indice i10 & $\begin{array}{c}\text { Número } \\
\text { de } \\
\text { Citações }\end{array}$ \\
\hline \multirow[t]{3}{*}{ UFPR } & 10 & $\begin{array}{l}\text { José Manoel Gonçalves } \\
\text { Gândara }\end{array}$ & 3 & 2013 & 17 & 29 & 1128 \\
\hline & $2^{0}$ & $\begin{array}{l}\text { Carlos Alberto Cioce } \\
\text { Sampaio }\end{array}$ & 2 & 2013 & 16 & 30 & 1012 \\
\hline & $3^{\circ}$ & Miguel Bahl & 3 & 2013 & 11 & 11 & 496 \\
\hline \multirow[t]{3}{*}{ USP } & $1^{0}$ & $\begin{array}{lll}\text { Luiz Gonzaga Godoi } \\
\text { Trigo }\end{array}$ & 3 & 2014 & 25 & 37 & 2604 \\
\hline & $2^{0}$ & $\begin{array}{ll}\text { Alexandre } & \text { Panosso } \\
\text { Netto } & \end{array}$ & 2 & 2014 & 18 & 30 & 1574 \\
\hline & $3^{\circ}$ & $\begin{array}{l}\text { Heros Augusto Santos } \\
\text { Lobo }\end{array}$ & 1 & 2017 & 10 & 12 & 370 \\
\hline \multirow[t]{3}{*}{ UAM } & $1^{0}$ & Mirian Rejowski & 3 & 2002 & 16 & 33 & 1119 \\
\hline & $2^{0}$ & Luiz Octavio Camargo & 3 & 2002 & 15 & 17 & 1683 \\
\hline & $3^{0}$ & Sergio Moretti & 3 & 2013 & 11 & 14 & 515 \\
\hline \multirow[t]{3}{*}{ UCS } & $1^{0}$ & Susana Gastal & 3 & 2000 & 17 & 22 & 1088 \\
\hline & $2^{0}$ & Mario Beni & 3 & 2000 & 14 & 15 & 4360 \\
\hline & $3^{0}$ & $\begin{array}{l}\text { Vania Beatriz Merlotti } \\
\text { Heradia }\end{array}$ & 3 & 2000 & 11 & 13 & 538 \\
\hline \multirow[t]{2}{*}{ UFRN } & $1^{\circ}$ & $\begin{array}{l}\text { Carlos Alberto Freire } \\
\text { Medeiros }\end{array}$ & 2 & 2008 & 14 & 17 & 1313 \\
\hline & $2^{0}$ & $\begin{array}{l}\text { Marcos Antonio Leite do } \\
\text { Nascimento }\end{array}$ & 2 & 2008 & 9 & 8 & 426 \\
\hline
\end{tabular}




\begin{tabular}{|c|c|c|c|c|c|c|c|}
\hline & $3^{0}$ & $\begin{array}{l}\text { Luiz Augusto Machado } \\
\text { Mendes Filho }\end{array}$ & 1 & 2008 & 9 & 6 & 173 \\
\hline \multirow[t]{3}{*}{ UECE } & $1^{0}$ & $\begin{array}{l}\text { Anderson Pereira } \\
\text { Portuguez }\end{array}$ & 2 & 2012 & 8 & 6 & 395 \\
\hline & $2^{\circ}$ & $\begin{array}{l}\text { Sara Joana Gadotti dos } \\
\text { Anjos }\end{array}$ & 3 & 2012 & 8 & 6 & 450 \\
\hline & $3^{\circ}$ & $\begin{array}{l}\text { Marcelo Martins de } \\
\text { Moura Fé }\end{array}$ & 1 & 2012 & 5 & 1 & 59 \\
\hline \multirow[t]{3}{*}{ UNIVALI } & 1 은 & Anete Alberton & 3 & 1997 & 9 & 9 & 425 \\
\hline & $2^{\circ}$ & $\begin{array}{l}\text { Sara Joana Gadotti dos } \\
\text { Anjos }\end{array}$ & 3 & 1997 & 8 & 6 & 450 \\
\hline & $3^{0}$ & $\begin{array}{l}\text { Francisco Antonio dos } \\
\text { Anjos }\end{array}$ & 3 & 1997 & 8 & 5 & 218 \\
\hline \multirow[t]{3}{*}{ UNB } & $1^{\circ}$ & $\begin{array}{l}\text { Everaldo Batista da } \\
\text { Costa }\end{array}$ & 1 & 2007 & 24 & 38 & 3104 \\
\hline & $2^{0}$ & Mario Beni & 3 & 2007 & 14 & 15 & 4360 \\
\hline & $3^{0}$ & $\begin{array}{l}\text { Neio Lucio de Oliveira } \\
\text { Campos }\end{array}$ & 3 & 2007 & 5 & 4 & 87 \\
\hline \multirow[t]{3}{*}{ UFF } & $1^{0}$ & $\begin{array}{ll}\text { Aguinaldo } & \text { Cesar } \\
\text { Fratucci } & \\
\end{array}$ & 3 & 2015 & 7 & 5 & 214 \\
\hline & $2^{0}$ & 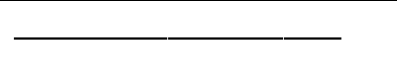 & - & 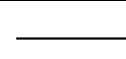 & - & & - \\
\hline & $3^{0}$ & $\overline{\mathrm{C}}$ & 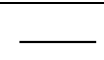 & & 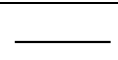 & & \\
\hline
\end{tabular}

Fonte: Juliana Ferreira dos Santos, a partir dos dados coletados no Google Acadêmico, 2018.

Comparando os dados do quadro 16, podemos perceber que são os mesmos docentes que os compõem. Há duas trocas de lugares apenas. A primeira mudança ocorre entre os docentes Sara dos Anjos e Anderson Portuguez, ambos da UECE: no índice $\mathrm{H}$, Portuguez está em $1^{\circ}$ e Sara dos Anjos, em 2o lugar; no índice i10, Sara dos Anjos assume o $1^{\circ}$ lugar e Anderson Portuguez, o $2^{\circ}$. A segunda alteração acontece na UFPR entre Carlos Sampaio e José Gandara: no índice H, Gandara está em $1^{\circ}$ e Sampaio, em 2o; no índice i10, é Sampaio que está em 1ํe Gandara, em $2^{\circ}$.

Outra peculiaridade que se observa é o número de docentes. No total, seriam possíveis 54 docentes diferentes, sendo 27 docentes distintos no quadro. Temos apenas 23 docentes. Esse número é obtido, retirando duas ausências no caso da UFF e a repetição de Sara dos Anjos e Mario Beni que estão em duas instituições concomitantemente: Sara dos Anjos está na UECE e na UNIVALI; e Beni está na UCS e na UNB.

Entre esses 23 docentes, temos os seguintes maiores índices. No índice H, Luiz Trigo, da USP, obteve o maior número com 25; seguido por Everaldo Costa, da UNB, com 24; e, em terceiro lugar, Alexandre Panosso, também da USP, com 18. No índice i10, Everaldo Costa passa ser o primeiro com i10 38; 
Luiz Trigo aparece em segundo lugar com 37; e a Mirian Rejowski permanece na terceira colocação, com 33 .

Considerando os mesmos 23 docentes, observamos que os menores índices são os seguintes. No índice $\mathrm{H}$ e i10, o último, o penúltimo e o antepenúltimo colocados são os mesmos. O último colocado é Marcelo Fé, da UECE, com início H 5, i10 1 e 59 citações; em penúltimo, está Neio Campos, da UNB, também com índice 5, i10 é 4 e com 87 citações; e, no antepenúltimo, está o Aguinaldo Fratucci, da UFF, com índice H 7 e i10 5.

Ainda considerando esse conjunto de 23 docente, os que têm mais citações são os seguintes. Em primeiro lugar, Mario Beni, da UNB e da UCS, com 4360. Em segundo lugar, está Everaldo Costa, da UNB, com 3104. Em terceiro lugar, está Luiz Trigo, da USP, com 2604. Os que possuem menos citações são os seguintes: o último colocado é Marcelo Fé, da UECE, com 59; o penúltimo é Neio Campos, da UNB, com 87; e o antepenúltimo é Luiz Mendes Filho, da UFRN, com 173 citações.

Com relação as faixas etárias, compreendemos a partir dos dados obtidos com no quadro que, dos 23 docentes, 14 estão na terceira faixa, isto é, com idade entre 61 anos ou mais. Isso corresponde a mais de $60 \%$ dos docentes. A segunda faixa, aqueles que possuem entre 45 a 60 anos, são apenas 5 , equivalente a cerca de $23 \%$. A primeira faixa, entre 31 a 44 anos, temos 4 docentes, por volta de $17 \%$.

Esses dados demonstram que a faixa etária mais avançada, isto é, com mais de 60 anos, não é um fator limitante para a indexação de dados nos bancos que estruturam os indicadores $\mathrm{H}$ e i10. Isso contraria o senso comum de que pesquisadores seniores teriam dificuldade em acompanhar os parâmetros do universo digital devido às dificuldades técnicas ou tecnológicas. Compreendemos, assim, que os dados coletados evidenciam que são esses pesquisadores seniores que possuem os maiores índices $\mathrm{H}$, i10, de citação. Está, portanto, invalidada a hipótese, nesta pesquisa, que o fator etário seja um limitador na indexação dos índices $\mathrm{H}$ e i10.

Para analisar o ano de ingresso dos docentes, temos que verificar cada instituição de ensino separadamente. Começamos pela UFPR. Ele tem dois pesquisadores na terceira faixa etária e um na segunda faixa, todos contratados no mesmo ano: 2013. Compreende-se, assim, que há um esforço institucional 
para divulgação dos trabalhos docentes, uma vez que todos os docentes da UFPR têm índice $\mathrm{H}$ e i10.

A USP também tem todos os seus docentes cadastrados no Google Acadêmico. $O$ diferencial é que a faixa etária é bem variada. Temos as três faixas etárias, mas elas obedecem uma relação proporcional entre idade e número de citações, porque o docente com maior faixa etária também é o que possui o maior número de citações, de índice $\mathrm{H}$ e i10, que, no caso, é o docente Luiz Trigo. $O$ ano de ingresso também variou, porque o terceiro colocado foi contratado três anos depois dos dois outros docentes.

A UECE também acompanha essa variação na faixa etária. Ela apresenta as três faixas etárias. Só que diferentemente da USP, todos foram contratados em 2012. Além disso, nem todos os docentes da UECE apresentam os indicadores, como já dissemos.

A UAM tem todos os três melhores colocados na terceira faixa etária. Os dois primeiros colocados nos dois indicadores foram contratados em 2002. O terceiro colocado foi contratado em 2013. Logo, depreendemos, nesse caso, que é o docente Sergio Moretti que já publicava e indexava seus trabalhos bem antes da sua efetivação na UAM, sendo possível deduzir que, nesse caso, não é necessariamente uma influência institucional, como na UFPR. Salientamos, novamente, que a UAM não tem todos os docentes com cadastro no Google Acadêmico.

A UCS e a UNIVALI possuem contextos bem semelhantes. As duas instituições têm os três melhores colocados caracterizados pela terceira faixa etária. E os três melhores colocados de cada instituições foram contratados no mesmo ano: na UCS, em 2000 e, na UNIVALI, em 1997. Pode-se dizer que nesse caso há uma influência institucional, mas isso tem que ser relativizado, porque nem todos os docentes dessas duas universidades possuem cadastro no Google Acadêmico.

A UFRN, dentre as nove instituições e os 23 docentes que compõem o quadro 16, possui os três melhores colocados mais jovens. Dois ocupam a segunda faixa e um está na primeira faixa etária. Todos contratados em 2008. Essa instituição também não tem todos os docentes cadastrados no Google Acadêmico. 
A UNB tem um contexto bem singular. O primeiro colocado nos dois índices, Everaldo Costa, está na primeira faixa e foi contratado mais tardiamente, em 2013. Já os dois outros melhores colocados estão na terceira faixa etária e foram contratados em 2007. Outra característica peculiar de Everaldo Costa é que, entre 23 docentes, ele é um dos que não possui formação inicial na área de turismo. Essa conjuntura demonstra que a área do turismo é inter e multidisciplinar, principalmente entre aqueles, como Everaldo Costa, que possuem altos índices de divulgação científica.

A UFF tem uma análise incompleta, porque possui, dentre os dez professores de seu programa, apenas um docente com cadastro disponível no Google Acadêmico. Esse docente, Aguinaldo Fratucci, como vimos acima, ficou ainda com os índices mais baixos comparado com os demais professores.

Os índices $\mathrm{H}$ e o $\mathrm{i} 10$ apresentados pelos docentes na área do turismo revelam valores de referência para propósitos de questionamentos da produção científica cumulativa de cada programa. Esses indicadores, a longo prazo, podem servir de referência a juízos dos seus dados, pois alguns docentes não camuflam estes índices. Todavia, por ora, seus dados precisam ser relativizados, uma vez que nem todos os docentes possuem cadastro no Google Acadêmico e nem toda publicação é indexada no banco de dados do Google. Por isso é preciso que alunos de mestrado e doutorado em turismo pesquisem sobre assuntos relacionados ao tema, construindo instrumentos de análise que possam inter-relacionar os dados, como fizemos ao inserir outros critérios aos índices $\mathrm{H}$ e i10, que no caso foram a faixa etária e o ano de ingresso no programa de pós-graduação.

Chauí (2014) afirma que o mais crítico numa universidade é a excessiva centralização, burocratização e a implementação do que chamamos de universidade operacional. Essa perspectiva constrói uma universidade produtivista, que pensa o ensino como uma laço de difusão de saberes que aborda a pesquisa como um censo de problemas a seres resolvidos imediatamente. $\mathrm{O}$ índice $\mathrm{H}$ apresenta limitações que não servem de base para uma interpretação crítica sobre a produção científica de um docente se considerar apenas os seus números de maneira isolada. Mas podemos dizer que os índices H e i10 não devem ser desprezados, mas sim aprimorados para que, 
futuramente, todos os pesquisadores tenham um cadastro, seja o do Google ou uma versão mais completa da Plataforma Lattes.

Embora essa análise apresente aspectos mais específicos e coletados em outro momento do que aqueles dos grafos de colaboração e do pageRank, temos uma análise complementar. Enquanto os grafos e o pageRank analisaram a colaboração entre os docentes, nesse caso do índice H e i10, observamos a pertinência da jornada de cada docente em sua instituição. Notamos que existem casos singulares como o do professor Everaldo Costa, da UNB, que possui uma vasta produção e uma formação inicial diferente da do turismo, bem como, de outro lado, o caso de Luiz Trigo, da USP, que tem também uma vasta produção e sua formação voltada à área do turismo e filosofia. De acordo com Glänzel e Schubert (2003), Oliveira et al. (2012) e Wainer et al. (2013), o desempenho de um docente pode modificar expressivamente dependendo de sua subárea de interesse e de suas inter-relações com o meio de produção.

Notamos que pode existir, como no caso da UFPR e da USP, uma influência institucional em divulgar a sua produção científica nas redes sociais digitais, como o Google Acadêmico, bem como pode existir a contrapartida daquela instituição que não estimula essa difusão, como demonstrou, majoritariamente, o caso da UFF. Em suma, é preciso melhorar os parâmetros de análise. Não é possível fiar-se apenas e somente em um ou dois princípios, é preciso criar uma rede de inter-relações, porque a partir dos pontos de intersecções é que poderemos apreender o que devemos melhorar e o que se deve estimular. Eis o que tentamos fazer neste capítulo ao correlacionar diferentes e diversos indicadores de produtividade acadêmica. 
Esta dissertação teve como objetivo analisar a produção bibliográfica dos docentes dos programas de pós-graduação stricto sensu em turismo no Brasil no período de 2013 a 2016. A análise e a discussão dos resultados apresentados cumpriu com o objetivo específico proposto, que era o de analisar quantitativa e qualitativamente a produção científica de artigos, livros e capítulos de livros dos docentes dos programas de pós-graduação stricto sensu em turismo.

Metodologicamente, a dissertação foi dividida em três capítulos. No primeiro capítulo foi relacionada a contextualização sobre a pós-graduação no Brasil e na área do turismo, além de abordar as questões teóricas retornando as seis etapas da formação dos cursos superiores em turismo no Brasil. Fizemos também uma discussão panorâmica de como está a pós-graduação stricto sensu em turismo atualmente e constatamos os avanços da área. Nessa reflexão, constatamos que a área de conhecimento do turismo no Brasil está dividida em duas vertentes: a teórica e a descritiva, confirmando as discussões de Ansarah (2002) e Tribe (1997).

No Capítulo 2, desenvolvemos os pressupostos teóricos da análise do conteúdo e demos início as primeiras análises das produções docentes selecionadas. Nesta parte, o trabalho metodológico foi importante para fomentar os resultados e discussões a serem aferidos sobre as produções docentes postas em análise. Investigou-se, nessa parte, a produtividade de artigos publicados por docente no período abordado, a verificação da Qualis e da nacionalidade dos periódicos e as nuvens de palavras das três unidades de registro, a saber: artigos em periódicos, livros e capítulos de livros.

$\mathrm{Na}$ análise da produtividade dos artigos publicados por docentes no período de 2013 a 2016, obtivemos 932 títulos. As nove instituições de ensino superior analisadas neste trabalho foram: UAM, UCS, UECE, UFF, UFPR, UFRN, UNB, UNIVALI e USP. Os programas de pós-graduação stricto sensu em turismo dessas instituições tiveram suas respectivas produtividades de artigos analisadas quantitativa e qualitativamente. As instituições que publicaram mais artigos quantitativamente foram a UFRN, UFPR e a UAM, e qualitativamente a UNIVALI, USP e a UFPR.

Sobre a nacionalidade dos periódicos, observou-se o crescimento na internacionalização da pesquisa brasileira nos programas de pós-graduação stricto sensu em turismo no período de 2013 a 2016. A organização ANPTUR é 
reflexo de tais avanços, pois ela, a cada ano, vem contando com mais participação de palestrantes internacionais. Dessa forma, a produção científica brasileira na área do turismo passou a figurar no cenário internacional com maior frequência.

Um fator que deve ser avaliado com mais atenção é a endogenia. Em nosso exame, as revistas das universidades selecionadas que caracterizaram endogenia foram: a UCS (Rosa dos Ventos) com quinze ocorrências; UNB (Revista cenário) com treze recorrências; UAM, (Revista Hospitalidade, Revista

da Universidade Anhembi) com sete ocorrências; UNIVALI (Revista Turismo Visão e Ação), com cinco casos e a UFPR ( Revista Turismo e Sociedade) com dez publicações. Esses casos devem ser observados para que a produção docente não fique focada em seu próprios círculos, mas seja, de fato, difundida.

Em relação às nuvens de palavras-chave dos artigos, as palavras mais recorrentes entre as universidades selecionadas foram: turismo, desenvolvimento e hospitalidade. Essa observação é importante destacar a presença da palavra desenvolvimento. Esse termo esteve, sobretudo, presente na UCS e na USP, no que diz respeito à categorização das três palavras-chave mais recorrentes nos artigos publicados pelos seus respectivos docentes. Quando verificamos a área de concentração da UCS, observamos que a palavra desenvolvimento está voltada para o âmbito regional. Isso confirma o porquê que as palavras-chave dos livros estavam relacionadas a outras palavras regionais como: Serra Gaúcha, Municípios e Palmares.

Nas palavras-chave dos títulos dos artigos, a USP e a UFRN enfatizaram a palavra desenvolvimento no sentido teórico e prático do termo. A USP e a UFRN confirmaram que sua área de concentração está ligada, de fato, ao sentido teórico proposto por este termo. Por outro lado, nas palavras-chave dos livros, somente a UCS e a UFPR não tiveram a palavra turismo, uma vez que escolheram palavras de caráter regionalista, como Palmares e Parána.

$\mathrm{Na}$ interpretação das palavras-chave dos capítulos de livros, mais uma vez na UFRN e na USP aparecem a palavra desenvolvimento, corroborando com a primeira análise das três palavras-chave dos artigos. Em contrapartida, na UECE também aparece a palavra desenvolvimento, mas, nesse caso, o termo está voltado para o desenvolvimento local, divergindo, assim, da visão da USP. Uma das hipóteses a ser conferida em trabalhos ulteriores é que essa 
divergência ocorra, porque a USP tem um mestrado de caráter acadêmico e a UECE, um mestrado profissional.

No Capítulo 3, abordamos o estudo da rede de colaboração e o pageranks dos docentes. Para isso, a análise foi pesquisado os índices $h$ dos três docentes mais produtivos de cada programa selecionado neste estudo. Sobre as contribuições da redes de colaboração, temos que admitir que existe uma tomada de decisão em nível institucional e individual. No âmbito institucional, verificou-se que nos programas de pós-graduação stricto sensu em turismo não há integração entre os docentes.

$\mathrm{Na}$ conjuntura individual, observou-se que os resultados podem auxiliar novos integrantes da comunidade acadêmica dos programas a identificar membros expoentes dentro da comunidade, com os quais possa ser interessante trabalhar. Ademais, pode acudir membros de outras programas do turismo a identificar possíveis parcerias para trabalhos em conjunto, propiciando, assim, a interdisciplinaridade que está na gênese dos programas stricto sensu em turismo no Brasil.

Com relação à investigação nos grafos de colaboração e no pagerank, a análise possibilitou a compreensão do encadeamento de algumas relações de colaboração. A avaliação do nível de colaboração entre os docentes dos programas permitiu que se verificasse que não há um bom nível de coautorias entre os docentes, e que existem relações biunívocos e unívocas.

Em relação ao Índice $H$, notou-se que é preciso melhorar as variáveis de análise. Não é possível ater-se apenas e somente em uma ou duas variáveis de produtividade. Diferentemente disso, é necessário conceber uma rede de interrelações, porque a partir dos pontos de cruzamentos que poderemos assimilar o que devemos aprimorar e o que se devemos estimular. Eis o que tentamos fazer com a interpretação dos dados ao correlacionar diferentes e diversos indicadores de produtividade acadêmica.

O desenvolvimento metodológico da dissertação, embasado na análise de conteúdo, foi um desafio superado. É valido destacar o ineditismo do trabalho, uma vez que a bibliografia sobre o tema é escassa na área do turismo e o uso da análise do conteúdo nesse ramo do conhecimento é ainda precário. De acordo com as linhas de pesquisa na área do turismo, apenas seis docentes desenvolvem a análise do conteúdo em seus respectivos programas. 
Este trabalho contribui na interpretação do desenvolvimento da pósgraduação stricto sensu em turismo no Brasil. No entanto, para chegar a está etapa encontramos dificuldades em todas as etapas da pesquisa e não somente na revisão bibliográfica. Durante a coleta de dados, deparamo-nos com erros cadastrados nos currículos dos docentes da Plataforma Lattes pelos docentes.

Defrontamo-nos com o acesso fechado do índice $\mathrm{H}$ nos cadastros dos docentes. Durante a análise, os dados coletados não eram uniformes, como supõe a lógica da cientificidade. Tivemos que investigar as incongruências e delimitar os programas, propondo caminhos de investigação que pudessem cumprir os critérios de cientificidade da coerência e da coesão dos dados, sem os quais nenhuma generalização é possível.

Essas dificuldades foram todas superadas. Por outro lado, com o trabalho finalizado, as deficiências também foram notadas. Por exemplo, falta realizar em trabalhos posteriores a análise dos grafos de colaboração de todos os docentes dos programas e a investigação da produção discente, que são demandas que este trabalho não cumpriou, mas que observa a necessidade e deixa como proposta para outros pesquisadores.

Por conseguinte, constatou-se, ainda, como conclusão deste trabalho que o fator tempo não é definidor para o maior ou menor índice de produção docente em um programa. Este estudo contribuiu não só para alagar o interesse neste campo, mas também oferece respostas a refutações suscitadas no âmbito acadêmico. Foi uma investigação que também teve, como intuito, mesmo que velado, despertar no leitor e no pesquisador o desejo para que outros estudos sejam feitos, como, por exemplo, uma pesquisa sobre o impacto social das produções científicas na comunidade e o que os egressos estão fazendo na vida profissional. Este foi o momento de averiguar o que a produção docente impacta na área do turismo e, agora, fica, para trabalhos futuros, ampliar esses resultados em prol da ciência e da cultura em nosso país. 
REFERÊNCIAS 
ANDRETTA, P. I. S. SILVA, E. G.; RAMOS, R. C. Aproximações sobre produção, produtividade e colaboração científica entre os departamentos de Ciência da Informação do Estado de São Paulo. Revista Digital de

Biblioteconomia e Ciência da Informação, v. 9, n. 2, p. 49-63, 2012.Disponível em:

$<$ http://www.brapci.inf.br/index.php/article/view/0000011686/79c70968c171fd96 99e36e1428abd304/>

ANPTUR-< https://www.anptur.org.br/seminario/2018>Acesso em: 13 mar. 2018.

ALVARENGA, L. Política e Estado: Um estudo bibliométrico de artigos na Revista Brasileira de estudos pedagógicos- 1994-1974. Revista Informação e Sociedade, Joao Pessoa, v. 13, N.1, p 77-120, 2003. Disponível em: $<$ http://www.brapci.inf.br/index.php/article/view/0000001606/31594db9268062c 7fb906490ed00521a> Acesso em: 20 de mar. De 2017.

ANSARAH, M. G. R. Formação e capacitação do profissional em turismo e hotelaria. Reflexões e cadastro das instituições educacionais no Brasil. São Paulo: Aleph, 2002.

BALBACHEVSKY, E. A pós-graduação no Brasil: Novos desafios para uma política bem sucedida. In: BROCK, Colin; SCHWARTZMAN, Simon (ed). Os desafios da educação no Brasil. Rio de Janeiro. Nova Fronteira, P. 275-304; 2005.

BALANCIERI, R. et al. A análise de redes de colaboração científica sob as novas tecnologias de informação e comunicação: um estudo na Plataforma Lattes. Ciência da Informação, Brasília, DF, v.34, n.1, p.64-77, jan./abr. 2005. Disponível em: <http://www.scielo.br/scielo.php?pid=s0100$19652005000100008 \&$ script $=$ sci abstract\&tlng=pt>. Acesso em: 17 mar. 2018.

BARABÁSI, A. L. Evolucion of the social network of scientific collaborations. Physica A: Statistical mechanics and its aplications, v. 311, n. 3, p. 590614, 2002, Disponível em:<http://arxiv.org/pdf/cond-mat/0104162.pdf>. Acesso em: 10 de julho de 2018.

BARATA, R. B.; GOLDBAUM, M. Perfil dos pesquisadores com bolsa de produtividade em pesquisa do CNPq da área de saúde coletiva. Cadernos de Saúde Pública, v. 19, n. 6, p. 1863-1876, 2003.

BARDIN, L. Análise de conteúdo. Trad. de Luís Antero Reto, Augusto Pinheiro. São Paulo: Edições 70, 1977.

BRUSADIN, L. B. A formação do bacharel em turismo com base nas estruturas curriculares e nos docentes dos cursos de graduação. Estudo de casos: Universidade de Espírito Santo do Pinhal e Universidade de Franca. Simpósio in: IV SEMINÁRIO DA ASSOCIAÇÃO BRASILEIRA DE PESQUISA DE PÓSGRADUAÇÃO EM TURISMO. UAMM - 27 a 28 de agosto de 2007. 
BOMFIM, N.R. Noção social de território: em busca de um conceito didático em geografia: a territorialidade. Ilhéus: Editus, 2009.

BOMENY, H. Newton Sucupira e os rumos da educação superior. Brasília. Paralelo 15, Coordenação de Pessoal de Nível Superior, 2001.

CAPES- <https://www.capes.gov.br> Acesso em 13 de mar. De 2018.

CAPES<http://www.capes.gov.br/images/stories/download/acessoainformacao/ Relatorio de Gestao CAPES 2016.pdf >acesso em 13 de mar. de 2018.

CASADO, Elías Sanz. et al. Study of interdisciplinarity in chemistry research based on the production of Puerto Rican scientists 1992-2001, Department de Biblioteconomía and Documentación. Universidad Carlos III de Madrid, Madrid, Spain, Vol. 9 No. 4, July 2004.

CAMPRUBÍ, R. \& COROMINA, L. Content analysis in tourism research. Tourism Management Perspectives, 18, pp. 134-140, 2016.

CHAUÍ,M. Contra a universidade operacional: A greve de 2014. 2014.

COSTA, C. O mundo do turismo é o mundo da viagem. Disponível em http://gerireliderar.com/ o-mundo-do-turismo-e-o-mundo-da-viagem; 2016 CRANE, Diana. Invisible colleges. Chicago: University of Chicago Press, 1972.

De Solla Price, D. J., \& Beaver, D. (1966). Collaboration in an invisible college. American Psychologist, 21(11), 1011-1018.

DIGIAMPIETRI, L. A. et al. Minerando e caracterizando dados de Currículos Lattes. In: BRAZILIAN WORSHOP ON SOCIAL NETWORK ANALYSIS AND MINING (BRASNAM) 1., Curitiba, 2012. Revista Sociedade Brasileira de Computação, 2012 a. Disponível em:

http://www.imago.ufpr.br/csbc2012a/anais csbc/eventos/brasnam/artigos/BRA SNAM\%23\%20Minerando\%20e\%20Caracterizando\%20Dados\%20de\%20Curri culos\%20Lattes.pdf. Acesso em: 10 julho de 2018

DIGIAMPIETRI, L. A., Mena-Chalco, J. P., Pérez-Alcázar, J. J., Tuesta, E. F., Delgado, K. V., Mugnaini, R., \& Silva, G. S. Minerando e caracterizando dados de currículos Lattes. 2012b. Brazilian Workshop on Social Network Analysis and Mining. Dispónivel em:

http://www.imago.ufpr.br/csbc2012/anais csbc/eventos/brasnam/artigos/BRAS NAM\%20\%20Minerando\%20e\%20Caracterizando\%20Dados\%20de\%20Curric ulos\%20Lattes.pdf. Acesso em: 10 julho de 2018.

DIGIAMPIETRI, L. A. Análise da Rede Social Acadêmica Brasileira. 2015. 160 f. Tese (Livre Docência) - Escola de Artes, Ciências e Humanidades, Universidade de São Paulo, São Paulo, 2015.

DANUELLO, J. C. OLIVEIRA, E. F. T. Análise cientométrica : produção científica e redes colaborativas a partir das publicações dos docentes dos 
programas de graduação em Fonoaudiologia no Brasil. Revista em Questão, v. 18, n. especial, p. 65-79, 2012.

EACH- Escola de Artes e Ciências e Humanidades- Universidade de São Paulo. Pós-graduação em turismo. Disponível em $<$ http://www5.each.usp.br/mestrado-academico-em-turismo/> Acesso em jun. de 2018.

FREIRA, M.A. Hospitalidade na formação profissional em turismo no Rio de Janeiro: em busca de categorias de análise. Dissertação de mestrado na Universidade Anhembi Morumbi, São Paulo, 2015.

FONSECA FILHO, A. D. S. Educação e turismo: Um estudo sobre a inserção do turismo no ensino fundamental e médio. Revista Brasileira de Pesquisa em Turismo, v.1, n 1. p. 15-27 São Paulo, 2007.

GAETA, M.C.D. Formação docente para o ensino superior: Uma inovação em cursos de Lato sensu. Tese (doutorado) Pontifíca Universidade Católica de São Paulo, 2007.

GLÄNZEL, W. \& SCHUBERT, A. A new classi_cation scheme of science_elds andsub_elds designed for scientometric evaluation purposes. Revista

Scientometrics, v.56. n.3. 357-367, 2003.

GARVEY, D. et al. Pospublication processing of scientic information In: communication: The essence of essence of Science: Oxford Pergamon Press, 1979.

GOMES, et al. Inserção do Lazer no contexto de Pós-Graduação. Stricto Sensu em turismo/hospitalidade no Brasil. Caderno virtual de turismo. Vol.8,n.3, p. 10-29, 2008.

GOMES, C. H. P. CAVALCANTE, P. S. LINS. W. C. B. Análise de redes de colaboração científica dos docentes do Programa de Pós-Graduação em Educação Matemática e Tecnologia da Universidade Federal de Pernambuco, Revista de Educação Matemática e Tecnologica Iberoamericana, v. 4, n 1 , p. 1-25, 2012.

GUIMARAES, V.M. A sociologia e os estudos do turismo: algumas divagações. Trabalho apresentado no Simpósio in/; V SEMINÁRIO DE PESQUISA EM TURISMO DO MERCOSUL. Caxias do Sul, 27 e 28 de junho de 2008.

HADDAD, A. E. MENA-CHALCO, J. SIDONE, O. Produção científica e redes de colaboração dos docentes vinculados dos programas de Pós-Graduação em economia no Brasil. Revista de economia, Vol 47, n 4, p. 620, 2017.

HAGSTROM, W. O. The scientific community. New York: Basic Books, 1995.

HALLAL, et al. O contexto de criação dos cursos de bacharelado em Turismo no Brasil. Simpósio in: X COLÓQUIO INTERNACIONAL SOBRE GESTÍON UNIVERSITÁRIA DA AMERICA DEL SUR. Mar del Plata, dezembro de 2010. 
HALFFMAN, W. RADDER; H. Manifesto Acadêmico: De uma Universidade ocupada a uma Universidade Pública, 2017.

HANNAM, K. KNOX; D. Discourse analysis in tourism research a critical perspective. Tourism Recreation Research, 30(2), pp. 23-30. 2005.

HOLANDA, L. A.; WIDMER, G. M. LEAL, S. R. A produção científica em turismo no Brasil: reflexões e proposições a partir de um estudo revisional. Simpósio em/; ANAIS BRASILEIROS DE ESTUDOS TURÍSTICOS, 4 (1), p. 72-79, 2014.

IBGE- https://www.ibge.gov.br acesso em 13 de mar. de 2018.

JAFARI, J. RITCHIE; J. R. Brent. Toward a framework for tourism education-problems and prospects. Annals of Tourism Research. GrãBretanha: Pergamon, v.8, n.1, p. 13-34, 1981.

JAFARI, J. La cientifizacion del turismo. Estudios y perspectivas en turismo, v. 3, n. 1, 1994.

JASONDAVIES-Disponível em: < http://www.jasondavies.com> Acesso em julho de 2017.

J. P. Mena-Chalco \& R. M. Cesar-Jr. Prospecção de dados acadêmicos de currículos Lattes através de scriptLattes. Capítulo de livro: "Bibliometria e Cientometria: reflexões teóricas e interfaces", páginas 109-128. São Carlos: Pedro \& João Editores. Maria Cristina Piumbato Innocentini Hayashi e Jacqueline Leta (Orgs.), 2013.

KOEBSCH, E. C.M. Estudo da área de turismo: em busca da adequação dos critérios de avaliação Qualis. Tese de doutorado em Ciência da informação. $\mathrm{Na}$ (ECA) Escola de Comunicações e Artes, São Paulo, 2017.

Krippendorf, K. Content analysis: an introduction to its methodology (2nd ed.). California: Sage Publications, Inc, 1990.

Content analysis: an introduction to its methodology (2nd ed.). California: Sage Publications, Inc, 2004.

LEAL, S. R. Pesquisa em turismo no Brasil: uma revolução silenciosa? Revista Turismo \& Sociedade, 4(1), 144- 147, 2011.

Internacionalização da pesquisa brasileira em turismo. Revista Turismo \& Desenvolvimento, Portugal, 1(17/18), p. 529-539, 2012.

LEAL, S. R. TRIBE, J. HOLANDA, L. A. d. Percepções de Docentes sobre a Voz dos Estudantes em Relação à Qualidade no Ensino Superior em Turismo no Brasil. Turismo em Análise, São Paulo, v. 24, n. 2, p. 459-478, 2013.

LEIPER, N. Towards a cohesive curriculum in tourism The Case for a Distinct discipline. Annals of Tourism Research, Menomonie, 1981. Disponível em: 
<http://www.periodicos.capes.br>. Acesso em: 04 jun. 2016.

LIMA, S. C. M. Imagem e identidade: Estudo sobre o professor universitário. Tese de doutorado da Universidade de Lisboa. 2012.

MARQUES. F. Pós-graduação em movimento, Revista Fapesp, 2017. http://revistapesquisa.fapesp.br/wp-content/uploads/2017/10/030035 capes 260.pdf acesso em 13. Aceso em Mar 2018.

. Os limites do índice-H. Supervalorização do indicador que combina quantidade e qualidade da produção científica gera controvérsia. Revista pesquisa Fapesp, 2017.

MAIA, M. F. S. COREGNATO, S. E. Co-autoria como indicador de redes de colaboração científica. Perspectivas em ciências da Informação. v.13 n.2, p. 18-31, 2008. Disponível em:

$<$ http://portaldeperiodicos.eci.ufmg.br/index.php/pci/article/view/215 $>$ Acesso em: 10 de julho 2018.

Martins, J. S. Quantofrenia e mérito. Coluna social, 2017.

MANGANTE, E. J.T.; ARAUJO, S. M.; SCHULZ, Peter. Visualization of ranking data: Geographical signatures in international collaboration, leadership and research impact. Vol 8, 2014.

MILGRAM, S. The small world problem. Psychology today, v. 1 p. 61-62, 1967, Disponível em: <http://www.scielo.br/pdf//bcos/v15n4.pdf >. Acesso em: 19 de julho de 2018.

MENEGHINI, R. Emerging Journls: The benefits of and chllenges for publisking scientific journals in and emerging countries. Emboreports, [S.I], v 13, n. 12, 2012.

MENDES, P. H. C. et al. Perfil dos pesquisadores bolsistas de produtividade científica em Medicina no CNPq, Brasil. Revista Brasileira de Educação Médica, v. 34, n. 4, p. 535-541, 2010.

MENA-CHALCO, J. P. DIGIAMPIETRI, L. A. CESAR-JUNIOR, R. M. Caracterizando as redes de coautoria de currículos Lattes. In: BRAZILIAN WORSHOP ON SOCIAL NETWORK ANALYSIS AND MINING (BRASNAM) 1., Curitiba, 2012. Sociedade Brasileira de Computação, Researchgate, 2012. Disponível em:

http://researchgate.net/publication/236118311_Caracterizando_as_redes_de_c oautoria_de_curriculos_lattes. Acesso em: 13 mar. 2018 MILAGRES, V. R. Programa de Pós-graduação em turismo no Brasil. Um olhar sobre a sustentabilidade. Brasília-DF, 2014.

MINOZZO, C. C. REJOWSKI, M. Periódicos científicos em turismo. Revista de la Asociación Latinoamericana de Carreras Universitárias de Turismo y Hotelería, v. 3, n. 1, p. 39-54, 2004. 
MORAES, L.B.B. VILAR, J.W.C. Turismo de sol e praia e ordenamento territorial no litoral Sergipano. IN VILAR,J.W,C, ARAUJO, H,M. Território, Meio ambiente e Turismo no Litoral Sergipano. São Cristovão: Editora UFS,2010.

MUELLER, S.P. O círculo vicioso que prende os periódicos nacionais. DataGramaZero-Revista de Ciência da Informação, 1999. Disponível em: http://www.dgz.org.br/dez99/Art 04.htm. Acesso em 20 de mar. De 2018.

MUGNAINI, R. Avaliação da Produção Científica Nacional: Contextualização e Indicadores. In: POBLACIÓN, D.A et al. Revistas Científicas: dos processos tradicionais às perspectivas alternativas de comunicação. Cotia, SP: Ateliê Editorial, 2007.

. Caminhos para a adequação da produção científica brasileira: impacto nacional versus internacional. 2006. 253f. Tese (doutorado) Programa de Pós-graduação em Ciência da Informação, Universidade de São Paulo, 2006.

MOTA. K. Qualidade da Educação superior em turismo e Hotelaria: Análise dos cursos de graduação reconhecidos no Nordeste Brasileiro. Tese (doutorado) Universidade do Vale do Itajaí (UNIVALI) centro de educação superior Balneário Camboríu, 2005.

NAVAS, CA.,. et al. Reflexões sobre conflitos de interesse, qualidade da formação e sistemas de avaliação no contexto dos programas da Área das Ciências Biológicas II da Capes. Documento eletrônico disponibilizado pela Coordenação de Área das Ciências Biológicas II da Capes 2017. doi: http://dx.doi,org/10.13140/RG.2.2.34051.40487/2.

NECHAR, M. Epistemologia crítica do turismo: o que é isso?, Comunicação no Simpósio in: I SEMINÁRIO INTERNACIONAL DE ESTUDOS CRÍTICOS EM TURISMO, 24-25 Março, Natal, Brasil.2010.

Oliveira, E. A. et al. Comparison of Brazilian researchers in clinical medicine: are criteria for ranking well-adjusted? Revista Scientometrics, v. 90 n.2.p. 429-443, 2012.

PEQUENO, E. A. Ensino superior em Turismo: uma análise da relação dos cursos acadêmicos de Turismo da cidade do Natal-RN e o mercado de trabalho na percepção dos egressos dos anos de 2009 e 2010. Dissertação de mestrado defendida na Universidade Federal do Rio Grande do Norte. Natal, 2012.

PRATES, M. Algumas considerações críticas sobre a pós-graduação brasileira transinformação, v.9, n 2, p. 16-21 maio/agosto, 1997.

PAN, R. K; FORTUNATO, S. Word And Collaboration Networks: Uncovering The Role of Geography In Science. Scientific Reports, 2012. 
PANOSSO NETTO, A. TRIGO, L.G.G. SILVEIRA. C.E. Knowledge Transfer To and Within Tourism: Academic, Industry and Government Bridges Bridging Tourism Theory and Practice, Volume 8, 113128 Copyright $r 2017$ by Emerald Publishing Limited All rights of reproduction in any form reserved ISSN: 2042-1443/doi:10.1108/S2042-144320170000008008. 2017.

PANOSSO NETTO; A. TRIGO; L. G. Cenários do turismo brasileiro. São Paulo: Aleph, 2009. (série turismo).

PANOSSO NETTO, A. NECHAR. C. M. Turismo: perspectiva crítica: textos reunidos-Assis: Triunfal Gráfica e Editora, 2016.

Plataforma Sucupira- https://sucupira.capes.gov.br acesso em 13 de mar. de 2017.

Plataforma Sucupira- https://geocapes.capes.gov.br/geocapes acesso em 13 de mar. 2018.

PEREIRA, J. C. R. BRONHARA, B. Índice H de docentes em Saúde Coletiva no Brasil. Revista de Saúde Pública, v. 5, n.2, p. 14-30, 2011.

PAGE, L. et al. The pagerank citation ranking: bringing order to the web. 1999. Stanford InfoLab, 1999.

PRICE, DEREREK J. de SOLLA. Little science, big science. New Cork: Columbia University Press, 1963.

QUEIROZ,D.G.C. Produção Intelectual Docente do Instituto matemática/UFRGS: análise dos artigos produzidos entre os anos 2007 e 2011, 2012.

REGO, S. Autoria e Integridade na Produção Científica. Revista Brasileira de Medicina, 2010.

REJOWSKI, Mirian. Realidade turísticas nas pesquisas científicas: Visão de pesquisadores e profissionais. São Paulo, SP. ECA (Escola de Comunicação e Artes) USP; 1996. Tese de livre docência.

Pesquisa científica em turismo no Brasil: comunicação, produtividade e posicionamento - Fase 2 (1990 a 2010). São Paulo: Universidade Anhembi Morumbi, (Relatório de pesquisa - processo CNPq ${ }^{\circ}$ 311757/2006-5), 2010.

Produção Científica em turismo: Análise de estudos

referenciais no exterior E no Brasil, v.21, n.2, p. 224-246, 2010. Disponível em: http://www.revistas.usp.br/rta/article/downloud/1421516085. Acesso em 20 abr. 016.

RUSCHMANN, D. V. M. Turismo: grande desafio dos anos 90/ II Seminário Latino-Americano. AMFORT: São Paulo-Brasil, 21 a 23 de maio de 1990- São 
Paulo: Escola de Comunicações e Artes/USP. Capitulo 3 Capacitação de docentes para o ensino do turismo em países em desenvolvimento. 1991.

SALES, D.P. Critérios de avaliação da produção científica em ciências sociais aplicadas. Inquirindo as bases de dados/ São Paulo: Ed. Unesp, 2009.

SANTOS, S. et al. Perfil dos pesquisadores da Saúde Coletiva no Conselho Nacional de Desenvolvimento Científico e Tecnológico. Physis, v. 19, n. 3, p. 761-775, 2013.

SILVA et al. Estâncias e Munícipios de Interesse Turístico. O exemplo de São Paulo como incentivo ao turismo para o Brasil. Ed. Juruá, 2018.

SILVA, M. P. TIRELO, F. MARQUES NETO, H. T. Uso do algoritmo Pagerank para a Priorização de Requisitos de Software. Instituto de Ciências Exatas e Informática, Departamento de Ciência e Computação, Pontifícia Universidade Católica rizonte, 2013.

SILVA,D.C.F.B. Professores do curso de tecnologia em hotelaria: conhecendo os saberes docentes. Dissertação a banca examinadora do programa de pós-graduação em educação da UNIMEP. Piracicaba, São-paulo, 2007.

SILVA, F. M. et al. Proposta metodológica para a geração de indicadores científicos: análise dos programas de pós-graduação em ciência da informação (PPGCl) da região nordeste. Revista Digital de Bibloteconomia e Ciência da Informação, v. 10, n. 1, p. 67-90, 2012b.

SANTOS, G. E. O. PANOSSO NETTO, A. WANG. X. Análise de Citações de Periódicos Científicos de Turismo no Brasil: Subsídios para a estimação de indicadores de impacto. Revista Brasileira de Pesquisa em Turismo RBTUR-2017.

SANTOS; R. NONATO, M. Produção científica: por que medir? O que medir? .Revista digital de biblioteconomia e ciência da informação, Campinas, v.1. n 1, p-22-38, jul/dez 2003.

SANTOS, O. E. G. LEAL, R. S. PANOSSO NETTO, A. O Brasil na literatura internacional de turismo: Análise das publicações em idioma inglês. Revista Brasileira de Pesquisa em Turismo. São Paulo, 9(3), pp. 459-478, set./dez. 2015.

SCRIPLATTES- Disponível em: <https://bitbucket.org/vlab4u>. Acessado em: 13 jul. 2017.

SGUISSARDI; V. Pós-graduação (em educação) no Brasil: Conformismo, neoprofissionalismo, Heteronomia e competitividade. In: Mancelo, Deise, Silva Júnior, João Reis; Oliveira, Joao Ferreira de (org). Reformas e políticas: educação superior e pós-graduação no Brasil. Campinas: Alinea,p. 137-164, 2008. 
SAVANI, D. A pós-graduação em educação no Brasil: Trajetória, situação atual e perspectivas. Revista diálogo Educacional. V. 1 n.1 p 1-95 jan/jun. 2002; SILVA, M. R. Análise bibliométrica da produção científica docente do programa de Pós-Graduação em Educação Especial da UFSCAR: 19982003-São Carlos, 2004.

SOARES, SR. CUNHA, M.I. Formação do professor: A docência universitária em busca de legitimidade [online]. Salvador: EDUFBA, 2010. 134 p. ISBN 97885-230677.http://static.scielo.org/scielobooks/cb/pdf/soares9788523211981.pdf Acesso em 12/09/2016.

SPOLON, A. P. G. Hospitalidade em rede: propriedades estruturais e arranjos relacionais da rede de produção de conhecimento científico em Hospitalidade, no Brasil (1990-2014). Tese (Pós-Doutoramento). 174 f. (il.). Escola de Artes, Ciências e Humanidades da Universidade de São Paulo (EACH-USP), São Paulo, 2015.

STEPCHENKOVA, S. KIRILENKO, A. P. \& MORRISON, A. M. (2009). Facilitating content analysis in tourism research. Journal of Travel Research, 47(4), pp. 454-469.

TEIXEIRA, S.H.A. Cursos Superiores de Turismo. Condicionantes Sociais da sua Implantação: Uma Abordagem Histórica (1968/1976). 2007. 71f. Dissertação (Mestrado em Educação) - Universidade São Francisco, Itatiba, 2007.

THOMAZ, P.G. ASSAD, R.S. MOREIRA, F.P. Uso do fator de impacto e do índice $\mathrm{H}$ para avaliar pesquisadores e publicações. Revista Arquivos Brasileiros de Cardiologia. V.96 n.2, São Paulo, 2011.

TOMAZZONNI, E.L. Coletânea de estudos turísticos. Ensino, Eventos, Hotelaria, Intercâmbio internacionais. Assis: Triunfal Gráfica e Editora, 2016.

TRIGO, L. G. G. A sociedade pós-industrial e o profissional em turismo. Campinas: Papirus, 1998.

A importância da educação para o turismo. In: Lage, B.HG; Melone, P.C. (org) Turismo teoria e pratica. São Paulo: Atlas, 2000.

Tribe, John. (2006a). The economic impacts of tourism. In: Beech, J.; Chadwick, S. (Eds.). The business of tourism management. Pearson Education. 1997. .The indiscipline of tourism. Annals of Tourism Research, v. 24, n. 4, 638-657. (1997a) The indiscipline of tourism. Annals of Tourism Research, 24 (3),

VEAL, A.J. Metodologia de pesquisa em lazer e turismo. Tradução Gleice Guerra, Mariana Aldrigui. São Paulo: Alep, 2011. 
VELOSO; A. A pós-graduação no Brasil: legados e desafios. Almanaque disciplinar de pesquisa. Universidade Unigranrio ANO I - Volume 1 - Número 1 2014 Artigo Especial.

VOGEL; M. J. M. Avaliação da Pós-graduação Brasileira: Análise dos quesitos utilizados pela Capes e das Críticas da comunidade acadêmica. 2015.

VANZ, S.A de S; STUMP, I. R. C. Colaboração Científica: revisão teóricoconceitual. Perspectivas em Ciência da Informação. v.15, n.2, p.42-55, maio./ago. 2010.

THOMAZ, P. G. ASSAD, R. S. MOREIRA, L.F. Uso do Fator de Impacto e do índice H para avaliar Pesquisadores e Publicações. Revista Arq. Bras Cardial, 2011.

Wainer, J.; Eckmann, M.; Goldenstein, S. \& Rocha, A. How productivity and impact differ across computer science subareas. Commun. ACM, 56(8):67-73, 2013. 
ANEXOS 


\section{ANEXO A: DOCENTES QUE POSSUEM O ÍNDICE H}

UAM: Universidade Anhembi Morumbi

Airton José Cavenaghi

\begin{tabular}{lrr} 
& Todos & Desde 2013 \\
\hline Citações & 58 & 38 \\
Índice h & 5 & 3 \\
Índice i10 & 0 & 0
\end{tabular}

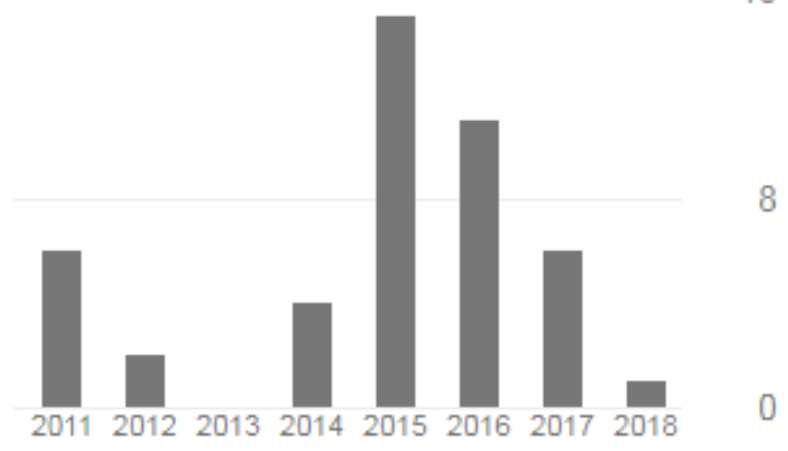

Claudio José Stefanini

\begin{tabular}{|c|c|c|}
\hline & Todos & Desde 2013 \\
\hline Citações & 18 & 15 \\
\hline Índice h & 3 & 2 \\
\hline Índice i10 & 0 & 0 \\
\hline
\end{tabular}

Carlos Alberto Alves 


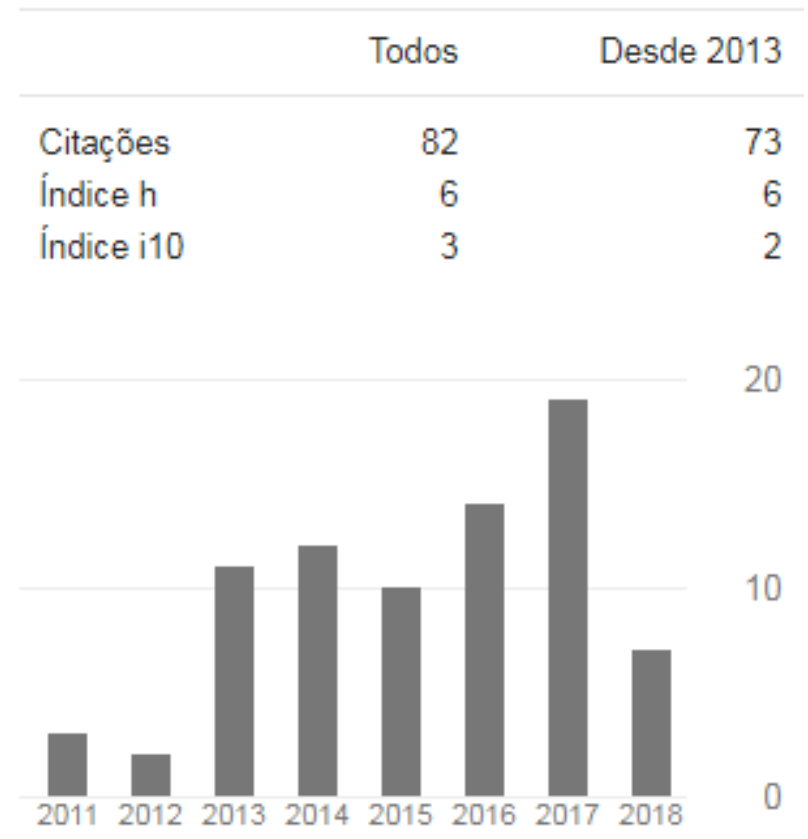

Elizabeth Kyoko Wada

\begin{tabular}{lrr}
\hline & Todos & Desde 2013 \\
\hline Citações & 201 & 138 \\
Índice h & 9 & 7 \\
Índice i10 & 8 & 5
\end{tabular}

60

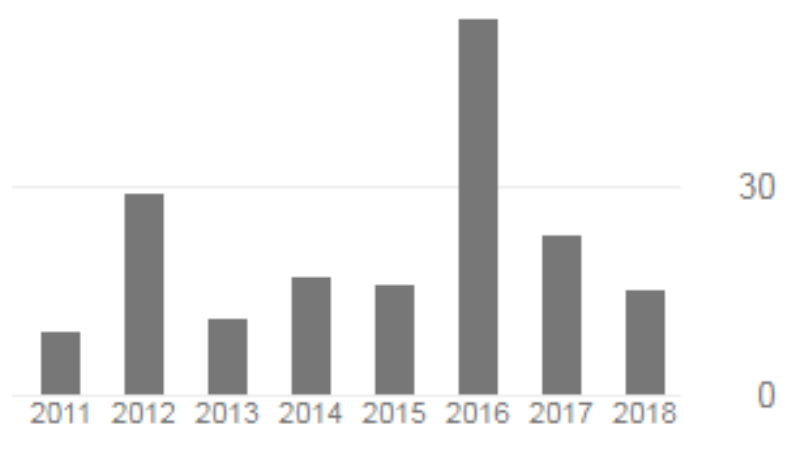

Luiz Octávio de Lima Camargo 


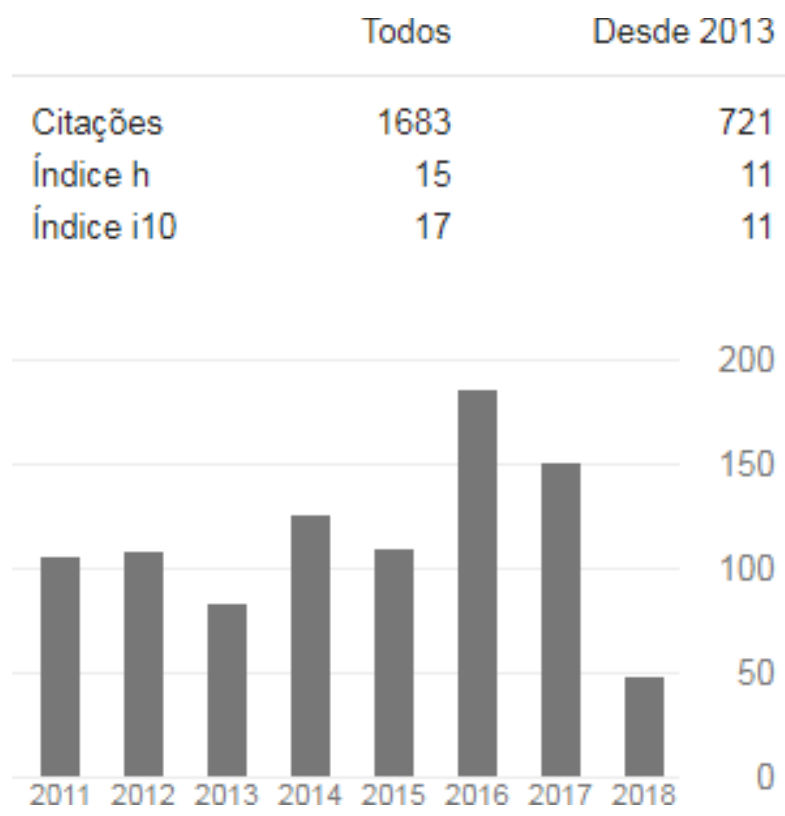

\section{Roseane Barcellos Marques}

\begin{tabular}{lrr} 
& Todos & Desde 2013 \\
\hline Citações & 20 & 16 \\
Índice h & 3 & 2 \\
Índice i10 & 0 & 0
\end{tabular}

6

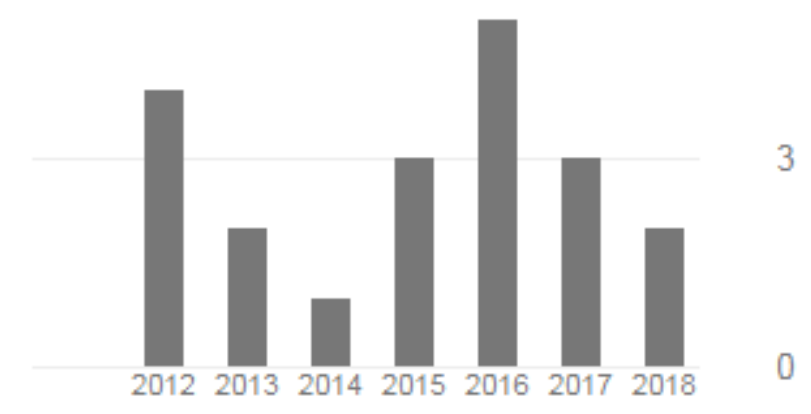

Maria Henriqueta Sperandio Garcia Gimenes Minasse 
Todos

Desde 2013

\section{Citações}

Índice $\mathrm{h}$

Índice $\mathrm{i10}$
254

8

8
173

8

6

38

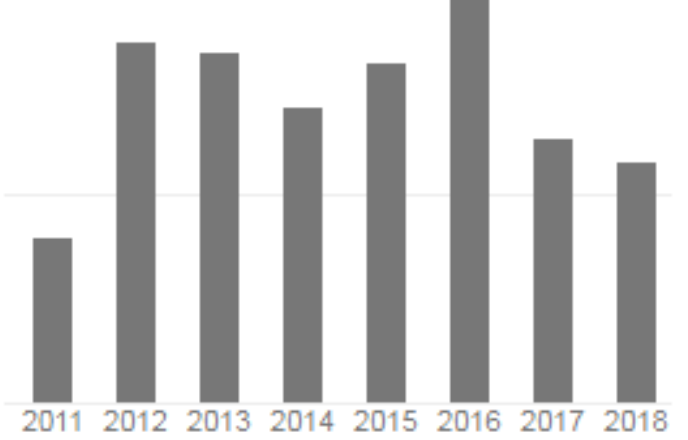

0

\section{Mirian Rejowski}

Todos Desde 2013

$\begin{array}{lrr}\text { Citações } & 1119 & 520 \\ \text { Índice h } & 16 & 12 \\ \text { Índice i10 } & 33 & 17\end{array}$

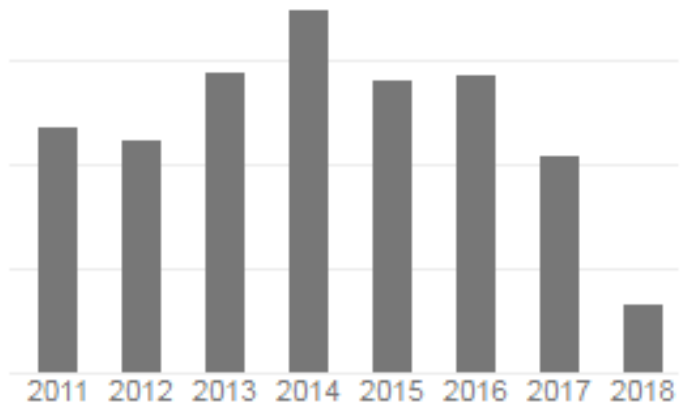

Sergio Luiz do Amaral Moretti 


\begin{tabular}{lrr} 
& Todos & Desde 2013 \\
\hline Citações & 515 & 361 \\
Índice h & 11 & 10 \\
Índice i10 & 14 & 12
\end{tabular}

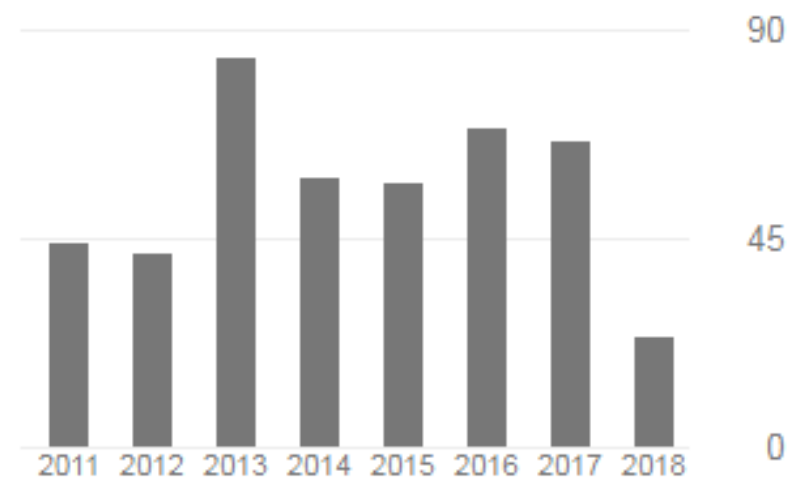

\section{UECE: Universidade Estadual do Ceará}

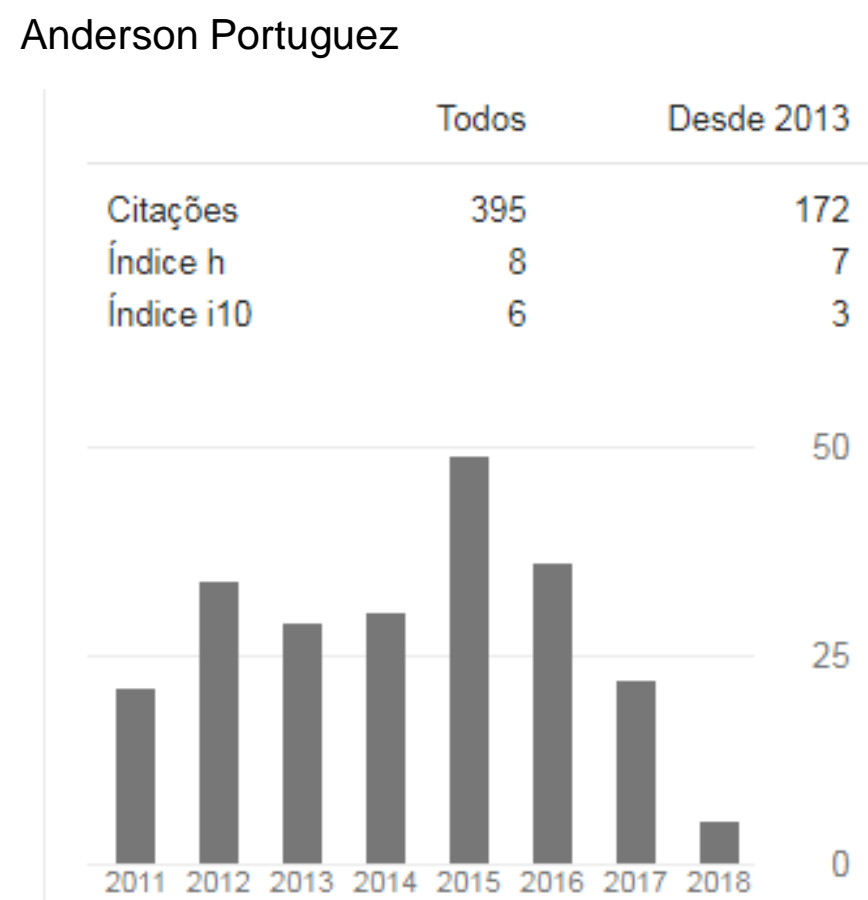

José clerton Martins 




Marcelo Martins de Moura Fe

Todos Desde 2013

$\begin{array}{lrr}\text { Citações } & 59 & 57 \\ \text { Índice h } & 5 & 5 \\ \text { Índice i10 } & 1 & 1\end{array}$



Sandra Maia Farias Vasconcelos 
Todos Desde 2013

Citações

Índice $\mathrm{h}$

Índice i10

61

4

3

10



5

Sara Joana Gadotti dos Anjos

\begin{tabular}{lrr} 
& Todos & Desde 2013 \\
\hline Citações & 450 & 264 \\
Índice h & 8 & 8 \\
Índice i10 & 6 & 5
\end{tabular}

70

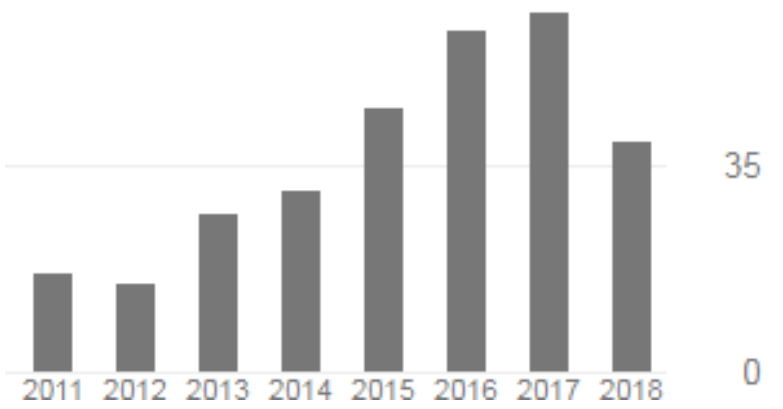


UFRN: Universidade Federal do Rio Grande do Norte

\section{Carlos Alberto Freire Medeiros}

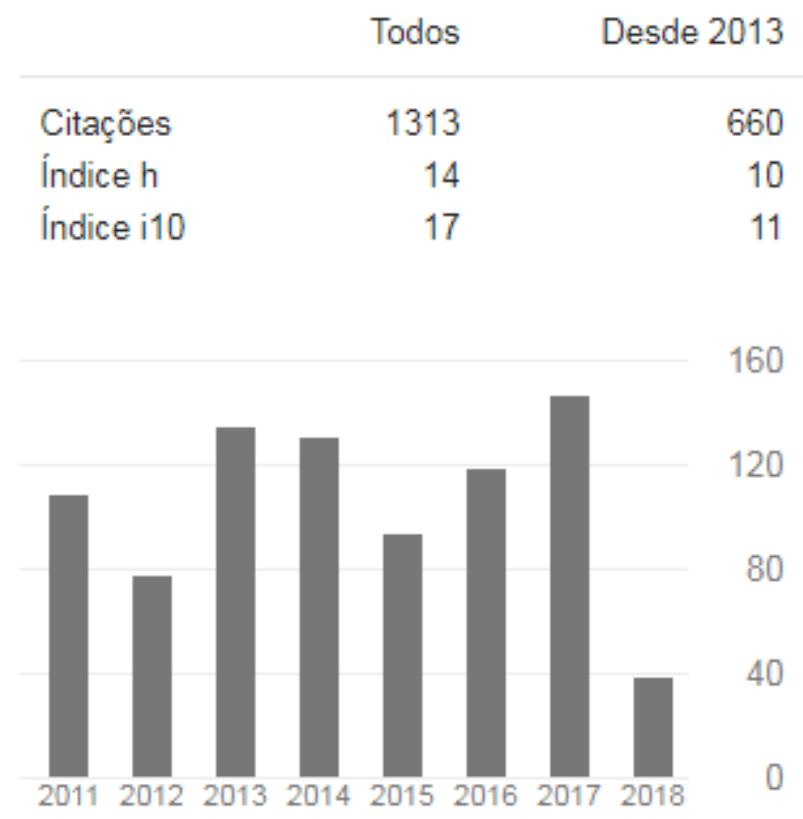

Francisco Fransualdo de Azevedo

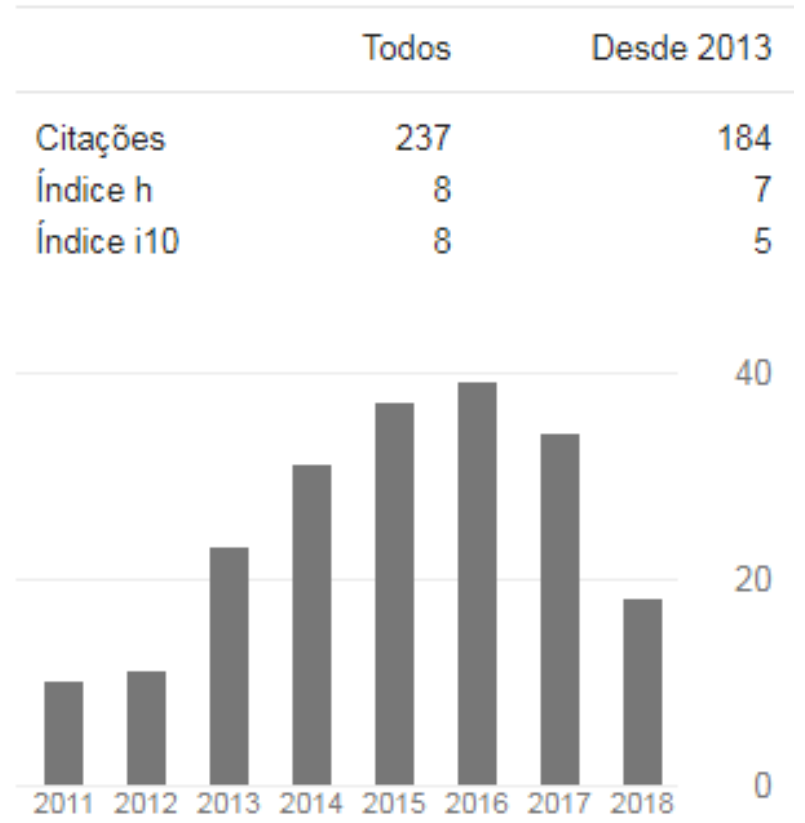


Luiz Augusto Machado Mendes Filho

Todos Desde 2013

$\begin{array}{lrr}\text { Citações } & 173 & 126 \\ \text { Índice h } & 9 & 7 \\ \text { Índice i10 } & 6 & 4\end{array}$

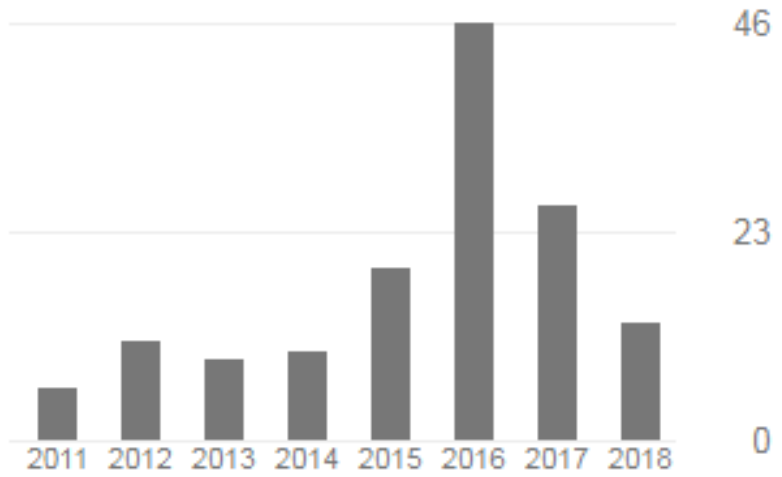

Marcos Antonio Leite do Nascimento

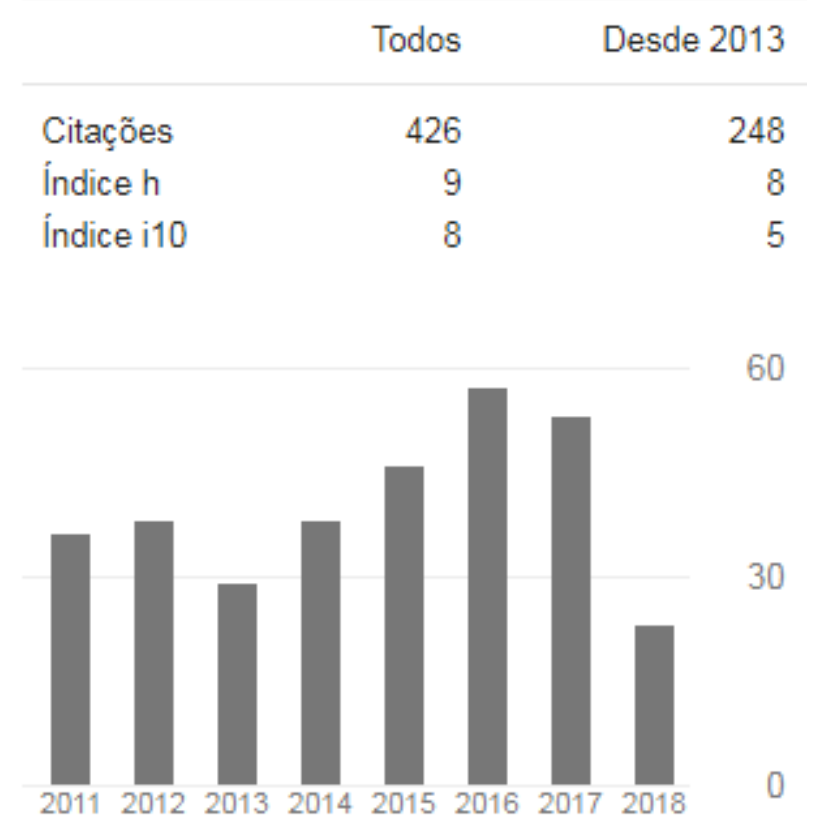


Sergio Rodrigues Leal

Todos Desde 2013

$\begin{array}{lrr}\text { Citações } & 117 & 71 \\ \text { Índice h } & 7 & 5 \\ \text { Índice i10 } & 4 & 1\end{array}$



\section{Silvana Pirillo Ramos}

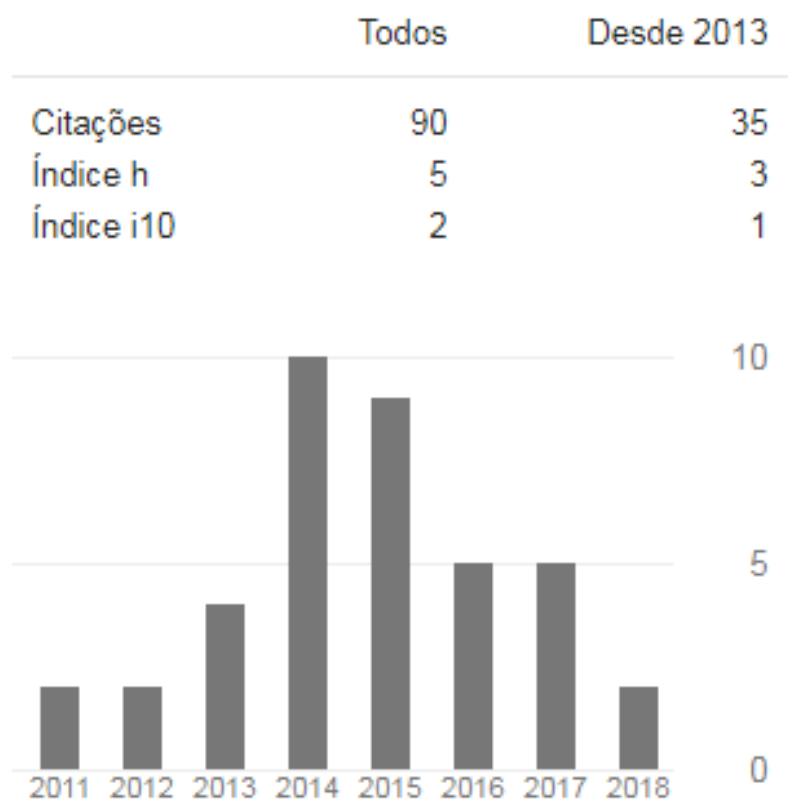


Wilker Ricardo de Mendonça Nobrega



UFF: Universidade Federal Fluminense

Aguinaldo César Fratucci

$\begin{array}{lrr}\text { Citações } & 214 & 158 \\ \text { Índice h } & 7 & 7 \\ \text { Índice i10 } & 5 & 4\end{array}$

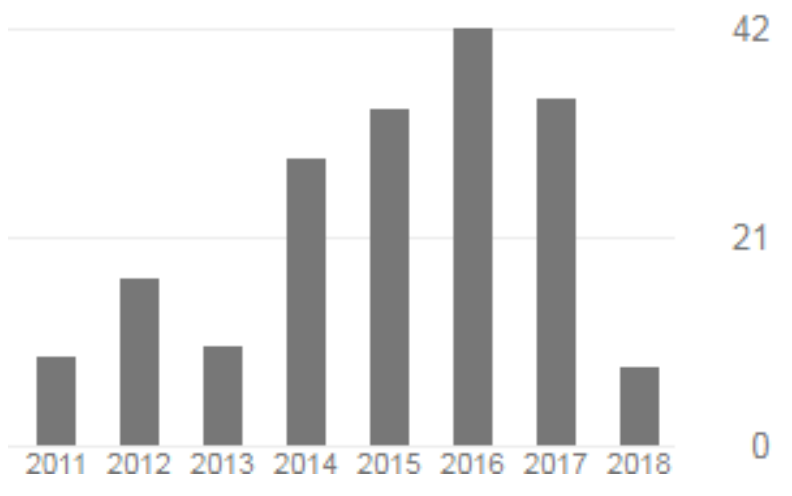


UFPR: Universidade Federal do Paraná

Marcia S. Massukado Nakatani

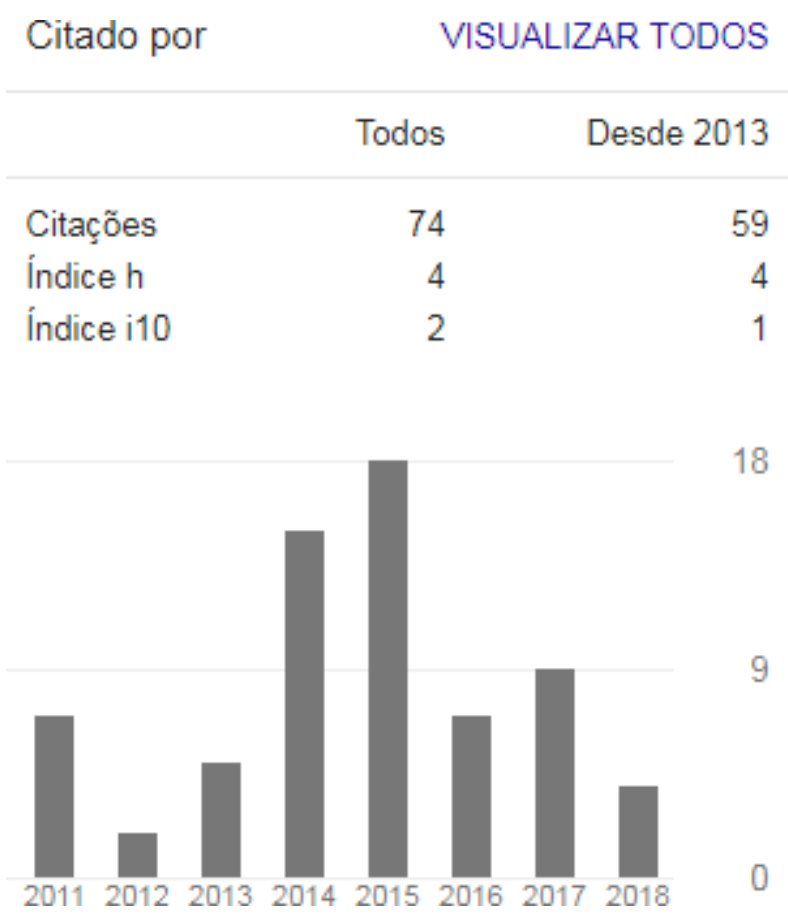

Alexandre Augusto Biz

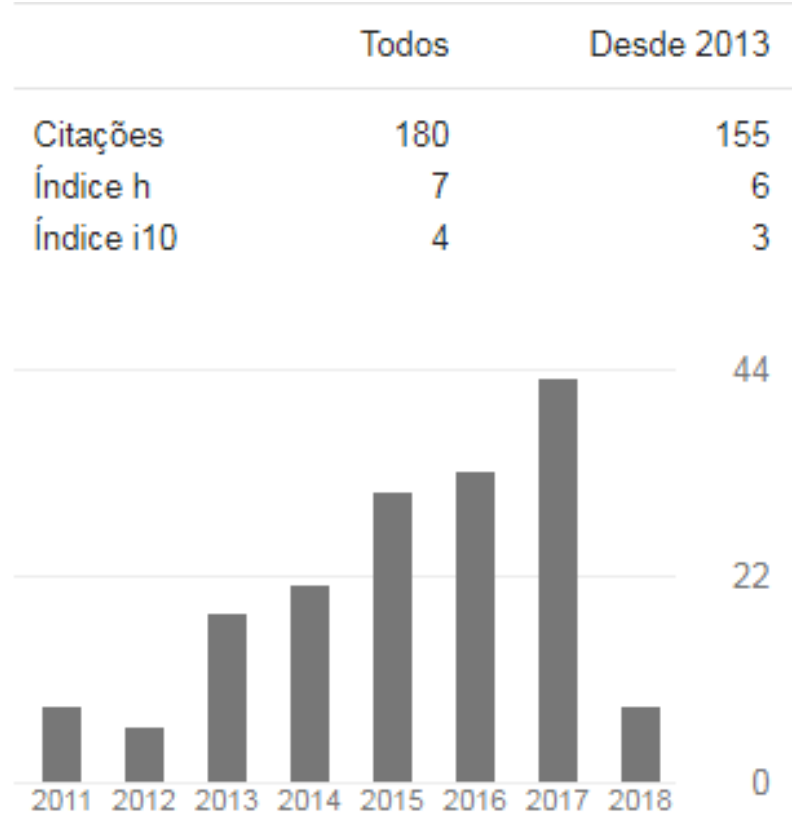


Bruno Martins Augusto Gomes

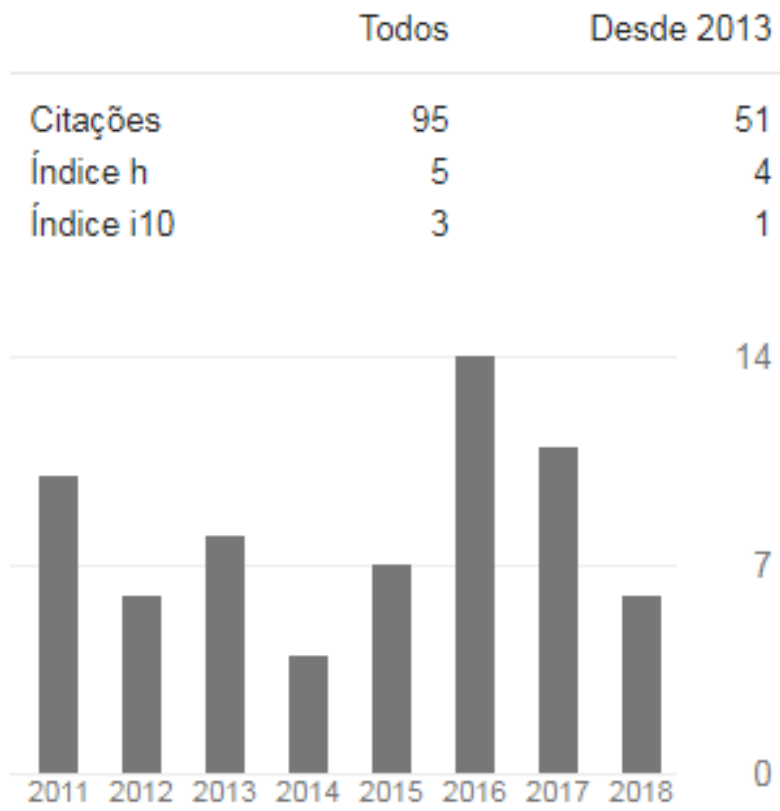

Carlos Alberto Cioce Sampaio

\begin{tabular}{lrr} 
& Todos & Desde 2013 \\
\hline Citações & 1012 & 545 \\
Índice h & 16 & 11 \\
Índice i10 & 30 & 16
\end{tabular}




Carlos Eduardo Silveira

\begin{tabular}{|c|c|c|}
\hline & Todos & Desde 2013 \\
\hline Citações & 125 & 81 \\
\hline Índice h & 6 & 5 \\
\hline Índice i10 & 2 & 2 \\
\hline & & 20 \\
\hline & & \\
\hline & & 10 \\
\hline & & \\
\hline & & \\
\hline & & 0 \\
\hline
\end{tabular}

Cinthia Maria de Sena Abrahão

\begin{tabular}{lrr} 
& Todos & Desde 2013 \\
\hline Citações & 13 & 12 \\
Índice h & 2 & 2 \\
Índice i10 & 0 & 0
\end{tabular}


Daniel Hauer Queiroz Telles

Todos Desde 2013

$\begin{array}{lrr}\text { Citações } & 39 & 30 \\ \text { Índice h } & 4 & 3 \\ \text { Índice i10 } & 0 & 0\end{array}$

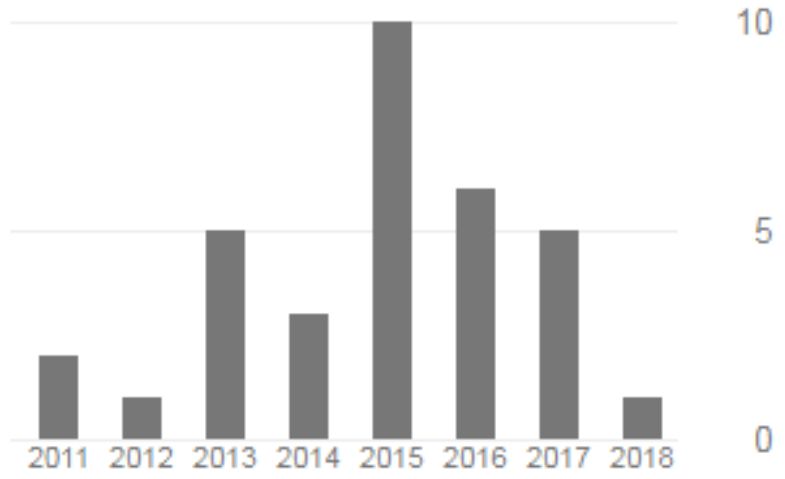

Graziela Scalise Horodyski

\begin{tabular}{lrr} 
& Todos & Desde 2013 \\
\hline Citações & 96 & 92 \\
Índice h & 6 & 6 \\
Índice i10 & 5 & 5
\end{tabular}




José Elmar Feger

\begin{tabular}{lrr} 
& Todos & Desde 2013 \\
\hline Citações & 51 & 37 \\
Índice h & 4 & 4 \\
Índice i10 & 0 & 0
\end{tabular}

10



José Manoel Gonçalves Gândara

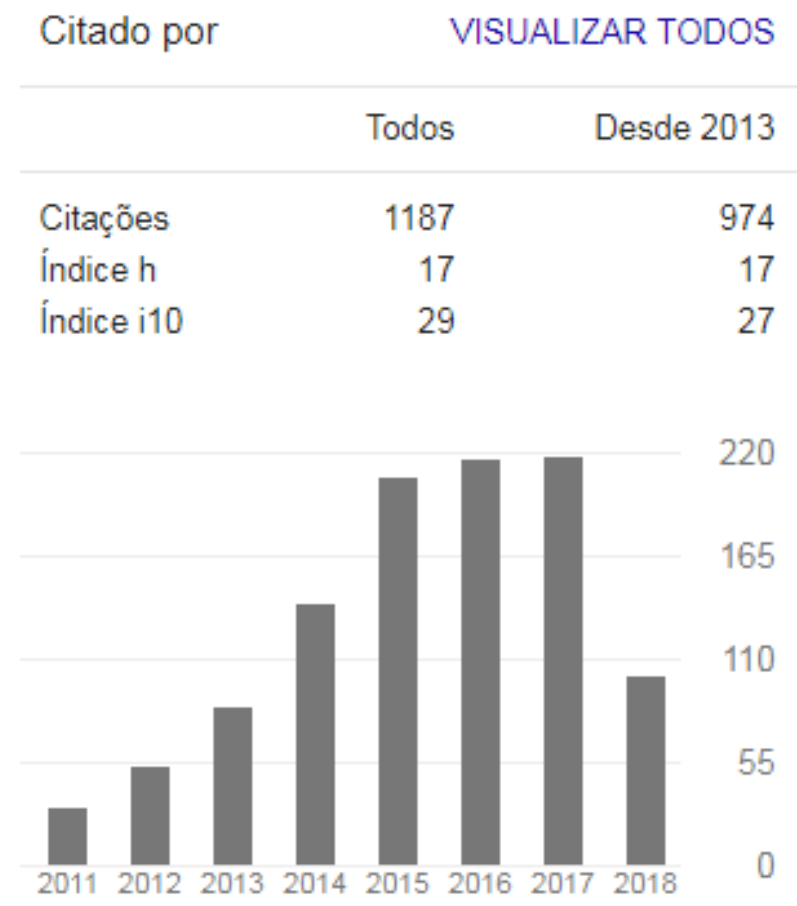


Leticia Bartoszeck Nitsche

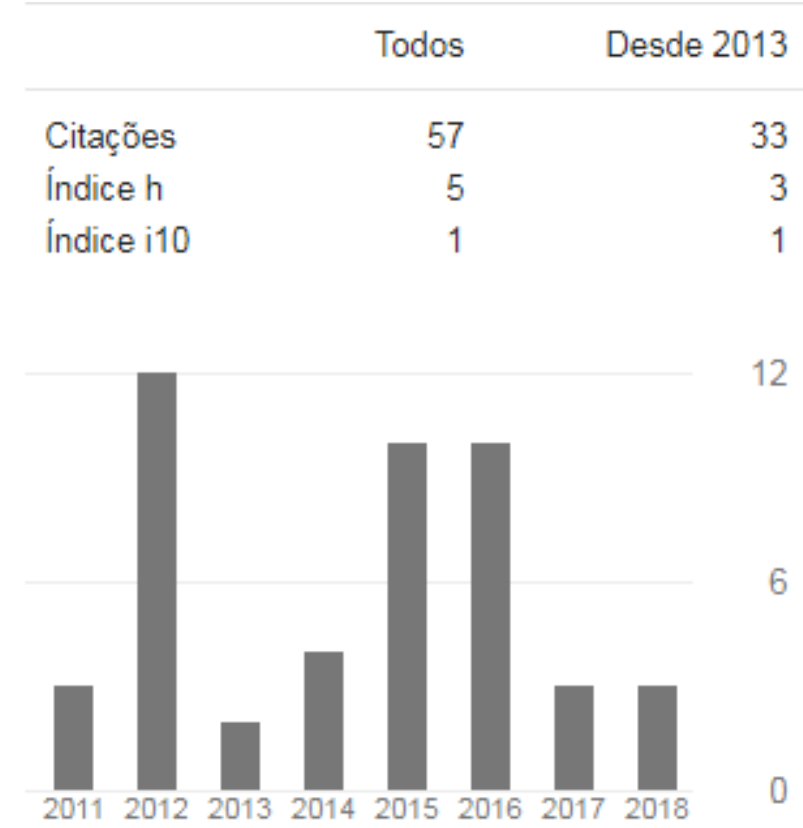

\section{Luiz Ernesto Brambatti}

\begin{tabular}{lrr} 
& Todos & Desde 2013 \\
\hline Citações & 48 & 25 \\
Índice h & 3 & 2 \\
Índice i10 & 2 & 1
\end{tabular}

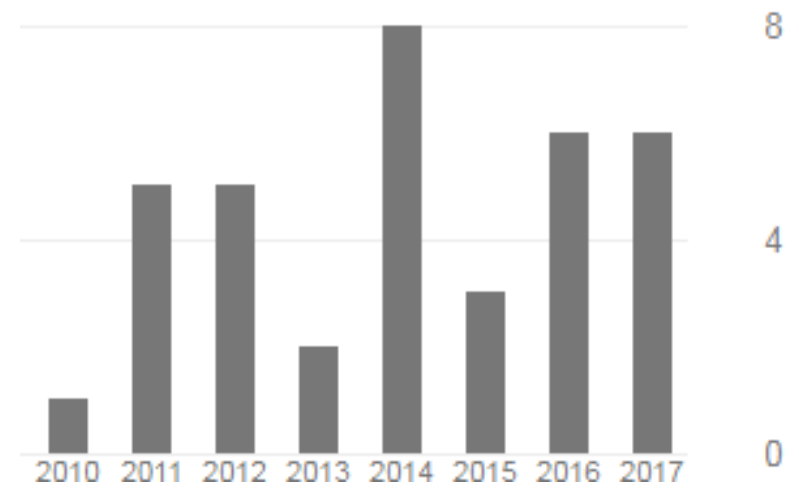


Marcelo Chemin

\begin{tabular}{lrr} 
& Todos & Desde 2013 \\
\hline Citações & 6 & 5 \\
Índice h & 1 & 1 \\
Índice i10 & 0 & 0
\end{tabular}

4

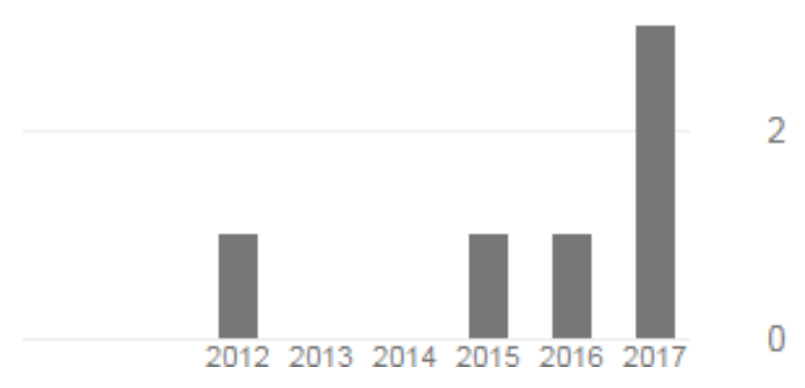

Marcos Aurelio Tarlombani da Silveira

\begin{tabular}{lrr} 
& Todos & Desde 2013 \\
\hline Citações & 315 & 125 \\
Índice h & 8 & 4 \\
Índice i10 & 7 & 4
\end{tabular}

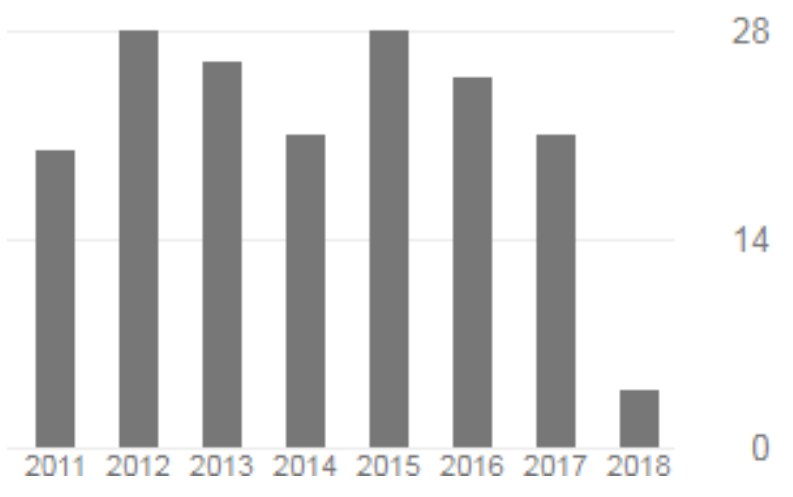


Margarete Araujo Teles

Todos Desde 2013

$\begin{array}{lrl}\text { Citações } & 10 & 8 \\ \text { Índice h } & 2 & 2 \\ \text { Índice i10 } & 0 & 0\end{array}$

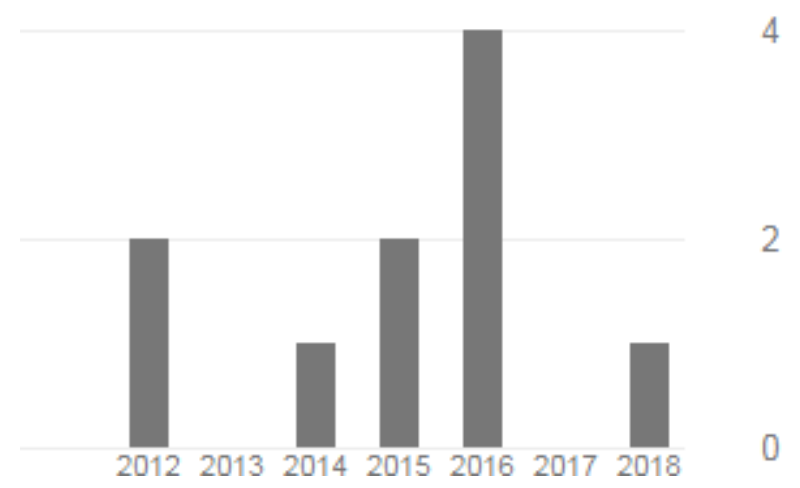

Miguel Bahl

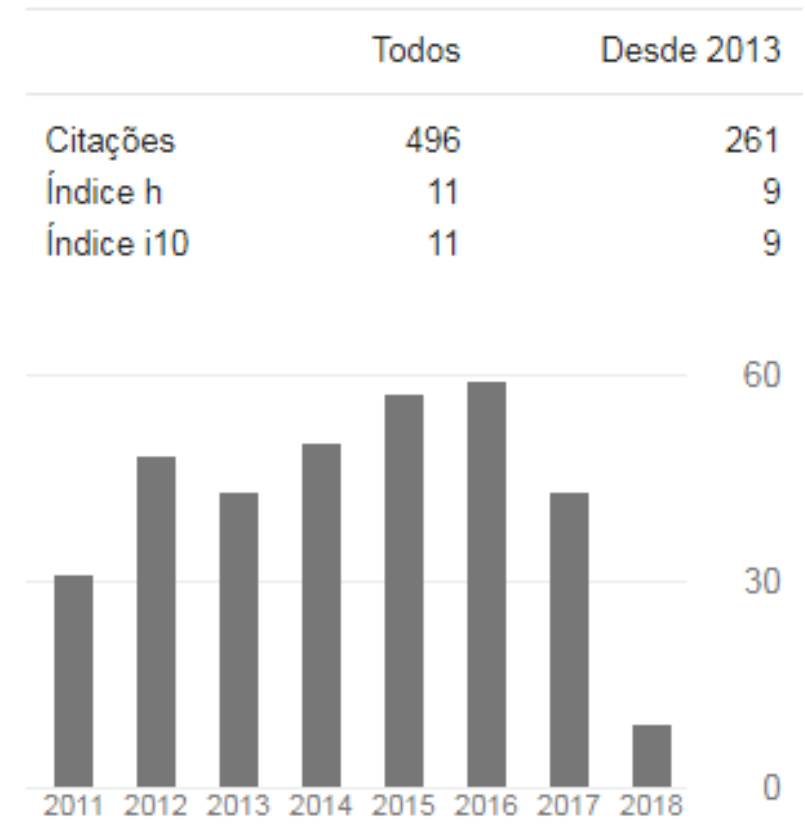


Silvana do Rocio de Souza

\begin{tabular}{|c|c|c|}
\hline & Todos & Desde 2013 \\
\hline Citações & 19 & 19 \\
\hline Índice h & 2 & 2 \\
\hline Índice i10 & 1 & 1 \\
\hline & & 10 \\
\hline & & \\
\hline & & 5 \\
\hline & & \\
\hline & & \\
\hline
\end{tabular}

\section{Vander Valduga}

Todos Desde 2013

\begin{tabular}{lrr}
\hline Citações & 167 & 126 \\
Índice h & 7 & 6 \\
Índice i10 & 5 & 4
\end{tabular}

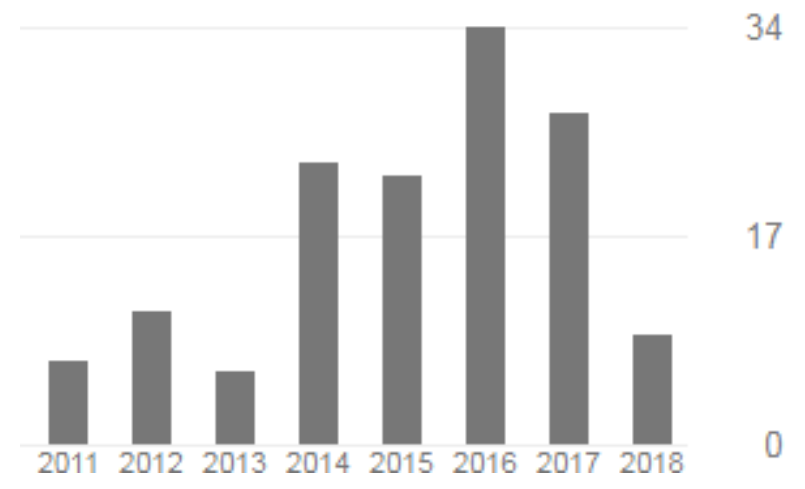

UNIVALI: Universidade Vale do Itajaí 
Sara Joana Gadotti dos Anjos

\begin{tabular}{lrr} 
& Todos & Desde 2013 \\
\hline Citações & 450 & 264 \\
Índice h & 8 & 8 \\
Índice i10 & 6 & 5
\end{tabular}

70

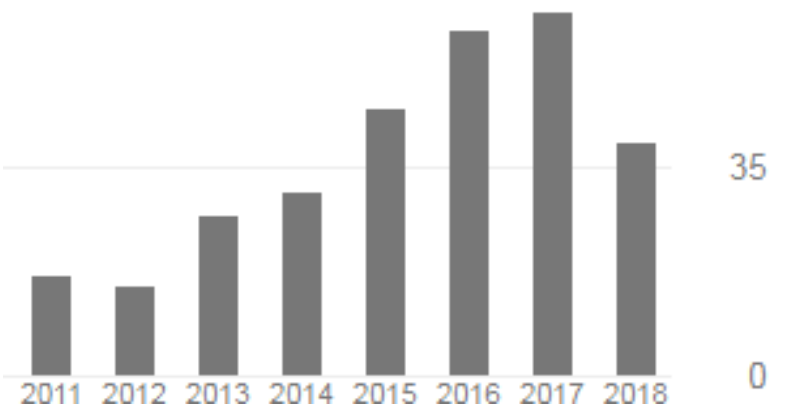

Anete Alberton

\begin{tabular}{lrr} 
& Todos & Desde 2013 \\
\hline Citações & 425 & 248 \\
Índice h & 9 & 9 \\
Índice i10 & 9 & 6
\end{tabular}

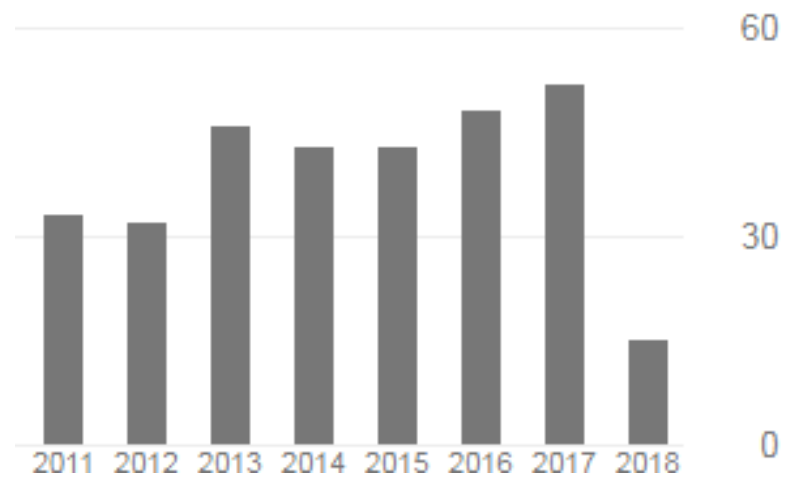


Francisco Antonio dos Anjos

\begin{tabular}{lrr} 
& Todos & Desde 2013 \\
\hline Citações & 218 & 173 \\
Índice h & 8 & 7 \\
Índice i10 & 5 & 4
\end{tabular}



Luiz Carlos da Silva Flores

\begin{tabular}{lrr} 
& All & Since 2013 \\
\hline Citations & 45 & 45 \\
h-index & 4 & 4 \\
i10-index & 3 & 3
\end{tabular}

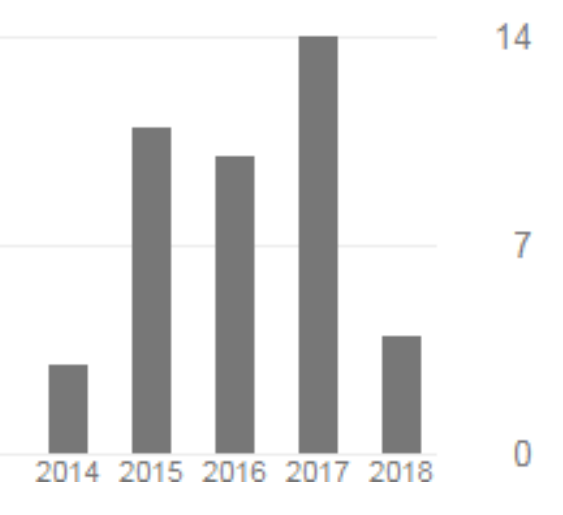


UCS: Universidade de Caxias do Sul

Susana de Araujo Gastal

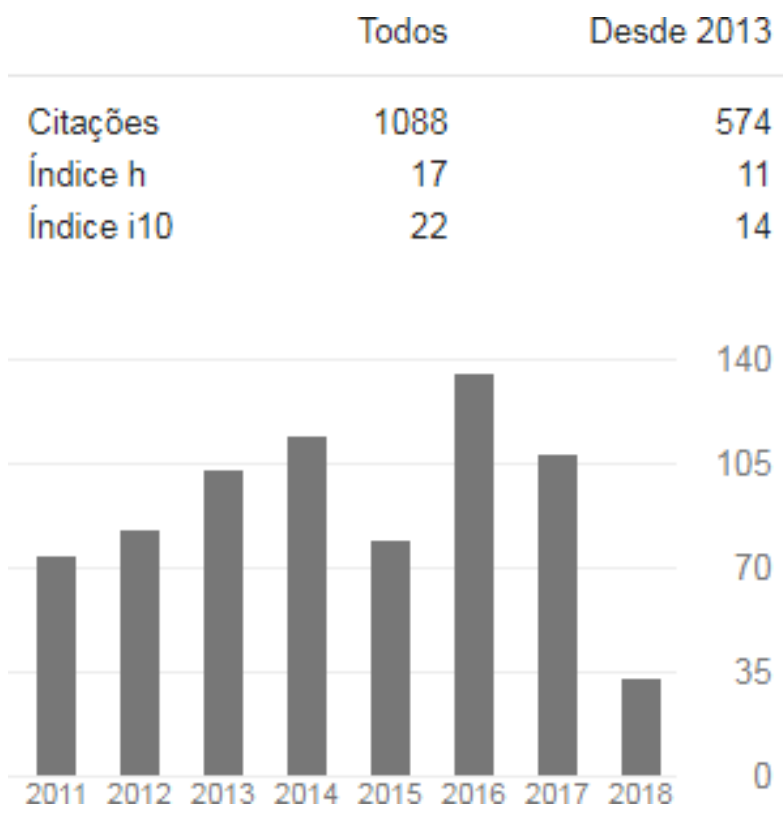

Luciane Todeschini Ferreira

Todos Desde 2013

$\begin{array}{lrr}\text { Citações } & 24 & 22 \\ \text { Índice h } & 4 & 4 \\ \text { Índice i10 } & 0 & 0\end{array}$

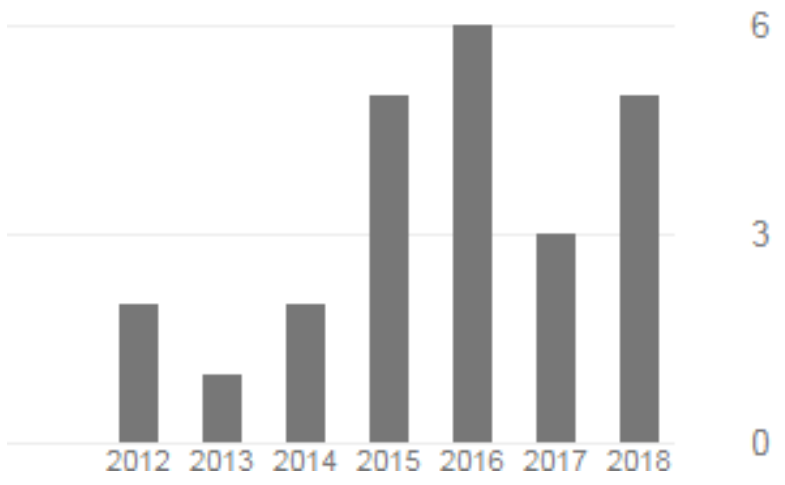

Marcia Maria Cappellano dos Santos 


\begin{tabular}{lrr} 
& Todos & Desde 2013 \\
\hline Citações & 92 & 75 \\
Índice h & 5 & 5 \\
Índice i10 & 2 & 2
\end{tabular}

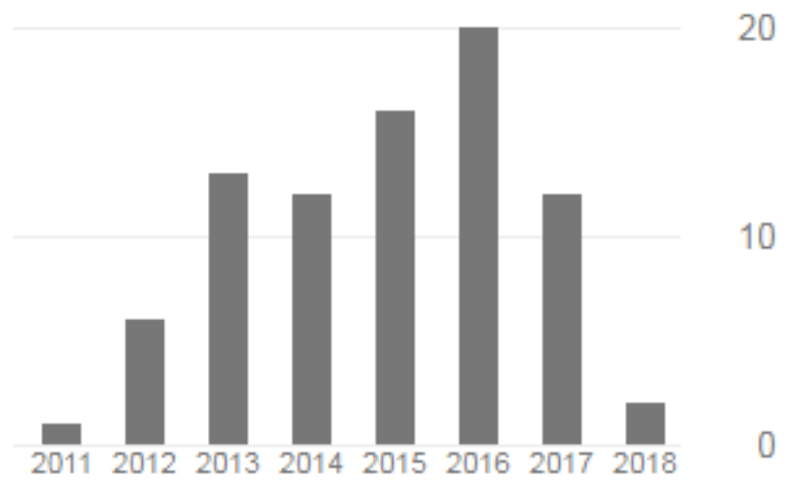

Maria Luiza Cardinale Baptista

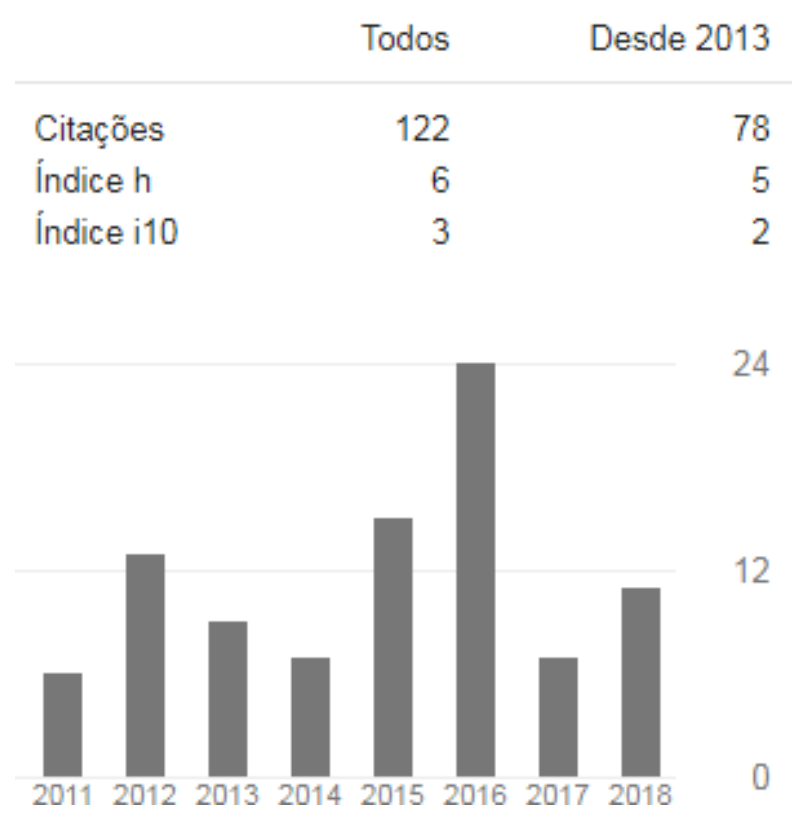


Mario Beni

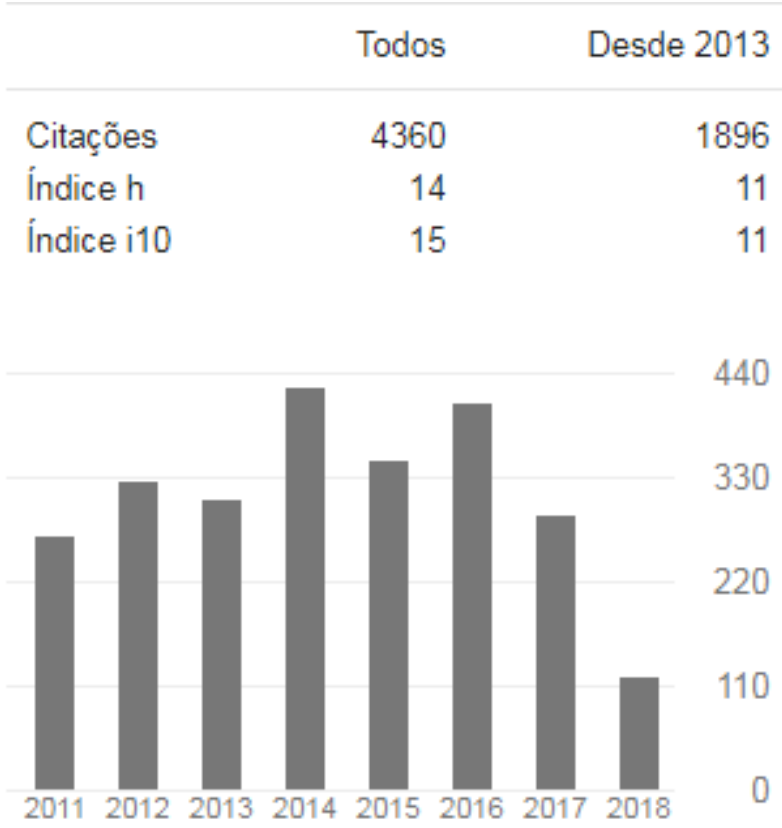

Rafael José dos Santos

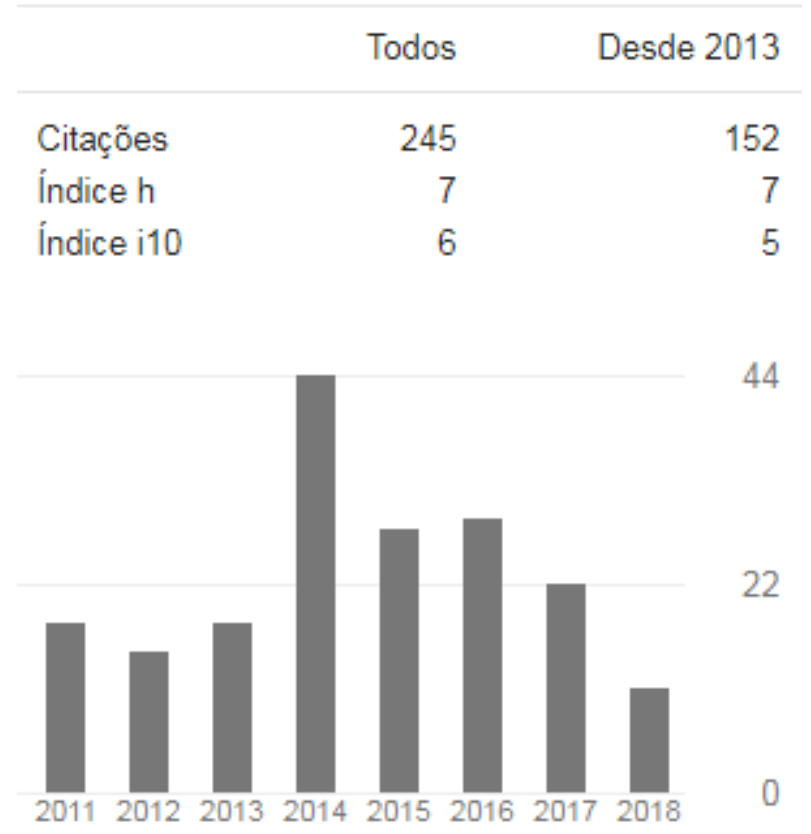

Silvio Luiz Gonçalves Vianna 


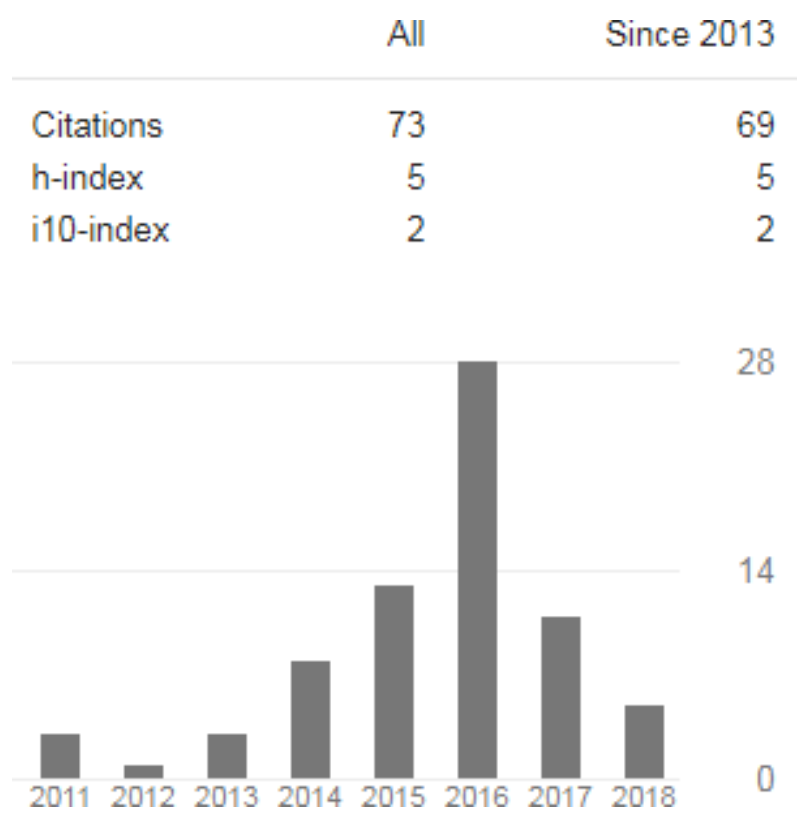

\section{Vania Beatriz Merlotti Heradia}

\begin{tabular}{lrr} 
& Todos & Desde 2013 \\
\hline Citações & 538 & 236 \\
Índice h & 11 & 8 \\
Índice i10 & 13 & 7
\end{tabular}

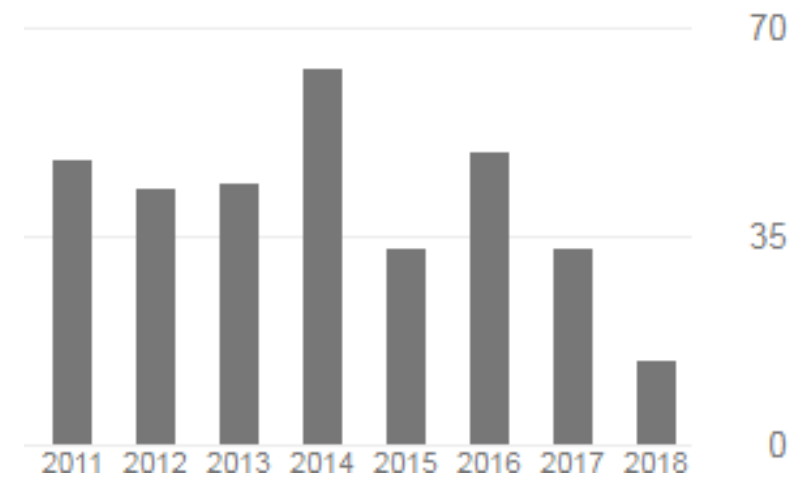

UNB: Universidade de Brasília

Mario Beni 


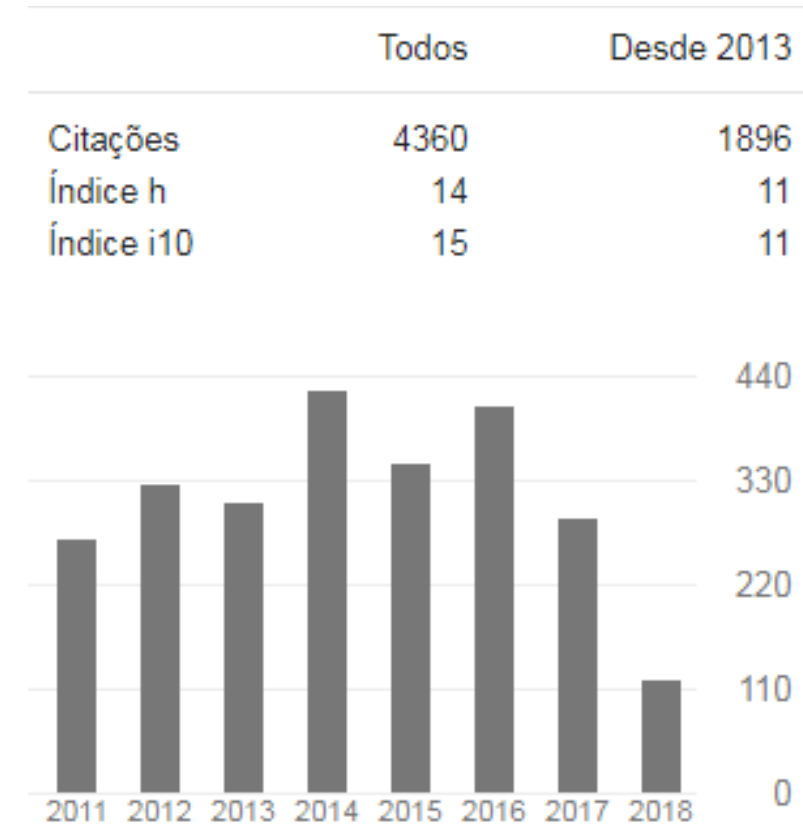

Neio Lucio de Oliveira Campos

\begin{tabular}{lrr} 
& Todos & Desde 2013 \\
\hline Citações & 87 & 39 \\
Índice h & 5 & 3 \\
Índice i10 & 4 & 1
\end{tabular}

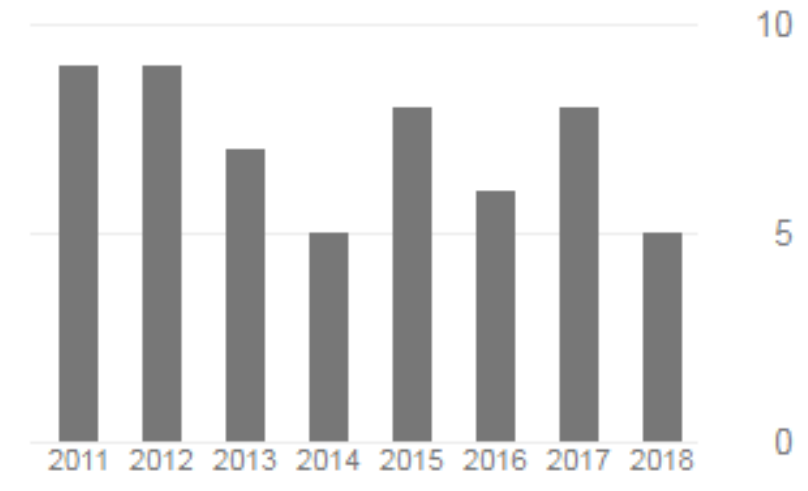

Everaldo Batista da Costa 


\begin{tabular}{|c|c|c|}
\hline & Todos & Desde 2013 \\
\hline Citações & 3104 & 2894 \\
\hline Índice $\mathrm{h}$ & 24 & 23 \\
\hline \multirow[t]{6}{*}{ Índice i10 } & 38 & 34 \\
\hline & & 1200 \\
\hline & & 900 \\
\hline & & \\
\hline & & 000 \\
\hline & & 300 \\
\hline 20112012 & & 0 \\
\hline
\end{tabular}

USP: Universidade de São Paulo

Alexandre Panosso Netto

\begin{tabular}{|c|c|c|}
\hline & Todos & Desde 2013 \\
\hline Citações & 1574 & 1088 \\
\hline Índice h & 18 & 16 \\
\hline Índice i10 & 30 & 25 \\
\hline & & 260 \\
\hline & 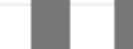 & 195 \\
\hline & & 130 \\
\hline & & 65 \\
\hline & & \\
\hline
\end{tabular}

Cinthia Harumy Watanabe Corrêa 


\begin{tabular}{lrr} 
& Todos & Desde 2013 \\
\hline Citações & 179 & 109 \\
Índice h & 6 & 5 \\
Índice i10 & 3 & 2
\end{tabular}



\section{Debora Cordeiro Braga}

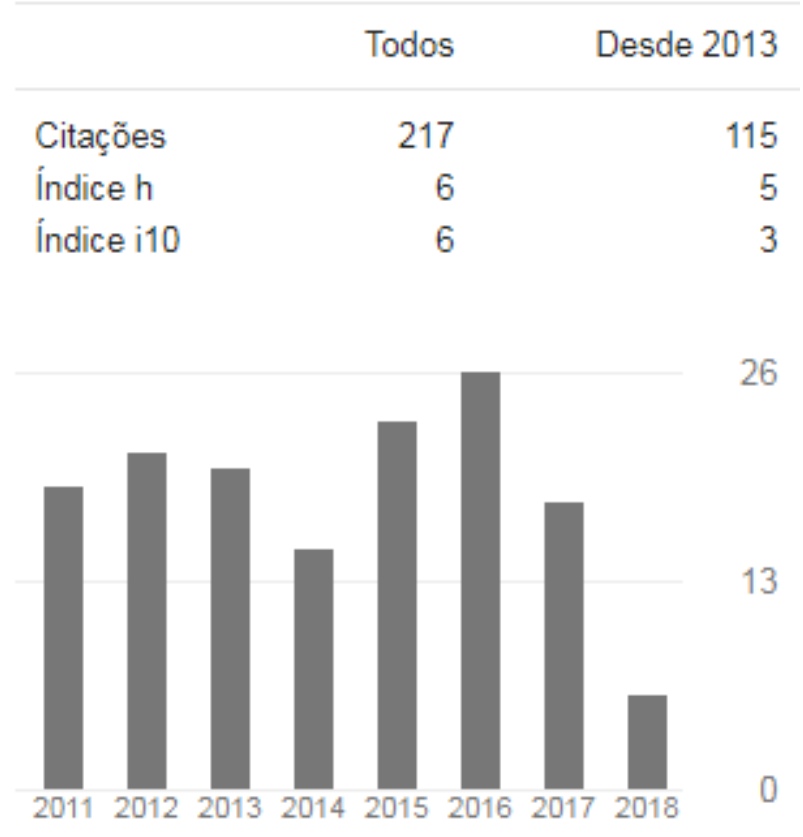


Karina Toledo Solha

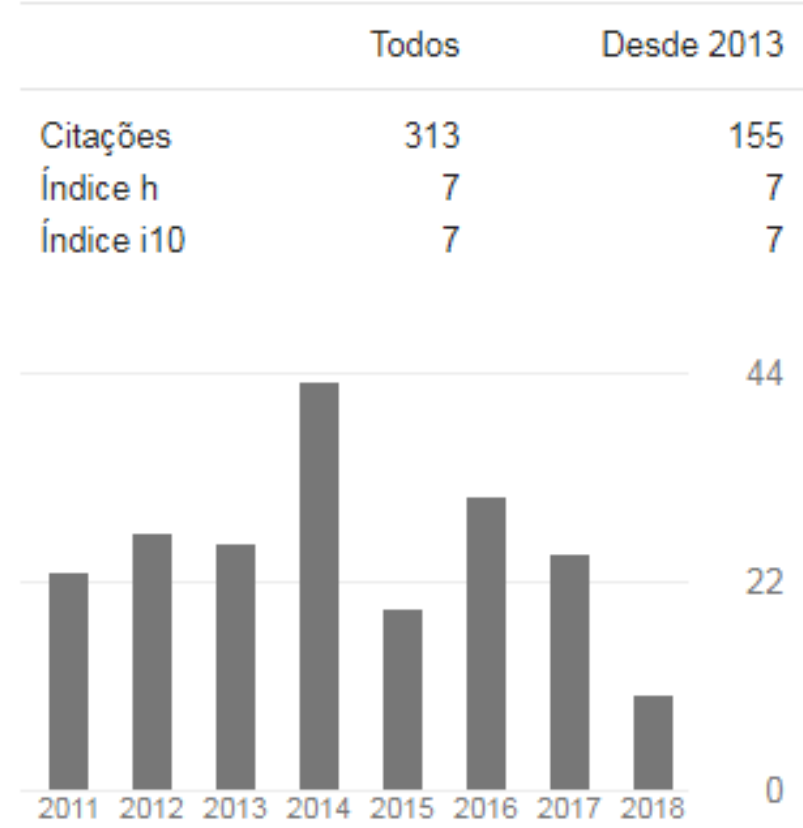

Edegar Luiz Tomazzonni



Sidnei Raimundo 
Todos Desde 2013

$\begin{array}{lrr}\text { Citações } & 100 & 63 \\ \text { Índice h } & 7 & 4 \\ \text { Índice i10 } & 3 & 0\end{array}$

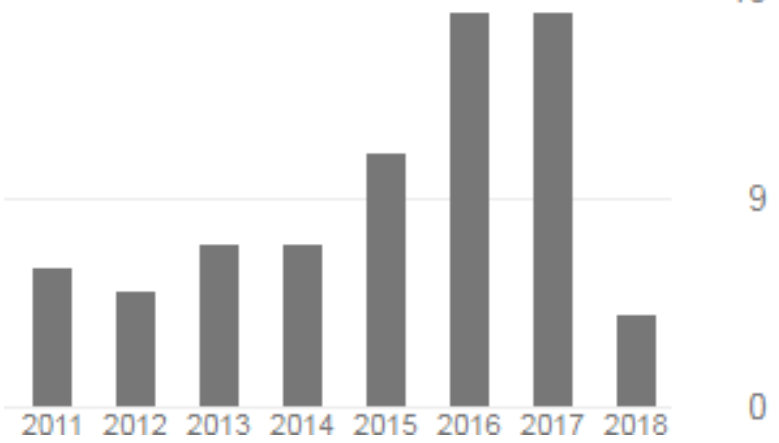

\section{Edmur Antonio Stoppa}

\begin{tabular}{lrr} 
& Todos & Desde 2013 \\
\hline Citações & 184 & 62 \\
Índice h & 8 & 4 \\
Índice i10 & 6 & 1
\end{tabular}

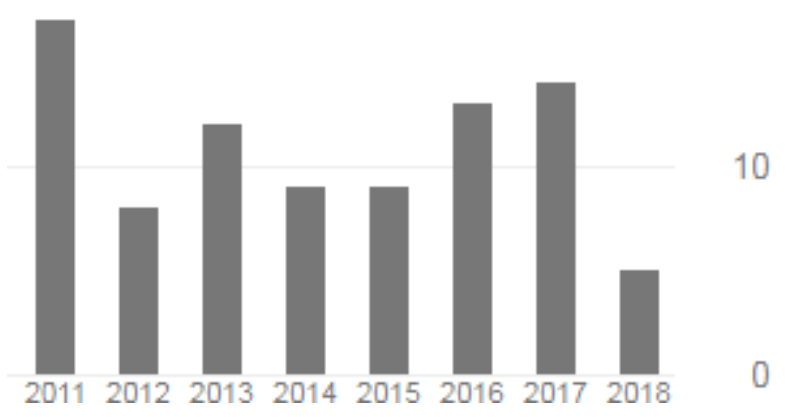

Glauber Eduardo de Oliveira Santos 
Todos Desde 2013

$\begin{array}{lrr}\text { Citações } & 437 & 378 \\ \text { Índice h } & 9 & 8 \\ \text { Índice i10 } & 9 & 7\end{array}$

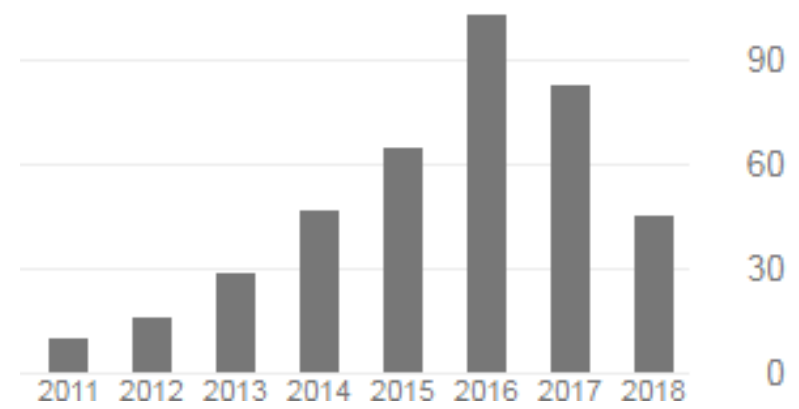

Luiz Gonzaga Godoi Trigo

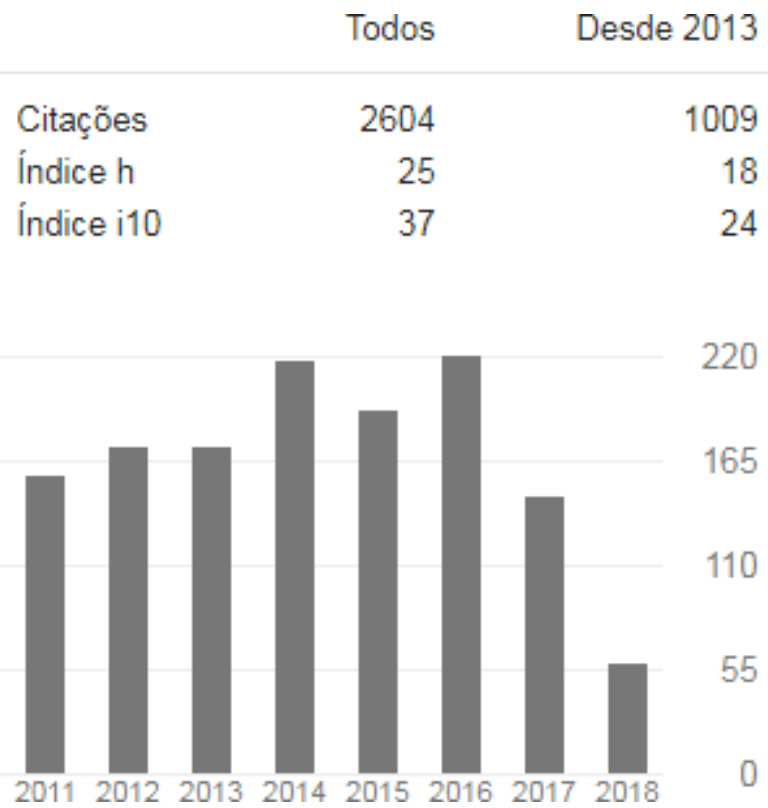

Reinaldo Miranda de Sá Teles 


\begin{tabular}{lrr} 
& Todos & Desde 2013 \\
\hline Citações & 76 & 49 \\
Índice h & 4 & 3 \\
Índice i10 & 3 & 1
\end{tabular}

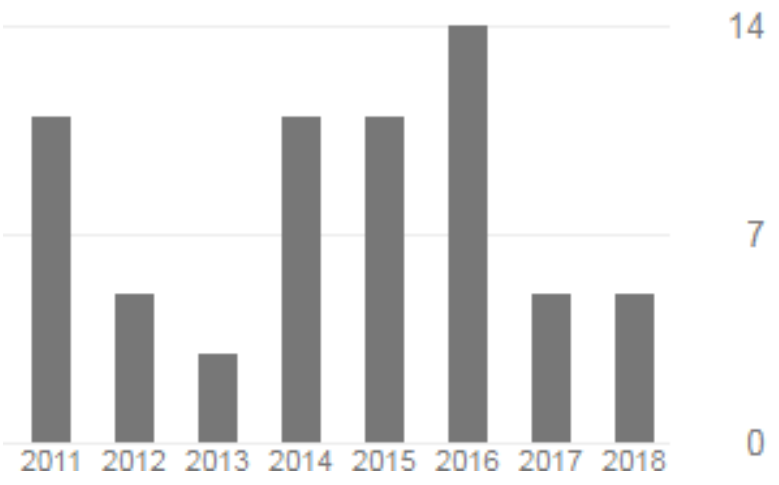

Ricardo Ricci Uvinha

\begin{tabular}{lrr} 
& All & Since 2013 \\
\hline Citations & 208 & 105 \\
h-index & 6 & 5 \\
i10-index & 2 & 1
\end{tabular}

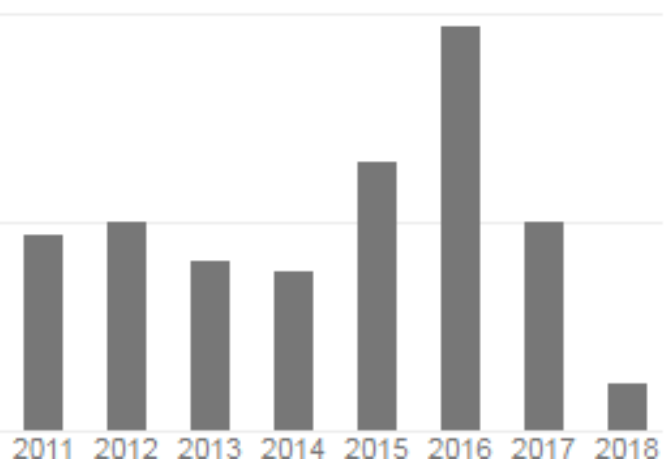


Thiago Allis



Heros Augusto Santos lobo




GEORGE BENINELLI ROSSI

\begin{tabular}{lrr} 
Citado por & \multicolumn{2}{c}{ VISUALIZAR TODOS } \\
\hline & Todos & Desde 2013 \\
\hline Citações & 262 & 151 \\
Índice h & 7 & 6 \\
Índice i10 & 4 & 4
\end{tabular}

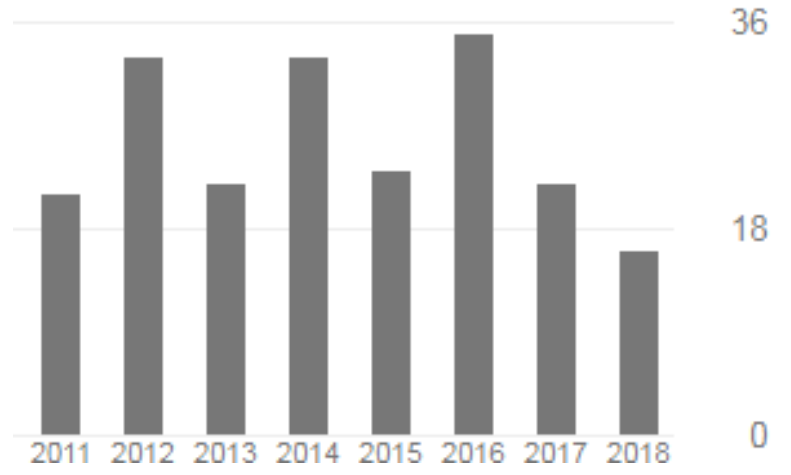


ANEXO B: ÍNDICE H DOS TRÊS DOCENTES MAIS PRODUTIVOS

\begin{tabular}{|l|l|}
\hline \multicolumn{1}{|c|}{ DOCENTES } & \\
\hline Luiz Gonzaga Godoi Trigo & 25 \\
\hline Everaldo Batista da Costa & \\
\hline Alexandre Panosso Netto & 24 \\
\hline José Manoel Gonçalves Gândara & 18 \\
\hline Susana Gastal & 17 \\
\hline Carlos Alberto Cioce & \\
\hline Mirian Rejowski & 17 \\
\hline Luiz Octavio Camargo & 16 \\
\hline Mario Beni & 16 \\
\hline Carlos Alberto Freire Medeiros & 15 \\
\hline Sergio Moretti & 14 \\
\hline Vania Beatriz Merlotti Heradia & 14 \\
\hline Miguel Bahl & 11 \\
\hline Heros Augusto Santos Lobo & 11 \\
\hline Marcos Antonio Leite do Nascimento & 11 \\
\hline Luiz Augusto Machado Mendes Filho & 10 \\
\hline Anete Alberton & 09 \\
\hline Sara Joana Gadotti dos Anjos & 09 \\
\hline Anderson Pereira Portuguez & 09 \\
\hline Francisco Antonio dos Anjos & 08 \\
\hline Aguinaldo Cesar Fratucci & 08 \\
\hline Marcelo Martins de Moura Fé & 08 \\
\hline Neio Lucio de Oliveira Campos & 07 \\
\hline Fonte: Juliana Ferreira dos Santos a partir dos dados coletados no Google Acadêmico,2018. \\
\hline & 05 \\
\hline
\end{tabular}

